
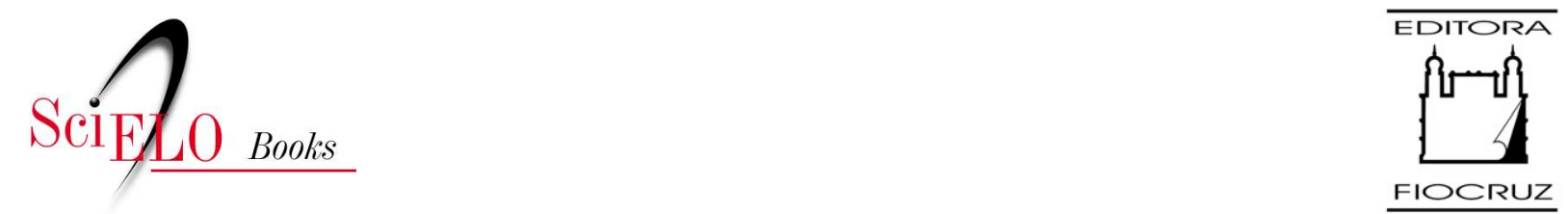

\title{
Cenários possíveis: experiências e desafios do mestrado profissional na saúde coletiva
}

\author{
Maria do Carmo Leal \\ Carlos Machado de Freitas
}

(Orgs.)

\section{SciELO Books / SciELO Livros / SciELO Libros}

LEAL, MC., and FREITAS, CM., orgs. Cenários possíveis: experiências e desafios do mestrado profissional na saúde coletiva [online]. Rio de Janeiro: Editora FIOCRUZ, 2006. 284 p. ISBN 857541-083-0. Available from SciELO Books 〈http://books.scielo.org $>$.

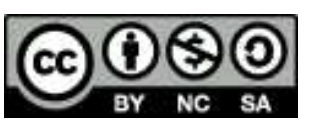

All the contents of this chapter, except where otherwise noted, is licensed under a Creative Commons Attribution-Non Commercial-ShareAlike 3.0 Unported.

Todo o conteúdo deste capítulo, exceto quando houver ressalva, é publicado sob a licença Creative Commons Atribuição - Uso Não Comercial - Partilha nos Mesmos Termos 3.0 Não adaptada.

Todo el contenido de este capítulo, excepto donde se indique lo contrario, está bajo licencia de la licencia Creative Commons Reconocimento-NoComercial-CompartirIgual 3.0 Unported. 


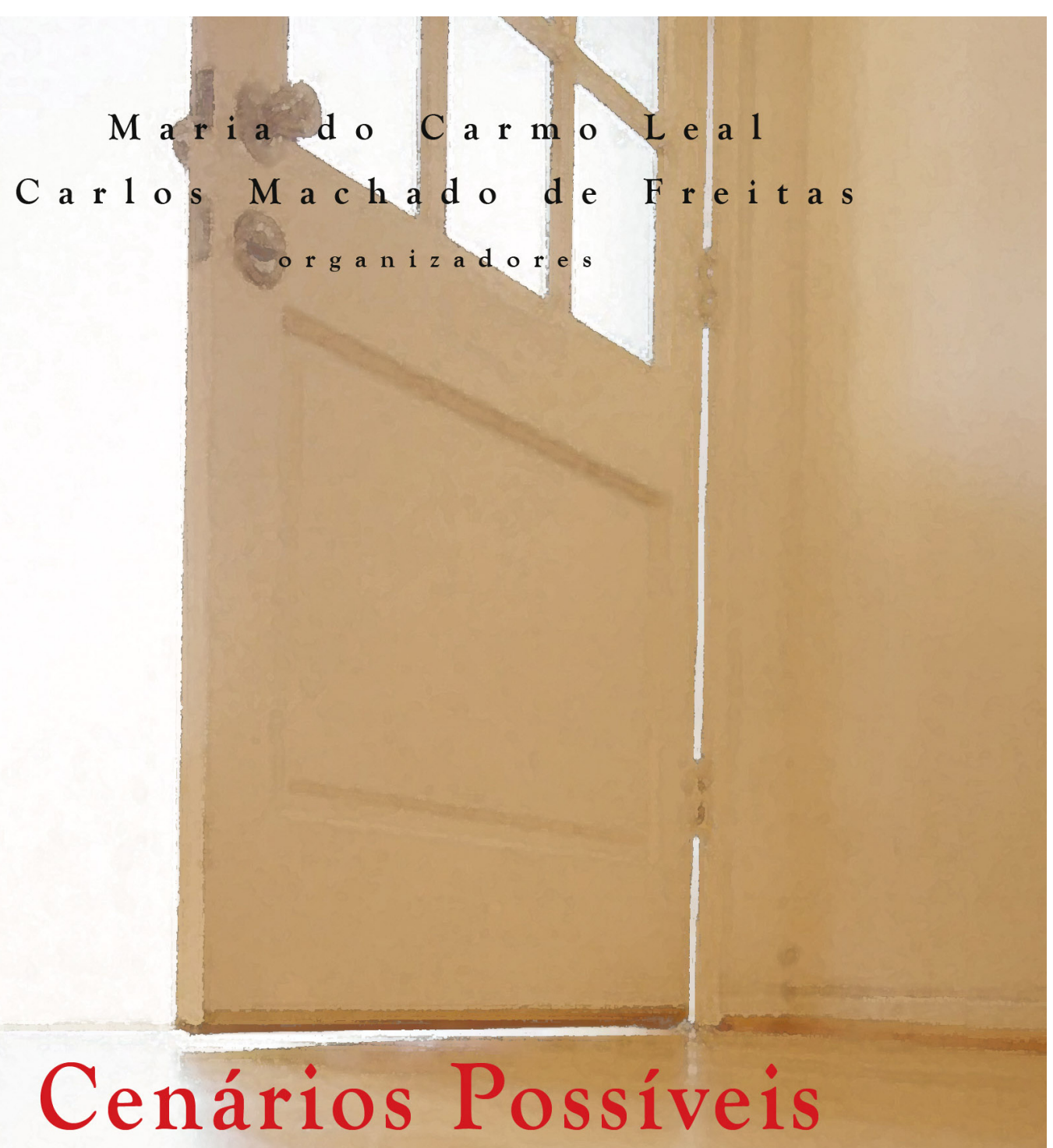

experiências e desafios do mestrado profissional na saúde coletiva

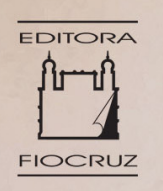


Entre todos aqueles seriamente envolvidos na construção do campo da Saúde Coletiva (SC) sempre existiu a clareza de que um dos pontos fortes deste processo deve ser a busca incessante de construir sólidas conexões entre as práticas cientifico-acadêmica e técnicoprofissional. Entretanto, até os meados da década de 1990, o nosso sistema de formação pós-graduada permitia apenas os mestrados e doutorados (pós-graduação stricto sensu) ditos 'acadêmicos'. Para a formação do profissional restavam os cursos de especialização e outras modalidades da pós-graduação lato sensu. $\mathrm{Na}$ prática, como forma de resistência a essa iníqua barreira no sistema formador, grande parte do alunado dos cursos de mestrado e doutorado 'acadêmicos' da SC tem sido constituida de profissionais que, por este caminho, buscam consolidar a sua formação. A proposta de criação dos Mestrados Profissionalizantes (MP), apresentada pela Capes em 1998, atendia a demandas formuladas pelas áreas do conhecimento com grande responsabilidade de formação profissional, sendo entendida como um estágio na equalização desta com a formação cientifica. Deve-se dizer que essa modalidade de formação pós-graduada já vinha sendo praticada em outros paises do mundo.
Como representante da área de SC e membro do Conselho Técnico-Cientifico da Capes, na época, busquei expressar esse espirito e fiz esforços que colaborassem para a consolidação da proposta. Entretanto, para surpresa de muitos, nos momentos seguintes formaram-se focos de resistência ao MP e, por incrivel que pareça, inclusive na nossa área. Este livro, ao apresentar à nossa comunidade um conjunto consolidado de experiências de $\mathrm{MP}$ em SC, é a resposta mais acabada a qualquer resistência, se esta porventura ainda existir. Porém, o que é mais importante, esta excelente safra fertiliza o terreno para a próxima etapa - a criação dos doutorados profissionais.

\section{Mauricio L. Barreto}

Professor titular em epidemiologia Instituto de Saúde Coletiva da Universidade Federal da Bahia 


\section{CENÁRIOS POSSÍVEIS}

EXPERIÊNCIAS E DESAFIOS DO MESTRADO

PROFISSIONAL NA SAÚDE COLETIVA 


\author{
FUNDAC̣ÃOOSWALDOCRUZ \\ Presidente \\ Paulo Marchiori Buss \\ Vice-Presidente de Ensino, Informação e Comunicação \\ Maria do Carmo Leal \\ EDITORAFIOCRUZ \\ Diretora \\ Maria do Carmo Leal \\ Editor Executivo \\ João Carlos Canossa Pereira Mendes \\ Editores Científicos \\ Nísia Trindade Lima e Ricardo Ventura Santos \\ Conselho Editorial \\ Carlos E. A. Coimbra Jr. \\ Gerson Oliveira Penna \\ Gilberto Hochman \\ Lígia Vieira da Silva \\ Maria Cecilia de Souza Minayo \\ Maria Elizabeth Lopes Moreira \\ Pedro Lagerblad de Oliveira \\ Ricardo Lourenço de Oliveira
}


Maria do Carmo Leal

Carlos Machado de Freitas

organizadores

\section{CENÁRIOS POSSÍVEIS}

EXPERIENCIAS E DESAFIOS DO MESTRADO

PROFISSIONAL NA SAÚDE COLETIVA

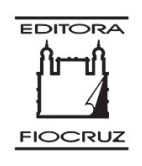


Copyright (C) 2006 dos autores

Todos os direitos desta edição reservados à

Fundação Oswaldo Cruz/Editora

\section{ISBN 85-7541-083-0}

Capa, projeto gráfico e editoração eletrônica

Adriana Carvalho e Carlos Fernando Reis

Revisão

Irene Ernest Dias

Catalogação na fonte

Centro de Informação Científica e Tecnológica

Biblioteca da Escola Nacional de Saúde Pública Sergio Arouca

L435c Leal, Maria do Carmo (org.)

Cenários possíveis: experiências e desafios do mestrado profissional na saúde coletiva. / Organizado por Maria do Carmo Leal e Carlos Machado de Freitas. ${ }^{-}$ Rio de Janeiro : Editora FIOCRUZ, 2006.

284 p., tab., graf.

1.Educação de pós-graduação. 2.Saúde pública-educação. I.Título.

CDD-20.ed. - 378.199

2006

EdITORA FIOCRUZ

Av. Brasil, 4036 - $1^{\circ}$ andar - sala 112 - Manguinhos

21041-361 - Rio de Janeiro - RJ

Tel.: (21) 3882-9039 e 3882-9041

Telefax: (21) 3882-9006

e-mail:editora@fiocruz.br

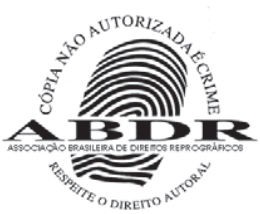

http://www.fiocruz.br/editora 


\section{AUTORES}

Carlos Augusto Grabois Gadelha

Graduado em ciências econômicas, mestre em economia e doutor em economia da indústria e da tecnologia. Professor e pesquisador da Escola Nacional de Saúde Pública/ Fiocruz, sendo coordenador do Mestrado Profissional em Gestão de Ciência e Tecnologia. Atualmente é secretário de Programas Regionais do Ministério da Integração Nacional. E-mail: gadelha@ensp.fiocruz.br

Carlos Machado de Freitas (organizador)

Graduado em história, mestre em engenharia de produção, doutor em saúde pública. Pesquisador titular do Centro de Estudos da Saúde do Trabalhador e Ecologia Humana, Escola Nacional de Saúde Pública/Fiocruz. Coordenador de curso no Mestrado Profissional em Vigilância em Saúde. Atualmente é coordenador da Pós-Graduação na Escola Nacional de Saúde Pública/Fiocruz.

E-mail: carlosmf@ensp.fiocruz.br 


\section{Carmen Fontes de Souza Teixeira}

Médica, mestre em saúde comunitária, doutora em saúde pública. Professora adjunta do Departamento de Saúde Coletiva do Instituto de Saúde Coletiva da Universidade Federal da Bahia. Coordenadora do Mestrado Profissional em Saúde Coletiva. Pesquisadora do Diretório de Planejamento \& Gestão em Saúde do ISC-UFBA. Consultora da Secretaria Municipal de Saúde de Salvador.

E-mail: carment@ufba.br

\section{Célia Regina Pierantoni}

Médica, mestre em endocrinologia, doutora em saúde coletiva. Professora adjunta do Departamento de Planejamento e Administração em Saúde, Centro Biomédico e Instituto de Medicina Social da Universidade do Estado do Rio de Janeiro (IMS/ Uerj). Coordenadora do Mestrado Profissional. Consultora da rede Acompanhamento de Sinais de Mercado de Trabalho do Setor Saúde com Foco em Enfermagem (Samets/ Profae/MS), representante da Associação Brasileira de Pós-Graduação em Saúde Coletiva (Abrasco) na Comissão Intersetorial de Recursos Humanos do Conselho Nacional de Saúde e coordenadora do Grupo de Trabalho Recursos Humanos e Profissões. Atualmente é diretora do Departamento de Gestão da Educação na Saúde da Secretaria de Gestão do Trabalho e da Educação em Saúde do Ministério da Saúde.

E-mail: pieranto@uerj.br

\section{Cristiane Machado Quental}

Economista, mestre e doutora em administração. Analista em C\& T da Escola Nacional de Saúde Pública/Fiocruz, coordenadora adjunta do Mestrado Profissional em Gestão de Ciência e Tecnologia em Saúde Escola Nacional de Saúde Pública/Fiocruz. E-mail: cquental@fiocruz.br

\section{Elizabeth Artmann}

Assistente social, mestre em saúde pública, doutora em saúde coletiva. Pesquisadora adjunta do Departamento de Administração e Planejamento em Saúde, Escola Nacional de Saúde Pública/Fiocruz. Coordenadora do Programa de Pós-Graduação em Saúde Pública da Escola Nacional de Saúde Pública.

E-mail:artmann@ensp.fiocruz.br 


\section{Estela Maria Motta Lima Leão de Aquino}

Médica, mestre em medicina social, doutora em saúde coletiva. Professora adjunta do Instituto de Saúde Coletiva da Universidade Federal da Bahia. Coordenadora do Musa - Programa Integrado de Pesquisa e Cooperação Técnica em Gênero e Saúde. Coordenadora para as regiões Norte-Nordeste do Programa Interinstitucional de Treinamento em Metodologia de Pesquisa em Gênero, Sexualidade e Saúde Reprodutiva. Coordenadora do Programa de Pós-Graduação em Saúde Coletiva (UFBA) de 2001 a 2003. Integrante do Colegiado de Pós-Graduação em Saúde Coletiva (UFBA) desde 2000. Vice-coordenadora do GT Gênero e Saúde da Associação Brasileira de Pós-Graduação em Saúde Coletiva (Abrasco).

E-mail: estela@ufba.br

\section{Francisco Javier Uribe Rivera}

Médico, mestre em saúde coletiva, doutor em saúde pública. Pesquisador titular do Departamento de Administração e Planejamento em Saúde, Escola Nacional de Saúde Pública. Consultor de planejamento em saúde da Coordenação de Aperfeiçoamento de Pessoal de Nivel Superior (Capes).

E-mail: uribe@ensp.fiocruz.br

\section{Ilara Hämmerli Sozzi de Moraes}

Assistente social, mestre e doutora em saúde pública. Pesquisadora titular do Departamento de Ciências Sociais da Escola Nacional de Saúde Pública/Fiocruz. Diretora geral do Centro de Informações em Saúde da Secretaria de Estado de Saúde/RJ e coordenadora da Rede de Centrais de Regulação em Saúde do Estado do Rio de Janeiro. Coordenadora Nacional da Câmara Técnica de Informação e Informática em Saúde do Conselho Nacional de Secretários de Saúde (Conass) e membro da Comissão Intersetorial de Comunicação e Informação em Saúde do Conselho Nacional de Saúde. Coordenadora do Mestrado Profissional de Gestão da Informação e Comunicação em Saúde da Ensp/Fiocruz. E-mail: ilara@ensp.fiocruz.br 


\section{Inês Dourado}

Médica, mestre em saúde pública, doutora em epidemiologia. Professora adjunta do Instituto de Saúde Coletiva da Universidade Federal da Bahia. Atual coordenadora do Programa de Pós-Graduação em Saúde Coletiva do Instituto de Saúde Coletiva da Universidade Federal da Bahia. Membro de Comitê Assessor do Programa Nacional de DST/Aids e do Programa Nacional de Imunizações do Ministério da Saúde. Membro de Comitê Assessor para pesquisas em sarampo e rubéola da Organização Mundial da Saúde desde 2001.

E-mail: maines@ufba.br

\section{Inês Echenique Mattos}

Médica, mestre em saúde pública, doutora em medicina preventiva. Pesquisadora adjunta do Departamento de Epidemiologia e Métodos Quantitativos em Saúde da Escola Nacional de Saúde Pública/Fiocruz. Representante da Escola Nacional de Saúde Pública no Grupo Assessor de Capacitação de Recursos Humanos da SVS em Epidemiologia e Vigilância à Saúde do Ministério da Saúde.

E-mail: imattos@ensp.fiocruz.br

Jairnilson Silva Paim

Médico, mestre em medicina, doutor honoris causa pela Universidade Estadual de Feira de Santana. Professor titular do Instituto de Saúde Coletiva da Universidade Federal da Bahia.

E-mail: jairnil@ufba.br

\section{Lígia Maria Vieira-da-Silva}

Médica, mestre em saúde comunitária, doutora em medicina preventiva. Professora adjunta do Instituto de Saúde Coletiva da Universidade Federal da Bahia.

E-mail:ligiamvs@ufba.br

\section{Maria do Carmo Leal (organizadora)}

Médica, mestre e doutora em saúde pública. Pesquisadora titular do Departamento de Epidemiologia e Métodos Quantitativos em Saúde da Escola Nacional de Saúde Pública/ Fiocruz. Atualmente é vice-presidente de Ensino, Informação e Comunicação/Fiocruz. E-mail: duca@ensp.fiocruz.br 


\section{Miguel Murat Vasconcellos}

Médico, mestre em medicina social, doutor em engenharia biomédica. Pesquisador titular do Departamento de Administração e Planejamento em Saúde da Escola Nacional de Saúde Pública/Fiocruz. Coordenador do curso Educação a Distância - Processos de Gestão e Tecnologias de Informação em Saúde, coordenador do curso de Especialização em Informações e Informática em Saúde e do curso de Mestrado Profissional em Gestão da Informação e Comunicação em Saúde.

E-mail: miguel@ensp.fiocruz.br

\section{Moisés Goldbaum}

Médico, mestre e doutor em medicina preventiva. Professor da Universidade de São Paulo, Faculdade de Medicina, Departamento de Medicina Preventiva. Foi presidente da Associação Brasileira de Pós-Graduação em Saúde Coletiva (Abrasco) e atualmente é secretário de Ciência e Tecnologia e Insumos Estratégicos, Ministério da Saúde.

E-mail:mgoldbau@usp.br

\section{Naomar Monteiro de Almeida Filho}

Médico, mestre em saúde coletiva, doutor em epidemiologia - antropologia médica. Professor titular do Instituto de Saúde Coletiva da Universidade Federal da Bahia. Reitor da Universidade Federal da Bahia. Presidente do Conselho Universitário, presidente do Conselho de Ensino, presidente do Conselho Deliberativo da Fundação de Apoio à Pesquisa e à Extensão (Fapex). Consultor de programas de saúde mental. Doctor of science honoris causa pela Mcgill University, Canadá.

E-mail: naomar@ufba.br

\section{Paulo Chagas Telles Sabroza}

Médico, mestre em saúde pública. Pesquisador titular do Departamento de Endemias Samuel Pessoa da Escola Nacional de Saúde Pública/Fiocruz, coordenador do Centro de Vigilância e Monitoramento de Endemias.

E-mail: sabroza@ensp.fiocruz.br 


\section{Ricardo Ventura Santos}

Graduado em ciências biológicas, mestre e doutor em antropologia. Pesquisador titular e chefe do Departamento de Endemias, Escola Nacional de Saúde Pública/Fiocruz. Professor adjunto IV, 20 horas, do Departamento de Antropologia, Museu Nacional/ UFRJ. Editor científico da Editora Fiocruz.

E-mail: santos@ensp.fiocruz.br

\section{Rita de Cássia Barradas Barata}

Médica, mestre e doutora em medicina. Professora adjunta do Departamento de Medicina Social da Faculdade de Ciências Médicas da Santa Casa de São Paulo. Foi presidente da Associação Brasileira de Pós-Graduação em Saúde Coletiva (Abrasco) e atualmente é coordenadora do Mestrado Profissional em Saúde Coletiva da Faculdade de Ciências Médicas da Santa Casa de São Paulo.

E-mail: rita.barata@fcmscsp.edu.br

\section{Silvana Granado Nogueira da Gama}

Graduada em enfermagem, mestre e doutora em saúde pública. Pesquisadora adjunta do Departamento de Epidemiologia e Métodos Quantitativos em Saúde da Escola Nacional de Saúde Pública/Fiocruz. Integrante do Comitê de Prevenção à Mortalidade Infantil e Fetal do Rio de Janeiro. Coordenadora de curso no Mestrado Profissional em Vigilância em Saúde.

E-mail: granado@ensp.fiocruz.br

\section{Tânia Celeste Matos Nunes}

Graduada em nutrição, mestre em saúde comunitária, doutora em saúde pública. Tecnologista sênior, aposentada. Foi vice-presidente de Ensino e Recursos Humanos da Fiocruz de janeiro de 2001 a março de 2005. Atualmente é coordenadora da Escola de Governo em Saúde, Escola Nacional de Saúde Pública/Fiocruz.

E-mail: tcnunes@fiocruz.br 


\section{Virginia Alonso Hortale}

Médica, mestre em saúde pública, doutora em saúde pública. Pesquisadora titular do Departamento de Administração e Planejamento em Saúde da Escola Nacional de Saúde Pública/Fiocruz. Atualmente é coordenadora geral da Pós-Graduação da Fiocruz.

E-mail: hortale@fiocruz.br

\section{Zulmira Maria de Araújo Hartz}

Médica, licenciada em educação, mestre e doutora em saúde comunitária. Pesquisadora titular, aposentada, do Departamento de Epidemiologia e Métodos Quantitativos em Saúde da Escola Nacional de Saúde Pública/Fiocruz, onde também exerceu as funções de coordenadora geral de Ensino e vice-diretora. Coordenadora geral de Pós-Graduação da Fundação Oswaldo Cruz de janeiro de 2002 a fevereiro de 2004. Atualmente, é pesquisadora e professora convidada do Departamento de Medicina Social e Preventiva da Universidade de Montreal.

E-mail: zulmira.hartz@umontreal.ca 


\section{SUMÁRIO}

Prefácio

Apresentação

1 Mestrado Profissionalizante em Saúde Coletiva

Moisés Goldbaum

2 Significado Estratégico do Mestrado Profissionalizante

na Consolidação do Campo da Saúde Coletiva

Carmen Teixeira

3 Formação e Capacitação de Recursos Humanos no Brasil: situação atual, desafios e perspectivas da pós-graduação em saúde coletiva Zulmira Maria de Araújo Hartz

Tânia Celeste Matos Nunes

4 Mestrado Profissionalizante em Saúde Pública: um olhar para as experiências internacionais Virginia Alonso Hortale 
5 A Experiência do Mestrado Profissional do Instituto

101 de Saúde Coletiva da UFBA, 2001-2004

Inês Dourado

Carmen Teixeira

Estela Aquino

Ligia Maria Vieira-da-Silva

Jairnilson Silva Paim

Naomar de Almeida Filho

6 Formação de Gestores para o Sistema de Saúde:

a experiência do Mestrado Profissional do Instituto

de Medicina Social da Uerj

Célia Regina Pierantoni

7 Mestrado Profissional em Gestão de Ciência e Tecnologia

em Saúde: a experiência da Fiocruz

Carlos Augusto Grabois Gadelha

Cristiane Quental

8 Desafios na Formação de Recursos Humanos para o SUS: a experiência

do Mestrado Profissionalizante da Ensp com a SAS-MS

Elizabeth Artmann

9 Gestão da Informação e Comunicação em Saúde: desenho

e implementação de uma proposta de ensino-aprendizagem

Ilara Hämmerli Sozzi de Moraes

Miguel Murat Vasconcellos

10 O Mestrado Profissionalizante em Vigilância em Saúde

da Escola Nacional de Saúde Pública Sergio Arouca

Paulo Sabroza

Maria do Carmo Leal

Silvana Granado Nogueira da Gama

Inês Matos 
11 Cenários Futuros do Mestrado Profissional da

Escola Nacional de Saúde Pública

Carlos Machado de Freitas

Francisco Javier Uribe Rivera

Elizabeth Artmann

Ricardo Ventura Santos

12 Avanços e Desafios do Mestrado Profissionalizante

Rita Barradas Barata 


\section{PREFÁCIO}

Fico muito feliz com a oportunidade de prefaciar este livro que discute a experiência da Fiocruz com o Mestrado Profissional (MP), pois hoje oferecemos nada menos do que cinco programas nesta modalidade de pós-graduação. Tenho a satisfação de ter aberto esta discussão como diretor da Escola Nacional de Saúde Pública (Ensp), alguns anos atrás, em acalorados debates que antecederam a implantação do primeiro programa na Instituição.

O Mestrado Profissional é uma inovação educacional lançada em outubro de 1995, por meio da Portaria n. 47 da Coordenação de Aperfeiçoamento de Pessoal de Nível Superior (Capes), que vem se firmando no contexto da pós-graduação brasileira, particularmente nos últimos anos. Mesmo assim, segundo a Capes, os mestrados profissionais não passam de 169 (ou 8\%) dos cerca de 2.055 cursos de mestrado recomendados pela instituição em 2005 e têm cerca de 5.100 alunos matriculados. As estimativas da Capes são de que, em cinco anos, o MP represente cerca de $25 \%$ do total de cursos de mestrado reconhecidos. As áreas com maior número de programas são: multidisciplinar, administração, odontologia e saúde coletiva; a maioria dos MP em saúde coletiva do país encontra-se na Fiocruz. Além desses, oferecemos MPs em tecnologia de medicamentos e gestão de ciência e tecnologia em saúde, ambos profundamente relacionados com práticas profissionais próprias da instituição. 
Os profissionais da saúde que desejavam aperfeiçoar-se para o exercício profissional e não para a prática acadêmica tinham, na última metade da década passada, apenas as residências como opção de especialização profissional pós-graduada. As residências foram implantadas no Brasil na década de 1940 e tiveram imenso prestígio - por sua qualidade e expansão - principalmente na década de 1970, quando foi criada, no Ministério da Educação e Cultura (MEC), a Comissão Nacional de Residência Médica. Minha própria experiência profissional começou em 1973-74 com a residência em pediatria do Hospital dos Servidores do Estado, no Rio de Janeiro, serviço do Prof. Luis Torres Barbosa, um pioneiro, aliás, na introdução da residência médica no Brasil e, justamente, numa instituição que de forma também pioneira albergou esta modalidade de formação de médicos. Em 1979 implantei e fui o primeiro coordenador da Residência em Saúde Pública da Ensp na sua nova fase (pósTAS - Treinamento Avançado em Serviço).

O modelo Residência Médica, entretanto, demonstrou seu esgotamento ao longo das décadas de 80 e 90 . O que era um projeto de formação muito respeitado e qualificado foi se deformando, passando a ser, em muitos casos, apenas um primeiro emprego mal remunerado, sem qualidades que justificassem investimentos de tempo e dedicação dos médicos recém-formados. A modalidade Residência estendeu-se, no seu período mais tardio, também às demais profissões da saúde.

São decorridos trinta anos desde que o Parecer n. 97.716 do Conselho Federal de Educação definiu e fixou as características dos cursos de mestrado e doutorado no Brasil. Para o doutorado o objetivo é proporcionar formação científica ou cultural ampla e aprofundada, desenvolvendo a capacidade de pesquisa e o poder criador nos diferentes ramos do saber, exigindo a defesa de tese que represente trabalho de pesquisa importando em real contribuição para o conhecimento do tema. Já o mestrado foi caracterizado ou como etapa preliminar na obtenção do grau de doutor, ou como grau terminal, devendo a dissertação de mestrado revelar domínio do tema escolhido e capacidade de sistematização. O caráter de terminalidade foi considerado relevante para aqueles que, desejando aprofundar a formação científica ou profissional recebida nos cursos de graduação, não almejassem ou não pudessem dedicar-se à carreira científica.

Destacou o parecer a importância de um programa eficiente de estudos pós-graduados para: 1) formar profissionais criadores, capazes de desenvolver novas técnicas e processos tendo em vista a expansão da indústria brasileira e as necessidades do desenvolvimento nacional em todos os setores; 2) transformar a universidade em centro criador e 3) formar professores qualificados para a expansão quantitativa do ensino superior. 
Naquele ato regularizador foi feita também uma clara distinção entre cursos de especialização (destinados a treinamento, formação de atitudes e habilidades, sem abranger o campo total do saber em que se insere a especialidade) e cursos de mestrado, que podem também implicar especialização e operar no setor técnico-profissional, mas sempre no contexto de uma área completa de conhecimento, ou dando ampla fundamentação à aplicação de uma técnica ou ao exercício de uma profissão.

Pode-se, portanto, identificar, na norma regularizadora, dois tipos de mestrado, diferenciados pelos seus objetivos centrais. Um deles tem como objetivo a realização de estudos avançados em uma disciplina específica, sem preocupação com suas aplicações. Corresponderia, na nomenclatura norte-americana, aos graus de Master of Arts (MA) e Master of Sciences (MS), sem designação específica da disciplina correspondente. Outro tipo visa à aplicação e extensão de conhecimentos a finalidades profissionais ou vocacionais. Diz respeito a graus como Master of Business Administration, Master of Arts in Education, Master of Engineering e Master of Arts in Teaching, nos Estados Unidos.

O desenvolvimento da pós-graduação no Brasil nos últimos trinta anos deu origem a cursos de mestrado que, com raras exceções, caracterizam-se predominantemente como o primeiro degrau para a qualificação acadêmico-científica necessária à carreira universitária. À época, a justificativa para essa ênfase acadêmica, com a exclusão da vertente profissional, era de que ela seria suficiente para assegurar também a formação de pessoal de alta qualificação para atuar nas áreas profissionais, nos institutos tecnológicos e nos laboratórios industriais.

Tal situação, dominante até os anos 80 , não conseguiu se sustentar diante da intensidade, urgência e variedade das demandas que a sociedade brasileira passa a fazer, desde então, ao sistema universitário. A rápida evolução do conhecimento passou a exigir, dos graduados, formação avançada e atualizada; em paralelo, as organizações governamentais e não-governamentais passaram a exigir constante elevação da qualidade e produtividade dos seus serviços. Em complemento, a abertura de mercado passa a demandar das empresas um nível de competitividade que as leva a buscar profissionais com formação pós-graduada, de preferência mestrado. A evolução do conhecimento, a melhoria do padrão de desempenho e a abertura do mercado induzem, então, à busca de recursos humanos que permitam uma transferência mais rápida dos conhecimentos gerados na universidade e nos institutos de pesquisa para a sociedade. Buscam-se em todo o mundo formas mais diretas de vinculação do aparelho formador com empresas, agências não-governamentais e governo.

Para atender a essas novas exigências e, de certa forma, complementar o espectro previsto para a pós-graduação no decreto supramencionado, a Capes lança, em 1995, as bases para a 
regulamentação do mestrado profissional. Segundo a portaria da Capes, esse modelo de mestrado estará voltado para a formação profissional, a fim de melhorar a qualificação de técnicos do governo e de empresas públicas e privadas. Além das atividades de ensino, ele prevê a aplicação das pesquisas e o repasse de tecnologia à sociedade. Com duração mínima de um ano, o MP incentiva a criação de projetos em parceria com os setores produtivo e governamental, assim como a oferta de atividades de extensão. Ao final do curso, o aluno deverá apresentar um trabalho, que pode não ser na forma da tradicional dissertação. No lugar dela, a avaliação pode ser feita, por exemplo, por meio de projetos, análises de casos e desenvolvimento de equipamentos e protótipos.

O que diferencia os dois tipos de mestrado são o perfil dos candidatos e o foco de atuação. Enquanto o acadêmico forma pesquisadores e docentes, o profissional qualifica para o mercado de trabalho. Os cursos de MP destinam-se a graduados em cursos superiores, com o objetivo de prepará-los para elaborar novas técnicas e processos ligados à sua atuação profissional, e devem comprovar contribuição inovadora para o desenvolvimento de atividades profissionais.

Recentemente a Capes lançou proposta estimulando a criação de MPs em áreas específicas, como: arquitetura e urbanismo, ciência da computação, ciência política, ciências agrárias, ciências biológicas, ciências sociais aplicadas, ecologia e meio ambiente, economia, enfermagem, engenharias, ensino de ciências e matemática, farmácia, fisioterapia/educação física, matemática/probabilidade e estatística, medicina, multidisciplinar, odontologia, planejamento urbano/demografia, saúde coletiva e zootecnia/recursos pesqueiros.

Comprometida com o avanço contínuo do Sistema Único de Saúde (SUS), a Fiocruz vislumbrou a oportunidade de contribuir para melhorar a governance deste sistema, por meio de pesquisas direcionadas para este fim, e criar os mestrados profissionais para atender às necessidades da gestão pública.

Com isso, surgiram na Fiocruz, nos últimos seis a sete anos, correspondendo ao início do século XXI, os mestrados profissionais, que são objeto da análise e reflexão de muitos coordenadores de programas e professores dos nossos cursos.

Da mesma forma, a Presidência da Fiocruz passou a fomentar a investigação aplicada em saúde pública, através do Programa de Desenvolvimento Tecnológico em Saúde Pública, que visa a desenvolver conhecimentos, instrumentos e mecanismos para o incremento da qualidade do sistema de saúde brasileiro nos seus vários campos de atuação: gestão de sistemas, serviços e organizações; epidemiologia; promoção e educação em saúde; saúde do trabalhador e tantas outras áreas que hoje compõem o sofisticado e abrangente campo de conhecimento e ação da saúde pública brasileira contemporânea. 
Deixo-os com a leitura da nossa experiência, estimando que, ao fazê-lo, todos os leitores sintam-se estimulados a também participar deste enorme esforço nacional em prol da melhoria do nosso sistema de saúde e, por conseqüência, da saúde da nossa população.

Paulo Marchiori Buss

Presidente da Fundação Oswaldo Cruz 


\section{APRESENTAÇÃO}

O Mestrado Profissional (MP), como modalidade nova de pós-graduação stricto sensu proposta pela Coordenação de Aperfeiçoamento de Pessoal de Nivel Superior (Capes), vem, nos últimos anos, recebendo grande acolhida na área da saúde coletiva. Instituições como o Instituto de Saúde Coletiva (ISC-UFBA), o Instituto de Medicina Social(IMS-Uerj), a Escola Nacional de Saúde Pública (Ensp-Fiocruz) e, mais recentemente, a Faculdade de Ciências Médicas da Santa Casa de São Paulo identificaram nessa nova modalidade a oportunidade para a formação qualificada dos quadros estratégicos e gestores para o Sistema Único de Saúde(SUS).

Este volume resulta desse esforço conjunto, procurando demonstrar, por meio de reflexões e experiências de vários autores, inseridos nas instituições que vêm desenvolvendo essa iniciativa, os desafios encontrados e as perspectivas do mestrado profissional na saúde coletiva.

No capítulo de abertura, de Moisés Goldbaum, que serviu de referência inicial para vários autores, encontramos um dos primeiros textos que procuraram sistematizar uma reflexão sobre o significado do mestrado profissional na área da saúde coletiva. Goldbaum, que na época em que escreveu o capítulo era representante da área de saúde coletiva na Capes, apresenta os pressupostos dessa agência para a criação dos cursos de mestrado profissional e chama a atenção para a importância de tal modalidade no provimento de recursos humanos 
atualizados em novos conhecimentos. Recursos humanos estratégicos, capazes tanto de acompanhar e incorporar os processos de inovação e produção de saber quanto de formular respostas para os problemas em suas áreas de atuação, incorporando a avaliação do impacto das intervenções aplicadas.

Carmen Teixeira, analisando o significado estratégico do mestrado profissional para a consolidação do campo da saúde coletiva, faz uma revisão do conceito, da demarcação e da política de formação de pessoal na área, identificando na experiência recente da criação dos MP um aspecto importante das relações entre a tendência da situação de saúde da população, a gestão e organização dos sistemas e serviços de saúde e a resposta das instituições de ensino da área da saúde coletiva, em nível de pós-graduação.

Zulmira Hartze Tânia Celeste situam o mestrado profissional como um elemento importante na formação de recursos humanos em saúde coletiva. Estabelecem uma ponte entre o capítulo de Moisés Goldbaum e o de Carmen Teixeira. Sua grande contribuição é situar a emergência do mestrado profissional dentro do contexto das necessárias mudanças na pósgraduação stricto sensu.

Como demonstra Virginia Hortale, por meio de um olhar para as experiências internacionais, a idéia do MPl como fundamental para a formação qualificada dos quadros estratégicos e gestores para os sistemas de saúde não é nova e nem circunscrita ao Brasil. A análise da experiência de países da América do Norte, Europa e América Latina demonstra que esses cursos possuem em comum a ampliação da interface com setores não acadêmicos e, com métodos pedagógicos bastante variados, procuram responder às necessidades socialmente definidas de formação de profissionais multidisciplinares com capacidade de resolver problemas na área da saúde pública.

Nos capítulos em que são relatadas e discutidas as experiências do ISC, do IMS e da Ensp encontramos a diversidade de interfaces estabelecidas com instituições que integram, direta e indiretamente, o campo da saúde coletiva, no tocante a públicos-alvo, organização dos cursos, estrutura curricular e dinâmica pedagógica.

Inês Dourado, Carmen Teixeira, Estela Aquino, Lígia Vieira, Jairnilson Paim e Naomar de Almeida Filho descrevem a experiência do ISC com seus cinco cursos (um em Docência de Saúde da Família, três em Gestão de Sistemas de Saúde e um em Epidemiologia em Serviços de Saúde), situando o mestrado profissional no âmbito da vocação do programa institucional e apresentando-o como uma experiência inovadora que contribui para o aperfeiçoamento das práticas sanitárias, agregando conhecimentos ao campo da saúde coletiva. Os autores enfatizam os desafios relacionados ao tempo de duração, à oferta de conteúdos teóricos de modo condensado e intensivo, à orientação semipresencial e às características particulares dos produtos finais de conclusão. 
Célia Pierantoni apresenta o curso de Mestrado Profissional em Administração de Saúde do IMS como uma formação de gestores para o SUS e identifica a sua origem na experiência acumulada pela instituição com o Curso de Especialização em Administração Hospitalar oferecido desde a segunda metade da década de 70 do século passado. Um curso que inicialmente tinha como público-alvo os médicos e depois passou a incorporar outras formações profissionais, adquirindo um perfil multidisciplinar. Para a autora, o MP responde aos processos de mudança que vêm ocorrendo tanto no mundo do trabalho como no próprio SUS.

Em relação à Ensp, sua experiência é apresentada em cinco capítulos, quatro deles referentes aos quatro diferentes cursos de mestrado profissional em andamento, ou já concluídos, e um capítulo que projeta o mestrado profissional nos cenários futuros de reorganização da instituição.

O MP em Gestão de Ciência \& Tecnologia (C\&T), que se destina à formação de gestores em ciência e tecnologia em saúde, é apresentado por seus coordenadores, Carlos Gadelha e Cristiane Quental. Os autores revelam os limites dos cursos tradicionais de pósgraduação nas áreas de administração e gestão no tratamento da interface entre C\&T e saúde. Para eles, o setor exige um tipo de formação específica que seja capaz de combinar os universos da C\&T, da saúde e da administração pública, provocando uma mudança cultural na instituição em que foram formados os alunos.

Na segunda experiência da Ensp, Elizabeth Artmann, além de relatar o caso do MP em Gestão de Sistemas e Serviços de Saúde, apresenta o 'olhar' dos alunos sobre o curso. A percepção dos alunos captada em entrevistas semi-estruturadas aprofunda temas como o alcance dos objetivos do curso, possiveis impactos/resultados atingidos, aspectos relacionados à seleção, avaliação, articulação e adequação dos conteúdos, bem como aos prazos e ao processo pedagógico. A partir do discurso coletivo dos alunos, a autora oferece sugestões para o aperfeiçoamento dos cursos de mestrado profissionalizante.

O MP em Gestão da Informação e Comunicação em Saúde, coordenado por Ilara de Moraes e Miguel Murat, trata do desafio de também articular três campos de saberes, a saúde, a informação e a comunicação. A partir desse desafio, os autores demonstram como procuraram superá-los criando uma estrutura curricular e de gestão do curso que permitisse ultrapassar a lógica fragmentadora dominante.

Na quarta experiência, Paulo Sabroza, Maria do Carmo Leal, Silvana Granado e Inês Matos descrevem o caso do MP em Vigilância em Saúde. Situam historicamente a vigilância e seus conceitos, de modo a contextualizar o curso e apresentálo como parte da necessidade de construção e consolidação de um novo projeto de saúde pública, em que devem se formar técnicas e políticas em saúde, e a contribuir para ampliar a base de inteligência do setor Saúde. 
Com base nas experiências que vêm sendo realizadas na Ensp e na necessidade identificada de reorganização do seu Programa de Pós-Graduação, Carlos Freitas, Javier Rivera, Elizabeth Artmann e Ricardo Santos situam o mestrado profissional dentro dos cenários futuros da instituição. Não só demonstram como o mestrado profissional é uma demanda que tende a permanecerea crescer na Enspena saúde coletiva como um todo, como apresentam esta modalidade como unidade de articulação entre o stricto sensu e o lato sensu, permitindo uma formação de profissionais ampla e modular, atendendo às demandas atuais e potenciais do SUS.

No último capítulo, 'Mestrado Profissionalizante: avanços e desafios', Rita Barradas Barata faz uma sumarização e apreciação crítica de toda a experiência relatada pelos autores nos capítulos anteriores, articulando a existência do mestrado profissional na área da saúde coletiva com a realidade dos cursos acadêmicos da pós-graduação stricto sensu, estabelecendo semelhanças e diferenças identificadas entre os dois tipos de cursos. A autora chama a atenção para os cenários que vão se descortinando a partir dessa coexistência tanto com a pós-graduação acadêmica quanto com o lato sensu, abrindo possibilidades de novas articulações na busca de uma maior possibilidade de resposta às crescentes demandas por formação de pessoal emanada do SUS. E também para a necessidade de uma avaliação adequada e pertinente dessa desafiante experiência.

A iniciativa da Fiocruz de organizar uma reflexão sobre o mestrado profissional na área da saúde coletiva baseada nas experiências aqui apresentadas se insere na missão da nossa instituição que, pelo seu lugar de instituto de ciência e tecnologia do Ministério da Saúde, com amplas responsabilidades na formação de pessoal, principalmente em nível de pósgraduação, sente-se compelida a participar do esforço nacional de promover maior aproximação entre o saber e o fazer no campo da saúde coletiva. Esperamos, com esta coletânea, não só colaborar para o debate sobre o mestrado profissional, mas também para sua ampliação na formação de quadros estratégicos para o SUS, com base na melhoria contínua das estratégias pedagógicas e no maior envolvimento das instituições que os demandam. E, com isso, atingir maior qualidade dos cursos e contribuir efetivamente para uma maior resolubilidade dos problemas enfrentados pelos serviços nacionais de saúde.

Os Organizadores 


\title{
MESTRADO PROFISSIONALIZANTE EM SAUUDE COLETIVA
}

\author{
Moisés Goldbaum
}

O processo de formação de recursos humanos de alta qualificação na área da saúde compreende vários níveis já bastante consolidados e largamente oferecidos em diferentes instituições e regiões do país.

Assim, encontram-se os diferentes cursos de especialização que se enquadram na condição de pós-graduação lato sensu, nos diferentes campos disciplinares, nos quais se pode reconhecer, a título de exemplo, os programas de residência médica em medicina preventiva e/ou social e os cursos de especialização em saúde pública. ${ }^{1}$ Ao lado desses programas identificam-se os programas de especialização de administração em saúde, que compreende as áreas de gestão e administração de serviços de saúde, em especial os hospitalares. Esses programas têm capacitado fundamentalmente profissionais que respondem a necessidades de serviços demandados em diferentes níveis de atuação, tanto nas instituições públicas quanto nas instituições de natureza privada. A extensa difusão desses programas permitiu a formação de um grande número de profissionais capacitados a responder às necessidades dos serviços de

\footnotetext{
${ }^{1}$ A abordagem aqui estará voltada para os programas da área de saúde. Isso significa que a área médica, que dispõe de amplos programas de formação pós-graduada, como o de residências médicas, não será objeto de análise.
} 
saúde, em diferentes regiões do país e em diversas áreas de atuação (veja-se, por exemplo, o apreciável contingente de recursos humanos treinados em vigilância epidemiológica ou os cursos de saúde pública locais ou descentralizados). Apesar dos resultados alcançados, a ampla difusão desses programas passou a exigir um sistema de validação e acompanhamento de sua qualidade que resulta nos recentes esforços de criação de sistemas de acreditação de cursos de especialização na área da saúde.

As demandas pela formação do conjunto de pesquisadores e docentes universitários encontram, no bem-sucedido sistema brasileiro de pós-graduação stricto sensu, as suas respostas. Os programas de mestrado acadêmico e doutorado das Instituições de Ensino Superior (IES) na área da saúde formam, anualmente, um formidável contingente de professores e pesquisadores. Primária e originariamente voltados para atender à demanda dessas IES, esses programas de pósgraduação vêm produzindo um grande contingente de recursos humanos que nem sempre encontram o espaço de atuação para o qual se pretende destinar. Ao lado desse objetivo primário, o sistema de pós-graduação acadêmico vem absorvendo também, principalmente na área da saúde coletiva, técnicos (inseridos ou não no mercado de trabalho) interessados no seu aprimoramento profissional, voltando-se para cobrir necessidades apresentadas pelos serviços de saúde. Esta última situação produz uma nítida distorção, uma vez que os objetivos de programas dessa natureza implicam uma formação para a docência aliadaà capacidade de realização e/ou condução de pesquisas de caráter acadêmico, não necessariamente de cunho operacional, característica maior das pesquisas conduzidas nos serviços de saúde. Além disso, o tempo de formação (em média 36 meses) dos mestrados, aliado ao fato de, com freqüência, não terem caráter de terminalidade, aprofundam essas distorções, gerando dificuldades de adaptação dos profissionais às responsabilidades a eles atribuídas nos serviços de saúde (embora, intuitivamente e de observações não sistemáticas, se possa depreender que seu desempenho experimenta uma sensivel melhora a partir dessa vivência acadêmica).

Recente iniciativa da Coordenação de Aperfeiçoamento de Pessoal de Nivel Superior (Capes-MEC) de incrementar, difundir e acreditar programas de mestrados profissionais vem ao encontro da demanda, apresentada pelos serviços de saúde, de profissionais de alto nível de qualificação. Os seus principais pressupostos estão expressos em portaria daquela agência:

- a necessidade de formação de profissionais pós-graduados aptos a elaborar novas técnicas e processos, com desempenho diferenciado de egressos dos cursos de mestrado que visem preferencialmente um aprofundamento de conhecimentos ou técnicas de pesquisa científica, tecnológica ou artística; 
- a relevância do caráter de terminalidade, assumido pelo mestrado que enfatize o aprofundamento da formação científica ou profissional conquistada na graduação;

- a inarredável manutenção de níveis de qualidade condizentes com os padrões da pós-graduação stricto sensu. (Capes/MEC. Portaria n. 080, de 16 de dezembro de 1998)

Entende-se o Mestrado Profissional (MP) como aquele que enfatiza o desenvolvimento de estudos e técnicas diretamente voltados para o desempenho de um alto nivel de qualificação profissional e que responde a necessidades socialmente definidas, diferentes daquelas apresentadas pelo setor acadêmico. Recentes normas estabelecidas pela própria Capes assinalam que

com a oferta de mestrado profissional, o Sistema Nacional de Pós-Graduação amplia sua interface com os setores não acadêmicos da sociedade brasileira, tendo em vista a formação de recursos humanos com o referido nivel de titulação para o exercício de profissões outras que não a de docente pesquisador; e, o mestrado profissional responde a necessidade socialmente definida de capacitação profissional de natureza diferente da propiciada pelo mestrado acadêmico. (Capes. Pressupostos para a avaliação de projetos de mestrado profissionalizante. Conselho Técnico-Científico. Reunião de 15/09/1999)

No dizer da mesma agência, os MPs devem

expressar associação entre teoria e aplicação, entre conhecimento fundamental e prática técnico-profissional; [deve] ser a demanda pela criação do curso decorrente, preferencialmente, do interesse comum de setores acadêmicos e dos setores não acadêmicos a serem beneficiados pelo tipo de qualificação prevista; constituir-se em iniciativa de instituição que seja qualificada para oferecer curso profissional que contribua, de forma criativa, para o desenvolvimento ou a indução do surgimento de campos de atividade profissional; e ter sua implantação e desenvolvimento respaldados em esquema eficiente de atividade comum do programa promotor com setores profissionais não acadêmicos relacionados com as áreas do curso. (Capes. Pressupostos para a avaliação de projetos de mestrado profissionalizante. Conselho Técnico-Científico. Reunião de 15/09/1999) 
Nessa circunstância, pode-se entender os programas de MP como uma modalidade que, diferentemente daquela dos programas acadêmicos, propõe-se a formar, enfatizando seu caráter de terminalidade, quadros funcionais estratégicos aptos e capazes na compreensão, definição e condução das políticas de intervenção sobre a saúde. Elaborada conjuntamente pelo demandante e o aparelho formador, essa proposta visa a prover recursos humanos que estejam atualizados quanto aos novos conhecimentos existentes e sejam capazes de, de um lado, acompanhar e incorporar os processos de inovação e produção de conhecimentos e, de outro, formular projetos voltados para responder aos problemas identificados na sua área de atuação e avaliar o impacto das intervenções aplicadas. A complexidade desses problemas na área da saúde exige o desenvolvimento de habilidades e competências que permitam responder aos objetivos descritos.

Observando-se o processo de implantação e consolidação do Sistema Único da Saúde (SUS), verifica-se a necessidade de recursos humanos que estejam habilitados a desempenhar seus papéis de gestores de sistemas de atenção à saúde, nos diferentes níveis de atuação. A formação desses recursos, antes suprida, em princípio e na maioria das situações, pelos cursos de especialização, se vê necessitada, a partir da nova realidade do SUS, de pessoal capacitado nas situações aqui expostas, e para o qual o MP se mostra uma modalidade de formação adequada. O MP na área da saúde e voltado para nichos de carência estratégica de pessoal pode, se adequadamente conduzido, prover quadros adaptados às novas necessidades encontradas no sistema de saúde brasileiro.

Assim, o desenho de programas de formação de recursos humanos altamente qualificados pode atender às necessidades específicas de cada um dos níveis de atuação, dando destaque para o suprimento de pessoal responsável pela definição e condução das grandes diretrizes técnicas dos órgãos do SUS (entenda-se, em primeiro plano, os órgãos governamentais das esferas federal, estaduais e municipais).

Considerando a capacidade extensa, porém limitada, de oferecer programas dessa natureza, é necessário buscar uma racionalidade de ofertas que não exponha à descontinuidade ou impeça a necessária expansão de programas ou projetos de outra natureza dos aparelhos formadores, haja vista o fato de que o credenciamento de programas de MP pela Capes prevê que as IES devem preencher requisitos básicos para poderem oferecê-los. ${ }^{2}$

\footnotetext{
${ }^{2}$ Cabe à Capes o credenciamento desses cursos em âmbito nacional; entre as exigências feitas, "é fundamental que seja demonstrado que a oferta do mestrado profissional não comprometerá o desempenho dos cursos de mestrado e doutorado oferecidos pelo programa" (Capes. Pressupostos para a avaliação de projetos de mestrado profissionalizante. Conselho Técnico-Científico. Reunião de 15/09/1999).
} 
De outro lado, e considerando essa limitação, um programa dessa natureza, ao prestar-se a formar recursos estratégicos, deveria dirigir-se prioritariamente aos quadros dirigentes-técnicos das instituições, com a perspectiva de uma concomitante criação de carreira funcional. Isso significa que o programa de MP estará voltado para fortalecer e consolidar a capacidade técnica dos gestores, não esquecendo que os cursos de pós-graduação, como por exemplo os de especialização, continuam representando uma boa fonte de formação de recursos humanos para a operação de ações em saúde.

Essa modalidade de formação de pessoal técnico pode ser pensada para grandes áreas de organização dos serviços de saúde. A título de exemplo, pode-se tomar a vigilância epidemiológica; um programa voltado para essa área deve ser oferecido de modo genérico, no qual pensar na atuação geral não signifique pensar cada uma das 'especialidades', embora cada um dos mestrandos possa tomar como objeto de sua investigação problemas de sua área de atuação. ${ }^{3}$

Dada a multidisciplinaridade que marca a atuação dos profissionais no campo da saúde, em especial os seus quadros estratégicos, é importante destacar a saúde coletiva como área privilegiada para atender às necessidades de formação de recursos humanos para o SUS. Entretanto, privilégio não significa exclusividade: áreas disciplinares outras, como as ciências farmacêuticas ou biológicas (quando se pensa, por exemplo, a vigilância sanitária), ou ciências da computação (quando se pensa a informação em saúde), devem ser, em conjunto e entre outras, acionadas para a adequada e abrangente formação dos recursos humanos para o SUS.

Dois exemplos podem ilustrar as considerações feitas até aqui: no campo da vigilância epidemiológica é possível conceber, a título de exercício, um programa que exponha o aluno a linhas de pesquisa e disciplinas que contemplem vários temas (epidemiologia das doenças transmissiveis, epidemiologia das doenças crônicas, epidemiologia das doenças profissionais) à luz das condições de vida e saúde; complementada sua atualização, o programa se completa com apresentação, pelo aluno, de um produto intelectual que compreenda seu objeto mais próximo de atuação, do seu posto de trabalho no serviço de saúde (doenças transmissíveis, doenças crônicas etc.).

Outro exemplo refere-se à gestão de $C \& T$ em saúde, na qual as transformações institucionais e de inovação gerencial estão a exigir recursos humanos que compreendam as várias dimensões envolvidas com a definição de políticas de C\&T em saúde, sua significância

\footnotetext{
${ }^{3}$ Como o produto esperado dos MPs, além da capacitação do mestrando, implica a apresentação de um trabalho de investigação (que no caso pode ser uma publicação oriunda de uma pesquisa de natureza operacional), este pode - e deve - envolver temas da área do aluno.
} 
estratégica e a busca de prioridades de pesquisa em saúde, cujas lógicas não obedecem, única e exclusivamente, à lógica dos serviços de saúde. Assim, um programa nesse campo deve contemplar a compreensão dos processos de geração de conhecimentos, difusão dos resultados da pesquisa, dos processos de incorporação tecnológica e das medidas de avaliação e impacto dessa atividade, o que significa a abordagem de gestão e administração em C\&T. Da mesma forma, o trabalho final deve contemplar a abordagem de tema que aprofunde o entendimento do objeto de atuação do técnico no seu posto de trabalho.

Cabe, finalmente, destacar os esforços que várias de nossas IES vêem empregando ao oferecer MPs, já credenciados, nas áreas de vigilância epidemiológica, vigilância sanitária, administração em saúde, gestão em ciência e tecnologia, gestão em informação e comunicação, programas de saúde de família. Os demais capítulos desta coletânea trazem, em detalhe, essas experiências que são uma demonstração inequívoca da importância desta modalidade de formação, em resposta às necessidades apresentadas pelos nossos serviços de saúde. 


\title{
SIGNIFICADO ESTRATÉGICO DO MESTRADO PROFISSIONALIZANTE NA CONSOLIDAÇÃO DO CAMPO DA SAÚDE COLETIVA
}

\author{
Carmen Teixeira
}

A criação e o desenvolvimento dos mestrados profissionalizantes em saúde coletiva constituem uma oportunidade para a reflexão acerca da situação atual e das tendências da própria saúde coletiva, como campo de saber e práticas, e, especialmente, nos estimulam a refletir sobre as diversas modalidades de formação de pessoal nessa área, identificando seus limites e suas perspectivas na conjuntura atual. Assim, tratarei, aqui, de recuperar, em linhas gerais, o processo de constituição do campo da saúde coletiva, suas tendências e perspectivas, para, em seguida, situar a proposta dos mestrados profissionalizantes no conjunto das diversas modalidades de formação de pessoal na área, discutindo seu significado estratégico no contexto do processo de reforma sanitária.

Com base em revisão da literatura recente sobre o tema, busquei inicialmente caracterizar o campo da saúde coletiva, como campo disciplinar, campo de aplicação tecnológica e campo de práticas sociais. Em seguida, sistematizo uma breve análise sobre as diversas modalidades de formação de pessoal em saúde coletiva no Brasil hoje, com o objetivo de situar a criação dos mestrados profissionalizantes e discutir sua especificidade e seu significado como modalidade de formação de pessoal e ampliação dos espaços de produção de conhecimentos e desenvolvimento tecnológico na área. Em vista disso, discuto a importância do mestrado 
profissionalizante em saúde coletiva para a formação de sujeitos comprometidos com os princípios e valores da reforma sanitária e para o aperfeiçoamento do processo de formulação de políticas, planejamento e gestão do Sistema Único de Saúde (SUS), bem como para a introdução e consolidação de inovações organizacionais, tecnológicas e operacionais nas práticas de saúde.

\section{SAÚDE COLETIVA: DEFINIÇÃO E CARACTERÍSTICAS DO CAMPO}

O desenvolvimento teórico-conceitual e prático-instrumental na área da saúde coletiva vem se dando ao longo dos últimos 25 anos, gerando uma reflexão de caráter epistemológico que estimula vários autores interessados na história, sociologia e filosofia da ciência e das práticas de saúde em nosso meio.

Em revisão abrangente sobre o tema, Almeida Filho (2000a) recuperou diversas aproximações realizadas por pesquisadores que analisam a saúde coletiva como campo de produção de conhecimentos sobre a problemática de saúde entendida em sua dimensão coletiva, social, ao mesmo tempo que identificou a existência de uma reflexão paralela que considera a saúde coletiva como um conjunto de práticas (econômicas, políticas, ideológicas, técnicas etc.) que tomam por objeto as necessidades sociais de saúde. $\mathrm{O}$ autor resgata a reflexão pioneira de Donnangelo (1982), para quem a saúde coletiva deve ser entendida como "conjunto de saberes" que subsidia práticas sociais realizadas por distintas categorias profissionais e outros atores sociais que se mobilizam para o enfrentamento dos problemas de saúde, na busca de respostas que ultrapassam a organização do cuidado individual e podem incidir sobre seus determinantes sociais e históricos.

Coerentemente com essa perspectiva, Paim (1982:18-19) afirma que a saúde coletiva "compreende a investigação dos determinantes da produção social das doenças e da organização dos serviços de saúde e o estudo da historicidade do saber e das práticas sobre as mesmas”, concepção que é reforçada por Teixeira (1985:89) quando define a saúde coletiva como "área de produção de conhecimentos que tem como objeto práticas e saberes de saúde, referidas ao coletivo enquanto campo estruturado de relações sociais onde a doença adquire significação". Já Ribeiro (1991) chama a atenção para o caráter interdisciplinar da saúde coletiva, identificando suas "disciplinas básicas" - epidemiologia, planejamento e administração em saúde e ciências sociais em saúde -, enumerando como objetos de investigação a situação de saúde, as políticas de saúde, a relação entre os processos de trabalho e doença e agravos, bem como as intervenções de grupos e classes sociais sobre a questão sanitária. 
Mais do que campo científico, porém, o entendimento da saúde coletiva como "âmbito de práticas" (Paim, 1992) se fundamenta na reflexão de Gonçalves (1992), que se debruçou sobre a organização tecnológica do trabalho em saúde e caracterizou a saúde coletiva como o conjunto de práticas que toma por objeto necessidades sociais de saúde e como instrumentos de trabalho distintos saberes e tecnologias, materiais e imateriais, organizando-se em atividades de intervenção sobre condições e modos de vida de grupos sociais e do ambiente onde vivem, independentemente dos sujeitos (tipo de profissional) que as realizem e do modelo de institucionalização.

Nessa perspectiva, Testa (1992) entende a saúde coletiva como uma prática social, uma construção histórica que supõe o redimensionamento teórico da saúde como "campo de força" da produção científica e âmbito de aplicação da tecnociência. Para Paim e Almeida Filho $(1998,2000)$ trata-se de um espaço no qual diferentes organizações e instituições sociais, constituídas por diversos agentes (especializados ou não), realizam ações concretas de promoção da saúde, dentro e fora do contexto convencionalmente reconhecido como 'setor Saúde'.

Recorrendo a Bourdieu $(1983,1996)$ para pensar a saúde coletiva como campo científico e campo de práticas, Almeida Filho propõe uma distinção (provisória e preliminar, segundo o autor) entre campo disciplinar, campo de aplicação tecnológica e campo de práticas sociais, para caracterizar a saúde coletiva (Figura 1). Assumindo que tais conceitos são simultaneamente caudatários e tributários do conceito de campo científico, este autor explicita que

campo disciplinar (CD) refere-se ao espaço histórico-social e institucional ocupado predominantemente com o desenvolvimento de processos de produção e aplicação de conhecimentos científicos, campo de aplicação tecnológica (CAT) indica espaços histórico-sociais e institucionais definidos por um predominio de atividades de aplicação de tecnologia (...) e campo de práticas sociais (CPS) refere-se ao espaço simbólico, histórico-social e institucional onde se efetivam processos semi-estruturados e não estruturados de exercício da prática comunal ou profissional. (Almeida Filho, 2000a:26-27)

Conforme esquematizado na Figura 1, o campo da saúde coletiva (CSC) incorpora integralmente um campo disciplinar - a epidemiologia (CD/EPI) -, um campo de aplicação tecnológica - o planejamento e gestão em saúde (CAT/PSG) - e um campo de práticas sociais - a promoção da saúde (CPS/PRS) (Almeida Filho, 2000a). Ainda segundo o autor, entre esses campos distintos observa-se uma grande área compartilhada que, não obstante, 
ainda permite preservar as especificidades de cada campo (respectivamente científico, tecnológico e de prática social).

Figura 1 - O campo da saúde coletiva

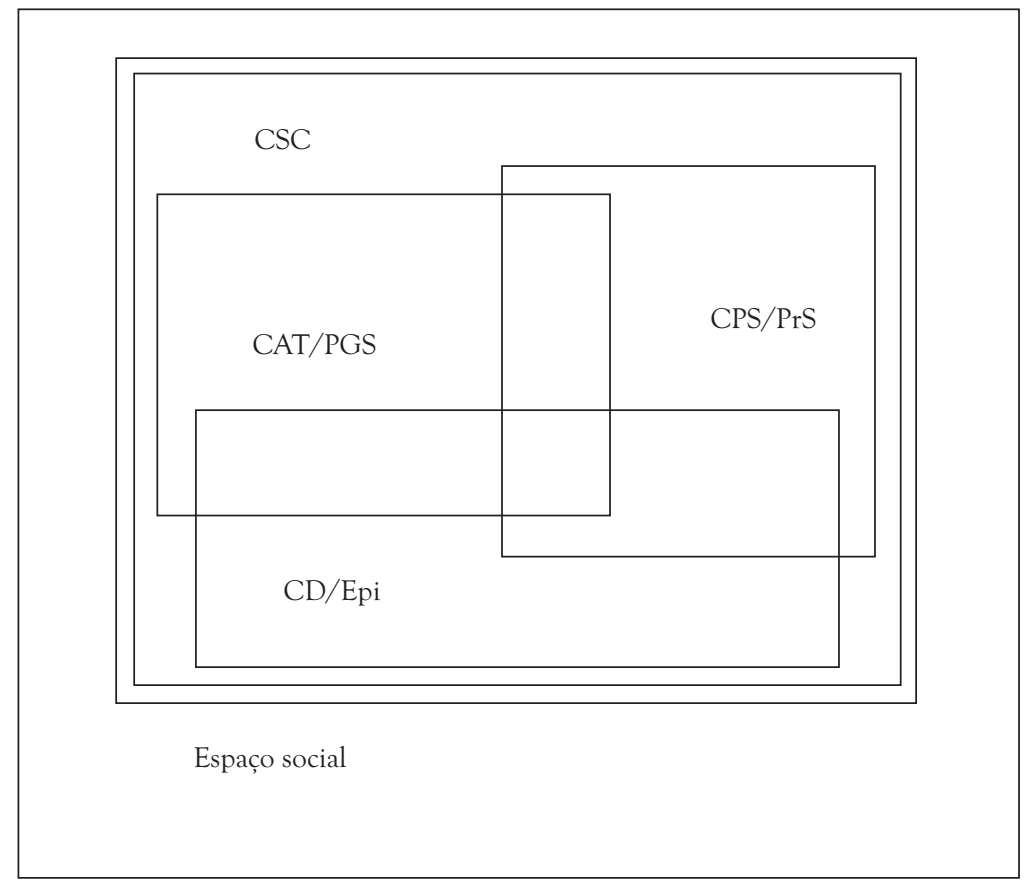
$[\mathrm{CSC}] \supset(\mathrm{CD} / \mathrm{Epi}),(\mathrm{CAT} / \mathrm{PGS}),(\mathrm{CPS} / \mathrm{PrS}),(\mathrm{CD} / \mathrm{Epi} \cap \mathrm{CPS} / \mathrm{PrS})$
$(\mathrm{CD} / \mathrm{Epi} \cap \mathrm{CAT} / \mathrm{PGS}),(\mathrm{CAT} / \mathrm{PGS} \cap \mathrm{CPS} / \mathrm{PrS})$
$(\mathrm{CD} / \mathrm{Epi} \cap \mathrm{CAT} / \mathrm{PGS} \cap \mathrm{CPS} / \mathrm{PrS})$

Fonte: Almeida Filho, 2000a:27.

Em suma, a saúde coletiva pode ser compreendida em seu processo de constituição histórica como o campo complexo de produção de conhecimentos sobre a problemática da saúde-doença-cuidado, que se desdobra em processos de desenvolvimento e experimentação tecnológica no âmbito de práticas sociais de promoção e proteção da saúde e prevenção de riscos e agravos, que abarcam desde a formulação e implementação de políticas públicas 'saudáveis', de caráter intersetorial, até a realização de ações que se materializam na prática cotidiana dos serviços de saúde e de organizações sociais voltadas para a melhoria das condições e dos modos de vida de indivíduos e grupos da população (Teixeira, 2000, 2002, 2003; Buss, 2003; Czeresnia, 2003). 
A constituição e a consolidação desse campo pressupõem e exigem a formação de sujeitos - especializados ou não, como sugere Almeida Filho (2000a) - capazes de se inserir em processos de produção de conhecimentos e de tecnologias, bem como na formulação e implementação de políticas e práticas que tomem como objeto condições, estilos e modos de vida de distintos grupos populacionais, operando, nesse percurso, um diálogo com outros campos disciplinares e outros âmbitos de prática, como por exemplo a clínica, a sociologia, a economia, a política, a antropologia, o direito etc.

A emergência da saúde coletiva se deu exatamente pelo processo de constituição de sujeitos que buscaram realizar esse diálogo, partindo da análise crítica das práticas de saúde vigentes, como foi o caso dos estudos pioneiros de Antonio Sergio Arouca (1975) e Maria Cecília Donnangelo (1976). Ao inaugurarem uma reflexão sobre os objetos, as práticas e as ideologias prevalentes em meados dos anos 70 no âmbito da medicina preventiva e comunitária, esses autores abriram espaço para o desenvolvimento conceitual que hoje fundamenta o campo da saúde coletiva, o qual vem se configurando como um campo extremamente dinâmico e diversificado, tanto em termos de áreas de produção de saberes quanto de práticas sociais voltadas para a promoção e melhoria da qualidade de vida e saúde.

Nesse contexto é que se insere a proposta de criação e desenvolvimento dos mestrados profissionalizantes em saúde coletiva, uma nova modalidade de formação de pessoal que vem se acrescentar às modalidades anteriores de formação especializada neste campo e cujo significado estratégico discutimos a seguir.

\section{FORMAÇÃO DE PESSOAL EM SAÚDE COLETIVA: ÂMBITOS E NÍVEIS}

O ensino das disciplinas do campo da saúde coletiva, bem como o desenvolvimento de atividades pedagógicas que reproduzem as práticas características desse campo, vem se institucionalizando em diversos âmbitos e níveis do processo de formação de pessoal na área de saúde nos últimos vinte anos.

De fato, a gestação do pensamento crítico que deu início ao surgimento desse campo se desenvolveu no âmbito acadêmico, desde meados dos anos 70 do século passado, conformando-se mais nitidamente nos espaços pedagógicos conquistados nos cursos de graduação ${ }^{1}$ da

${ }^{1}$ Estamos considerando que os primórdios do ensino da saúde coletiva remontam aos anos 60 , com a criação dos departamentos de Medicina Preventiva e Social e departamentos correlatos nas demais escolas da área da saúde. 
área de saúde e, principalmente, nos programas de pós-graduação, ${ }^{2}$ os quais vieram a constituir, inclusive, a Associação Brasileira de Pós-Graduação em Saúde Coletiva (Abrasco), no início dos anos 80 .

Odebate sobre o ensino da saúde coletiva tem acompanhado a expansão da base institucional da Abrasco, que na época de sua criação contemplava os programas de pós-graduação stricto sensu e os cursos de pós-graduação lato sensu, loci dos quais emanava uma preocupação com a inserção da saúde coletiva no âmbito dos diversos cursos de graduação na área da saúde.

Com a implementação do processo de reforma do sistema de saúde no Brasil, durante os anos 90, e diante dos desafios colocados para a área de saúde pública/coletiva no nível internacional, ${ }^{3}$ o ensino das disciplinas e atividades vinculadas a este campo tende a se espraiar para outras profissões e outros níveis de formação de pessoal, como, aliás, já vem ocorrendo a partir dos esforços de capacitação e educação permanente desenvolvida no âmbito doSUS.

O locus institucional do ensino da saúde coletiva, no momento atual, envolve disciplinas e atividades ministradas por departamentos de diversas escolas e cursos - de medicina, enfermagem, odontologia, farmácia, nutrição, engenharia sanitária etc. - que se responsabilizam, direta ou indiretamente, pelo ensino de epidemiologia, política, planejamento e/ou administração em saúde, e das ciências sociais em saúde, sob diversas denominações.

Nos últimos anos, por força do movimento em prol das reformas curriculares na área da saúde, desencadeado por um conjunto de atores vinculados a instituições e cursos que se fazem representar por entidades como a Comissão Interinstitucional Nacional de Avaliação do Ensino Médico (Cinaem), a Associação Brasileira de Educação Médica (Abem), a Associação Brasileira de Enfermagem (Aben), a Associação Brasileira de Ensino Odontológico(Abeno) e outras, várias delas aglutinadas na Rede Unida, as concepções e práticas de saúde coletiva tendem a se expressar na definição de objetivos curriculares e aparecem mencionadas nas competências profissionais das diversas áreas, o que cria o desafio para vários outros departamentos e escolas de formação superior da área de saúde (Rede Unida, 1998; CNE, 2001).

\footnotetext{
2 Também situamos os primórdios do ensino da saúde coletiva nos programas de pós-graduação em medicina preventiva, social ou comunitária, nos quais se ancorou nos anos 70 a partir da crítica aos movimentos ideológicos da área, ampliando-se consideravelmente nos anos 80 em termos do número de cursos de mestrado e doutorado, residências e cursos de especialização desenvolvidos no país.

3 Ver, por exemplo, o debate realizado no final da década de 90 e início do século atual, sobre a educação em saúde pública na região das Américas (Costa Rica, 1997; México, 1998; Havana, Cuba, 2000). Ver OPS/OMS, 1999; OPS, Alaesp, 2001.
} 
Mais recentemente, inclusive, tem se proposto a criação do curso de graduação em saúde coletiva (UFRJ e UFBA), voltado para a formação de profissionais capazes de atuar crítica e criativamente nos espaços criados pelo processo de reorientação do modelo de atenção à saúde no país, de modo a contribuir para o fortalecimento das atividades de promoção e proteção da saúde, prevenção de riscos e agravos em grupos populacionais específicos, e de planejamento e gestão de serviços de saúde em vários níveis do sistema (Paim, 2001, 2002; Aquino \& Medina, 2002).

A elaboração de tal proposta desencadeou um intenso debate na área, desdobrado em eventos específicos realizados nos últimos anos, como o Congresso Nacional da Rede Unida (Londrina, 2003) e o Congresso da Abrasco (Brasília, 2003). Configurou-se uma situação aparentemente sem perspectiva de consenso sobre a pertinência dessa proposição a curto prazo.

Além da expansão e diversificação do ensino de saúde coletiva no âmbito da graduação, os anos 90 assistiram à consolidação da formação pós-graduada, seja lato sensu (especialização, residência), seja stricto sensu (mestrados e doutorados), espaço privilegiado do processo de produção de conhecimentos e experimentação tecnológica desenvolvida no campo da saúde coletiva. De fato, no âmbito dos cursos de pós-graduação stricto sensu vem se ampliando e consolidando um conjunto heterogêneo de grupos e linhas de pesquisa que determinam, de certo modo, os limites e a configuração do campo, ${ }^{4}$ enquanto os cursos de pós-graduação lato sensu se constituem em espaços de aplicação tecnológica, pela incorporação de tecnologias leves utilizadas nas atividades desenvolvidas nas diversas áreas temáticas que se fundamentam nas disciplinas nucleares ao campo da saúde coletiva.

O conjunto de cursos de pósgraduação acaba funcionando, assim, como uma rede de 'observatórios' das tendências da situação de saúde da população, 'laboratórios' de pesquisa acerca de seus determinantes e condicionantes, e 'rede' cujas malhas retêm o que de mais importante acontece do ponto de vista da política, da gestão e da organização dos sistemas, dos serviços e dos recursos envolvidos nas práticas de atenção à saúde das pessoas e grupos da população.

Finalmente, cabe registrar que o ensino das disciplinaseixo do campo da saúde coletiva e o desenvolvimento de atividades práticas que se fundamentam em conhecimentos, métodos e técnicas derivadas da epidemiologia, do planejamento e gestão em saúde e das ciências sociais

\footnotetext{
${ }^{4}$ Ver mapeamento realizado pela Abrasco em 1996, publicado no número inaugural da revista Ciência e Saúde Coletiva, que expressa as tendências na produção de conhecimentos em epidemiologia, planejamento \& gestão em saúde e ciências sociais (Teixeira \& Sá, 1996). O exame do conteúdo dos diversos números da revista pode, inclusive, ser um indicador das tendências da produção na área, bem como a realização de algumas pesquisas que tomam por objeto a produção científica nesse campo, com base no banco de dados da Capes e em outras fontes de informação (Ayres, 2000; Levcovitz et al., 2003).
} 
em saúde não apenas tendem a se espraiar de modo a atingir o ensino das profissões de saúde nos nível da graduação e da pós-graduação. Eles também alcançaram o ensino médio ${ }^{5}$ e a educação permanente em saúde, ${ }^{6}$ este último através, principalmente, dos cursos introdutórios oferecidos pelos Pólos de Formação em Saúde da Família às equipes do Programa Saúde da Família(PSF).

Nesse contexto é que floresceu a proposta de criação do Mestrado Profissionalizante ${ }^{8}$ (MP), modalidade de formação de pessoal em saúde coletiva que detém, a nosso ver, um significado estratégico não só para a qualificação dos sujeitos que atuam na gestão e operacionalização das políticas e práticas de saúde consentâneas com os princípios e diretrizes da reforma sanitária em nosso meio. Tal modalidade constitui, também, um espaço privilegiado de produção de saberes e desenvolvimento tecnológico em áreas críticas para a consolidação do campo da saúde coletiva, isto é, sua validação como campo de conhecimentos e de práticas que incidem favoravelmente sobre a melhoria das condições, dos estilos e modos de andar a vida dos diversos grupos da população.

\section{MESTRADO PROFISSIONALIZANTE EM SAÚDE COLETIVA: SIGNIFICADO ESTRATÉGICO}

A principal característica do mestrado profissionalizante reside, a nosso ver, no fato de ser ele oferecido a partir do estabelecimento de uma parceria entre instituições de serviços e instituições de ensino, levando-as ao mais alto grau de aproximação, em um processo que se

\footnotetext{
${ }^{5}$ Por meio dos cursos oferecidos pelas escolas técnicas do SUS, embora a maioria das atividades esteja voltada para o fortalecimento do processo de formação de pessoal que atua no âmbito do modelo médico-assistencial hegemônico, como tem sido o caso da experiência recente do Projeto de Profissionalização dos Trabalhadores da Área de Enfermagem (Profae) (Brasil, 2003a).

${ }^{6}$ Cabe registrar também o esforço continuado de capacitação nas áreas de vigilância em saúde (epidemiológica e sanitária) e os numerosos cursos de capacitação de gestores de unidades de saúde (Gerus) e de sistemas locais de saúde realizados particularmente na segunda metade dos anos 90, a partir da intensificação do processo de municipalização da gestão do SUS. A iniciativa de desenvolvimento desses cursos tem partido, geralmente, das instituições de serviços (MS, SES e SMS) que contam com apoio técnico e financeiro de organizações internacionais, como a Organização Pan-Americana da Saúde (Opas), e com a participação de docentes provindos de núcleos e programas de saúde coletiva nos vários estados e regiões do país (Mota, 2003). Ver também Ribeiro \& Motta, 1996.

${ }^{7}$ No momento atual os Pólos de Capacitação em Saúde da Família, criados na maioria dos estados onde se avançou na implantação do PSF a partir de 1994, estão sendo substituídos pelos Pólos de Educação Permanente no âmbito do SUS, conforme proposta adotada pela Secretaria de Gestão do Trabalho e Educação em Saúde (Segetes/Ministério da Saúde) (Brasil, 2003a, 2003b).

${ }^{8}$ Uma síntese das características gerais do mestrado profissional encontra-se em Virmond, 2002.
} 
tenta institucionalizar desde que se discute a necessidade de 'integração ensino-serviço', forma de superação dos modelos tradicionais de formação na área de saúde, quais sejam, o 'modo escolar', distanciado da realidade concreta, e o 'modo em serviço', nela mergulhado. Ambos os modelos apresentam vantagens e desvantagens, as quais se situam em um gradiente de aproximação e distanciamento entre a reflexão crítica sobre as práticas cotidianas e o aprendizado instrumental de métodos e técnicas utilizados nos processos de trabalho no âmbito das instituições de serviços.

A criação do mestrado profissionalizante pode ser entendida como o resultado de uma busca pelo estabelecimento de um quantum de aproximação e distanciamento que permita a maximização das vantagens e a minimização das desvantagens presentes nos dois modelos. Nessa perspectiva, a implantação do MP em Saúde Coletiva pode ser vista como a possibilidade de institucionalização de um espaço onde pode se conjugar o que há de melhor no ambiente acadêmico, ou seja, o interesse pela produção de conhecimentos, a partir da crítica sistemática ao conhecimento existente e da abertura à identificação de novos problemas, objetos e abordagens, com o que há de melhor no ambiente dos serviços. Isto é, o desafio cotidiano de encontrar soluções aos problemas, de formular políticas e desenvolver estratégias que incidam efetivamente sobre estruturas e práticas insuficientes e/ou inadequadas para o enfrentamento e resolução dos problemas existentes.

Para que essa possibilidade se concretize é necessário, entretanto, que a parceria estabelecida entre as instituições de serviço e de ensino - o Ministério da Saúde, as secretarias estaduais e municipais e as Instituições de Ensino Superior (IES) - possa constituir-se de fato em uma oportunidade de diálogo e negociação, não apenas em termos do financiamento dos cursos, mas em torno do projeto político-pedagógico, dos conteúdos programáticos necessários e possíveis de serem abordados, dos problemas a serem pesquisados e dos produtos esperados do curso.

Isso pressupõe que, desde o primeiro momento do contato entre as instituições interessadas, a que demanda o curso e a que o oferece, seja desenvolvido um processo de análise prévia dos problemas, necessidades e demandas institucionais, cotejando-se tais elementos com o enfoque adotado nos cursos em questão, os quais devem adotar um desenho curricular suficientemente flexível a ponto de permitir uma certa adaptação aos requerimentos desejados pela instituição conveniada com o programa de pós-graduação que oferece o MP.

Desse modo, é necessário que durante a execução do curso se criem condições para um monitoramento contínuo do desenvolvimento do processo de ensino-aprendizagem e da elaboração dos produtos finais, os quais se pretende que se insiram no processo de produção 
de conhecimentos e experimentação tecnológica na área de saúde coletiva, e especificamente representem uma contribuição à gestão, ao planejamento, à avaliação e à organização das práticas de saúde coletiva no âmbito do SUS.

Além disso, cabe pensar que o MP pode se constituir em um espaço que permita a reflexão e incorporação, pelos distintos sujeitos, de valores éticos e políticos coerentes com a excelência acadêmica e o compromisso com a eficiência, efetividade, qualidade e humanização das práticas de gestão e atenção à saúde no âmbito do sistema público. Desse modo, a reflexão pedagogicamente orientada na interface entre os problemas dos serviços e o acervo de conhecimentos e tecnologias desenvolvidas no campo da saúde coletiva pode se tornar o cenário de problematização do sentido histórico da formação de pessoal e da mudança das práticas de saúde em nosso meio.

Desdobrando essa argumentação, cabe recuperar a distinção que existe entre o mestrado e doutorado acadêmicos e os mestrados profissionalizantes, no que diz respeito ao recorte dos objetos de conhecimento e intervenção adotados como ponto de partida para a formulação da proposta político-pedagógica dos cursos. No âmbito dos mestrados e doutorados acadêmicos em saúde coletiva, tem prevalecido o recorte disciplinar, base da estruturação das distintas 'áreas de concentração', quais sejam, epidemiologia, planejamento e gestão em saúde e ciências sociais em saúde. Já no mestrado profissionalizante, vem sendo adotada a lógica que privilegia a constituição de áreas temáticas, com especificação mais clara dos problemas e práticas envolvidos em recortes específicos, como é o caso da 'gestão de sistemas de saúde', 'epidemiologia em serviços de saúde', 'vigilância sanitária' etc.

Isso reflete, por um lado, a diversificação de linhas de pesquisa e de intervenção, que impõe a busca de expansão das fronteiras do conhecimento disciplinar, ao tempo que exige o aprofundamento no estudo de problemáticas específicas, em suas várias dimensões epidemiológica, social, política e cultural. Com isso, a tendência é que se estabeleçam áreas temáticas que expressam, de um lado, a delimitação de objetos e a experimentação de abordagens inovadoras em seu estudo, ao tempo que absorvem a necessidade de vinculação dos resultados dos estudos à busca imediata de alternativas de solução para os problemas geradores.

Talvez seja o caso de se pensar que essa tendência no campo da saúde coletiva configura um duplo desafio. Por um lado, a necessidade de desenvolvimento de estudos e pesquisas que assumam a interdisciplinaridade na constituição dos objetos e na seleção das estratégias de pesquisa (Almeida Filho, 2000b), avançando no alargamento das fronteiras do conhecimento no campo e, por outro, a necessidade de se desenvolver estudos e pesquisas 'operacionais', que 
tenham como finalidade subsidiar a tomada de decisões e a incorporação de conhecimentos e tecnologias que impliquem o aperfeiçoamento das políticas e práticas de saúde.

Assim, o mestrado profissionalizante se situa, ao nosso ver, no pólo mais instrumental dessa tendência bipolar, sendo o espaço onde pode se dar a produção de novos conhecimentos e a aproximação entre os conhecimentos e tecnologias existentes e a prática concreta. Por conta disso, os produtos dos $\mathrm{MPs}^{9}$ podem ser estudos de síntese que subsidiem a formulação de políticas e projetos, bem como textos que contenham os resultados da elaboração e experimentação de instrumentos de trabalho, 'tecnologias leves', a serem incorporadas à gestão, promoção ou prevenção de riscos e agravos, ou estudos de caso desenvolvidos no âmbito das organizações de saúde, cujos resultados contribuam para a introdução de inovações gerenciais, organizativas e operacionais no processo de produção das ações e serviços.

Analisando especificamente o significado dessa proposta no contexto do movimento pela reforma sanitária e especificamente no processo de construção do SUS, cabe considerar que a implementação dos cursos de mestrado profissionalizante representa a conformação de um espaço de formação de profissionais e trabalhadores de saúde coletiva, que podem vir a se constituir em "sujeitos epistêmicos, avaliadores e públicos" (Testa, 1991), responsáveis pelo desencadeamento de mudanças nas organizações e práticas de saúde.

Os egressos do MP, nas diversas áreas temáticas nas quais vêm sendo desenvolvidos os cursos, se inserem no debate das alternativas de organização e gestão dos sistemas e práticas de saúde na sociedade contemporânea e no Brasil, em particular, podendo vir a atuar na consolidação do processo de descentralização e democratização da gestão do SUS e da implementação de propostas alternativas de organização das práticas de saúde, como é o caso da promoção e vigilância da saúde.

\section{COMENTÁRIO FINAL}

A implantação dos cursos de MP em saúde coletiva tem gerado um debate entre os profissionais da área, desdobrado em oficinas de trabalho e eventos específicos promovidos pela Abrasco, inclusive durante os Congressos Brasileiros de Saúde Coletiva ocorridos nos

\footnotetext{
${ }_{9}^{9}$ Para uma reflexão sobre a natureza dos produtos finais dos cursos de mestrado profissional, ver Roesch, 2001. Os relatos das experiências em curso, contidos nos demais capítulos deste volume, oferecem um panorama das tendências da produção científica e tecnológica pelos mestrados profissionalizantes, podendo vir a ser objeto de estudos específicos.
} 
últimos anos. Durante esses eventos, várias questões têm sido colocadas e críticas têm sido formuladas, abarcando preocupações e discordâncias com relação à forma de financiamento, à estrutura curricular dos cursos, ao tempo de duração, ao fato de que muitos deles se realizam de forma semipresencial, questionando-se, no limite, a qualidade dos produtos finais e a pertinência da criação desses cursos.

Evidentemente, todos esses aspectos continuarão a ser objeto de debates e fomentam, inclusive, a busca de aperfeiçoamento progressivo das propostas em andamento, as quais podem vir a ser objeto de avaliações específicas por parte da comunidade científica da área, para além da submissão dos cursos às normas de avaliação da Coordenação de Aperfeiçoamento de Pessoal de Nível Superior (Capes). Esse, aliás, é outro dos pontos que vêm sendo discutidos. A implantação dos mestrados profissionais coloca o desafio de rever os critérios de avaliação dos cursos de pós-graduação, agregando elementos que possam captar a sua especificidade e a sua contribuição ao avanço do conhecimento, ao desenvolvimento tecnológico na área e, principalmente, a repercussão que o processo de qualificação de dirigentes e técnicos de alto nível no âmbito das organizações gestoras do SUS no âmbito nacional e estadual podem vir a ter no processo de gestão e avaliação de políticas e na reorientação de programas e práticas de saúde no SUS.

A revisão que apresentei nos itens anteriores tenta contribuir para que este debate não se esgote na análise dos aspectos operacionais dos cursos, nem se circunscreva às características dos cursos atuais, e sim possa projetar a reflexão sobre a pertinência e a importância estratégica dessa modalidade de formação de pessoal em saúde coletiva, no contexto mais geral de consolidação do campo, tanto em termos da produção científica e tecnológica quanto, principalmente, pela sua contribuição na diversificação de estratégias de formação de pessoal que aproximem a prática acadêmica do 'mundo da vida'. A idéia é agregar relevância aos esforços que vêm sendo feitos no âmbito das instituições de ensino-pesquisa para que a utopia da saúde coletiva não se desvaneça diante das dificuldades e ameaças de caráter ideológico e possa florescer, apesar das limitações político-institucionais e financeiras com as quais trabalhamos cotidianamente.

\section{REFERÊNCIAS BIBLIOGRÁFICAS}

ALMEIDA FILHO, N. Intersetorialidade, transdisciplinaridade e saúde coletiva: atualizando um debate em aberto. Revista de Administração Pública, 34 (6):11-34, nov.dez. 2000a. 
ALMEIDA FILHO, N. A Ciência da Saúde. São Paulo: Hucitec, 2000b.

AQUINO, R. \& MEDINA, M. G. Perfil e competências do profissional de saúde coletiva. ISCUFBA, 2002. (Texto elaborado para o Seminário Interno sobre a Criação do Curso de Graduação em Saúde Coletiva.)

AROUCA, A. S. S. O dilema preventivista: contribuição para a compreensão e crítica da medicina preventiva, 1975. Tese de Doutorado, Campinas: Faculdade de Ciências Médicas, Universidade Estadual de Campinas.

AYRES, I. B. S. J. Política e gestão em saúde coletiva: análise temática de teses e dissertações produzidas no Brasil entre 1993 e 1998, 2000. Dissertação de Mestrado, Salvador: Instituto de Saúde Coletiva, Universidade Federal da Bahia.

BOURDIEU, P. O campo científico. In: ORTIZ, R. (Org.) Pierre Bourdieu. São Paulo: Ática, 1983.

BOURDIEU, P. Razões Práticas: sobre a teoria da ação. Campinas: Papirus, 1996.

BRASIL. Ministério da Saúde. Secretaria de Gestão do Trabalho e de Educação na Saúde. Pólos de Educação Permanente: diretrizes para sua organização. Brasília: Ministério da Saúde, 2003a.

BRASIL. Ministério da Saúde. Secretaria de Gestão do Trabalho e de Educação na Saúde. Política de Educação e Desenvolvimento para o SUS. Caminhos para a Educação Permanente em Saúde. Pólos de Educação Permanente em Saúde. (Informação para a reunião do Conasems), Brasília, 16 de setembro de 2003b.

BUSS, P. M. Uma introdução ao conceito de promoção da saúde. In: CZERESNIA, D. \& FREITAS, C. M. (Orgs.) Promoção da Saúde: conceitos, reflexões, tendências. Rio de Janeiro: Editora Fiocruz, 2003.

CONSELHONACIONAL DE EDUCAÇÃO. Novas diretrizes curriculares para os cursos da área de saúde. Brasília, 2001. www.educação.gov.br

CZERESNIA, D. O conceito de saúde e a diferença entre prevenção e promoção. In: CZERESNIA, D. \& FREITAS, C. M. (Orgs.) Promoção da Saúde: conceitos, reflexões, tendências. Rio de Janeiro: Editora Fiocruz, 2003.

DONNANGELO, M. C. F. Saúde e Sociedade. São Paulo: Duas Cidades, 1976. 
DONNANGELO, M. C. F. A pesquisa na área de saúde coletiva no Brasil: década de 70. In: ABRASCO. Ensino da Saúde Pública, Medicina Preventiva e Social no Brasil. Rio de Janeiro: Abrasco, Ensp, 1982.

GONÇALVES, R. B. M. Práticas de Saúde, Processos de Trabalho e Necessidades. São Paulo: Cefor, 1992. (Cadernos Cefor, Textos, 1)

LEVCOVITZ, E. et al. Produção de Conhecimentos em Política, Planejamento e Gestão em Saúde (PPEGG) e Políticas de Saúde no Brasil, 1974-2000. Brasília: Opas, 2003.

MOTA, M. L. Capacitação de gestores municipais de saúde: desafios e perspectivas, 2003. Dissertação de Mestrado, Salvador: Instituto de Saúde Coletiva, Universidade Federal da Bahia.

OPS/OMS. II Conferencia Panamericana de Educación en Salud Publica. Reforma sectorial y Funciones Esenciales de Salud Publica: desafios para el desarrollo de los recursos humanos. Washington, D. C.: OPS, 1999.

OPS/OMS. ALAESP. Educación en Salud Publica: nuevas perspectivas para las Americas. Washington, D. C.: OPS, 2001.

PAIM, J.S. Desenvolvimento teórico-conceitual de ensino em saúde coletiva. In: ABRASCO. Ensino da Saúde Pública, Medicina Preventiva e Social no Brasil. Rio de Janeiro: Abrasco, Ensp, 1982.

PAIM, J. S. Collective health and the challenges of practice. In: PAHO. The Crisis of Public Health: reflections for the debate. Washington, D. C.: Paho, 1992.

PAIM, J. S. Transición paradigmática y desarrollo curricular en salud publica. In: OPS/ OMS. ALAESP. Educación en Salud Publica: nuevas perspectivas para las Americas. Washington, D. C.: OPS/OMS, 2001.

PAIM, J. S. O objeto e a prática da saúde coletiva: o campo demanda um novo profissional? (Texto elaborado para discussão no I Seminário e Oficina de Trabalho Graduação em Saúde Coletiva: pertinência e possibilidades, ISC-UFBA, 5-6 de setembro de 2002.)

PAIM, J. S. \& ALMEIDA FILHO, N. Saúde coletiva: uma "nova saúde pública" ou campo aberto a novos paradigmas? Revista de Saúde Pública, 32(4):299-316, 1998.

PAIM, J. S. \& ALMEIDA FILHO, N. A Crise da Saúde Pública e a Utopia da Saúde Coletiva. Salvador: Casa da Qualidade Editora, 2000. 
REDE UNIDA. Contribuição para as novas diretrizes curriculares dos cursos de graduação na área da saúde. Olho Mágico, 16:8-26, abr-maio-jun. 1998.

RIBEIRO, E. \& MOTTA, J. Educação permanente como estratégia de reorganização dos serviços de saúde. Saúde para Debate, 12:39-44, jul. 1996.

RIBEIRO, P. T. A instituição do campo científico da saúde coletiva no Brasil, 1991. Dissertação de Mestrado, Rio de Janeiro: Escola Nacional de Saúde Pública.

ROESCH, S. M. A. Proposta para a dissertação de Mestrado Profissional. Londres, fev. 2001 (versão preliminar), $14 \mathrm{p}$.

TEIXEIRA, C. F. Modelos de atenção voltados para a qualidade, efetividade, eqüidade e necessidades prioritárias de saúde. Caderno da $11^{a}$ Conferência Nacional de Saúde, dez. 2000.

TEIXEIRA, C. F. (Org.) Promoção e Vigilância da Saúde. Salvador: Ceps-ISC, 2002.

TEIXEIRA, C. F. A mudança do modelo de atenção à saúde no SUS: desatando nós e criando laços. Saúde em Debate, 27(65):257-277, 2003.

TEIXEIRA, C. F. \& SÁ, M. C. Planejamento \& Gestão em saúde: situação atual e perspectivas para a pesquisa, o ensino e a cooperação técnica na área. Ciência $\mathcal{G}$ Saúde Coletiva, 1:80-103, 1996.

TEIXEIRA, S. F. As ciências sociais em saúde no Brasil. In: NUNES, E. D. (Org.) As Ciências Sociais em Saúde na América Latina: tendências e perspectivas. Brasília: Opas, 1985.

TESTA, M. Pensar em Saúde. Porto Alegre: Intermédica, 1991.

TESTA, M. Salud Publica: acerca de su sentido y significado. In: OPS: la crisis de la salud publica. Reflexiones para el debate. Washington, D. C.: OPS, 1992. (Publicación científica, 540)

VIRMOND, M. Mestrado Profissional: uma síntese. Salusvita, 21(2):117-130, 2002. 


\title{
FORMAÇÃO E CAPACITAÇÃO DOS RECURSOS HUMANOS NO BRASIL
}

\author{
SITUAÇÃO ATUAL, DESAFIOS E PERSPECTIVAS \\ DA PÓS-GRADUAÇÃO EM SAÚdE COLETIVA
}

\author{
Zulmira Maria de Araújo Hartz \\ Tânia Celeste Matos Nunes
}

O incremento quantitativo mas regionalmente desigual da pós-graduação stricto sensu e a velocidade do desenvolvimento técnico-científico e suas aplicações no campo da saúde têm constituído um campo de preocupações permanente para os atores educacionais, tradicionalmente afeitos a esta modalidade, bem como para os gestores e trabalhadores do sistema de atenção e de Ciência \& Tecnologia (C\&T) em saúde, dadas a constante diversificação e a complexidade das qualificações profissionais requeridas para a implementação das políticas de saúde.

Se o campo científico e de práticas sociais da saúde coletiva tem também constituído objeto de questionamentos na formação dos profissionais da saúde das diversas modalidades de ensino, a chamada 'formação de alto nível', em suas implicações éticas e sociais, já era destacada na 2 ${ }^{a}$ Conferência Nacional de Recursos Humanos para a Saúde (Minayo, 1993) e deverá, juntamente com a preocupação com a qualidade dos cursos, continuar balizando o debate da pós-graduação stricto sensu, conjunturalmente reforçado pela necessidade de revisão do processo de avaliação conduzido pela Coordenação de Aperfeiçoamento de Pessoal de Nivel Superior (Capes), como instância reguladora e de fomento do Ministério da Educação. Uma outra vertente a ser explorada é a necessária interface com a formação profissional, 
particularmente no que concerne à emergência dos Mestrados Profissionais (MP), indispensável à compreensão das novas perspectivas de capacitação.

Pretendemos abordar, com base em uma revisão documental e bibliográfica, alguns dos tópicos aqui mencionados, realizando uma descrição panorâmica e regional da oferta de programas e cursos por regiões e unidades da federação brasileira, seguida de uma apreciação dos principais desafios que estiveram associados à implementação dos MP até 2002. O principal eixo das discussões é dado pelo conjunto de textos do Fórum de Pró-Reitores (Foprop) que trataram dos novos paradigmas, das alternativas de fomento e da regionalização da pesquisa e da pós-graduação em geral, reflexões que expressavam tanto as fragilidades quanto as virtudes do meio acadêmico nessa instância institucional tratada como a mais legítima e representativa da pesquisa e da pós-graduação (Prata \& Bergman, 2003).

\section{EVOLUÇÃO E REGIONALIZAÇÃO DA PÓS-GRADUAÇÃO EM SAÚDE COLETIVA}

A desigualdade é o calcanhar de Aquiles da civilização brasileira. Não é diferente no campo da saúde. Os indicadores regionais e os referentes a diferentes grupos sociais dentro de cada região demonstram profunda discriminação social quanto à saúde, em qualquer aspecto da intervenção pública ou privada a ela atinente.

R. Guimarães, 2003

A noção de indissociabilidade do ensino-pesquisa, que tornou obrigatória, na universidade, a titulação mínima de mestrado para professores assistentes e de doutorado para professores adjuntos, constituiu um dos principais fatores que influenciaram a implantação da pós-graduação, a partir da lei 5.540 de 1968, que tratou da reforma do ensino superior. Mas foi a criação do Conselho Nacional de Pós-Graduação (interministerial), em janeiro de 1974, que efetivamente estabeleceu as bases das políticas específicas para a área, com a elaboração do I Plano Nacional de Pós-Graduação (PNPG), que vigorou de 1975 a 1980.

A implantação dos PNPG, tendo como pressuposto a necessidade de se estimular a formação de cientistas, pesquisadores e técnicos capazes de gerar conhecimentos que favorecessem maior autonomia tecnológica e o conseqüente desenvolvimento socioeconômico do país, tem sua viabilização financeira relacionada aos órgãos de fomento como Finep (Financiadora de Estudos e Projetos), CNPq (Conselho Nacional de Desenvolvimento Científico e Tecnológico), Capes (Coordenação de Aperfeiçoamento de Pessoal de Nivel 
Superior) e fundações estaduais de amparo à pesquisa: Fapesp, Faperj, Fapemig etc. (Beatriz \& Machado, 2003).

Além da idéia mestra de fortalecer o magistério universitário e de formar pesquisadores que atendessem às necessidades setoriais e regionais da sociedade, presente nos seus objetivos, e que resultou na implantação do Plano Institucional de Capacitação de Docentes e Técnicos (PICDT), em 1976, o I PNPG também se destacou pela criação do sistema de avaliação e da diretriz de criação das pró-reitorias de Pesquisa e Pós-Graduação, viabilizando a institucionalização dessas atividades (Beatriz \& Machado, 2003; Prata \& Bergman, 2003).

O II PNPG, que vigorou de 1986 a 1989, teve o papel de consolidar o projeto original, buscando melhor coordenação das instâncias governamentais e maior compatibilização das atividades de ensino-pesquisa com as prioridades nacionais, o que se continuou, no III PNPG (1986-1989), ampliando-se a integração com o sistema de Ciência \& Tecnologia e com a comunidade científica por meio da criação do Conselho Técnico Científico (CTC) da Capes em 1986, de alta relevância no processo de avaliação.

O IV PNPG, embora se considere que esteve vigente de 1998-2002, nunca foi oficialmente lançado, não surpreendendo que uma de suas principais diretrizes - diminuição das desigualdades regionais na oferta e no desempenho da pós-graduação - continue como prioridade máxima nas contribuições apresentadas pelo Fórum de Pró-Reitores de Pesquisa e de Pós-Graduação (Foprop) como proposta para o V PNPG (Prata \& Bergman, 2003).

De fato, percebe-se que, apesar da grande expansão dos programas de pós-graduação no período, o que poderíamos chamar de 'geografia do conhecimento' não é muito diferente da 'geografia da renda', e que as áreas de exclusão no concernente ao acesso a esses bens continuam fazendo o mesmo contorno da 'geografia da fome'.

Até 1973, o país contava apenas com 195 cursos de mestrado e 68 de doutorado, que haviam titulado aproximadamente 3.500 mestres e 500 doutores (Prata \& Bergman, 2003). Em 2002, o país contava com 1.570 programas em uma oferta de 1.540 cursos de mestrado e 841 cursos de doutorado. Dos 1.570 programas, 910 estavam na região Sudeste $(57,9)$, mas olhando-se apenas os cursos de doutorado, estes correspondiam a uma concentração de 70\% nesta mesma região. Os alunos de mestrado e doutorado já se elevavam a mais de cem mil em 2002, dos quais 69,4\% estavam matriculados em Instituições de Ensino Superior (IES) da região Sudeste (Bortolozzi, 2003). A grande área de ciências da saúde apresentava uma taxa ainda mais elevada de concentração (72\%), a região Norte e Centro-Oeste, apenas 0,3\% e $2 \%$, enquanto que o Nordeste e o Sul do Brasil apresentavam menor diferença inter-regional (15\% e 11\%, respectivamente) (Silva, 2003). 
A área da saúde coletiva, embora evoluindo com uma relação de menor discrepância, nos cursos de mestrado, continuava excluindo completamente a região Norte do acesso à pósgraduação e fortalecendo a formação de doutorado na região Sul (Tabela 1). Ao se observar a tendência de evolução dos alunos matriculados e titulados, a variabilidade incremental favorece o sul do Brasil também no mestrado (Tabela 2), sendo a região Centro-Oeste ainda mais penalizada por um crescimento negativo no período. Um dado positivo, quando se analisam os números da evolução dos matriculados e titulados nos programas de doutorado, está no fato de a taxa da variabilidade de crescimento do Sudeste ter sido inferior à da média nacional, indicando uma perspectiva de potencial melhoria da concentração relativa desses programas na região (Tabela 3).

Tabela 1 - Subárea de Saúde Coletiva: cursos de mestrado, doutorado e docentes - Brasil, 1996 e 2002

\begin{tabular}{l|c|c|c|c|c|c}
\hline \multirow{2}{*}{ Região } & \multicolumn{2}{c|}{ Mestrado } & \multicolumn{2}{c|}{ Doutorado } & \multicolumn{2}{c}{ Docentes } \\
\cline { 2 - 7 } \multicolumn{1}{c|}{ Ano } & 1996 & 2002 & 1996 & 2002 & 1996 & 2002 \\
\hline Norte & - & - & - & - & - & - \\
Nordeste & 2 & 6 & 1 & 1 & 29 & 96 \\
Sudeste & 9 & 11 & 6 & 6 & 322 & 377 \\
Sul & 3 & 5 & - & 3 & 32 & 56 \\
Centro-Oeste & 1 & 1 & - & - & 12 & 16 \\
\hline TOTAL & 15 & 23 & 7 & 10 & 395 & 545 \\
\hline
\end{tabular}

Fonte: www.capes.gov.br, dez.2003.

Tabela 2 - Subárea de Saúde Coletiva: alunos de mestrado* no Brasil em 1996 e 2002

\begin{tabular}{l|r|r|r|r|r|r}
\hline \multirow{2}{*}{ Região } & \multicolumn{3}{c|}{ Matriculados } & \multicolumn{3}{c}{ Titulados } \\
\cline { 2 - 7 } Norte & 1996 & 2002 & Var. & 1996 & 2002 & Var. \\
Nordeste & - & - & - & - & - & - \\
Sudeste & 60 & 154 & 2,56 & 20 & 81 & 4,05 \\
Sul & 653 & 875 & 1,33 & 144 & 310 & 2,15 \\
Centro-Oeste & 25 & 144 & 5,76 & 4 & 62 & 15,5 \\
\hline TOTAL & 21 & 10 & $-0,48$ & 2 & 11 & 5,5 \\
\hline
\end{tabular}

* Excluídos os cursos de mestrado profissional.

Fonte: www.capes.gov.br, dez.2003. 
Tabela 3 - Subárea de Saúde Coletiva: alunos de doutorado no Brasil em 1996 e 2002

\begin{tabular}{l|c|c|c|c|c|c}
\hline \multirow{2}{*}{ Região } & \multicolumn{3}{c|}{ Matriculados } & \multicolumn{3}{c}{ Titulados } \\
\cline { 2 - 7 } \multicolumn{1}{c|}{ Ano } & 1996 & 2002 & $\%$ & 1996 & 2002 & $\%$ \\
Norte & - & - & - & - & - & - \\
Suddeste & 9 & 42 & 4,66 & 3 & 8 & 2,66 \\
Sul & 346 & 671 & 1,93 & 76 & 165 & 2,17 \\
Centro-Oeste & - & 31 & - & - & 4 & - \\
\hline TOTAL & - & - & - & - & - & - \\
\hline
\end{tabular}

Fonte: www.capes.gov.br, dez.2003.

A compreensão e a solução de tais problemas não podem ocorrer sem uma rigorosa análise acompanhada de incentivos que favoreçam um programa sustentável de investimentos na produção científica, pois a consolidação da pesquisa seria o primeiro passo para uma vigorosa pós-graduação. Embora os órgãos de fomento em C\&T tenham adotado orientações políticas para diminuir o desequilíbrio regional, os resultados obtidos não são satisfatórios. Assim é que a região Sudeste, tendo $43 \%$ da população brasileira, recebe $60 \%$ dos recursos de fundos setoriais de CT\&I, possuindo 63\% dos doutores brasileiros e $64 \%$ das bolsas da Capes (Bortolozzi, 2003). Entre as iniciativas tentadas, com algum sucesso e muitas contradições, para minimizar essas desigualdades da pós-graduação e da pesquisa, como parte dos programas de capacitação institucional, destacam-se o PICDT, substituído pelo PQI (Programa de Qualificação Interinstitucional), e os mestrados interinstitucionais.

No PICDT, a IES recebia uma cota de bolsas, o que lhe permitia a programação dos docentes a serem qualificados anualmente. O PQI introduziu novas exigências, como a escolha do programa de treinamento e da linha de pesquisa, a formação do grupo de pesquisa na IES de origem, e

tanto a instituição quanto o docente vivem uma total incerteza quanto à aprovação ou não do projeto pela Capes. O número de projetos que foram atendidos pelo PQI mostra uma relação perversa entre as regiões. As IES das regiões $\mathrm{N}, \mathrm{NE}$ e $\mathrm{CO}$, que têm corpo docente com maior necessidade de treinamento, tiveram menos da metade dos seus projetos aprovados. (Ferreira da Silva, 2003:111, 113)

Os mestrados interinstitucionais, considerados de grande importância sobretudo na região Norte, onde foram realizados 14 cursos, continuam aguardando incentivos à sua 
implementação, embora sua continuidade e consolidação estejam sendo reivindicadas pelo Foprop (Hardy, 2003). Exemplos recentes dessas iniciativas no campo da saúde coletiva foram os dois cursos de mestrado interinstitucional promovidos na região Norte, pela Escola Nacional de Saúde Pública/Fiocruz, em Belém (1999-2001) e Manaus (2002-2004), bem como um curso de doutorado interinstitucional, em caráter experimental, realizado de 1999 a 2003 com um consórcio de três IES de Recife, coordenado em parceria com o Centro de Pesquisa Aggeu Magalhães (CPqAM/ Fiocruz), o qual favoreceu a viabilidade do atual programa de doutorado dessa unidade da Fiocruz e vem recebendo excelentes avaliações da Capes. Apesar do registro promissor de tais experiências, a sua realização se fez com inúmeras dificuldades para as instituições patrocinadoras, pois apenas o curso de Belém obteve apoio financeiro da Capes. Ambas as estratégias - programas consorciados e mestrados/doutorados interinstitucionais - integram a atual proposta dos Planos Regionais de Pesquisa e Pós-Graduação que foram elaborados como contribuição ao V PNPG pelo Foprop (Lima et al., 2003).

\title{
MESTRADOS PROFISSIONAIS EM SAÚDE: AVANCOOS E PERSPECTIVAS
}

\begin{abstract}
Um bom governo precisa de profissionais com habilidades e credenciais para gerar e traduzir achados de pesquisa em sólido aconselhamento científico. O governo deve ter a capacidade interna requerida para assimilar, interpretar e extrapolar o conhecimento obtido, para atender a suas necessidades. Pesquisadores do governo têm de ser tão bons quanto seus colegas ou parceiros externos para formar essas parcerias e com elas contribuir.
\end{abstract}

Kevin Keough, 2002

O contexto atual é marcado por mudanças aceleradas nas tecnologias de informação e comunicação, pelo acirramento da competição econômica e pela aceleração do processo de globalização, favorecendo um grande impacto no desenvolvimento econômico e social. Assim, para um país se tornar ou se manter competitivo é cada vez mais crucial a aquisição de capacidade para gerar e absorver conhecimentos e inovações, o que exige maiores investimentos em pesquisa, desenvolvimento tecnológico, educação e treinamento. Neste cenário, a gestão do conhecimento coloca-se como um fator essencial para vincular ciência e tecnologia ao desenvolvimento nacional, tornando-se necessário considerar a revolução em curso nos processos de produção. 
Modelos organizacionais com estruturas ágeis e flexíveis, que permitam a organização de grupos multidisciplinares, voltados para a resolução de problemas, tornam-se elementos essenciais para o novo paradigma do conhecimento científico e tecnológico. A introdução sistemática de formas de pensar o futuro e de definição de focos e de estratégias em modelos interativos, sem a rigidez dos sistemas tradicionais de planejamento, impõe-se como uma necessidade da administração pública na área.

Ainda que os mestrados profissionalizantes estejam sendo considerados por alguns apenas "uma modalidade de cursos de especialização com upgrade" (Neves, 2003), sua importância fica evidenciada no próprio texto da Capes (2002):

com a oferta de mestrado profissional, o Sistema Nacional de Pós-Graduação amplia sua interface com os setores não acadêmicos da sociedade brasileira, tendo em vista a formação de recursos humanos com o referido nivel de titulação para o exercício de profissões outras que não a de docente pesquisador (...) o mestrado profissional responde a necessidade socialmente definida de capacitação profissional de natureza diferente da propiciada pelo mestrado acadêmico.

Ainda que correspondam a apenas $5 \%$ da totalidade dos cursos de mestrado recomendados pela Capes e a menos de 10\% no conjunto das ciências da saúde (Tabelas 4 e 5), a criação dos MP no campo da saúde levou em conta seus princípios fundadores, enfatizando-se que o universo setorial é fortemente demarcado, assim como suas necessidades de conhecimento, e que, na concepção geral de gestão estratégica, as finalidades das organizações são os elementos centrais para uma administração eficaz e eficiente.

Tabela 4 - Distribuição dos cursos de mestrado pelas grandes áreas - Brasil, 2002

\begin{tabular}{l|c|c}
\hline \multirow{2}{*}{ Grandes áreas } & \multicolumn{2}{|c}{ Cursos de mestrado } \\
\cline { 2 - 3 } & Acadêmico & Profissionalizante \\
\hline Ciências Agrárias & 194 & 01 \\
Ciências Biológicas & 166 & 05 \\
Ciências da Saúde & 331 & 24 \\
Ciências Exatas e da Terra & 195 & 08 \\
Ciências Humanas & 256 & 06 \\
Ciências Sociais Aplicadas & 189 & 24 \\
Engenharias & 190 & 23 \\
Lingüística, Letras e Artes & 99 & 01 \\
\hline TOTAL & 1.620 & 92 \\
\hline
\end{tabular}

Fonte: www.capes.gov.br, dez.2003 
Tabela 5 - Distribuição dos cursos de mestrado na área de ciências da saúde

\begin{tabular}{l|c|c}
\hline Mestrados em Ciências da Saúde & Acadêmico & Profissionalizante \\
\hline Educação Física & 13 & - \\
Enfermagem & 20 & 01 \\
Farmácia & 18 & 01 \\
Fisioterapia e Terapia Ocupacional & 02 & - \\
Fonoaudiologia & 05 & - \\
Medicina & 165 & 06 \\
Nutrição & 07 & 01 \\
Odontologia & 73 & 12 \\
Saúde Coletiva & 27 & 03 \\
\hline TOTAL & 330 & 24 \\
\hline
\end{tabular}

Fonte: www.capes.gov.br, dez.2003.

Os MPs em saúde surgem, portanto, como uma iniciativa voltada tanto para a capacitação dos quadros gestores, associada à promoção do desenvolvimento institucional, quanto para a capacitação de profissionais das organizações e da política de ciência e tecnologia em saúde, partindo do reconhecimento de que a gestão é uma das variáveis centrais para a geração e aplicação dos conhecimentos produzidos.

A criação dos MPs buscou responder aos desafios atuais apresentados pela sociedade do conhecimento, que demanda um profissional com perfil aberto, criativo, questionador e capaz não apenas de se adaptar, mas de gerar e propor mudanças, motivado e instrumentalizado para se capacitar, em caráter permanente, e consciente desta necessidade. Esses profissionais devem se preparar para atuar como formadores e indutores de processos de mudança em seus espaços de trabalho, mediante a adoção de novos conceitos de gestão estratégica que abarquem os três grandes universos nos quais a proposta se insere: universo da ciência e tecnologia; universo da saúde; universo da gestão pública.

O objetivo geral de "implementar novos mecanismos de gestão nas instituições de saúde (...) estimulando a geração de conhecimentos e de inovações e sua aplicação no desenvolvimento econômico e social" (Programa do MP em Gestão de C\&T em Saúde, Fiocruz, 2002) poderia representar o conjunto de iniciativas complementado pelos seguintes objetivos específicos:

- Contribuir para a construção de capacitações organizacionais estratégicas para a gestão do conhecimento científico e tecnológico em saúde. 
- Promover intervenções no processo de trabalho, desenvolvendo e utilizando novos métodos e ferramentas para a promoção, o acompanhamento e a avaliação de inovações gerenciais.

- Capacitar gestores envolvidos com processos dinâmicos de transformação institucional e inovação gerencial em saúde.

Como principal resultado do processo de formação em nível de mestrado profissional, esperam-se profundas mudanças nos modelos de gestão das instituições cujos quadros estejam se capacitando nesses cursos, bem como a conformação de modelos paradigmáticos neste campo que sirvam de exemplo para outras organizações. A definição e adoção de critérios de seleção estratégica de alunos comprometidos com processos de mudança e que atendam primordialmente aos novos desafios gerenciais de suas unidades é peça-chave no processo de construção desse mestrado.

Assim, identifica-se a necessidade imperiosa de um processo de qualificação de alto nível, dirigido às diferentes necessidades dos gestores em saúde nas suas diversas áreas de atuação: pesquisa, ensino, desenvolvimento tecnológico, produção de bens, informação, serviços e desenvolvimento institucional. O setor Saúde se enquadra em uma das expectativas enunciadas na publicação do Foprop, a de que o MP não seja aberto à demanda espontânea, e sim tratado como um projeto institucional (Gazzola, 2003).

Por se tratar de um mestrado com perspectiva multidisciplinar, consubstanciada na articulação intrínseca de diferentes campos de conhecimento, deve-se contar, para tanto, com professores de formação e experiência de trabalho a ela relacionadas. Isso porque um dos maiores desafios desse processo está no fato de que o profissional em formação necessita adquirir competências 'mediadoras', para traduzir não apenas pesquisa em decisões como também decisões em questões de investigação. Aqui, traduzir pesquisa significa, em um processo iterativo, a capacidade de explicar aos gestores os principais conceitos, métodos científicos e limitações do estudo em relação às suas expectativas. De outro lado, o desafio também reside em explicar aos pesquisadores as contingências relativas aos valores, prazos, características, políticas e organizacionais etc. (Pourvouirville, 1999).

A relevância e a oportunidade da iniciativa dos MP para a gestão das organizações governamentais de atenção à saúde, ou daquelas que geram conhecimentos científicos e tecnológicos, um dos aspectos essenciais do campo da saúde pública, também parecem incontestáveis. Entende-se, portanto, como programas de MP aqueles que, diferentemente dos programas acadêmicos, se propõem a formar quadros funcionais estratégicos, enfatizando 
um caráter de terminalidade, aptos para a compreensão, definição e condução das políticas de intervenção no processo saúde-doença.

Elaborada conjuntamente entre o demandante e o aparelho formador, essa proposta visa a prover recursos humanos que estejam atualizados nos novos conhecimentos existentes e sejam capazes de, por um lado, acompanhar e incorporar os processos de inovação e produção de conhecimentos e, por outro, formular projetos voltados para responder aos problemas identificados e avaliar o impacto das intervenções aplicadas na sua área de atuação. A formação desses recursos, antes suprida, em princípio e na maioria das situações, pelos cursos de especialização, se vê necessitada, a partir da nova realidade apresentada pelo SUS, de pessoal capacitado nas situações aqui expostas. O MP se mostra, nesse caso, uma modalidade de formação adequada.

No arcabouço que configura o estágio atual do SUS, com suas demandas por profissionalização, os cursos de especialização assumem, neste momento, caráter de iniciação, quando mencionados como perspectivas pessoais, e de 'primeiros passos do aprimoramento de processos', quando avaliados em sua vinculação à organização do trabalho em saúde pública. Evidencia-se, dessa forma, que os MP em saúde coletiva ocupam um vazio que passou a existir no universo atual de demandas, e que sua incorporação pelo sistema nacional de formação provoca um rearranjo de caráter agregador entre esta e as demais modalidades até então existentes para a preparação de quadros estratégicos para o sistema de saúde.

Para Goldbaum (2003), o MP na área da saúde, voltado para nichos de carência estratégica de pessoal, pode, se adequadamente conduzido, prover quadros adaptados às novas necessidades encontradas no sistema de saúde brasileiro. Assim, o desenho de programas de formação de recursos humanos, altamente qualificados, pode atender às necessidades específicas de cada um dos níveis de atuação, dando destaque ao quadro de pessoal responsável pela definição e pela condução das diretrizes técnicas dos órgãos governamentais das esferas federal, estadual e municipal do SUS.

Não obstante os argumentos promissores de sustentabilidade da proposta, acima analisados, vemos ainda com muita preocupação os seguintes pontos:

- Há um estímulo para a criação de cursos sem que haja clareza de concepção, de objetivos e de critérios para a avaliação de propostas.

- Embora seja classificado como programa stricto sensu, na prática o MP tem transposto para este domínio características indesejáveis do lato sensu: a especialização per si; a possibilidade de extinção dos cursos em um curto espaço de tempo por falta de deman- 
da do setor empresarial; a complementação salarial dos docentes; a dificuldade de controle da expansão dos cursos, entre outras. A criação do mestrado auto-sustentável gera modelos de atuação docente diferenciados, que privilegiam esta modalidade em detrimento dos programas de graduação e de pós-graduação tradicionalmente mantidos por agências e órgãos públicos.

No intuito de fortalecer alianças formadoras de opinião e de suporte às decisões da Capes, favoráveis à sustentabilidade dos $\mathrm{MP}$ em saúde coletiva, um rico debate se estabeleceu no âmbito do Congresso da Associação Brasileira de Pós-Graduação em Saúde Coletiva (Abrasco), reafirmando o acerto desta opção de pós-graduação para o estágio atual de implantação do Sistema Único de Saúde. Ele foi reforçado com os dados apresentados pelos três programas de pós-graduação referentes à conclusão dos trabalhos de dissertação da maioria dos alunos, com indicativos claros, na variedade dos temas abordados, da qualidade das contribuições ao processo de governança do SUS.

Atualmente, a ampliação das possibilidades de vagas dos MP continua restrita, dada sua vinculação a critérios anteriormente desenvolvidos para os mestrados acadêmicos. Ainda que alterações venham ocorrendo, evitando-se excessivas ampliações ou prejuízo da qualidade conquistada, considera-se indispensável discutir o assunto, com vistas à sua continuidade. Finalmente, vale ressaltar que as instituições gestoras desses mestrados têm algumas preocupações sobre o processo de avaliação coordenado pela Capes, atualmente em vigor, que ainda não se consolidou no tratamento dessa modalidade, notadamente no que se refere à implantação de comitês, com uma conseqüente proposta específica de avaliação.

No seminário sobre MP promovido em 2003, o grupo temático Ciências da Vida reiterou a necessidade de definir parâmetros diferenciados de avaliação em relação aos mestrados acadêmicos, sugerindo-se que se dê continuidade, por intermédio da comissão, à elaboração de propostas orientadoras de avaliação, mas também apreciando-se alternativas de acreditação (CTC-Capes, 2003). O fato de darmos destaque às ciências da vida não lhes restringe os questionamentos que nos parecem comuns ao conjunto das áreas, a exemplo da indagação de Gazzola (2003): qual seria, então, a especificidade do mestrado profissional? A que projeto de maior fôlego ele pode ser associado e de que modo proceder para que venha a enriquecer a pós-graduação?

A necessidade de se ampliar o debate sobre o papel do mestrado, seja ele acadêmico ou profissional, é compartilhada por Bergman (2003), vice-presidente do Foprop, para quem a redução nos tempos de fomento e titulação alterou as expectativas de contribuição do 
mestrado acadêmico ao desenvolvimento das pesquisas, mas pode ter um papel relevante na formação de profissionais qualificados para lidar com as inovações tecnológicas e informacionais como elemento essencial ao desenvolvimento.

Retomando o ponto de vista das articulações intersetoriais, consideramos pertinente recomendar uma contínua ação política do Ministério da Saúde no âmbito do MECCapes que viabilize as alternativas de manutenção dessa modalidade de pós-graduação, essencial ao avanço da profissionalização do Sistema Único de Saúde brasileiro, e procure superar eventuais dificuldades indicadas no debate da comunidade científica. Parece igualmente recomendável que seja criado um fórum permanente de discussão e monitoramento das experiências já em curso, como forma de enriquecimento e de vigilância da qualidade, necessária a qualquer atividade dessa natureza. Apesar dos avanços ocorridos na formulação e implementação de políticas de formação de recursos humanos para a saúde em todos os níveis, a modalidade de mestrados profissionais requer um maior estreitamento desses laços como garantia de qualidade, com reforço ao Sistema Único de Saúde brasileiro.

\section{À GUISA DE CONCLUSÃO}

Praticar, conhecer, praticar outra vez e conhecer de novo, esta é a postura teórica de uma pós-graduação. Ela se opõe ao ativismo, que despreza a teoria e estimula o empirismo funcionalista, e ao academicismo, que, com base em atitude, linguagem e produção herméticas, estimula apenas a reprodução institucional do saber e torna as unidades de ensino prisioneira de sua própria lógica.

Maria Cecília de Souza Minayo, 1993

Ao reler essa passagem da professora Cecília Minayo, que evoca a falsa contradição entre teoria e prática dos que se colocavam nos pólos do ativismo ou academicismo, na década passada, não podemos deixar de associá-la a uma outra visão equivocada que ainda opõe o MP ao mestrado acadêmico. Pensamos que, na verdade, a implantação do MP torna concreta a percepção baconiana de que as aplicações tecnológicas são o objetivo fundamental da pesquisa científica, verdade e utilidade compondo, na unidade $C \& T$, a plena realização da produção do conhecimento (Lacey, 2002). No campo da saúde, a viabilidade e desenvolvimento dessa 'unidade' estaria na dependência de uma Política Nacional de Ciência, Tecnologia e Inovação em Saúde (PNCT\&I/S), em que o Ministério da Saúde assumisse maior participação no seu fomento e estruturação (Guimarães, 2003a, 2003b). 
É, assim, desejável que o papel do Ministério da Saúde em C\&T esteja em consonância com as políticas de recursos humanos - seja na definição de prioridades, seja na sua absorção -, pois uma primeira apreciação mostra que

os setores de CËT e educacional não vêm se atualizando (em termos de absorção ou respostas) frente ao conjunto de profissionais qualificados que eles próprios vêm criando (...) o equacionamento deste desafio pressupõe a correção das injustiças criadas com a excessiva concentração de recursos e pessoal nos eixos Sul-Sudeste do país. (Goldbaum, 2003b:10)

Torna-se ainda fundamental problematizar conceitos e práticas institucionais que recolocam na pauta dos debates da 'sociedade do conhecimento' as propostas de 'capacitação x formação' e produtividade x avaliação como dimensões indissociáveis da construção e democratização do saber, mas que podem se tornar competitivas nas políticas educacionais e de autonomia universitária (Chauí, 2003). Três precauções sumarizam a questão:

- A ênfase nos processos de educação continuada e permanente, como estratégia pedagógica indispensável às mudanças incessantes do mercado de trabalho, não pode se reduzir à aquisição de técnicas de 'adestramento' ou a treinamentos que respondam às necessidades empresariais ou organizacionais e descuidar do núcleo fundamental do trabalho universitário de 'formação'. Formação é aqui entendida como transformação interna de um suposto saber de natureza científica trazendo, em sua relação temporal, de ordem simbólica, o passado de sua cultura, ao 'estimular a passagem do instituinte ao instituído'.

- Remetendo a discussão da produtividade acadêmica para o plano filosófico, é questionável uma equivalência entre publicação e produção de conhecimento. $\mathrm{O}$ aumento quantitativo precisaria ser tomado cum grano salis, pois pode exprimir pouca qualidade e inovação se considerarmos que: a) os processos de avaliação acadêmicos, dos quais dependem a obtenção do financiamento de pesquisas e a ascensão na carreira, são baseados no número de publicações e no ranking dos periódicos e b) os centros de pesquisa só conseguem financiamento público se continuamente 'provarem' que estão alcançando novos conhecimentos, trazendo como problema de fundo a velocidade imposta ao trabalho científico. Tais imposições levariam ao abandono do livro pelo paper, a substituição da incerteza criativa, geradora da inovação, pela insegurança produtora do medo, inibidora da criação e fomentadora de submissão ao instituído. 
- Uma 'sociedade de conhecimento' só pode produzir realmente uma 'explosão do conhecimento', no sentido epistemológico, com o resgate da autonomia relativa de produção do saber universitário que rompa com as amarras da compressão espacial-temporal da lógica de mercado, com ênfase na avaliação de produtividade. Nessa perspectiva se valorizaria a função docente de formação como "obra de pensamento" que "só é fecunda quando pensa e diz o que sem ela não poderia ser pensado nem dito (...) quando o presente é apreendido como aquilo que exige de nós o trabalho da interrogação, da reflexão e da crítica, de tal maneira que nos tornamos capazes de elevar ao plano do conceito o que foi experimentado como questão, pergunta, problema, dificuldade" (Chauí, 2003:9).

\section{REFERÊNCIAS BIBLIOGRÁFICAS}

BEATRIZ, A. \& MACHADO, K. Pós-graduação: pensamento e ação integrados para a consolidação do SUS. Radis - Comunicação em Saúde, 2(7):10-15, 2003.

BERGMANN, J. Avaliação da educação superior. In: Reflexões do Fórum de Pró-Reitores de Pesquisa e Pós-Graduação. XIX Encontro Nacional de Pró-Reitores de Pesquisa e PósGraduação das IES Brasileiras. Goiânia. Anais... Goiânia: Foprop, 2003.

BORTOLOZZI, F. Necessidades e ações para o desenvolvimento regional: planos regionais de pesquisa e pós-graduação. In: Reflexões do Fórum de Pró-Reitores de Pesquisa e PósGraduação. XIX Encontro Nacional de Pró-Reitores de Pesquisa e Pós-Graduação das IES Brasileiras. Goiânia. Anais... Goiânia: Foprop, 2003.

CAPES. Parâmetros para Análise de Projetos de Mestrado Profissional, julho de 2002.(Mimeo.)

CHAUÍ, M. A universidade pública sob nova perspectiva. 26ª Reunião Anual da Anped, Poços de Caldas, 2003.

CTCCAPES. Seminário sobre Mestrado Profissional, 2003. (Mimeo.)

FERREIRA DASILVA, J. Programas de capacitação institucional. In: Reflexões do Fórum de Pró-Reitores de Pesquisa e Pós-Graduação. XIX Encontro Nacional de Pró-Reitores de Pesquisa e Pós-Graduação das IES Brasileiras. Goiânia. Anais... Goiânia: Foprop, 2003.

GAZZOLA, A. L. A. Mestrado profissional e especialização. In: Reflexões do Fórum de PróReitores de Pesquisa e Pós-Graduação.XIX Encontro Nacional de Pró-Reitores de Pesquisa e Pós-Graduação das IES Brasileiras. Goiânia. Anais... Goiânia: Foprop, 2003. 
GOLDBAUM, M. Reflexões sobre a pós-graduação em saúde coletiva no Brasil. Boletim Abrasco, 87:9-10, nov.2002-abr.2003.

GUIMARÃES, R. Pesquisa em saúde: a hora do salto. Jornal da Ciência, 518:8, 2003a.

GUIMARÃES, R. Bases para uma política nacional de ciência, tecnologia e inovação em saúde. Cadernos de Estudos Avançados, 1(2):21-33, $2003 \mathrm{~b}$.

HARDY, E. R. Mestrados e doutorados interinstitucionais. In: Reflexões do Fórum de PróReitores de Pesquisa e Pós-Graduação.XIXEncontro Nacional de Pró-Reitores de Pesquisa e Pós-Graduação das IES Brasileiras. Goiânia. Anais... Goiânia: Foprop, 2003.

KEOUGH, K. How science informs the decisions of government. Canadian Journal of Public Health, 23(2):104-108, 2002.

LACEY, H. Máquinas de verdade. Folha de S.Paulo. São Paulo, 31 jul. 2002, Mais!, p.16-17.

LIMA, E. M. et al. Planos regionais de pesquisa e pós-graduação. In: Reflexões do Fórum de Pró-Reitores de Pesquisa e Pós-Graduação. XIX Encontro Nacional de Pró-Reitores de Pesquisa e Pós-Graduação das IES Brasileiras. Goiânia. Anais... Goiânia: Foprop, 2003.

MINAYO, M. Formação de profissionais de saúde na pós-graduação stricto sensu: proposta. Jornal da Reforma Sanitária, número especial, p.20, 1993.

NEVES M. S. Sobre doutores e mestres. In: Reflexões do Fórum de Pró-Reitores de Pesquisa e Pós-Graduação. XIX Encontro Nacional de Pró-Reitores de Pesquisa e Pós-Graduação das IES Brasileiras. Goiânia. Anais... Goiânia: Foprop, 2003.

PRATA, A. T. \& BERGMAN, J. R. Introdução. In: Reflexões do Fórum de Pró-Reitores de Pesquisa e Pós-Graduação. XIX Encontro Nacional de Pró-Reitores de Pesquisa e PósGraduação das IES Brasileiras. Goiânia. Anais... Goiânia: Foprop, 2003.

POURVOUIRVILLE, G. Pesquisa em saúde pública: entre a ciência e a ação? Cadernos de Saúde Pública, 15(4):889-894, 1999.

SILVA, M. Pós-graduação em saúde. In: Reflexões do Fórum de Pró-Reitores de Pesquisa e Pós-Graduação. XIX Encontro Nacional de Pró-Reitores de Pesquisa e Pós-Graduação das IES Brasileiras. Goiânia. Anais... Goiânia: Foprop, 2003. 


\title{
MESTRADO PROFISSIONALIZANTE EM SAÚDE PÚBLICA
}

\author{
UM OLHAR PARA AS EXPERIENCIAS INTERNACIONAIS
}

\author{
Virginia Alonso Hortale
}

Há quase quatro décadas, o Ministério da Educação, ao estabelecer a natureza da pósgraduação e a implantação do mestrado no Brasil, baseou-se na experiência norte-americana e definiu o mestrado como "grau autônomo por ser um nível da pósgraduação que proporciona maior competência científica ou profissional para aqueles que não desejam ou não podem dedicar-se à carreira científica" (MEC, 1965).

Paradoxalmente, a modalidade denominada 'profissionalizante' desde sua implantação, em 1994, ainda não alcançou consenso quanto à sua natureza, aos seus produtos e ao seu impacto na sociedade brasileira. Há aqueles que dizem que ela é somente uma atualização de cursos de especialização de natureza generalista; e aqueles que consideram necessária a ampliação da interface com setores não acadêmicos da sociedade, formando recursos humanos para o exercício de profis sões que não a de docente pesquisador. Ena área da saúde pública há exemplos de mestrados profissionalizantes criados para capacitar quadros gestores de organizações quer de saúde quer de

\footnotetext{
${ }^{1}$ De acordo com o Dicionário Aurélio Eletrônico (1998), o termo 'profissionalizante' significa "ensino destinado a formar técnicos em determinados ofícios ou profissões". No entanto usa-se freqüentemente o termo 'profissional' ("aquele que exerce uma atividade por profissão ou ofício") para referir-se ao curso. Como ainda não há um termo único, usaremos ambos como sinônimos.
} 
ciência e tecnologia em saúde, reconhecendo-se que a gestão é uma das variáveis centrais para a geração e aplicação dos conhecimentos produzidos visando à inovação.

Ainda hoje não há respostas sobre quais áreas do conhecimento podem efetivamente contribuir para realizar as inovações ${ }^{2}$ necessárias à sociedade a partir da formação ${ }^{3}$ de 'mestres profissionais'. Para contribuir com esse debate, fomos buscar em algumas experiências internacionais de programas de mestrado em saúde pública elementos comuns à experiência brasileira e, na medida do possível, problematizamos suas diferenças.

Como ponto de partida para realizar a busca das experiências, baseamo-nos no conceito de mestrado profissionalizante da Coordenação de Aperfeiçoamento de Pessoal de Nivel Superior (Capes, 1995), que enfatiza estudos e técnicas diretamente voltados para o desempenho de um alto nível de qualificação profissional. Cabe lembrar que o termo 'profissionalizante' é utilizado somente no Brasil; nos países selecionados, os mestrados na área da saúde pública com características semelhantes às aqui mencionadas recebem, na maioria das vezes, o nome da subárea em que o curso foi realizado.

Como método de trabalho, fizemos uma busca não exaustiva em sítios internet de programas de mestrado oferecidos na Europa, América do Norte, América do Sule Central, eselecionamos aqueles mais semelhantes à definição aqui adotada e cujos documentos encontravamse em inglês, francês, italiano ou espanhol e estavam atualizados para o biênio 2003-2004. Verificamos que no sítio da Organização Mundial da Saúde e de sua regional Europa havia uma pequena quantidade disponivel de documentos sobre capacitação de profissionais da saúde, diferentemente da regional Américas. Isso pode ser explicado pelo fato de, na Europa, a formação de profissionais ser de competência quase exclusiva das universidades, com exceção de Espanha, Portugal e Itália.

Selecionamos um total de 38 programas - dez localizados na América do Norte, quatro nas Américas do Sul e Central e 24 na Europa - e sintetizamos seus objetivos e conteúdos obrigatórios em quadros.

Para a análise, adotamos a concepção de Franco (2000) para estudos desse tipo, que implica um confronto que vai além do mero conhecimento do outro e a comparação de si próprio com o que se vê no outro. Nessa perspectiva, conhecendo as características essenciais e comuns aos programas, identificamos os aspectos divergentes da concepção construída a partir da nossa própria experiência e do atual estado de conhecimento sobre o tema.

\footnotetext{
${ }^{2}$ A respeito do termo 'inovação', ver artigo de Conde e Araújo-Jorge (2003), em que as diversas concepções existentes na literatura são analisadas e nos ajudam a entender seu uso na área da saúde coletiva.

${ }^{3} \mathrm{O}$ termo 'formação' é aqui entendido como "uma prática social específica e como uma verdadeira instituição que cumpre certas funções sociais relacionadas com a reprodução, regulação e legitimação do sistema social" (Estevão, 2001:185).
} 
É importante esclarecer como funcionou o nosso 'olhar' na elaboração do trabalho aqui apresentado. Estamos de acordo com Franco (2000), quando afirma que as experiências que vivenciamos ou das quais estivemos bem próximos podem ajudar a diminuir o viés da mera revisão bibliográfica. Neste trabalho há um desequilíbrio tanto na apresentação como na discussão das experiências, principalmente aquelas relativas aos programas desenvolvidos nos paises europeus. O tratamento dos dados foi mais elaborado, pois quando da elaboração desta pesquisa tivemos a oportunidade de conhecer mais de perto o atual contexto de reformas por que passam esses sistemas de educação superior.

Embora haja limitações no desenvolvimento de uma pesquisa que toma por base somente sítios de internet, as conclusões a que chegamos foram fruto, em grande medida, do conhecimento prévio acumulado ao longo dos últimos dez anos exercendo atividades na área da pósgraduação.

Do ponto de vista conceitual, embora tenhamos adotado a definição da Capes para mestrado profissionalizante, ao longo da busca bibliográfica observamos que o termo 'mestrado em saúde pública' tinha relação tanto com a modalidade profissional quanto com a acadêmica, o que explica o fato de a maioria dos programas selecionados terem essa concepção. Por outro lado, há em alguns países selecionados diferenças na compreensão do queé uma formação pósgraduada, pelo menos entendendo-a em nossa perspectiva, da denominada educação permanente. ${ }^{4}$

Sabemos que não fizemos uma pesquisa extensiva na qual todas as variáveis estavam bem definidas, porém podemos considerar que os programas selecionados representam o que há de mais atual no campo da saúde pública. Em particular, entre 2003 e 2004 identificamos uma oferta maior de cursos na área de gestão, o que se explica por ser esta - a formação de quadros para gerenciar sistemas de saúde em constante reformulação - uma demanda sentida nos sistemas de saúde desses países.

Este trabalho foi dividido da seguinte forma: 1) síntese das principais características de mestrado implantados nos diferentes sistemas educacionais, visando ao melhor entendimento da terminologia usada; 2) descrição comentada dos programas desenvolvidos em 12 países: Argentina, Canadá, Colômbia, Cuba, Dinamarca, Espanha, Estados Unidos, Finlândia,

\footnotetext{
${ }^{4} \mathrm{Na}$ área da educação há duas vertentes predominantes: educação continuada e educação permanente. A primeira é entendida como uma atualização de conhecimentos, geralmente em formato disciplinar e baseada em técnicas de transmissão com fins de atualização técnica. A segunda incorpora a vivência dos profissionais ao processo ensino-aprendizagem, modifica as estratégias pedagógicas de ensino em um processo de construção e reconstrução do conhecimento sem a tradicional conformação disciplinar. Esta última, na América Latina, na área do desenvolvimento de recursos humanos em saúde, foi construída teórica e metodologicamente e tem sido implementada em diversos programas de formação (Davini, Nervi \& Roschke, 2002). Nos países de língua inglesa, o termo lifelong learning pode ser traduzido como educação permanente, já que é considerado um instrumento para promover a sociedade do conhecimento ou da informação (Kokosalakis, 2000).
} 
Inglaterra, Itália, México e Portugal; 3) discussão dos elementos comuns e divergentes nos programas e 4) considerações finais.

\section{SISTEMAS EDUCACIONAIS E PRINCIPAIS CARACTERÍSTICAS DOS PROGRAMAS DE MESTRADO5}

A tradição anglo-saxônica, em particular nos Estados Unidos da América e na GrãBretanha, representa a mais variada e complexa representação de graus de mestrado. $\mathrm{O}$ mestrado 'de curta duração' é realizado logo após a graduação, em um ou dois anos, e inclui uma dissertação com realização de pesquisa; já o mestrado 'de longa duração' incorpora o último ano da graduação. Nos últimos 25 anos, muitas universidades aproveitaram sua autonomia para introduzir programas de longa duração, especialmente nos campos da administração, matemática, ciências e engenharia. Na Irlanda, após o bacharelado de três a quatro anos, são necessários de um a três anos para se obter o título de mestre.

Nos países nórdicos, a Dinamarca foi um dos primeiros países a introduzir o sistema denominado $3+2^{6}$ paralelamente ao tradicional sistema único e, no final de 1980, passou a

\footnotetext{
${ }^{5}$ As informações referentes aos países europeus e da América do Norte foram retiradas do estudo de Tauch e Rauhvargers (2002).

${ }^{6}$ A denominação $3+2$ significa um sistema universitário de créditos, baseado fundamentalmente em dois ciclos: graduação e pós-graduação. Na maioria dos países o bacharelado equivale a 180 créditos e o mestrado, a 60 créditos, perfazendo um total de 240 créditos do denominado European Credit Transfer System (ECTS), sistema europeu de transferência de créditos. Cada crédito equivale a 20-25 horas de trabalho intra e extraclasse. $\mathrm{O}$ título recebido no primeiro ciclo deverá ter um valor específico para o mercado de trabalho europeu. O segundo ciclo levará à obtenção de um mestrado ou doutorado. No primeiro ciclo, o currículo é baseado em competências adquiridas ao longo do curso, e não no tempo dedicado ao curso. Ou seja, estudantes que completarem a graduação deverão ter, entre outras competências, as de conhecer o campo de estudo acima do ciclo secundário e aplicar o conhecimento adquirido no campo profissional de escolha. Estudantes que completarem o mestrado deverão ter alcançado um nível de conhecimento e compreensão para lhes permitir integrar conhecimentos complexos, formular julgamentos e comunicar suas conclusões a um público especializado ou não. É importante destacar que esta é uma, entre outras metas da Declaração de Bolonha (1999), a serem alcançadas até o ano 2010. Essa declaração estabelece que até 2010 deverá ser consolidado o Espaço Europeu de Educação Superior, com três objetivos: aumentar a competitividade e a atratividade em nível internacional da educação superior européia; melhorar a inserção dos graduados europeus no mercado de trabalho e desenvolver a mobilidade interna e externa de estudantes e graduados. As outras metas são: desenvolver um sistema de graus comparáveis e compreensíveis para estudantes e empregadores; estabelecer um sistema uniforme de créditos (ECTS); desenvolver programas de intercâmbio para estudantes e docentes; estabelecer mecanismos de cooperação entre as instituições de educação superior para garantir a qualidade da formação; promover a discussão da educação superior européia nas dimensões de desenvolvimento curricular, cooperação interinstitucional, planos de mobilidade e programas integrados de estudo, treinamento e pesquisa.
} 
oferecer programas de bacharelado com duração de três a três anos e meio e de mestrado com duração de dois a três anos. As universidades são as únicas a serem credenciadas para oferecer mestrado. A Suécia também segue o sistema 3 + 2. Nesse país uma nova modalidade, chamada 'mestrado profissional', foi recentemente introduzida, como um importante componente de educação permanente para candidatos inseridos no mercado de trabalho.

Na Noruega, o novo sistema implantado no final de 2003 segue um padrão diferenciado: $3+2+3$. Somando-se ao mestrado de 120 European Credit Transfer System (ECTS) está o mestrado internacional, com 60-90 ECTS, e o mestrado baseado na experiência de trabalho, também com 60-90 ECTS. Nesse país, todas as instituições públicas de educação superior podem oferecer mestrado. Na Finlândia está sendo introduzido um novo tipo de programa de mestrado e implementado um 'verdadeiro' sistema $3+2$, pois o bacharelado não levava a graus independentes, mas compunha o programa de mestrado de cinco anos. Os novos programas de mestrado são concluídos em dois anos e são também oferecidos somente nas universidades.

Nos Países Bálticos, foram introduzidos nos últimos dez anos programas de mestrado em todas as áreas, ea maioria dos programas de graduação é estruturada no sistema 3+2. Para o mestradoé necessário completar de 60 a 120 créditos, se for realizado após o bacharelado, que requer de 180 a 240 créditos. Na Letônia, o grau de mestrado ( 60 a 120 créditos) era inicialmente entendido como exclusivamenteacadêmico, não sendo oferecido para treinamento profissional após o bacharelado. Apesar de programas de treinamento profissional terem sido criados sem possibilidade de acesso ao doutorado, a introdução do mestrado profissional em 2000 resolveu o problema.

Entre os países do Sudeste e do Oeste europeus, a Itália iniciou em 1999 a reforma do seu sistema educacional, e a 'láurea' é alcançada após três anos ou 180 créditos. Há dois tipos de pós-graduação: especialista, com 300 ECTS (dois anos) ou 120 ECTS; e o mestrado universitário de $1^{\circ}$ nível (um ano ou 60 créditos), que, no entanto não fazem parte do sistema $3+2$. A atual lei menciona mais três graus: doutorado, diploma de especialização (um a cinco anos ou 60-300 ECTS) e mestrado universitário de $2^{\circ}$ nível (um ano ou 60 créditos).

$\mathrm{Na}$ Grécia, a graduação é concluída após quatro a cinco anos de curso (seis, no caso de medicina). As universidades oferecem um tipo de mestrado chamado 'diploma de especialização', após um a dois anos de curso. A Espanha possui uma modalidade de pós-graduação denominada 'máster', geralmente de orientação profissional, regulada e reconhecida pelas universidades, que no entanto não dá acesso ao doutorado. Em Portugal, está em discussão um modo de ajustar os quatro graus acadêmicos existentes (bacharelado, licenciatura, mestrado e doutorado) aos princípios da Declaração de Bolonha. 
Na França discute-se a introdução do sistema $3+2$ como adaptação ao regulamento da União Européia. Com isso, pode-se encontrar a modalidade 'profissional' na página de internet do Ministério de Educação, dividindo espaço com as modalidades 'pesquisa' e 'especializado'. Na Holanda, o sistema passará a ser 3+2. Na Alemanha, foi introduzido em 1998 o sistema $3+2$ em bases experimentais, e todos os seus programas serão credenciados. Na Áustria, em 1997, foi possível passar a oferecer programas de mestrado de 60 a 120 ECTS (e bacharelado de 180 a 210). Na Suíça, ainda está em elaboração um projeto de lei para adequar o sistema aos princípios da Declaração de Bolonha, tendo o bacharelado 180 créditos e o mestrado, 90 créditos.

Entre os países da Europa Central e do Leste, a Hungria está atualmente introduzindo o sistema 3 + 2. Na Bulgária ele foi introduzido em 1995. Na Polônia, o sistema é de cinco a cinco anos e meio, e confere o grau de mestre. Há programas profissionais na graduação com duração de três a três anos e meio com grau de licenciatura. Nos últimos dois anos o sistema está em transformação para o $3+2$. Na República Tcheca, embora seja permitido por lei cursar um mestrado de curta duração, este ainda não é valorizado. Na Eslovênia, o programa de mestrado de 120 ECTS é oferecido desde 1993, embora com a graduação de longa duração. Na Romênia, com características semelhantes às dos programas da Eslovênia, há programas de mestrado de um e dois anos de duração e oferecidos somente pelas universidades.

Os sistemas educacionais dos países latino-americanos têm tradição de centralização, com forte participação do Estado nas reformas da educação superior empreendidas. Além disso, seus modelos educacionais são reproduções de modelos europeus que estabelecem uma hierarquia entre a pesquisa e o ensino. A reforma do Estado ocorrida nas duas últimas décadas nesses países, com vistas à sua maior inserção no mercado globalizado, privilegiou a descentralização das políticas educacionais. E estas, com a exigência de que todos os países tenham mercados competitivos, devem ter como meta maior investimento na formação de recursos humanos para aumentar a produtividade em todos os setores. Nesse contexto, aumenta a demanda por educação superior, e a resposta é o aumento de instituições universitárias de caráter privado.

$\mathrm{Na}$ Argentina, por exemplo, é na década de 90 que se registra maior expansão dos cursos de pós-graduação devido, entre outros fatores, ao aumento do número de universidades públicas e privadas com oferta diferenciada na área de pós-graduação, à consolidação da área de pesquisa e ao estabelecimento de um novo 'mercado profissional', com a exigência de maior competitividade e incorporação de novas tecnologias. Embora a pós-graduação estivesse menos atrelada às tradicionais práticas institucionais e pedagógicas, os cursos não consegui- 
ram romper com essa lógica, permanecendo inalterados seus objetivos, conteúdos didáticopedagógicos e processos de avaliação (Fernández Lamarra, 2002).

De acordo com Rosar \& Krawczyk (2001:39), esse processo significou a privatização das relações sociais no interior do sistema público de ensino, "tornando mais complexo o quadro de institucionalização de estruturas públicas e privadas no âmbito da educação". As autoras sugerem que os diversos estudos realizados nos sistemas educacionais propuseram o mesmo tipo de descentralização, significando que as realidades educacionais desses países foram padronizadas artificialmente para atender às estratégias de inserção desses países no mercado mundial propostas nas reformas de Estado empreendidas.

Na Europa, todos os países da União Européia ((UE) estão em uma fase de transição, com a implementação de reformas em seus sistemas de educação superior para adequá-los até o ano de 2010 aos princípios da Declaração de Bolonha. O resultado desse processo, de acordo com relatórios sobre o assunto, aprovados na Comissão de Educação da União Européia, será o de aumentar a competitividade das universidades européias em relação às universidades americanas e levar a que elas atraiam mais estudantes de todo o mundo. Na América Latina, apesar de não haver maiores avanços, existe um homólogo à UE - o Mercosul -, e também aqui se firmou um compromisso na área da educação superior para tornar compatíveis os sistemas educativos, o reconhecimento dos estudos e a homologação de títulos, com o objetivo de facilitar a circulação de estudantes e profissionais da região.

O mestrado, nesse contexto, passa a assumir um papel determinante se tiver como objetivo uma qualificação por competências, possibilitando melhorar a inserção do profissional no mercado de trabalho e criar condições para fortalecer a concepção de educação permanente que as universidades assumiram mais recentemente como um dos seus objetivos para promover a sociedade da informação e do conhecimento. ${ }^{?}$

\section{OS PAÍSES E SEUS PROGRAMAS DE MESTRADO}

\section{América do Norte: Estados Unidos, Canadá e México}

Dos três países, são os Estados Unidos (EUA) que possuem um sistema de pós-graduação organizado há mais tempo, tendo sido possivel encontrar informação sobre 45 programas de

\footnotetext{
${ }^{7}$ Para maiores detalhes sobre essa temática, há uma pesquisa realizada em alguns países europeus e publicada no ano 2000 na European Journal of Education (vol. 3).
} 
Master in Public Health (MPH) nos catálogos de agências de acreditação ${ }^{8}$ da área. É importante destacar que sempre encontramos nos documentos a informação de que a natureza dos programas de MPH é profissional, embora em alguns deles fosse explicitado o componente acadêmico dos conteúdos. ${ }^{9}$

Também de igual importância é o fato de o termo MPH nos EUA significar o primeiro nível de formação profissional em saúde pública, não se confundindo com os Master of Business Administration (MBA) e sua variante MBA Executivo. ${ }^{10}$ De acordo com os folhetos de propaganda, ele não é o primeiro curso após a graduação, e atrai profissionais com outros títulos de pós-graduação que tenham alguma experiência. São cursos que proporcionam uma visão geral do campo da saúde pública, e o candidato, para ser admitido, deve provar ter experiência na área. Há também o denominado Mestrado em Ciências na área de Saúde Pública (MSPH), que é um grau de natureza profissional, preparando, no entanto para uma área específica da saúde pública.

\footnotetext{
${ }^{8}$ O termo 'acreditação' aqui não significa credenciamento, nem certificação, e apresenta características que o diferenciam da avaliação tradicional: a) reconhece (ou não) que um curso, programa ou instituição de educação superior alcança determinado padrão, podendo ser mínimo ou de excelência; b) envolve uma avaliação por padrões (benchmarking assessment); c) os achados são baseados em critérios de qualidade, nunca em considerações políticas; d) os achados incluem sempre elementos binários - sim ou não. De acordo com os critérios das agências americanas de acreditação (http://www.ceph.org/), o mestrado pode ser de dois tipos: a) profissional - prepara estudantes com conhecimento do objeto e dos métodos necessários no campo de prática e requer o desenvolvimento da capacidade de organizar, analisar, interpretar e comunicar conhecimento de forma ampliada; b) acadêmico - prepara estudantes para a carreira acadêmica e de pesquisa, através da pesquisa, aquisição, organização e disseminação de novo conhecimento em uma disciplina ou campo de estudo.

${ }^{9}$ De acordo com a definição do Dicionário Aurélio Eletrônico (1998), 'academia' pode ter dois significados: a) relativo à atividade filosófica, na qual se incluem os estabelecimentos de ensino superior; b) "Escola onde se ministra o ensino de práticas desportivas ou lúdicas, prendas, etc.". Na nossa opinião, pode significar maior flexibilidade para se adotar a terminologia 'profissionalizante' como um processo de natureza acadêmica, embora voltado para o serviço.

${ }^{10} \mathrm{O}$ Master of Business Administration (MBA) é um programa voltado prioritariamente para profissionais do setor privado e tem como objetivo qualificá-los para cargos de gerência na indústria, na administração e na economia, entre outros. Tem origem nos EUA em 1900 e é adotado na Inglaterra na década de 60; no restante dos países, somente a partir da década de 80 . Observaram-se nos últimos vinte anos as seguintes tendências na conformação desse programa: diminuição do tempo dos cursos de dois anos para um ano, por razões de competitividade; maior diversidade de tipos de cursos com diferentes estruturas (modulares, tempo parcial, consórcios internacionais, para o setor público etc); aumento da internacionalização dos programas permitido pela globalização dos mercados e facilitando a inserção de profissionais em outros países. O termo 'MBA Executivo' pode ter várias definições, mas essencialmente indica que o programa é voltado para gestores com muitos anos de experiência relevante. São profissionais que ocupam altos cargos executivos nas empresas e não têm disponibilidade para seguir um curso em tempo integral. O termo geralmente indica que o programa é apropriado para esse público em tempo parcial ou modular. Tanto nos Estados Unidos como no Canadá existem programas de MBA em saúde, sem que tenhamos encontrado menção ao fato de eles serem ou não equiparados aos MPH (Glossário de Termos MBA).
} 
Para fins deste trabalho, selecionamos quatro programas oferecidos pelas universidades de Berkeley e Harvard e pela Escola de Saúde Pública Johns Hopkins e sintetizados no Quadro 1.

$\mathrm{Na}$ Universidade de Berkeley, o mestrado é realizado em conjunto com a Faculdade de Administração. Ao final do curso o aluno recebe um título conjunto: mestre em saúde pública e em administração de negócios. O mesmo acontece com a Escola de Saúde Pública Johns Hopkins, que, além do tradicional mestrado em saúde pública, oferece um programa de mestrado em associação com a Escola de Administração da mesma universidade, com titulação conjunta.

Na Universidade de Harvard, o mestrado é organizado em sete subáreas: Efetividade Clínica; Saúde da Família e da Comunidade; Gestão de Cuidados de Saúde; Saúde Internacional; Métodos Quantitativos; Direito e Saúde Pública; Saúde Ocupacional e Ambiental. Há um tronco comum para as disciplinas obrigatórias.

Nesses programas, não é explicitada a carga horária total, e sim o número de créditos, que varia conforme o regulamento de cada instituição. O tempo para concluir o curso é de um ano, se realizado em tempo integral. Os objetivos definidos vão desde a aquisição de conhecimentos teóricos até as habilidades práticas. As disciplinas oferecidas são as que tradicionalmente compõem o campo da saúde pública, nas suas vertentes quantitativa e qualitativa. Nos casos dos mestrados voltados para a formação de gestores, são incorporadas outras disciplinas contemporaneamente associadas à área de gestão de qualidade. Conteúdos sobre questões éticas são ministrados em todos os cursos.

No Canadá, identificamos na Universidade de Montreal (Departamentos de Administração de Saúde e de Medicina Social e Preventiva), sintetizados no Quadro 1, dois programas de mestrado voltados para a formação em saúde comunitária e em administração de serviços de saúde, este último subdividido em três subáreas: Sistemas e Políticas de Saúde; Avaliação das Intervenções e dos Serviços de Saúde e Gestão; Estratégia e Planejamento. Como nesses programas existem duas alternativas de trabalho de conclusão (elaboração de dissertação e desenvolvimento de trabalho de campo dirigido), a oferta das disciplinas obrigatórias é flexível. No primeiro programa, ela está relacionada com o formato do trabalho de conclusão; no segundo, depende da subárea escolhida. Recentemente, passou a ser oferecido um programa denominado MBA-Santé, em conjunto com a Escola de Altos Estudos Comerciais (HEC) da Universidade de Montreal. A carga horária indicada no folheto informativo é "de acordo com o ritmo trepidante do mundo do trabalho em que estão inseridos os profissionais". 
Freqüentando o curso em tempo parcial (de sexta-feira a domingo), o aluno pode concluí-lo em menos de dois anos.

Observamos nesses mestrados conteúdos semelhantes aos dos mestrados dos EUA, com, no entanto, a introdução de conteúdos voltados para a área do meio ambiente, os quais, na nossa opinião, permitem ao aluno incorporar uma visão mais contemporânea do campo da saúde pública.

No México, selecionamos dois programas com oferta regular na Escola de Saúde Pública do Instituto Nacional de Saúde Pública (Insp): Mestrado em Saúde Pública e Mestrado em Gerência e Direção em Saúde. Esses programas estão sintetizados no Quadro 1. O primeiro é subdividido em cinco áreas de concentração: Epidemiologia; Administração de Saúde; Bioestatística; Saúde Ambiental; Ciências Sociais e do Comportamento. É composto de dois eixos: básico, com disciplinas obrigatórias; e de integração, com disciplinas relacionadas às subáreas. No segundo, embora os objetivos também se localizem no campo acadêmico (docência e investigação), os títulos das disciplinas e dos conteúdos nos pareceram mais voltados para o campo profissional. O tempo de duração do curso é de 18 meses, em tempo integral (Quadro 1).

Em síntese, todos os programas selecionados oferecem conteúdos compatíveis com as necessidades de formação teórica, operacional e metodológica do campo da saúde pública. Em alguns deles os conteúdos são mais tradicionais do campo; em outros, acompanham-se as inovações tecnológicas e do conhecimento. E, no geral, a natureza e os objetivos a que se propõem incluem a qualificação de profissionais para resolver problemas do campo da saúde pública.

\section{EUROPA}

Os países da União Européia, após a Declaração de Bolonha de 1999, iniciaram reformas em seus sistemas educacionais superiores para se adequarem a essa resolução. ${ }^{11}$ No que se refere à pós-graduação, de acordo com Tauch e Hauhvargers (2002), ainda há muita heterogeneidade na percepção de diferenças entre os perfis de mestrado acadêmico e profissional. Países como Bulgária, Chipre, República Tcheca, Dinamarca, Hungria, Polônia, Malta e Eslováquia afirmam que não fazem distinção entre os diferentes perfis; a Noruega está buscando um nome apropriado mas não faz distinções, em princípio. Na Áustria há programas de mestrado estritamente profissionalizantes e que não dão acesso ao doutorado.

\footnotetext{
${ }^{11}$ A Declaração de Bolonha não está no âmbito estrito da União Européia, pois foi elaborada por um conjunto de ministros da Educação europeus, e não tem valor legal no âmbito europeu. Portanto, não se caracteriza como um mandato da União Européia que obriga os países-membros ao seu cumprimento; é um acordo que só tem validade se os governos signatários o implementarem em seus respectivos países (Hortale \& Mora, 2004).
} 
Na Holanda, tanto a universidade quanto as escolas de altos estudos oferecem mestrados acadêmicos e profissionalizantes, dependendo da natureza da demanda. Na Alemanha, programas com perfil mais acadêmico levarão ao Master of Arts (MA) e Master of Sciences (MSc), enquanto um programa mais aplicado levará ao mestrado profissional (engenharia, p. ex.). A diferente terminologia não implica uma diferenciação de acesso ao doutorado. Na Suíça ainda não há diferenciações, mas há propostas de, no futuro, as universidades oferecerem programas mais acadêmicos e as Écoles des Hautes Études, programas mais profissionais.

$\mathrm{Na}$ maioria dos países essa heterogeneidade não perturba a reforma em curso, mesmo com a implementação de novos programas de mestrado profissional. Na França, por exemplo, a distinção entre as modalidades faz parte do núcleo central da sua reforma para não afetar a progressão ao doutorado acadêmico. Nesse país, a formação profissional pós-graduada está concentrada nas universidades; no entanto; na área da saúde as secretarias de Saúde têm autonomia para oferecer cursos de pós-graduação.

Para este trabalho, procurando mostrar a diversidade existente, selecionamos países que oferecem regularmente programas de mestrado em saúde pública na universidade ou em instituições da área da saúde. Entre eles estão: Dinamarca, Espanha, Finlândia, Inglaterra, Itália, Portugal. ${ }^{12} \mathrm{O}$ Quadro 2 sintetiza as características dos programas de mestrado nesses países.

$\mathrm{Na}$ Universidade de Aarhus, Dinamarca, é oferecido um programa de mestrado de dois anos de duração, cujos conteúdos são os tradicionais do campo. Aqui também os conteúdos de ética aparecem, confirmando sua importância na área. Embora não tenhamos conhecido o programa em maiores detalhes, identificamos na descrição dos objetivos do curso a vertente da 'saúde pública baseada em evidências', de introdução recente no campo da saúde pública.

$\mathrm{Na}$ Espanha, os 14 programas selecionados cobrem um amplo espectro de subáreas: Gestão, Epidemiologia, Avaliação e Economia da Saúde, acompanhando as inovações no campo da saúde. Sete deles são oferecidos por instituições de saúde, seis por universidades e um é oferecido em conjunto universidade/instituição de saúde. Em alguns desses programas, os objetivos descritos não guardam relação direta com os conteúdos oferecidos, o que pode ser explicado quer pelo caráter formativo quer pelo informativo, com carga horária variando entre 500 e 1.000 horas (na maioria das vezes, mais próxima de 500 horas).

${ }^{12}$ Não selecionamos a França, um dos países que possuem uma escola de saúde pública pertencente ao Ministério da Saúde e que oferecem cursos de formação para os futuros quadros dos ministérios da Saúde e da Ação Social, porque apesar de seus objetivos e conteúdos guardarem semelhanças com a modalidade Mestrado Profissionalizante, para o sistema educacional francês é considerada uma escola paramédica, e o grau por ele conferido é denominado Diploma de Estudos Universitários Científicos e Técnicos. 
Na Finlândia, o programa é oferecido pela Escola de Saúde Pública da Universidade de Tampere e cobre as subáreas da Saúde Comunitária, Epidemiologia, Biometria, Gerontologia, Saúde Ocupacional, Psiquiatria Social, Políticas Sociais e de Saúde e Economia da Saúde. Os conteúdos são oferecidos sob o formato de créditos e há obrigatoriedade de cumprir 60 créditos, dos quais 12 são destinados aos conteúdos da subárea de escolha.

$\mathrm{Na}$ Inglaterra, a Universidade de Londres, por intermédio da London School of Hygiene and Tropical Medicine, oferece três tipos de programas de mestrado: em Saúde Pública, em Epidemiologia e em Política, Planejamento e Financiamento. O primeiro pode ser caracterizado como um 'guarda-chuva', pois o aluno escolhe entre quatro opções de cursos: Geral, Saúde Ambiental, Promoção da Saúde, Gestão de Serviços de Saúde, Pesquisa em Serviços de Saúde. Em todos, a titulação é a de mestre em ciências, e a duração do curso é de um ano (em tempo integral), sem especificação da carga horária total. Os objetivos e os conteúdos não fogem aos tradicionais do campo, com ênfase em conteúdos quantitativos.

Na Itália, dos seis programas oferecidos entre os anos 2003 e 2004, quatro são voltados para formar gestores para o sistema de saúde. Os outros dois são voltados para formar profissionais para coordenar programas de promoção e educação e de comunicação em saúde, recentemente configuradas como áreas estratégicas para aumentar a efetividade dos sistemas de saúde. Quanto aos conteúdos, além daqueles tradicionais do campo, é interessante observar a introdução de conteúdos do campo da psicologia e da comunicação nos programas de promoção e de comunicação, embora não tenhamos informações sobre o seu nível de aprofundamento. As cargas horárias, em geral, não ultrapassam 500 horas.

Em Portugal, a Escola Nacional de Saúde Pública oferece um programa de mestrado em saúde pública com três áreas de especialização: Ciências da Saúde Pública; Promoção e Proteção da Saúde; Política e Administração de Saúde. Sua carga horária é adaptada ao ECTS, ou seja, 60 créditos. O programa oferece disciplinas obrigatórias, comuns a todas as subáreas. Seus conteúdos não se afastam dos conteúdos tradicionais do campo, com ênfase, no entanto, aparentemente um pouco maior no enfoque qualitativo.

Na Itália e na Espanha, a grande maioria dos programas é oferecida a gestores ou profissionais do sistema de saúde. Sabemos, no entanto que a oferta não é regular, já que depende da demanda. Nesses países, como já dito aqui, nem sempre é uma instituição acadêmica que oferece o programa; este pode também ser oferecido por órgão com delegação do Ministério de Educação ou de um setor do Ministério da Saúde responsável pela educação continuada, ou ainda por uma instituição de natureza privada. Na Itália, a maior parte dos programas é 
oferecida por intermédio das secretarias de Saúde (órgão das regiões autônomas) que têm legislação própria para a formação denominada 'em serviço'. ${ }^{13}$

Já na Espanha, essa formação, denominada 'máster', não faz parte do sistema de educação superior formal, embora seja oferecida tanto pelas universidades (com autonomia para oferecer cursos de pós-graduação) quanto pelas secretarias de Saúde de algumas regiões autônomas ou em conjunto com o Instituto de Saúde Carlos III (instância de formação do Ministério da Saúde).

\section{América Latina}

Entre os programas de mestrado associados à Associação Latino-Americana e do Caribe em Educação em Saúde Pública (Alaesp) nos quais se indicava o sítio internet da Argentina, Chile, Colômbia, Cuba, Guatemala, Panamá, Peru e Venezuela, selecionamos somente aqueles com programas oferecidos regularmente e que não explicitavam a formação exclusiva para a pesquisa: Argentina, Colômbia e Cuba.

Na Argentina, o Conselho Nacional de Avaliação e Acreditação Universitária (Coneau), órgão autônomo ligado ao Ministério da Educação, Ciência e Tecnologia, é responsável pelo credenciamento da educação superior, funcionando desde 1996. Na área da saúde pública e áreas afins existem 21 programas de mestrado credenciados. Para fins deste trabalho, escolhemos aqueles avaliados como 'muito bons' e oferecidos regularmente: mestrado em saúde pública da Universidade de Buenos Aires e da Universidade Nacional de Rosário.

O mestrado em saúde pública da Universidade de Buenos Aires dura aproximadamente dois anos e oferece os conteúdos tradicionais do campo. Entre seus objetivos, destaca-se o de formar profissionais com a "capacidade de enfocar a saúde pública como campo interdisciplinar, intra e extra-setorial”. No mestrado em saúde pública da Universidade Nacional de Rosário a carga horária é de 700 horas, com tempo de duração de quatro anos (disciplinas cursadas em dois anos e elaboração de trabalho de conclusão em dois anos). Seus objetivos estão de acordo com os objetivos tradicionais do campo da saúde pública.

Na Colômbia, o mestrado em saúde pública oferecido pela Universidade de Antioquia dura aproximadamente dois anos. Adota, como modalidade pedagógica, sessões presenciais e semipresenciais, esta última para atender àqueles profissionais que não podem sair em tempo integral de suas instituições. Destacamos que, de acordo com estudo recente (IIES,

\footnotetext{
${ }^{13}$ Desde 2002, há uma lei instituindo o Programa Nacional de Formação Continuada dos profissionais da saúde, para atender a um dos itens da Declaração de Bolonha. Alguns dos cursos de mestrado aqui apresentados estão credenciados por esse programa.
} 
2002a), a titulação de mestre não é condição para ingressar no doutorado. O oferecimento dos cursos de mestrado, doutorado e pós-doutorado está restrito às universidades. Devido à autonomia universitária, os cursos de especialização podem ser oferecidos nas universidades, devendo, no entanto, passar por um processo de avaliação posterior. Por outro lado, os cursos de mestrado, doutorado e pós-doutorado devem ser credenciados previamente.

Em Cuba, no início da década de 90 já era oferecido um programa de mestrado em saúde pública com perfil profissionalizante. $O$ atual programa passou por uma completa revisão, a partir de estudo avaliativo (Pérez \& Ayzaguer, 2000), que concluiu pela necessidade de rever quer conteúdos, quer práticas de acordo com as mudanças ocorridas no perfil epidemiológico da população e no sistema de saúde. Assim, o atual programa propõe o enfoque humanista e ético para desenvolver métodos e procedimentos na gerência dos sistemas e serviços de saúde. Foi um dos poucos países que durante a década de 90 conseguiram manter seu sistema de educação superior com bons níveis de qualidade apesar da situação econômica do país (IIES, 2002b).

Vale destacar que todos os programas seguem, aparentemente, a tradição da corrente crítica latino-americana, incorporando os conteúdos básicos das áreas de ciências sociais e formulação de políticas, imprescindiveis à formação do profissional de saúde pública.

\section{ELEMENTOS COMUNS E DIVERGENTES NOS PROGRAMAS}

Para fins comparativos, subdividimos nossa discussão em aspectos básicos e comuns aos programas; características essenciais; outros aspectos de interesse.

- O principal aspecto básico e comum à maioria deles é a ampliação da interface com setores não acadêmicos e a capacidade de responder a necessidade socialmente definida de capacitação profissional. É um aspecto que na Europa, por exemplo, faz parte dos princípios da Declaração de Bolonha, sendo mais explícito nos países em que tradicionalmente essa tendência era marcante, como Espanha e Itália.

Um outro aspecto também comum aos programas é o perfil do profissional ao final do curso, que pode ser assim resumido: aquele com capacidade de resolver problemas na área da saúde pública.

- As características essenciais dos programas podem ser assim sintetizadas:

- Em todos os programas, o perfil profissional para o acesso é multidisciplinar, embora em alguns deles se dê maior preferência às profissões da área da saúde. 
- Na maioria dos programas, embora não haja exigência explícita, a clientela já deve estar inserida no mercado de trabalho. Nos países europeus que estão passando por modificações na estrutura da graduação, os programas de mestrado têm conteúdos e perfis profissionais muito diversificados, o que fez com que uma das metas da Declaração de Bolonha seja desenvolver um sistema de graus comparáveis e compreensíveis para estudantes e empregadores, em que fique clara a diferença entre a graduação e a pós-graduação. ${ }^{14}$ Há várias iniciativas em curso para definir resultados de aprendizado, habilidades e competências ao final tanto da graduação quanto do mestrado (Bologna Process, 2003).

- Os conteúdos são transmitidos em módulos ou disciplinas, com predominância da segunda forma. Nos EUA e no Canadá há predomínio do enfoque quantitativo.

- Os métodos pedagógicos são muito variados. Em alguns deles identifica-se uma grande associação entre teoria e prática, percebida de forma indireta pelos conteúdos voltados para a inovação; no entanto, não foi possível perceber se há algum distanciamento.

- Pudemos observar que a carga horária dos programas varia entre 500 e 1.400 horas. Por isso, é possível imaginar que em alguns programas os conteúdos estariam sendo oferecidos com caráter mais informativo do que formativo e os conteúdos considerados obrigatórios não englobariam suficientemente os objetivos definidos.

- Além dos aspectos aqui destacados relacionados especificamente às experiências, é interessante comentar alguns outros que ajudam a entender os contextos em que os programas são oferecidos.

- Na América Latina, por exemplo, éa Organização Pan-Americana da Saúde(Opas) a instituição que orienta sua cooperação na região na área de formação pós-graduada de profissionais da saúde. Eessa orientação se dá, mais recentemente, na lógica da Educação Permanente(EP), justificada pela rapidez com que esses profissionais se desatualizam em relação às numerosas inovações na área. Recente documento da Opas (Davini, Nervi \& Roschcke, 2002) recorda que as reformas dos sistemas de saúde da região que incluem processos de descentralização e desenvolvimento de novas práticas de gestão significam a oportunidade para, de um lado, capacitar o maior número possível de profissionais e, de outro, verificar se os enfoques educacionais então existentes são

${ }^{14}$ Ver nota 6. 
adequados ou não. No mesmo documento é apresentado um estudo desenvolvido entre os anos 2000 e 2001, em oito países da América Latina e Caribe, sobre o alcance e os limites da implementação de projetos de capacitação na lógica da EP. Esse estudo teve como ponto de partida algumas perguntas: quais são as características das propostas de capacitação desenvolvidas e quais são os resultados da sua implementação? Que fatores favoreceram ou não o desenvolvimento das propostas? As propostas representaram importantes mudanças nas práticas de capacitação que até então eram desenvolvidas nos serviços? Os processos de capacitação conseguiram alcançar de maneira efetiva as mudanças nos serviços? - Os projetos de capacitação desenvolvidos circunscreveram-se quer ao campo da gestão local, regional ou central, quer ao da atenção primária, secundária e terciária, com predominância da primeira em ambos os campos e com um forte componente de inversão e desenvolvimento institucional dos ministérios da Saúde nesses países. Eram propostas modalidades de formação inovadoras e flexíveis, com prioridade para a EP, com foco na melhoria do desempenho dos profissionais nas funções que já ocupavam, e, em escala menor, na capacitação de novos profissionais. No entanto, houve pouca sistematização téorico-metodológica durante o desenvolvimento dos projetos. Observou-se que isso ocorreu nos países em que tanto a produção do conhecimento como o debate sobre a educação de adultos, popular e nas organizações, estão mais avançados. O estudo constatou também a existência de informação pouco sistematizada sobre o impacto das formações na mudança dos sistemas de saúde.

- De acordo com Brito (2000), as reformas na formação de profissionais para acompanhar as reformas dos sistemas de saúde na América Latina têm duas perspectivas: a) preparar pessoal profissional e técnico para os serviços e b) melhorar o desempenho dos profissionais já nos serviços. A formação proposta é generalista para ambos os casos, respondendo a processos como extensão de cobertura e criação de novos modelos de atenção.

- Quanto aos outros países, há relatos mostrando que nos últimos dez anos ocorreram modificações da oferta de programas de mestrado em alguns países: aos tradicionais MSc e MPH se junta o MBA, para formar profissionais de alto nível com habilidades de gestão e direção, visando a atender às inovações ocorridas na área da saúde que as novas tecnologias de informação e comunicação permitiram. Como exemplos temos o Canadá, a Itália e a Espanha, já apresentados aqui. 


\section{CONSIDERAC̣ÕES FINAIS}

Nos últimos anos vem se fortalecendo a idéia de que a era do conhecimento leva à absorção de novos formatos organizacionais e que grande parte desse processo está associado à qualificação profissional e à qualidade dos conhecimentos produzidos. De acordo com Catani, Oliveira e Dourado (2001:71), "na ótica empresarial tem prevalecido o entendimento de que os novos perfis profissionais e os modelos de formação exigidos atualmente pelo paradigma de produção capitalista podem ser expressos resumidamente, em dois aspectos: polivalência e flexibilidade profissionais". E para o desenvolvimento desse 'profissional multicompetente' seria necessário identificar as habilidades cognitivas e competências sociais para o exercício de diferentes profissões e, conseqüentemente, repensar os atuais programas de formação. Para esses mesmos autores, os processos de reforma curricular podem ser vistos sob dois prismas: a) o das universidades como "oxigenação dos componentes curriculares (...), não se reduzindo às demandas e parâmetros do mercado de trabalho" (p. 77) e b) o da política oficial dos anos 90 , reduzindo a função social da educação ao ideário da preparação para o trabalho em um mercado em plena mutação.

Na medida do possivel, o trabalho que aqui apresentamos procurou refletir essa tendência, já em curso em grande número de países, e servir de contribuição ao aperfeiçoamento dos programas e das propostas de reforma do sistema de pós-graduação hoje em curso no Brasil.

Quadro 1 - Principais características de programas de mestrado na área de saúde pública América do Norte

\begin{tabular}{|c|l|l|l|}
\hline País & \multicolumn{1}{|c|}{ Nome do Curso } & \multicolumn{1}{|c|}{ Objetivos } & \multicolumn{1}{c|}{ Conteúdos Obrigatórios } \\
\hline Canadá & $\begin{array}{l}\text { Mestrado em Saúde } \\
\text { Comunitária com } \\
\text { Dissertação } \\
\text { (Universidade de } \\
\text { Montreal). }\end{array}$ & $\begin{array}{l}\text { Formar individuos para } \\
\text { contribuir na resolução de } \\
\text { problemas de saúde da } \\
\text { comunidade com base em uma } \\
\text { compreensão global da saúde dos } \\
\text { indivíduos e das comunidades e } \\
\text { de suas interações com o meio } \\
\text { ambiente social e físico. }\end{array}$ & $\begin{array}{l}\text { Fundamentos de ética em saúde } \\
\text { pública, Pesquisa em saúde } \\
\text { comunitária, Conceitos básicos } \\
\text { em epidemiologia, Análise } \\
\text { epidemiológica, Introdução à } \\
\text { bioestatística, Introdução às } \\
\text { teorias da medida, Análise de } \\
\text { dados categoriais, Introdução aos } \\
\text { modelos lineares, Análise } \\
\text { multidimensional confirmativa, } \\
\text { Análise multidimensional } \\
\text { exploratória, Pesquisa qualitativa } \\
\text { em saúde, Avaliação normativa, } \\
\text { Modelização e avaliação, Pesquisa } \\
\text { avaliativa, Ciências humanas e } \\
\text { sociais em saúde pública, } \\
\text { Organização dos serviços de } \\
\text { saúde, Meio ambiente e saúde. }\end{array}$ \\
\hline
\end{tabular}


Quadro 1 - Principais características de programas de mestrado na área de saúde pública América do Norte (continuação)

\begin{tabular}{|c|c|c|c|}
\hline País & Nome do Curso & Objetivos & Conteúdos Obrigatórios \\
\hline Canadá & $\begin{array}{l}\text { Mestrado em Saúde } \\
\text { Comunitária com } \\
\text { Estágio ou Trabalho } \\
\text { Dirigido (Universidade } \\
\text { de Montreal). }\end{array}$ & $\begin{array}{l}\text { Formar profissionais capazes de } \\
\text { analisar o estado de saúde de } \\
\text { uma população em função do } \\
\text { conjunto de determinantes da } \\
\text { saúde, estabelecer prioridades } \\
\text { levando em conta o contexto } \\
\text { social, conceber e desenvolver } \\
\text { políticas, programas e } \\
\text { intervenções para promover e } \\
\text { proteger a saúde, bem como de } \\
\text { prevenir os problemas de saúde, } \\
\text { contribuir para a realização e } \\
\text { avaliação de suas politicas, } \\
\text { programas e intervenções e } \\
\text { comunicar-se com os diretamente } \\
\text { interessados. }\end{array}$ & $\begin{array}{l}\text { Fundamentos e ética em saúde } \\
\text { pública, Ciências humanas e } \\
\text { sociais em saúde pública, } \\
\text { Organização dos serviços de } \\
\text { saúde, Meio ambiente e saúde, } \\
\text { Conceitos de base de } \\
\text { bioestatística, Introdução à } \\
\text { bioestatística, Conceitos básicos } \\
\text { em epidemiologia, Análise } \\
\text { epidemiológica, Práticas de saúde } \\
\text { pública }\end{array}$ \\
\hline Canadá & $\begin{array}{l}\text { Mestrado em } \\
\text { Administração de } \\
\text { Serviços de Saúde } \\
\text { (Universidade de } \\
\text { Montreal) }\end{array}$ & $\begin{array}{l}\text { Formar gestores competentes que } \\
\text { contribuam para o melhor } \\
\text { funcionamento da sua } \\
\text { organização, promovendo e } \\
\text { melhorando a saúde e o bem- } \\
\text { estar dos indivíduos e da } \\
\text { população; formar analistas, } \\
\text { conselheiros e pesquisadores } \\
\text { aptos a contribuir para uma } \\
\text { melhor compreensão do } \\
\text { funcionamento e desempenho } \\
\text { das organizações e do sistema de } \\
\text { saúde, assim como para o } \\
\text { desenvolvimento de intervenções } \\
\text { eficientes. }\end{array}$ & $\begin{array}{l}\text { Programa com dissertação - } \\
\text { Metodologia de pesquisa, Análise } \\
\text { do sistema de saúde, Pesquisa } \\
\text { operacional em saúde (ou } \\
\text { Introdução à bioestatística), } \\
\text { Introdução à pesquisa qualitativa, } \\
\text { Análise e interpretação de dados } \\
\text { qualitativos (ou Tratamento de } \\
\text { dados, Análise de dados } \\
\text { categoriais, Introdução aos } \\
\text { modelos lineares). } \\
\text { Programa com trabalho dirigido - } \\
\text { Instrumentos de gestão } \\
\text { sociossanitária, Metodologia de } \\
\text { pesquisa, Análise do sistema de } \\
\text { saúde, Introdução à pesquisa } \\
\text { qualitativa. }\end{array}$ \\
\hline Canadá & $\begin{array}{l}\text { MBA em Saúde } \\
\text { (oferecimento } \\
\text { conjunto: Universidade } \\
\text { de Montreal e Escola de } \\
\text { Altos Estudos } \\
\text { Comerciais) }\end{array}$ & $\begin{array}{l}\text { Formar gestores aptos a: } \\
\text { desenvolver liderança em um } \\
\text { contexto multidisciplinar; } \\
\text { gerenciar redes de } \\
\text { estabelecimentos de saúde; } \\
\text { enfrentar mudanças; inovar em } \\
\text { um sistema em constante } \\
\text { mutação; analisar o sistema de } \\
\text { saúde nas dimensões } \\
\text { organizacionais, econômicas, } \\
\text { sociológicas, técnicas, } \\
\text { epidemiológicas e jurídicas; } \\
\text { avaliar as apostas e riscos; tomar } \\
\text { decisões; implementar estratégias; } \\
\text { avaliar os resultados. }\end{array}$ & $\begin{array}{l}\text { Gestão em saúde, Sistema de } \\
\text { saúde, Trabalho do gestor e } \\
\text { estrategista, Habilidades de } \\
\text { gestão, Estrutura e processos } \\
\text { administrativos, Estatística } \\
\text { aplicada à gestão, Economia da } \\
\text { saúde, Linguagem contábil, } \\
\text { Controle orçamentário, Marketing } \\
\text { nas organizações de saúde, } \\
\text { Gestão do desempenho, Gestão } \\
\text { financeira, Gestão estratégica de } \\
\text { recursos humanos, Gestão } \\
\text { estratégica, Gestão de operações e } \\
\text { logística, Tecnologia de } \\
\text { informação. }\end{array}$ \\
\hline
\end{tabular}


Quadro 1 - Principais características de programas de mestrado na área de saúde pública América do Norte (continuação)

\begin{tabular}{|c|c|c|c|}
\hline País & Nome do Curso & Objetivos & Conteúdos Obrigatórios \\
\hline EUA & $\begin{array}{l}\text { Mestrado em Saúde } \\
\text { Pública (Escola de } \\
\text { Saúde Pública Johns } \\
\text { Hopkins) }\end{array}$ & $\begin{array}{l}\text { Preparar profissionais com } \\
\text { conhecimentos e habilidades em } \\
\text { várias disciplinas para definir, } \\
\text { avaliar criticamente e resolver } \\
\text { problemas no campo da saúde } \\
\text { pública, que os tornem aptos a } \\
\text { trabalhar de forma efetiva com o } \\
\text { amplo espectro das questões de } \\
\text { saúde pública. }\end{array}$ & $\begin{array}{l}\text { Estatística e computação, } \\
\text { Estatística em saúde pública, } \\
\text { Sistemas de informação em } \\
\text { saúde, Princípios de } \\
\text { epidemiologia, História da saúde } \\
\text { pública, Resolução de problemas } \\
\text { na saúde pública, Questões éticas } \\
\text { na saúde pública. }\end{array}$ \\
\hline EUA & $\begin{array}{l}\text { Mestrado em Saúde } \\
\text { Pública/MBA (Escola } \\
\text { de Saúde Pública Johns } \\
\text { Hopkins e Escola de } \\
\text { Estudos Profissionais } \\
\text { em Negócios e } \\
\text { Educação Johns } \\
\text { Hopkins) }\end{array}$ & $\begin{array}{l}\text { Transmitir conhecimentos e } \\
\text { habilidades nos princípios da } \\
\text { saúde populacional, assim como } \\
\text { financiamento e gestão, para } \\
\text { gerenciamento e liderança de } \\
\text { agências e organizações de saúde. }\end{array}$ & $\begin{array}{l}\text { Saúde ambiental, Saúde de } \\
\text { populações, Princípios de } \\
\text { epidemiologia, Solução de } \\
\text { problemas na saúde pública, } \\
\text { Análise de objetivos, Métodos } \\
\text { estatísticos, Gestão de } \\
\text { organizações de saúde, Economia } \\
\text { médica, Liderança moral, } \\
\text { Contabilidade financeira, } \\
\text { Economia médica, Seguros de } \\
\text { saúde, Planejamento estratégico, } \\
\text { Gestão financeira, Gestão de } \\
\text { marketing, Comportamento } \\
\text { organizacional, Integração da } \\
\text { informação tecnológica, Prática } \\
\text { clínica, Questões legais, } \\
\text { Negociação. }\end{array}$ \\
\hline EUA & $\begin{array}{l}\text { Mestrado em Saúde } \\
\text { Pública e MBA } \\
\text { (Universidade da } \\
\text { Califórnia, Berkeley) }\end{array}$ & $\begin{array}{l}\text { Dar proficiência nos aspectos da } \\
\text { administração e de serviços nas } \\
\text { áreas da saúde e indústrias de } \\
\text { tecnologia. }\end{array}$ & $\begin{array}{l}\text { Saúde pública, Métodos } \\
\text { epidemiológicos, Estatística, } \\
\text { Contabilidade, Microeconomia, } \\
\text { Introdução ao sistema financeiro, } \\
\text { Comportamento organizacional, } \\
\text { Marketing, Gerência operacional, } \\
\text { Macroeconomia, Ética, } \\
\text { Estratégias em contextos de } \\
\text { globalização, Gestão estratégica } \\
\text { de serviços de saúde. }\end{array}$ \\
\hline EUA & $\begin{array}{l}\text { Mestrado em Saúde } \\
\text { Pública (Universidade } \\
\text { de Harvard) }\end{array}$ & $\begin{array}{l}\text { Enfatizar o aprendizado ativo e } \\
\text { direto do estudante na busca de } \\
\text { solução de problemas, com a } \\
\text { aquisição de habilidades } \\
\text { necessárias à prática da saúde } \\
\text { pública. }\end{array}$ & $\begin{array}{l}\text { Bases éticas da prática em saúde } \\
\text { pública, Prática em saúde da } \\
\text { família e da comunidade, Prática } \\
\text { de gestão de cuidados de saúde, } \\
\text { Prática de saúde ocupacional, } \\
\text { Prática de métodos quantitativos. }\end{array}$ \\
\hline
\end{tabular}


Quadro 1 - Principais características de programas de mestrado na área de saúde pública América do Norte (continuação)

\begin{tabular}{|c|c|c|c|}
\hline País & Nome do Curso & Objetivos & Conteúdo Obrigatório \\
\hline México & $\begin{array}{l}\text { Mestrado em Saúde } \\
\text { Pública (Instituto } \\
\text { Nacional de Saúde } \\
\text { Pública) }\end{array}$ & $\begin{array}{l}\text { Formar profissionais da saúde } \\
\text { pública capazes de planejar, } \\
\text { organizar, dirigir e avaliar planos } \\
\text { e programas dirigidos à } \\
\text { prevenção e ao controle de } \\
\text { necessidades e danos à saúde, } \\
\text { assim como de identificar } \\
\text { necessidades e riscos que } \\
\text { permitam melhores decisões na } \\
\text { implementação de ações de } \\
\text { saúde. }\end{array}$ & $\begin{array}{l}\text { Bases éticas e filosóficas em saúde } \\
\text { pública, Ciências sociais em } \\
\text { saúde pública, Ciências do } \\
\text { comportamento em saúde } \\
\text { pública, Organização dos sistemas } \\
\text { de saúde, Administração em } \\
\text { saúde, Epidemiologia, } \\
\text { Bioestatística básica e } \\
\text { processamento de dados, } \\
\text { Fundamentos de saúde } \\
\text { ambiental, Metodologia de } \\
\text { pesquisa em administração em } \\
\text { saúde. }\end{array}$ \\
\hline México & $\begin{array}{l}\text { Mestrado em Gerência } \\
\text { e Direção em Saúde } \\
\text { (Instituto Nacional de } \\
\text { Saúde Pública) }\end{array}$ & $\begin{array}{l}\text { Formar profissionais para um } \\
\text { bom desempenho em cargos de } \\
\text { direção no setor público ou } \\
\text { privado, ou como alto } \\
\text { funcionário de instituições } \\
\text { dedicadas ao campo da saúde, } \\
\text { com o desenvolvimento da } \\
\text { docência e pesquisa em } \\
\text { instituições acadêmicas e de } \\
\text { pesquisa. }\end{array}$ & $\begin{array}{l}\text { Bases éticas e filosóficas em saúde } \\
\text { pública, Organização dos sistemas } \\
\text { de saúde, Legislação em saúde, } \\
\text { Administração em saúde, } \\
\text { Epidemiologia, Bioestatística } \\
\text { básica e processamento de dados, } \\
\text { Direção e liderança, Metodologia } \\
\text { de pesquisa em sistemas e } \\
\text { serviços de saúde. }\end{array}$ \\
\hline
\end{tabular}


Quadro 2 - Principais características de programas de mestrado na área de saúde pública

\begin{tabular}{|c|c|c|c|}
\hline País & Nome do Curso & Objetivos & Conteúdos Obrigatórios \\
\hline Dinamarca & $\begin{array}{l}\text { Mestrado em Saúde } \\
\text { Pública (Universidade } \\
\text { de Aarhus) }\end{array}$ & $\begin{array}{l}\text { Formar profissionais para avaliar } \\
\text { com base científica a qualidade e } \\
\text { validade da existência de } \\
\text { evidências e produzir evidências } \\
\text { de forma sistemática, de modo a } \\
\text { otimizar o planejamento e a } \\
\text { gestão em serviços de saúde e } \\
\text { sociais. }\end{array}$ & $\begin{array}{l}\text { Epidemiologia, Bioestatística, } \\
\text { Métodos quantitativos e } \\
\text { qualitativos, Teoria da ciência e } \\
\text { ética, Condições de vida e saúde, } \\
\text { Organização, gestão e economia } \\
\text { dos serviços sociais e de saúde, } \\
\text { Prevenção de doenças e } \\
\text { promoção da saúde. }\end{array}$ \\
\hline Espanha & $\begin{array}{l}\text { Mestrado em } \\
\text { Administração e } \\
\text { Direção de Serviços de } \\
\text { Saúde (Instituto de } \\
\text { Educação Continuada) }\end{array}$ & $\begin{array}{l}\text { Formar profissionais que estejam } \\
\text { em condições de realizar com } \\
\text { êxito o planejamento, a } \\
\text { organização, gestão e avaliação de } \\
\text { um serviço de saúde, que } \\
\text { conheçam os fundamentos } \\
\text { políticos, sociais, jurídicos e } \\
\text { econômicos do sistema de saúde, } \\
\text { além dos princípios da } \\
\text { administração e direção sanitária; } \\
\text { adquiram atitudes e destreza } \\
\text { necessárias para gerenciar serviços } \\
\text { de saúde; manejem técnicas e } \\
\text { metodologias mais comuns na } \\
\text { gestão clínica e sanitária; } \\
\text { disponham de habilidades } \\
\text { precisas para poder examinar } \\
\text { criticamente o sistema local de } \\
\text { saúde; sejam capazes de implantar } \\
\text { processos de mudança, } \\
\text { trabalhando em equipe e em } \\
\text { situações de grande incerteza; } \\
\text { possuam conhecimentos, } \\
\text { habilidades e atitudes necessárias } \\
\text { para tomar decisões informadas } \\
\text { no âmbito da organização de } \\
\text { saúde. }\end{array}$ & $\begin{array}{l}\text { Saúde pública, Sociologia da } \\
\text { saúde, Marco jurídico em saúde, } \\
\text { Economia da saúde, Política de } \\
\text { saúde e planejamento estratégico, } \\
\text { Bioética, Marketing sanitário, } \\
\text { Técnicas de análise quantitativa } \\
\text { aplicada à gestão sanitária, } \\
\text { Epidemiologia clínica, Avaliação } \\
\text { econômica, Sistemas de } \\
\text { informação em saúde, Pesquisa } \\
\text { em serviços de saúde, Arquitetura } \\
\text { sanitária, Financiamento, } \\
\text { Organização e gestão, } \\
\text { Contabilidade e análise de } \\
\text { estados financeiros, Gestão e } \\
\text { controle econômico-financeiro, } \\
\text { Administração em saúde: } \\
\text { inovação organizativa e } \\
\text { tecnológica, Gestão clínica, } \\
\text { Gestão da qualidade assistencial, } \\
\text { Análise de decisões, Estratégias e } \\
\text { habilidades para a liderança e } \\
\text { motivação, Documentação } \\
\text { científica e medicina baseada em } \\
\text { evidências, Gestão do } \\
\text { conhecimento e comunicação. }\end{array}$ \\
\hline Espanha & $\begin{array}{l}\text { Mestrado em Saúde } \\
\text { Pública (Universidade } \\
\text { Pompeu Fabra) }\end{array}$ & $\begin{array}{l}\text { Contribuir para a formação de } \\
\text { profissionais especializados no } \\
\text { âmbito da saúde pública, assim } \\
\text { como proporcionar a formação } \\
\text { docente complementar; } \\
\text { proporcionar as habilidades } \\
\text { necessárias para identificar, } \\
\text { caracterizar e avaliar os problemas } \\
\text { de saúde pública em um contexto } \\
\text { multidisciplinar. }\end{array}$ & $\begin{array}{l}\text { Fundamentos de saúde pública, } \\
\text { Estatística de saúde pública, } \\
\text { Princípios de epidemiologia, } \\
\text { Saúde ambiental e do trabalho, } \\
\text { Saúde e sistema de saúde, Saúde } \\
\text { e sociedade, Métodos de estudo } \\
\text { em saúde pública, Promoção da } \\
\text { saúde. }\end{array}$ \\
\hline
\end{tabular}


Quadro 2 - Principais características de programas de mestrado na área de saúde pública (continuação)

\begin{tabular}{|c|c|c|c|}
\hline País & Nome do Curso & Objetivos & Conteúdos Obrigatórios \\
\hline Espanha & $\begin{array}{l}\text { Mestrado Universitário } \\
\text { em Economia da Saúde } \\
\text { e Direção de } \\
\text { Instituições Públicas } \\
\text { (Universidade de } \\
\text { Granada e Escola } \\
\text { Andaluza de Saúde } \\
\text { Pública) }\end{array}$ & $\begin{array}{l}\text { Desenvolver em uma perspectiva } \\
\text { multidisciplinar os } \\
\text { conhecimentos, habilidades e } \\
\text { atitudes que capacitem os } \\
\text { participantes para a direção, } \\
\text { organização e gestão de centros } \\
\text { de saúde. Formar profissionais } \\
\text { que conheçam os fundamentos } \\
\text { da economia da saúde e da } \\
\text { economia das organizações e } \\
\text { instituições de saúde; sejam } \\
\text { capazes de analisar e } \\
\text { compreender as políticas de } \\
\text { saúde e os sistemas de saúde com } \\
\text { diferentes enfoques e marcos } \\
\text { conceituais; conheçam os } \\
\text { fundamentos políticos, sociais, } \\
\text { jurídicos e economicos do } \\
\text { sistema de saúde; conheçam os } \\
\text { princípios, modelos e enfoques } \\
\text { de direção, organização e gestão } \\
\text { dos serviços de saúde; adquiram } \\
\text { métodos, técnicas e instrumentos } \\
\text { precisos para analisar as } \\
\text { organizações de saúde, planejar e } \\
\text { dirigir os serviços, gerenciar seus } \\
\text { recursos humanos e econômicos } \\
\text { e avaliar os resultados com } \\
\text { critérios de qualidade, eficácia e } \\
\text { eficiência. Fomentar atitudes de } \\
\text { responsabilidade individual, } \\
\text { trabalho em equipe, iniciativa e } \\
\text { caráter empreendedor, assim } \\
\text { como o compromisso com os } \\
\text { valores de eficiência, eqüidade e } \\
\text { solidariedade. }\end{array}$ & $\begin{array}{l}\text { Introdução à economia, } \\
\text { Economia pública, Economia da } \\
\text { saúde, Avaliação econômica de } \\
\text { tecnologias de saúde, Política e } \\
\text { gestão de saúde, Financiamento, } \\
\text { Organização e direção estratégica } \\
\text { de organizações de saúde, Gestão } \\
\text { de organizações de saúde, } \\
\text { Experiências e inovações em } \\
\text { gestão, Marketing de serviços de } \\
\text { saúde, Gestão clínica e gestão de } \\
\text { processos, Sistemas de } \\
\text { informação e gestão de pacientes, } \\
\text { Contabilidade e gestão } \\
\text { orçamentária em centros de } \\
\text { saúde, Relações de trabalho no } \\
\text { sistema nacional de saúde, } \\
\text { Sistemas de retribuição, Carreira } \\
\text { profissional e incentivos nas } \\
\text { organizações de saúde, Estatística, } \\
\text { Epidemiologia e resultados em } \\
\text { saúde, Métodos quantitativos e } \\
\text { estatísticos de gestão empresarial, } \\
\text { Metodologia de redação } \\
\text { científica. }\end{array}$ \\
\hline
\end{tabular}


Quadro 2 - Principais características de programas de mestrado na área de saúde pública (continuação)

\begin{tabular}{|c|c|c|c|}
\hline País & Nome do Curso & Objetivos & Conteúdos Obrigatórios \\
\hline Espanha & $\begin{array}{l}\text { Mestrado Universitário } \\
\text { em Saúde Pública e } \\
\text { Gestão de Serviços } \\
\text { Sociais e de Saúde } \\
\text { (Escola Andaluza de } \\
\text { Saúde Pública) }\end{array}$ & $\begin{array}{l}\text { Formar profissionais capazes de } \\
\text { compreender o conceito e as } \\
\text { funções da saúde pública a partir } \\
\text { da análise da sua evolução } \\
\text { histórica e da avaliação crítica dos } \\
\text { modelos existentes na atualidade; } \\
\text { de analisar e compreender de } \\
\text { maneira integral a situação atual } \\
\text { dos sistemas de bem-estar, de } \\
\text { saúde e sociais na Andaluzia, } \\
\text { Espanha, Europa e América } \\
\text { Latina; de conhecer o estado } \\
\text { atual e realizar análise das } \\
\text { políticas públicas com especial } \\
\text { ênfase nos setores Saúde e Social; } \\
\text { de analisar e intervir sobre a } \\
\text { situação de saúde das populações } \\
\text { e identificar os principais } \\
\text { problemas, seus determinantes e } \\
\text { as necessidades dos diferentes } \\
\text { grupos populacionais, na ótica da } \\
\text { saúde pública; de conhecer e usar } \\
\text { métodos e técnicas de pesquisa } \\
\text { epidemiológica e social, aplicáveis } \\
\text { em saúde pública e gestão de } \\
\text { serviços para compreender e } \\
\text { modificar as situações } \\
\text { indesejáveis de saúde e adequar } \\
\text { os estilos e procedimentos da } \\
\text { gestão dos serviços; de } \\
\text { compreender as bases e usar os } \\
\text { métodos e técnicas necessários } \\
\text { para analisar as organizações, } \\
\text { planejar e dirigir os serviços, } \\
\text { gerenciar recursos humanos e } \\
\text { econômicos e avaliar intervenções } \\
\text { e programas; de desenvolver e } \\
\text { fortalecer uma atitude } \\
\text { responsável individual e de } \\
\text { liderança efetiva na organização } \\
\text { social e de saúde. }\end{array}$ & $\begin{array}{l}\text { Sistemas e políticas de saúde e } \\
\text { bem-estar, Métodos de pesquisa } \\
\text { em saúde pública, Gestão de } \\
\text { serviços sociais e de saúde, Saúde } \\
\text { pública na perspectiva da } \\
\text { promoção da saúde. }\end{array}$ \\
\hline
\end{tabular}


Quadro 2 - Principais características de programas de mestrado na área de saúde pública (continuação)

\begin{tabular}{|c|c|c|c|}
\hline País & Nome do Curso & Objetivos & Conteúdos Obrigatórios \\
\hline Espanha & $\begin{array}{l}\text { Mestrado em } \\
\text { Administração em } \\
\text { Saúde (Escola Nacional } \\
\text { de Saúde do Instituto } \\
\text { de Saúde Carlos III) }\end{array}$ & $\begin{array}{l}\text { Formar profissionais capazes de } \\
\text { entender os fundamentos } \\
\text { científicos das disciplinas } \\
\text { relacionadas com a direção e } \\
\text { administração em saúde, adquirir } \\
\text { visão estratégica e capacidade } \\
\text { analítica para compreender, } \\
\text { avaliar, pesquisar, formular } \\
\text { alternativas diante de problemas, } \\
\text { desenvolver iniciativas, } \\
\text { ferramentas e habilidades para } \\
\text { responder aos principais } \\
\text { processos e desafios colocados e } \\
\text { assimilar os instrumentos e } \\
\text { hábitos de autoformação que } \\
\text { facilitarão sua atividade futura. }\end{array}$ & $\begin{array}{l}\text { Fundamentos de saúde pública e } \\
\text { administração em saúde, Marco } \\
\text { político, social e normativo, } \\
\text { Marco econômico e introdução à } \\
\text { economia do bem-estar, Sistemas } \\
\text { de saúde e planejamento em } \\
\text { saúde, Fundamentos de } \\
\text { estatística, Epidemiologia e } \\
\text { demografia, Análise econômica e } \\
\text { contábil orientada para a gestão, } \\
\text { Economia da saúde e avaliação } \\
\text { econômica, Gestão de recursos } \\
\text { humanos, Direção e controle } \\
\text { econômico-financeiro, Funções } \\
\text { de produção, Logística e } \\
\text { processos críticos horizontais, } \\
\text { Processos de direção e sistemas } \\
\text { de informação para a gestão } \\
\text { aplicada, Novas tendências em } \\
\text { gestão de recursos humanos, } \\
\text { Avaliação econômica e decisão } \\
\text { clínica, Planejamento e gestão de } \\
\text { contratos, Gestão orçamentária e } \\
\text { administração pública, Modelos } \\
\text { de organização, Gestão da } \\
\text { qualidade e mudanças } \\
\text { tecnológicas, Novos paradigmas } \\
\text { na gestão clínica. }\end{array}$ \\
\hline Espanha & $\begin{array}{l}\text { Mestrado em Saúde } \\
\text { Pública (Escola } \\
\text { Nacional de Saúde do } \\
\text { Instituto de Saúde } \\
\text { Carlos III) }\end{array}$ & $\begin{array}{l}\text { Capacitar os participantes para } \\
\text { descrever, analisar e interpretar } \\
\text { problemas epidemiológicos e } \\
\text { sociais no âmbito da saúde } \\
\text { pública; para desenvolver } \\
\text { estratégias de promoção da saúde } \\
\text { e prevenção de doenças; para } \\
\text { conhecer os elementos do } \\
\text { planejamento e gestão dos } \\
\text { serviços de saúde e para } \\
\text { desenvolver e interpretar } \\
\text { corretamente pesquisas no campo } \\
\text { da saúde. }\end{array}$ & $\begin{array}{l}\text { Introdução à saúde pública, } \\
\text { Métodos quantitativos, Doenças } \\
\text { infecciosas, Promoção da saúde, } \\
\text { Saúde ambiental, ocupacional e } \\
\text { alimentar, Planejamento em } \\
\text { saúde, Administração e gestão em } \\
\text { saúde, Medicina preventiva } \\
\text { hospitalar. }\end{array}$ \\
\hline
\end{tabular}


Quadro 2 - Principais características de programas de mestrado na área de saúde pública (continuação)

\begin{tabular}{|c|c|c|c|}
\hline País & Nome do Curso & Objetivos & Conteúdos Obrigatórios \\
\hline Espanha & $\begin{array}{l}\text { Mestrado em Saúde } \\
\text { Pública e Gestão em } \\
\text { Saúde (Escola } \\
\text { Valenciana de Estudos } \\
\text { para a Saúde) }\end{array}$ & $\begin{array}{l}\text { Capacitar para a saúde pública } \\
\text { nacional e internacional por } \\
\text { meio dos instrumentos de } \\
\text { estatística, informática e } \\
\text { epidemiologia avançada, } \\
\text { habilitando para avaliar, } \\
\text { gerenciar e planejar serviços de } \\
\text { saúde e sociais e preparando para } \\
\text { gestão hospitalar, incluindo } \\
\text { qualidade hospitalar. }\end{array}$ & $\begin{array}{l}\text { Saúde pública, Saúde pública } \\
\text { internacional, Sociologia da } \\
\text { saúde, Administração e legislação } \\
\text { sanitária, Estatística, informática } \\
\text { e demografia aplicadas, } \\
\text { Epidemiologia e métodos } \\
\text { epidemiológicos avançados, } \\
\text { Planejamento, gestão e avaliação } \\
\text { em saúde e serviços sociais, } \\
\text { Promoção e educação para a } \\
\text { saúde, Saúde do meio ambiente, } \\
\text { Medicina preventiva hospitalar. }\end{array}$ \\
\hline Espanha & $\begin{array}{l}\text { Mestrado em Saúde e } \\
\text { Meio Ambiente } \\
\text { (Centro Universitário } \\
\text { de Saúde Pública - } \\
\text { Universidade } \\
\text { Autônoma de Madrid) }\end{array}$ & $\begin{array}{l}\text { Transmissão de conhecimentos, } \\
\text { atividades e habilidades no uso } \\
\text { de técnicas de controle e } \\
\text { avaliação dos fatores de risco } \\
\text { ambiental. }\end{array}$ & $\begin{array}{l}\text { Introdução à saúde ambiental, } \\
\text { Epidemiologia ambiental, } \\
\text { Princípios de toxicologia } \\
\text { ambiental aplicada, Alimentação } \\
\text { e saúde pública, Análise } \\
\text { geográfica e temporal do meio } \\
\text { ambiente, Avaliação do impacto } \\
\text { ambiental em saúde, Gestão } \\
\text { ambiental na empresa na } \\
\text { perspectiva da qualidade total, } \\
\text { Crise ecológica, Saúde e educação } \\
\text { ambiental. }\end{array}$ \\
\hline Espanha & $\begin{array}{l}\text { Mestrado em Segurança } \\
\text { e Saúde no Trabalho e } \\
\text { Prevenção de Riscos } \\
\text { (Centro Universitário } \\
\text { de Saúde Pública - } \\
\text { Universidade } \\
\text { Autônoma de Madri) }\end{array}$ & $\begin{array}{l}\text { Formar profissionais aptos a } \\
\text { estabelecer o marco geral das } \\
\text { condições de trabalho e saúde; } \\
\text { avaliar riscos e estabelecer } \\
\text { medidas preventivas; a identificar } \\
\text { as condições ambientais e físicas } \\
\text { do local de trabalho; a } \\
\text { determinar os fatores } \\
\text { ergonômicos e psicossociais dos } \\
\text { postos de trabalho; a fazer a } \\
\text { aproximação entre a análise da } \\
\text { saúde e o bem-estar dos } \\
\text { trabalhadores; a utilizar os } \\
\text { métodos de pesquisa aplicáveis } \\
\text { na saúde do trabalhador; a } \\
\text { conhecer e aplicar o âmbito } \\
\text { legislativo e do trabalho; a } \\
\text { planejar, programar e gerenciar a } \\
\text { segurança e saúde do } \\
\text { trabalhador. }\end{array}$ & $\begin{array}{l}\text { Condições de trabalho e saúde, } \\
\text { Legislação, Seguridade, Higiene, } \\
\text { Ergonomia e psicosociologia } \\
\text { aplicada, Formação e técnicas de } \\
\text { comunicação, Medicina do } \\
\text { trabalho, Técnicas afins ao meio } \\
\text { ambiente, Gestão da prevenção. }\end{array}$ \\
\hline
\end{tabular}


Quadro 2 - Principais características de programas de mestrado na área de saúde pública (continuação)

\begin{tabular}{|c|c|c|c|}
\hline País & Nome do Curso & Objetivos & Conteúdos Obrigatórios \\
\hline Espanha & $\begin{array}{l}\text { Mestrado em } \\
\text { Epidemiologia Aplicada } \\
\text { (Centro Nacional de } \\
\text { Epidemiologia e Escola } \\
\text { Nacional de Saúde do } \\
\text { Instituto de Saúde } \\
\text { Carlos III) }\end{array}$ & $\begin{array}{l}\text { Formar pessoal de saúde pública } \\
\text { no campo da epidemiologia } \\
\text { aplicada, orientada para a } \\
\text { resolução de problemas; reforçar } \\
\text { a capacidade de resposta das } \\
\text { administrações sanitárias aos } \\
\text { problemas de vigilância } \\
\text { epidemiológica e às emergências } \\
\text { em saúde pública (epidemias, } \\
\text { desastres naturais ou } \\
\text { provocados); reforçar a } \\
\text { capacidade de avaliar a } \\
\text { efetividade das atividades e } \\
\text { programas de promoção da saúde } \\
\text { e prevenção de doenças crônicas } \\
\text { em nível nacional, autonômico, } \\
\text { provincial e local; promover e } \\
\text { incentivar a formação continuada } \\
\text { em epidemiologia fortalecendo o } \\
\text { processo epidemiológico, de } \\
\text { comunicação e profissionalização. }\end{array}$ & $\begin{array}{l}\text { Fundamentos de epidemiologia, } \\
\text { Introdução à vigilância da saúde } \\
\text { pública, Análise epidemiológica } \\
\text { em vigilância, Estatística aplicada, } \\
\text { Epidemiologia especial, } \\
\text { Estratégias em saúde pública, } \\
\text { Comunicação em saúde pública. }\end{array}$ \\
\hline Espanha & $\begin{array}{l}\text { Mestrado em Direção e } \\
\text { Gestão de Serviços de } \\
\text { Saúde (Universidade de } \\
\text { Alcalá) }\end{array}$ & $\begin{array}{l}\text { Facilitar a formação de alto nível } \\
\text { no âmbito sanitário, centrando-se } \\
\text { especificamente nos aspectos } \\
\text { relativos à gestão, de maneira a } \\
\text { dotar os participantes dos } \\
\text { conhecimentos e habilidades } \\
\text { necessários para enfrentar as } \\
\text { exigências e os desafios que se } \\
\text { produzem nesse âmbito. }\end{array}$ & $\begin{array}{l}\text { Introdução à seguridade social, } \\
\text { Técnicas atuariais de previsão } \\
\text { social, O setor Saúde, Introdução } \\
\text { geral à gestão, Gestão assistencial, } \\
\text { Gestão dos serviços de suporte, } \\
\text { Gestão da qualidade, Temas } \\
\text { emergentes, Desenvolvimento } \\
\text { diretivo, Âmbito internacional. }\end{array}$ \\
\hline Espanha & $\begin{array}{l}\text { Mestrado em Saúde } \\
\text { Pública (Universidade } \\
\text { de Santiago de } \\
\text { Compostela) }\end{array}$ & $\begin{array}{l}\text { Formar e preparar profissionais } \\
\text { com bases e ferramentas para } \\
\text { lograr maior eficiência no } \\
\text { emprego dos recursos humanos e } \\
\text { materiais postos a serviço da } \\
\text { atenção à saúde. }\end{array}$ & $\begin{array}{l}\text { Bioestatística e informática, } \\
\text { Método epidemiológico, } \\
\text { Epidemiologia especial, Modelos } \\
\text { de saúde e seguridade social, } \\
\text { Administração e gestão em saúde, } \\
\text { Planejamento e gestão de serviços } \\
\text { sócio-sanitários, Qualidade em } \\
\text { centros hospitalares, Segurança e } \\
\text { higiene hospitalar, Bioética, } \\
\text { Deontologia e direito sanitário. }\end{array}$ \\
\hline
\end{tabular}


Quadro 2 - Principais características de programas de mestrado na área de saúde pública (continuação)

\begin{tabular}{|c|c|c|c|}
\hline País & Nome do Curso & Objetivos & Conteúdos Obrigatórios \\
\hline Espanha & $\begin{array}{l}\text { Mestrado em Saúde } \\
\text { Pública e Gestão de } \\
\text { Serviços de Saúde } \\
\text { (Universidade Miguel } \\
\text { Hernandez) }\end{array}$ & $\begin{array}{l}\text { Formar profissionais capazes de } \\
\text { incorporar em sua prática } \\
\text { habilidades e atitudes que } \\
\text { favoreçam a intervenção e a } \\
\text { pesquisa no campo da saúde } \\
\text { pública, assim como de } \\
\text { compreender os aspectos } \\
\text { conceituais e metodológicos da } \\
\text { saúde pública, do planejamento } \\
\text { em saúde e da gestão de serviços } \\
\text { de saúde. }\end{array}$ & $\begin{array}{l}\text { Conceitos básicos de saúde } \\
\text { pública, História da saúde } \\
\text { pública, Informação e } \\
\text { documentação científica, } \\
\text { Estratégias de promoção e } \\
\text { educação para a saúde, Estatística } \\
\text { aplicada à saúde, Fundamentos } \\
\text { epidemiológicos, Desenho de } \\
\text { protocolos de pesquisa, } \\
\text { Planejamento, gestão e avaliação } \\
\text { em saúde, Metodologia de } \\
\text { pesquisa em saúde pública. }\end{array}$ \\
\hline Finlândia & $\begin{array}{l}\text { Mestrado em Saúde } \\
\text { Pública (Escola de } \\
\text { Saúde Pública da } \\
\text { Universidade de } \\
\text { Tampere) }\end{array}$ & $\begin{array}{l}\text { Familiarizar os estudantes com o } \\
\text { campo multidisciplinar da saúde } \\
\text { pública. }\end{array}$ & $\begin{array}{l}\text { Perspectiva em saúde pública, } \\
\text { Gerontologia e envelhecimento } \\
\text { populacional, Saúde mental, } \\
\text { História e sociologia da saúde, } \\
\text { Pesquisa social, Política social e } \\
\text { de saúde, Métodos em economia } \\
\text { da saúde, Introdução à saúde } \\
\text { ocupacional, Teoria e avaliação } \\
\text { da promoção da saúde, } \\
\text { Epidemiologia de doenças } \\
\text { infecciosas e crônicas, } \\
\text { Epidemiologia, Estatística } \\
\text { computacional e Pesquisa } \\
\text { qualitativa. }\end{array}$ \\
\hline Inglaterra & $\begin{array}{l}\text { Mestrado em Saúde } \\
\text { Pública (Universidade } \\
\text { de Londres) }\end{array}$ & $\begin{array}{l}\text { Os objetivos do programa estão } \\
\text { relacionados às opções de curso: } \\
\text { prover o aluno de conhecimentos } \\
\text { e habilidades necessárias para } \\
\text { melhorar a saúde da população; } \\
\text { dar-lhe bases para a pesquisa e } \\
\text { prática no ambiente e na saúde; } \\
\text { provê-lo de bases teóricas da } \\
\text { promoção da saúde a formulação } \\
\text { de políticas de promoção e } \\
\text { avaliação de programas de } \\
\text { promoção, de bases teóricas e } \\
\text { instrumentais para a } \\
\text { compreensão da gestão } \\
\text { estratégica de serviços de saúde e } \\
\text { de conhecimentos e métodos } \\
\text { usados em estudos sobre sistemas } \\
\text { e serviços de saúde. }\end{array}$ & $\begin{array}{l}\text { Estatística básica para a saúde } \\
\text { pública e políticas, Epidemiologia } \\
\text { básica, Introdução à economia da } \\
\text { saúde e princípios de pesquisa } \\
\text { social. }\end{array}$ \\
\hline
\end{tabular}


Quadro 2 - Principais características de programas de mestrado na área de saúde pública (continuação)

\begin{tabular}{|c|c|c|c|}
\hline País & Nome do Curso & Objetivos & Conteúdos Obrigatórios \\
\hline Itália & $\begin{array}{l}\text { Mestrado em Promoção } \\
\text { da Saúde e Educação } \\
\text { em Saúde } \\
\text { (Universidade de } \\
\text { Estudos de Perugia) }\end{array}$ & $\begin{array}{l}\text { Formar profissionais aptos a } \\
\text { coordenar e avaliar ações de } \\
\text { promoção da saúde em nível } \\
\text { regional e local; a elaborar, } \\
\text { coordenar e avaliar projetos de } \\
\text { educação em saúde na } \\
\text { perspectiva da promoção da } \\
\text { saúde; a elaborar, coordenar e } \\
\text { avaliar, em rede, projetos de } \\
\text { educação em saúde na } \\
\text { perspectiva da promoção da } \\
\text { saúde; a elaborar e gerenciar } \\
\text { sistemas de informação e centros } \\
\text { de documentação de suporte à } \\
\text { promoção da saúde e educação } \\
\text { em saúde no contexto dos } \\
\text { serviços de saúde; a ativar e } \\
\text { apoiar a melhoria contínua da } \\
\text { qualidade dos serviços envolvidos } \\
\text { em ações de promoção da saúde e } \\
\text { em projetos de educação em } \\
\text { saúde; a coordenar e apoiar } \\
\text { projetos multidisciplinares de } \\
\text { pesquisa para a análise e } \\
\text { avaliação de necessidades e } \\
\text { demandas de saúde no campo da } \\
\text { promoção e da educação em } \\
\text { saúde; a elaborar e apoiar } \\
\text { processos de formação em serviço } \\
\text { para profissionais envolvidos nas } \\
\text { ações de promoção da saúde e } \\
\text { projetos de educação em saúde. }\end{array}$ & $\begin{array}{l}\text { Fundamentos e organização da } \\
\text { promoção e educação em saúde, } \\
\text { Prática em promoção e educação } \\
\text { em saúde: programação e } \\
\text { pesquisa, comunicação e } \\
\text { aprendizagem, animação e } \\
\text { avaliação, Gestão de programas } \\
\text { de promoção da saúde e } \\
\text { educação em saúde: alguns } \\
\text { instrumentos. }\end{array}$ \\
\hline Itália & $\begin{array}{l}\text { Mestrado em Controle } \\
\text { de Azienda de Saúde } \\
\text { (Universidade de } \\
\text { Estudos La Sapienza) }\end{array}$ & $\begin{array}{l}\text { Fornecer instrumentos } \\
\text { conceituais e métodos de análise } \\
\text { para a avaliação e controle das } \\
\text { atividades no âmbito dos sistemas } \\
\text { complexos de saúde, com o } \\
\text { objetivo de favorecer a integração } \\
\text { das diversas funções de gestão } \\
\text { empresarial pública. }\end{array}$ & $\begin{array}{l}\text { Estatística, Demografia, } \\
\text { Epidemiologia, Economia, } \\
\text { Informática, Modelos } \\
\text { organizacionais na área pública, } \\
\text { Gestão da empresa pública de } \\
\text { saúde enquanto um sistema } \\
\text { complexo, Gestão clínica e seus } \\
\text { instrumentos, Processo de } \\
\text { programação, gestão e avaliação } \\
\text { na azienda de saúde, } \\
\text { Necessidades de saúde e recursos } \\
\text { existentes, Sistema de informação } \\
\text { na azienda de saúde. }\end{array}$ \\
\hline
\end{tabular}


Quadro 2 - Principais características de programas de mestrado na área de saúde pública (continuação)

\begin{tabular}{|c|c|c|c|}
\hline País & Nome do Curso & Objetivos & Conteúdos Obrigatórios \\
\hline Itália & $\begin{array}{l}\text { Mestrado em } \\
\text { Comunicação em } \\
\text { Saúde Pública (Centro } \\
\text { de Formação } \\
\text { Permanente e } \\
\text { Atualização do Pessoal } \\
\text { do Sistema de Saúde) }\end{array}$ & $\begin{array}{l}\text { Fornecer metodologias e } \\
\text { instrumentos de elaboração e } \\
\text { gestão eficaz da comunicação em } \\
\text { saúde pública, melhorando a } \\
\text { capacidade de oferecer apoio e } \\
\text { consultoria aos profissionais de } \\
\text { saúde e à sociedade. }\end{array}$ & $\begin{array}{l}\text { Processos de comunicação verbal } \\
\text { e não verbal, Obstáculos à } \\
\text { comunicação eficaz, Habilidade } \\
\text { específica na relação interpessoal } \\
\text { com o usuário, Escuta ativa, } \\
\text { comunicar para mudar o estilo de } \\
\text { vida, Instrumentos e jogos para } \\
\text { mudar comportamentos, } \\
\text { Marketing de saúde, Elementos } \\
\text { de sociologia e antropologia } \\
\text { médica, Promoção e educação em } \\
\text { saúde, Planejamento da } \\
\text { avaliação, Desenvolvimento de } \\
\text { projetos e instrumentos } \\
\text { audiovisuais para promover a } \\
\text { saúde, Comunicação em } \\
\text { situações patológicas (afetivas, } \\
\text { fumo, álcool, drogas, doping, } \\
\text { anorexia, bulimia, obesidade e } \\
\text { jogo de azar), Percepção do risco } \\
\text { e modelos teóricos de } \\
\text { comunicação do risco, Liderança, } \\
\text { gestão de conflitos, dinâmica de } \\
\text { grupo, Gestão do estresse. }\end{array}$ \\
\hline Itália & $\begin{array}{l}\text { Mestrado em Promoção } \\
\text { e Educação para a } \\
\text { Saúde (Centro de } \\
\text { Formação Permanente } \\
\text { e Atualização do Pessoal } \\
\text { do Sistema de Saúde) }\end{array}$ & $\begin{array}{l}\text { Transmitir metodologias e } \\
\text { instrumentos sobre temas de } \\
\text { educação em saúde para a } \\
\text { elaboração, coordenação e gestão } \\
\text { de intervenções no setor Saúde. }\end{array}$ & $\begin{array}{l}\text { Modelos culturais relativos aos } \\
\text { conceitos de saúde e doença, } \\
\text { Princípios de promoção da saúde, } \\
\text { Modelos e abordagens em } \\
\text { educação em saúde, Metodologia } \\
\text { de elaboração de intervenção em } \\
\text { educação e promoção da saúde, } \\
\text { Avaliação de intervenções em } \\
\text { educação e promoção da saúde, } \\
\text { Promoção da saúde como } \\
\text { processo comunicativo, Papel das } \\
\text { instituições locais e de } \\
\text { voluntariado, Documentação em } \\
\text { educação em saúde, Banco de } \\
\text { dados, análise crítica e } \\
\text { interpretação de pesquisas } \\
\text { realizadas, Centros de } \\
\text { documentação. }\end{array}$ \\
\hline
\end{tabular}


Quadro 2 - Principais características de programas de mestrado na área de saúde pública (continuação)

\begin{tabular}{|c|c|c|c|}
\hline País & Nome do Curso & Objetivos & Conteúdos Obrigatórios \\
\hline Itália & $\begin{array}{l}\text { Mestrado em Gestão de } \\
\text { Serviços de Saúde } \\
\text { (Centro de Formação } \\
\text { Permanente e } \\
\text { Atualização do Pessoal } \\
\text { do Sistema de Saúde) }\end{array}$ & $\begin{array}{l}\text { Formar profissionais capazes de } \\
\text { analisar o processo de } \\
\text { empresariamento da saúde; de } \\
\text { utilizar os instrumentos para } \\
\text { responsabilização e envolvimento } \\
\text { dos profissionais; de aplicar as } \\
\text { principais técnicas de } \\
\text { planejamento em saúde; de } \\
\text { definir mercado e especialmente } \\
\text { as principais características que } \\
\text { regulam o mercado em saúde: } \\
\text { eficácia, eficiência e eqüidade; de } \\
\text { programar o orçamento e utilizar } \\
\text { os relatórios como instrumento } \\
\text { de otimização dos recursos; de } \\
\text { gerenciar recursos humanos; de } \\
\text { aplicar o sistema de avaliação } \\
\text { para os profissionais de saúde; de } \\
\text { identificar as prioridades a serem } \\
\text { enfrentadas para a melhoria } \\
\text { contínua da qualidade. }\end{array}$ & $\begin{array}{l}\text { Gestão e organização da azienda } \\
\text { de saúde, Processos de } \\
\text { comunicação verbal e não-verbal, } \\
\text { Economia em saúde e economia } \\
\text { da saúde, demanda e produção } \\
\text { da saúde, Papel da avaliação } \\
\text { econômica em saúde, Sistema de } \\
\text { informação territorial e } \\
\text { hospitalar, Sistema DRG, Gestão } \\
\text { de recursos humanos, Custos, } \\
\text { orçamento, Benchmarking, } \\
\text { Qualidade em saúde, Acreditação } \\
\text { e sistemas de qualidade, } \\
\text { Avaliação de tecnologia, } \\
\text { Avaliação de programas, projetos } \\
\text { e serviços. }\end{array}$ \\
\hline Itália & $\begin{array}{l}\text { Mestrado em Melhoria } \\
\text { da Qualidade dos } \\
\text { Serviços de Saúde } \\
\text { (Centro de Formação } \\
\text { Permanente e } \\
\text { Atualização do Pessoal } \\
\text { do Sistema de Saúde) }\end{array}$ & $\begin{array}{l}\text { Fornecer os conhecimentos } \\
\text { metodológicos e desenvolver as } \\
\text { habilidades para promover, } \\
\text { elaborar, coordenar e avaliar } \\
\text { autonomamente políticas e } \\
\text { programas de melhoria contínua } \\
\text { da qualidade; desenvolver } \\
\text { competências para conceber e } \\
\text { organizar sistemas de qualidade, } \\
\text { com o objetivo de responder às } \\
\text { mudanças e ao desenvolvimento } \\
\text { que vive cada região e, em } \\
\text { particular, cada azienda de saúde. }\end{array}$ & $\begin{array}{l}\text { Introdução à qualidade, } \\
\text { Dimensões da qualidade, } \\
\text { Atenção à saúde baseada em } \\
\text { evidências, Organização do } \\
\text { sistema de qualidade em uma } \\
\text { azienda de saúde, Qualidade } \\
\text { percebida, gestão eficaz da } \\
\text { comunicação, Carta de serviços, } \\
\text { gestão por processos, } \\
\text { instrumentos de gestão por } \\
\text { projeto e da qualidade, } \\
\text { Indicadores e padrões, } \\
\text { acreditação e certificação ISO, } \\
\text { Avaliação tecnológica, Gestão } \\
\text { econômico-financeira, Sistema } \\
\text { DRG, Gestão de risco. }\end{array}$ \\
\hline
\end{tabular}


Quadro 2 - Principais características de programas de mestrado na área de saúde pública (continuação)

\begin{tabular}{|c|c|c|c|}
\hline País & Nome do Curso & Objetivos & Conteúdos Obrigatórios \\
\hline Portugal & $\begin{array}{l}\text { Mestrado em Saúde } \\
\text { Pública (Escola } \\
\text { Nacional de Saúde } \\
\text { Pública) }\end{array}$ & $\begin{array}{l}\text { Formar profissionais aptos a } \\
\text { reunir, analisar e apresentar com } \\
\text { rigor o estado atual do } \\
\text { conhecimento sobre as principais } \\
\text { questões da saúde pública; a } \\
\text { participar no planejamento, } \\
\text { execução e avaliação de ações } \\
\text { concretas no sistema de saúde } \\
\text { português; a contribuir, como } \\
\text { profissional e cidadão, para a } \\
\text { melhoria da saúde e dos sistemas } \\
\text { de saúde tanto no país como no } \\
\text { conjunto da Europa e, sempre } \\
\text { que a oportunidade se } \\
\text { apresentar, num âmbito ainda } \\
\text { mais ampliado, particularmente } \\
\text { nos países de língua oficial } \\
\text { portuguesa; a refletir e avaliar } \\
\text { crítica e continuamente sua } \\
\text { prática profissional; a produzir } \\
\text { novos conhecimentos através da } \\
\text { sua participação em estudos de } \\
\text { investigação em saúde pública. }\end{array}$ & $\begin{array}{l}\text { Introdução à saúde pública, } \\
\text { Epidemiologia, Estatística, } \\
\text { Sociologia da saúde, Introdução à } \\
\text { informação e à investigação em } \\
\text { saúde, Economia da saúde, } \\
\text { Introdução à promoção e à } \\
\text { proteção da saúde, Ambiente e } \\
\text { saúde, Políticas de saúde, } \\
\text { Introdução à política e } \\
\text { administração de saúde. }\end{array}$ \\
\hline
\end{tabular}

Quadro 3 - Principais características de Programas de Mestrado na área de Saúde Pública América do Sul e Central

\begin{tabular}{|c|c|c|c|}
\hline País & Nome do Curso & Objetivos & Conteúdos Obrigatórios \\
\hline Argentina & $\begin{array}{l}\text { Mestrado em Saúde } \\
\text { Pública (Universidade } \\
\text { de Buenos Aires) }\end{array}$ & $\begin{array}{l}\text { Formar recursos humanos com } \\
\text { capacidade de enfocar a saúde } \\
\text { pública como campo } \\
\text { interdisciplinar, inter e extra- } \\
\text { setorial; de reconhecer a } \\
\text { relevância de considerar os atores } \\
\text { sociais, suas representações e } \\
\text { práticas no campo da saúde } \\
\text { pública; de avaliar as } \\
\text { características atuais e tendências } \\
\text { de processos sociais, econômicos } \\
\text { e ambientais e políticos na sua } \\
\text { relação com as condições de vida } \\
\text { e saúde com o conjunto social; de } \\
\text { propor linhas de ação de redução } \\
\text { de riscos selecionados de adoecer } \\
\text { e morrer; de promover a pesquisa } \\
\text { em saúde pública nos seus } \\
\text { diferentes componentes; de } \\
\text { resolver os problemas de saúde } \\
\text { mediante o enfoque de } \\
\text { planejamento-programação- } \\
\text { execução-avaliação. }\end{array}$ & $\begin{array}{l}\text { Situação de saúde e } \\
\text { determinantes da saúde-doença, } \\
\text { Transição e mudança em saúde, } \\
\text { Recursos, sistemas e serviços de } \\
\text { saúde. }\end{array}$ \\
\hline
\end{tabular}


Quadro 3 - Principais características de programas de mestrado na área de saúde pública América do Sul e Central (continuação)

\begin{tabular}{|c|c|c|c|}
\hline País & Nome do Curso & Objetivos & Conteúdos Obrigatórios \\
\hline Argentina & $\begin{array}{l}\text { Mestrado em Saúde } \\
\text { Pública (Universidade } \\
\text { Nacional de Rosário) }\end{array}$ & $\begin{array}{l}\text { Formar profissionais com } \\
\text { capacidade para pesquisar e } \\
\text { utilizar conhecimentos científicos } \\
\text { para a resolução de problemas no } \\
\text { campo da saúde pública; para } \\
\text { aprofundar o conhecimento dos } \\
\text { fundamentos teórico- } \\
\text { metodológicos das disciplinas } \\
\text { que conformam o campo } \\
\text { específico da saúde pública, em } \\
\text { particular em epidemiologia, } \\
\text { planejamento e gestão de serviços } \\
\text { de saúde e políticas de saúde; } \\
\text { para promover o } \\
\text { desenvolvimento de uma atitude } \\
\text { analítica, crítica e criativa em } \\
\text { relação aos problemas colocados } \\
\text { pelo seu campo de atuação. }\end{array}$ & $\begin{array}{l}\text { Epidemiologia, Estatística, } \\
\text { Demografia, Modelos de gestão e } \\
\text { organizações de saúde, Gestão de } \\
\text { serviços de saúde, Teoria e } \\
\text { métodos de planejamento em } \\
\text { saúde, Estado, direitos sociais e } \\
\text { saúde, Modelo e financiamento } \\
\text { de sistemas de saúde, Economia } \\
\text { da saúde, Políticas de saúde no } \\
\text { marco das políticas sociais, } \\
\text { Metodologia de pesquisa. }\end{array}$ \\
\hline Colômbia & $\begin{array}{l}\text { Mestrado em Saúde } \\
\text { Pública (Universidade } \\
\text { de Antioquia) }\end{array}$ & $\begin{array}{l}\text { Formar profissional capaz de } \\
\text { interpretar os problemas de } \\
\text { saúde e neles intervir, orientado } \\
\text { para o exercício da autogestão e } \\
\text { da autoformação, proativo, capaz } \\
\text { de trabalhar em equipe e com } \\
\text { responsabilidade social, e de } \\
\text { aplicar de maneira criativa os } \\
\text { avanços dos distintos campos } \\
\text { disciplinares e do conhecimento } \\
\text { para a solução de problemas } \\
\text { comunitários e institucionais. }\end{array}$ & $\begin{array}{l}\text { Situação de saúde pública no } \\
\text { país, Determinantes ideológicos, } \\
\text { éticos, econômicos, políticos e } \\
\text { administrativos, Condições gerais } \\
\text { de execução do sistema de } \\
\text { prestação de serviços de saúde. }\end{array}$ \\
\hline Cuba & $\begin{array}{l}\text { Mestrado em Saúde } \\
\text { Pública (Escola } \\
\text { Nacional de Saúde } \\
\text { Pública de Cuba) }\end{array}$ & $\begin{array}{l}\text { Desenvolver, com enfoque } \\
\text { humanista e ético, métodos e } \\
\text { procedimentos das ciências da } \\
\text { saúde pública na gerência dos } \\
\text { sistemas e serviços de saúde; } \\
\text { aplicar os fundamentos } \\
\text { científicos da saúde pública no } \\
\text { desenho e na execução de } \\
\text { pesquisas que permitam ao } \\
\text { profissional analisar o estado de } \\
\text { saúde da população e os fatores } \\
\text { que o determinam, assim como } \\
\text { propor alternativas de solução de } \\
\text { acordo com os recursos } \\
\text { disponíveis. }\end{array}$ & $\begin{array}{l}\text { Saúde pública, Epidemiologia, } \\
\text { Estatística e demografia, } \\
\text { Metodologia de pesquisa, } \\
\text { Sistemas e serviços de saúde, } \\
\text { Economia da saúde, Políticas, } \\
\text { planos e programas, Promoção da } \\
\text { saúde, Gestão dos serviços de } \\
\text { saúde, Avaliação e controle em } \\
\text { saúde. }\end{array}$ \\
\hline
\end{tabular}




\section{REFERÊNCIAS BIBLIOGRÁFICAS}

BOLOGNA PROCESS. Conclusions and recommendations of the Conference. Conference on Master-level Degrees - March, 14-15, 2003, Finland.

BRITO QUINTANA, P. E. Impacto de las reformas del sector salud sobre los recursos humanos y el sector laboral. Revista Panamericana de Salud Pública, 8(1/2): 43-54, 2000.

CATANI, A. M.; OLIVEIRA, J. F. \& DOURADO, L. F. Política educacional, mudanças no mundo do trabalho e reforma curricular dos cursos de graduação no Brasil. Educação e Sociedade, 22(75):67-83, 2001.

CONDE, M. V. F. \& ARAÚJO-JORGE, T. C. Modelos e concepções de inovação: a transição de paradigmas, a reforma da C\& $\mathrm{T}$ brasileira e as concepções de gestores de uma instituição pública de pesquisa em saúde. Ciência e Saúde Coletiva, 8(3):727-741, 2003.

COORDENAÇÃO DEAPERFEIÇOAMENTO DE PESSOAL. Portaria n. 47, de 17 de outubro de 1995. Programa de Flexibilização do Modelo de Pós-Graduação Senso Estrito em Nivel de Mestrado.

DAVINI, M. C.; NERVI, L. \& ROSCHKE, M. A. Organização Pan-Americana da Saúde Capacitação do Pessoal dos Serviços de Saúde: projetos relacionados com os processos de reforma setorial. Quito: Opas, 2002. (Observatório de Recursos Humanos de Saúde, 3)

DECLARAÇÃO DE BOLONHA (The Bologna Declaration). Joint Declaration of the European Ministers of Education, June 1999.

http://europa.eu.int/comm/education/policies/educ/bologna/bologna_en.html (acesso em 30/6/2004)

ESTEVÃO, C. V. Formação, gestão, trabalho e cidadania: contributos para uma sociologia crítica da formação. Educação e Sociedade, 22(77):185-206, 2001.

FERNÁNDEZ LAMARRA, N. La Educación Superior en la Argentina. Buenos Aires: Instituto Internacional para la Educación Superior en América Latina y el Caribe, 2002.

FRANCO, M. C. Quando nós somos o outro: questões teórico-metodológicas sobre os estudos comparados. Educação e Sociedade, 21(72):197-230, 2000.

HORTALE, V.A. \& MORA, J. G. Tendências das reformas da educação superior na Europa no contexto do processo de Bolonha. Educação Ė Sociedade, 25(88):937-960, 2004.

INSTITUTO INTERNACIONAL para la Educación Superior en América Latina y el Caribe. La Educación Superior en Colombia: informe. Bogotá, abr. 2002a. 
INSTITUTO INTERNACIONAL para la Educación Superior en América Latina y el Caribe. La Educación Superior en Cuba: informe. La Habana, 2002b.

KOKOSALAKIS, N. Editorial. European Journal of Education, 35(3):253-255, 2000.

MINISTÉRIO DA EDUCAÇÃO E CULTURA. Parecern. 977/65, Cesu, aprovado em 3 de dezembro de 1965.

PÉREZ, N. R. \& AYZAGUER, L. C. S. Evaluación de la maestría en salud pública de Cuba: base para un proyecto de superación profesoral. Salud Pública, 26(1):35-49, 2000.

ROSAR, M. F. F. \& KRAWCZYK, N. R. Diferenças da homogeneidade: elementos para o estudo da política educacional em alguns países da América Latina. Educação Ė Sociedade, ano XXII, 75:33-47, ago. 2001.

TAUCH, C. \& RAUHVARGERS, A. (Eds.) Survey on Master Degrees and Joint Degrees in Europe. Brussels: European University Association e European Comission (Directorate General for Education and Culture), 2002.

\section{Páginas Internet dos Programas de Mestrado} na Área de Saúde Pública

Centro de Formação Permanente e Atualização do Pessoal do Sistema de Saúde, Itália http://www.cefpas.it (acesso em 28/05/2004)

Escola Andaluza de Saúde Pública, Espanha http://www.easp.es/web/formacion/formacion_masters.asp?.idSub=354\&_idSec=298\&idCab=298 (acesso em 28/05/2004)

Escola Nacional de Saúde Pública, Cuba http://www.ensap.sld.cu/html/msaludpublica.htm (acesso em 31/05/2004)

Escola Nacional de Saúde Pública, Portugal http://www.ensp.unl.pt/ensino_mestrad_2003.shtm (acesso em 27/05/2004)

Escola de Saúde Pública da Universidade Tampere, Finlândia http://www.uta.fi/laitokset/tsph/master.html (acesso em 29/05/2004)

Escola Valenciana de Estudos para a Saúde, Espanha http://www.san.gva.es/ (acesso em 28/05/2004)

Instituto de Educação Continuada, Espanha http://www.mastermas.com/masters/Masteren-Administracion-y-Direccion-de-ServiciosSanitarios-104511.HTML (acesso em 29/05/2004) 
Instituto Nacional de Saúde Pública, México

http://www.insp.mx/ (acesso em 13/07/2004)

Instituto de Saúde Carlos III, Espanha http://www.isciii.es/publico/drvisapi.dll?MIval=cw_usr_view_SHTML\&ID=5922 \&preview=false\& type=Folder (acesso em 15/06/2004)

Universidade Autônoma de Madrid, Espanha http://www.uam.es/otroscentros/saludpublica/cusp/msma.htm (acesso em 15/07/2004)

Universidade de Aarhus, Dinamarca http://www.mph.au.dk/Indexeng.htm (acesso em 15/06/2004)

Universidade de Antioquia, Colômbia http://guajiros.udea.edu.co/fnsp/ContenidosHtm/Docencia/Maestriahttm(acessoem01/06/2004)

Universidade de Berkeley, Estados Unidos da América http://sph.berkeley.edu:7133/degrees/degreeprog/ (acesso em 28/05/2004)

Universidade de Buenos Aires, Argentina http://www.fmed.uba.ar/ (acesso em 29/05/2004)

Universidade de Estudos La Sapienza, Itália http://www.dssp.uniroma1.it/istig/master/bandomaster.htm (acesso em 28/05/2004)

Universidade de Estudos de Perugia, Itália http://www.unipg.it/ dipigmed/attivita'/master_pr_salute.html(acesso em 28/05/2004)

Universidade de Harvard, Estados Unidos da América http://www.hsph.harvard.edu/mph/ (acesso em 29/05/2004)

Universidade Johns Hopkins, Estados Unidos da América http://www.jhsph.edu/academics/MPH/ (acesso em 29/05/2004)

Universidade de Londres (London School of Hygiene and Tropical Medicine) http://www.lshtm.ac.uk/prospectus/masters/msph.html (acesso em 15/06/2004)

Universidade de Montreal, Canadá http://www.mdas.umontreal.ca/etudes/deuxieme_cycle.htm\#225(acesso em 03/06/2004)

Universidade Nacional de Rosário, Argentina http://www.unr.edu.ar/posgrados.htm (acesso em 25/06/2004)

Universidade Pompeu Fabra, Espanha http://www.upf.edu/cexs/3rcicle/master/cast/ index.htm (acesso em 25/06/2004) 


\title{
A EXPERIÊNCIA DO MESTRADO PROFISSIONAL DO INSTITUTO DE SAÚDE COLETIVA DA UFBA, 2001-2004'
}

\author{
Inês Dourado \\ Carmen Teixeira \\ Estela Aquino \\ Lígia Maria Vieira-da-Silva \\ Jairnilson Silva Paim \\ Naomar de Almeida Filho
}

Os cursos de mestrado profissional foram instituídos pela Coordenação de Aperfeiçoamento de Pessoal de Nível Superior (Capes) em 1995, e seus fundamentos encontram-se sistematizados em documento intitulado Programa de Flexibilização do Modelo de PósGraduação Senso Estrito em Nivel de Mestrado (Capes, 1995). Essa modalidade de formação pós-graduada encontra-se atualmente consolidada em várias universidades e instituições de ensino superior no Brasil, principalmente nas áreas de administração, engenharia, informática, e comunicação (Virmond, 2002).

Na área da saúde coletiva, o debate sobre a possibilidade de implantação desses cursos se iniciou durante uma oficina realizada no Congresso de Saúde Coletiva de 1998, a partir da qual alguns programas de pós-graduação da área formularam projetos e iniciaram a execução desses cursos em parceria com instituições de saúde nos níveis nacional e estadual (ou em diversos âmbitos do sistema de saúde). No momento atual, outros projetos se encontram em fase de instalação, implementação ou consolidação, o que estimula a reflexão acerca dos resultados alcançados e dos desafios colocados aos diversos programas para a manutenção e aperfeiçoamento dessa experiência.

${ }^{1}$ Uma versão deste texto foi publicada na Revista Brasileira de Pós-Graduação, 4, 2005. 
Considerando a iniciativa da Escola Nacional de Saúde Pública (Ensp) de promover o debate entre coordenadores e docentes dos referidos cursos acerca da situação atual e das perspectivas dessa modalidade de formação na atual conjuntura, este capítulo tem como objetivos:

- Descrever o projeto político-pedagógico do Mestrado Profissionalizante em Saúde Coletiva do Instituto de Saúde Coletiva (ISC).

- Avaliar a experiência acumulada nos últimos quatro anos com a realização de cinco edições do curso.

- Analisar a contribuição do mestrado profissionalizante para o aperfeiçoamento do projeto institucional e da prática de ensino-pesquisa no ISC.

- Analisar a contribuição do mestrado profissionalizante para a formação de pessoal e para a prática em saúde coletiva no Brasil e na Bahia.

\section{O PROGRAMA DE PÓS-GRADUACÃO EM SAÚdE COLETIVA DO INSTITUTO DE SAÚDE COLETIVA - UFBA}

O Conselho Federal de Educação do Ministério da Educação definiu em 1965 as bases conceituais do ensino de pós-graduação lato sensu e stricto sensu no país por meio do parecer 977/65 (Brasil, 1965), que até hoje orienta a compreensão desses cursos. O Programa de Pós-Graduação em Saúde Coletiva da Universidade Federal da Bahia (PPGSC/UFBA), que completou trinta anos de existência em 2003, tem como objetivo desenvolver uma perspectiva inovadora de ensino integrado à pesquisa e a cooperação técnica, enfatizando a natureza transdisciplinar da saúde coletiva e privilegiando a integração entre estudantes, pesquisadores e profissionais de distintas áreas e formação diversificada. O PPGSC foi criado em 1973 com o então Mestrado em Saúde Comunitária no antigo Departamento de Medicina Preventiva. Em 1989, implantou-se o Doutorado em Saúde Pública, inicialmente apenas com área de concentração em Epidemiologia. A partir da fundação do Instituto de Saúde Coletiva, em 1995, todos os cursos de pós-graduação senso estrito foram transferidos para a nova unidade. Atualmente, existem três áreas de concentração no mestrado e no doutorado: Epidemiologia; Planejamento e Gestão em Saúde; Ciências Sociais em Saúde.

OPPGSC já titulou 47 alunos de doutorado e 245 de mestrado (no período 1973-2003), sendo que apenas no ano de 2003 foram titulados 16 alunos do mestrado acadêmico, nove do doutorado e 19 do mestrado profissional. O PPGSC tem sido considerado como centro de excelência, alcançando o grau A pelo sistema de avaliação da Capes, desde 1982, nível 5 a 
partir de 1998 e nível 6 a partir de 2004. Na última década, a perspectiva de redução do tempo médio de titulação e de consolidação das áreas de concentração dos cursos envolveu ajustes na estrutura curricular, os quais foram expressos no atual regimento do programa, aprovado em 2000. Neste fica definido o tempo de duração máxima de 24 meses para o mestrado acadêmico e 48 meses para o doutorado.

O projeto pedagógico do Mestrado e Doutorado em Saúde Coletiva prevê a formação do aluno a partir da sua incorporação em grupos de pesquisa que compõem a estrutura do ISC. Esses grupos organizam-se em torno das principais linhas de pesquisa, havendo freqüentemente intercâmbio de professores de diferentes formações, o que fortalece e consolida a prática multidisciplinar. As principais linhas de pesquisa em desenvolvimento no ISC incluem: análise da situação de saúde, avaliação de sistemas, programas e serviços de saúde, saúde e trabalho, gênero e saúde, família e saúde, violência urbana e saúde, macro e microdeterminantes das doenças infecciosas/deficiências nutricionais, epidemiologia das doenças crônico-degenerativas, políticas e planificação de sistemas locais de saúde, processos socioculturais e saúde/doença-cuidado e metodologia e tecnologia em saúde, informação em saúde, economia da saúde, vigilância sanitária. Essas linhas de pesquisa integram o Diretório de Grupos de Pesquisa do CNPq, que conta com os seguintes grupos cadastrados: a) Epidemiologia das doenças infecciosas e deficiências nutricionais; b) Epidemiologia das doenças crônicas não transmissíveis; c) Modo de vida, qualidade de vida e saúde; d) Musa-Programa de estudos em gênero e saúde; e) Pisat-Programa Integrado de Saúde Ambiental e do Trabalhador; f) Planificação e gestão em saúde.

A integração da pós-graduação à graduação se dá de forma sistemática e permanente, seja por meio da participação do corpo docente e discente do programa em disciplinas e atividades oferecidas aos cursos de graduação, seja por meio do engajamento de alunos dos diferentes níveis nos programas integrados de pesquisa e cooperação técnica do ISC. Docentes do programa orientam bolsistas de iniciação científica financiados pelo Conselho Nacional de Desenvolvimento Científico e Tecnológico (CNPq), pela Fundação de Amparo à Pesquisa do Estado da Bahia (Fapesb) e mediante convênios nacionais e internacionais vinculados aos grupos de pesquisa, nos quais também se integram os alunos de pós-graduação senso estrito e senso lato.

Os processos de avaliação no PPGSC encontram-se bem consolidados, sendo implementados de forma permanente e sistemática. A avaliação do desempenho discente, com base nas normas legais, é efetuada em diferentes momentos do percurso acadêmico, envolvendo: disciplinas e atividades (pesquisa orientada, tirocínio docente, exame de 
qualificação e exame de dissertação ou tese). Particularmente, em relação ao produto intermediário (projeto) e final (dissertação ou tese), o exame é feito sempre com a presença de avaliadores externos da seguinte forma: a) exame de qualificação - ao final do segundo semestre para o mestrado e do quarto semestre para o doutorado, consiste no exame do projeto de dissertação ou tese por três examinadores (no doutorado, obrigatoriamente um externo ao programa), todos com doutorado; b) defesa de dissertação ou tese - o exame é feito por banca constituída por três examinadores (pelo menos um externo) no mestrado e cinco (pelo menos dois externos) no doutorado, obrigatoriamente, todos com nível de titulação de doutorado. A avaliação do programa é efetuada também em diferentes momentos: pelo corpo discente - em quase todas as disciplinas por meio de questionário aplicado entre os alunos e analisado pela representação discente, respeitando-se o anonimato, sem participação do corpo docente e da coordenação. Além disso, também são feitas avaliações, com discentes, em diversas disciplinas, por meio de estratégias qualitativas visando a obter subsídios para a sua reformulação, bem como em reuniões periódicas da coordenação com discentes e docentes para avaliação e planejamento das atividades e processos do programa e em seminários anuais para avaliação global do programa, envolvendo docentes, discentes e pesquisadores.

O PPGSC encontra-se consolidado nas três áreas de concentração do doutorado e mestrado acadêmico (Epidemiologia, Planejamento e Gestão em Saúde, Ciências Sociais em Saúde). A tendência geral de crescimento do programa reflete-se no incremento do número de vagas para os cursos acadêmicos - o que atende a demanda crescente, especialmente no doutorado - e na implantação de uma nova modalidade de curso - os mestrados profissionalizantes. A ampliação do corpo docente e a titulação em nível de doutorado de quadros do ISC, credenciados como docentes do PPGSC, têm permitido o aumento do quadro de orientadores, com o fim de atender às novas demandas.

\section{MESTRADO PROFISSIONALIZANTE EM SAÚDE COLETIVA: UMA PROPOSTA INOVADORA}

Após trinta anos de estabelecimento das bases conceituais do ensino de pós-graduação no país, a Coordenação de Aperfeiçoamento de Pessoal de Nível Superior implanta uma nova modalidade de curso de pós-graduação, os mestrados profissionais, profissionalizantes ou técnicos, entendidos como cursos stricto sensu (Capes, 1995). A Capes também legitima e delibera sobre mecanismos de avaliação (Capes, 1998). 
Antes de iniciar a descrição da experiência do mestrado profissional no ISC, vale a pena transcrever uma definição recente sobre essa modalidade de curso que se encontra na página da Capes:

Mestrado Profissional é a designação do Mestrado que enfatiza estudos e técnicas diretamente voltadas ao desempenho de um alto nivel de qualificação profissional. Esta ênfase é a única diferença em relação ao acadêmico. Confere, pois, idênticos grau e prerrogativas, inclusive para o exercício da docência, e, como todo programa de pós-graduação stricto sensu, tem a validade nacional do diploma condicionada ao reconhecimento prévio do curso (Parecer CNE/CES 0079/2002).

Responde a uma necessidade socialmente definida de capacitação profissional de natureza diferente da propiciada pelo mestrado acadêmico e não se contrapõe, sob nenhum ponto de vista, à oferta e expansão desta modalidade de curso, nem se constitui em uma alternativa para a formação de mestres segundo padrões de exigência mais simples ou mais rigorosos do que aqueles tradicionalmente adotados pela pós-graduação. (www.capes.gov.br - acesso em set. 2004)

O PPGSC do ISC/UFBA implantou, em 2001, o curso de Mestrado Profissionalizante (MP), nova modalidade de formação pós-graduada que tem como finalidade principal a formação de profissionais que atuam como dirigentes e técnicos no âmbito do sistema de serviços de saúde, contribuindo assim para a elevação da qualidade da gestão, planejamento, organização e operacionalização das ações e serviços.

O projeto do MP do ISC obteve aprovação do Colegiado do PPGSC em 14 de agosto de 2000, parecer de aprovação nas instâncias superiores da UFBA em 13 de setembro de 2000 (Parecer CEPGP 126/2000), e aprovação pela Capes em 12 de dezembro de 2000 . O projeto do curso prevê a abertura de vagas em seis áreas de concentração: Gestão de Sistemas de Saúde; Epidemiologia em Serviços de Saúde; Vigilância Sanitária; Docência em Saúde da Família; Sistemas de Informação em Saúde; Avaliação de Tecnologias em Saúde.

Essas áreas são oferecidas de acordo com o estabelecimento de parcerias entre o ISC e instituições de saúde federais, estaduais ou municipais, levando-se em conta a capacidade operacional do PPGSC, especialmente a disponibilidade de docentes/orientadores para serem envolvidos nas atividades pedagógicas. A equipe de docentes do PPGSC/ISC constitui, em princípio, o corpo docente do MP. Outros profissionais, com doutorado na área da saúde 
coletiva e reconhecida experiência na realização de pesquisas e consultorias técnicas em temas específicos da área, também podem ser credenciados pelo PPGSC para atuar como orientadores.

De acordo com a decisão do Colegiado, o PPGSCP só pode oferecer cursos de mestrado profissional se dispuser de quadro docente e de orientação, mantendo-se a razão número de orientandos por docente dentro dos parâmetros recomendados pela Capes. Assim, evidencia-se o compromisso do Colegiado com a qualidade dos programas acadêmicos e, conseqüentemente, dos mestrados profissionais.

\section{SELEÇÃO DOS CANDIDATOS}

A seleção de candidatos ao MP-ISC/UFBA é feita em duas etapas distintas. Na etapa de pré-seleção, a comissão de seleção examina a seguinte documentação: diploma de curso superior, curriculum vitæ do candidato modelo Lattes e plano de estudos, do qual deverão constar o tema de investigação, os objetivos e o desenho do estudo previsto, encaminhada pela instituição parceira que requer a inscrição dos candidatos, diretamente ao ISC, em prazo definido no edital de seleção. A segunda etapa consiste na aplicação de prova de conhecimentos gerais em saúde coletiva, de caráter eliminatório, no exame do currículo e do plano de estudos. Os temas selecionados e a bibliografia básica para a prova de conhecimentos são divulgados com antecedência de no mínimo 60 dias e incluem conhecimentos gerais em epidemiologia, política de saúde e ciências sociais em saúde.

\section{PROJETO POLÍTICO.PEDAGÓGICO}

O MP é uma variante do curso de Mestrado em Saúde Coletiva do PPGSC do ISC/ UFBA, oferecido a profissionais que atuam em vários níveis do sistema de serviços de saúde. Apresenta uma organização inovadora, sob a forma de módulos, oficinas de trabalho e supervisão à distância, por meios eletrônicos, intercalados com momentos de orientação presencial. O perfil esperado do egresso do MP está, em linhas gerais, delineado no conjunto dos objetivos terminais do curso, que contemplam:

- Produzir conhecimentos e desenvolver tecnologias em saúde coletiva, enfatizando sua incorporação à prática institucional em diversos níveis.

- Promover a incorporação do enfoque epidemiológico no processo de formulação de políticas, planejamento, programação, gestão e avaliação de sistemas e serviços de saúde. 
- Difundir conhecimentos, métodos, técnicas e instrumentos de trabalho na área de gestão, planejamento, programação, organização de serviços e avaliação em saúde.

- Contribuir para a democratização da informação técnico-científica na área de saúde coletiva, fornecendo subsídios para a mobilização social em torno da promoção da saúde e bem-estar.

- Inserir-se, de forma crítica e criativa, em processos sociais de construção da cidadania, subsidiando distintos sujeitos sociais na articulação de interesses em torno da melhoria dos níveis de saúde e da qualidade de vida.

Outros objetivos específicos são definidos para cada área de concentração, levando-se em conta a demanda da instituição convenente, por exemplo: Docência em Saúde da Família (movimentos de reforma do ensino médico; abordagens pedagógicas inovadoras); Gestão de Sistemas de Saúde (políticas e estratégias de construção do SUS, programas e projetos do Ministério da Saúde); Epidemiologia em Serviços de Saúde (análise da situação de saúde, políticas e práticas de vigilância epidemiológica).

A estrutura curricular contempla um núcleo básico de conhecimentos em saúde coletiva, comum às diversas áreas de concentração, as quais constituem campos de prática que demandam conhecimentos e tecnologias específicos. O conteúdo teórico é oferecido em três módulos comuns às diversasáreas e três outros específicos, contemplando aspectos conceituais, metodológicos e instrumentais da respectiva área de concentração e duas disciplinas optativas. A prática de investigação articulada aos serviços de saúde é desenvolvida na instituição de origem do mestrando, tomandose como ponto de partida problemas gerenciais, organizativos e operacionais do cotidiano institucional que demandem a produção de conhecimentos e o desenvolvimento de tecnologias para seu enfrentamento e superação. A orientação do trabalho prático é realizada sob a forma presencial, em oficinas de pesquisa orientada, atividade complementada por supervisão à distância mediante meios eletrônicos.

O produto final do mestrado profissionalizante, de acordo com a legislação específica da Capes, pode ser uma dissertação, um projeto de pesquisa ou de intervenção na área específica em que atua o mestrando, um estudo de caso ou ainda uma proposta de desenvolvimento tecnológico ou instrumental que contribua para o desenvolvimento gerencial, organizativo e operacional de sistemas, programas e serviços de saúde. Como no mestrado acadêmico, incentivamos a apresentação da dissertação em forma de artigo científico no modelo a ser enviado para publicação.

O curso tem uma duração prevista de 12 meses, com momentos de 'concentração' durante a realização dos módulos teóricos e oficinas de pesquisa orientada e momentos de 
'dispersão', correspondentes ao trabalho de campo. Totaliza 800 horas (240 teóricas, 80 teórico-práticas e 480 horas práticas), que correspondem a 26 créditos, sendo 13 equivalentes às aulas teóricas, três equivalentes a atividades teórico-práticas e dez créditos correspondentes às atividades práticas.

\section{DESENHO CURRICULAR}

O eixo do processo de ensino-aprendizagem é o desenvolvimento de uma prática de investigação, ao longo de 12 meses. Os temas das investigações a serem desenvolvidas pelos alunos do MP devem ser coerentes com as demandas da instituição patrocinadora do curso, bem como com as linhas de pesquisa existentes no ISC/UFBA, de modo a facilitar a definição de professores orientadores que deverão dispor de um mínimo de duas horas por semana para atender o mestrando.

A supervisão do trabalho de pesquisa é feita de duas formas: a) à distância, através de meios eletrônicos e b) em dez 'oficinas de pesquisa orientada', de oito horas cada, uma vez por mês, nas quais os alunos têm oportunidade de apresentar e discutir o andamento do processo de investigação diretamente com os orientadores.

Os conteúdos teóricos que subsidiam a definição dos objetos de investigação, o desenho do estudo, a coleta e processamento de dados e a análise e discussão dos resultados, por sua vez, são oferecidos de forma modular, em seis módulos de 40 horas, ministrados a intervalos regulares durante os seis primeiros meses de realização do curso, em espaços a serem definidos pela instituição patrocinadora. O exame de qualificação e a defesa da dissertação são realizados no ISC, em um esforço de proporcionar aos mestrandos um mínimo de 'ambiência acadêmica', ao tempo que permitem que estes conheçam as instalações e a dinâmica de trabalho da instituição.

\section{Pesquisa Orientada (PO)}

A prática de investigação dos alunos do MP é desenvolvida desde o primeiro momento do curso, iniciando-se com a elaboração do anteprojeto de pesquisa de cada aluno. Este é aperfeiçoado e operacionalizado ao longo do processo de desenvolvimento da $\mathrm{PO}$, sob supervisão contínua do orientador designado. A orientação é feita principalmente em meio eletrônico (e-mail), e os produtos parciais são apresentados nas oficinas de PO.

Algumas das linhas de pesquisa desenvolvidas pelo ISC oferecem condições para a inserção dos mestrandos do MP, na medida em que abordam questões vinculadas à formulação e avaliação de políticas, planos e programas de saúde, gestão, organização e controle de sistemas 
de serviços de saúde em geral, epidemiologia das doenças transmissíveis, ou em áreas críticas, como é o caso dos sistemas de informação em saúde, saúde do trabalhador. Desse modo, pode-se prever a vinculação dos mestrandos às seguintes linhas de pesquisa:

Quadro 1 - Linhas atuais de pesquisa do PPGSC do ISC/UFBA

\begin{tabular}{|l|}
\hline \multicolumn{1}{|c|}{ Linhas de Pesquisa } \\
\hline Análise de situação de saúde segundo condições de vida \\
Avaliação de políticas, sistemas e serviços de saúde \\
Avaliação de tecnologias em saúde \\
Economia da saúde \\
Epidemiologia das doenças crônico-degenerativas \\
Epidemiologia das doenças transmissíveis \\
Gestão de sistemas locais de saúde \\
Organização de sistemas e serviços de saúde (modelos assistenciais) \\
Planejamento e programação em saúde \\
Saúde da família \\
Saúde da mulher \\
Saúde do trabalhador \\
Sistemas de informação em saúde \\
Vigilância sanitária
\end{tabular}

\section{AVALIAÇÃO DOS ALUNOS}

Na implementação dos cursos de mestrado profissionalizante no ISC tem sido adotada, como estratégia de programação, acompanhamento e avaliação, a organização de oficinas pedagógicas periódicas, reunindo os docentes dos diversos módulos, orientadores e tutores. Cada oficina, além de funcionar como um espaço de reflexão e troca de experiência entre o corpo docente, tem sido o momento privilegiado de construção do consenso em torno dos produtos finais do mestrado profissional. Desse modo, vem se desenvolvendo um debate em torno do processo de investigação/intervenção e dos produtos (artigos, estudos de síntese, projetos tecnológicos, manuais etc.).

A avaliação dos alunos é feita em diversos momentos do curso:

- Em cada módulo, segundo modalidade definida por cada docente.

- Nas oficinas de PO, nas quais os alunos elaboram seus projetos e os aperfeiçoam em termos da construção do quadro teórico e da coleta e processamento dos dados. 
Seqüencialmente, os alunos apresentam os relatórios parciais, bem como os resultados finais em termos da análise dos dados, redação dos resultados, discussão e conclusões.

- Exame de qualificação: ao final do primeiro semestre do curso, os mestrandos se submetem a um exame de qualificação, que consta de uma prova com questões relativas ao conteúdo teórico do curso e da apreciação do projeto de pesquisa por uma comissão formada por dois professores do programa, sendo um o orientador, e um terceiro externo ao PPGSC, todos com doutorado. Caso o aluno não seja aprovado, há possibilidade de se submeter novamente ao exame, em um prazo definido pela coordenação do curso, desde que não exceda o décimo segundo mês.

- Defesa do produto final: de acordo com a natureza da área e os objetivos do curso de MP, o produto final pode ser apresentado sob uma das seguintes formas:

- Dissertação ou monografia contendo resultados de trabalho de campo.

- Revisão de literatura: estudo de síntese.

- Artigo pronto para publicação em revista da área.

- Proposta de intervenção em uma área específica da prática institucional - por exemplo, uma proposta de aperfeiçoamento do sistema de informação, um projeto de organização de um sistema microrregional de saúde, um projeto de implantação do sistema de auditoria, controle e avaliação no âmbito municipal etc.

- Projetos de aplicação tecnológica.

A apreciação do produto final segue o mesmo critério do exame de qualificação na formação da banca examinadora.

O PPGSC tem uma gestão colegiada, cujos membros são eleitos pelo corpo docente do ISC. Cada coordenador de curso de mestrado profissional integra esse colegiado, que tem uma coordenação geral. O programa segue um Regimento Interno e as Normas Complementares para Cursos de Pós-Graduação Stricto Sensu na UFBA para balizar a tomada de decisões.

\section{A EXPERIÊNCIA DO MESTRADO PROFISSIONALIZANTE DO PPGSC DO ISC/UFBA, 2001.2004}

Durante o período 2001 a 2004, foram oferecidas cinco turmas: a primeira (julho 2001setembro 2002) em parceria entre o ISC, o Ministério da Saúde (MS) e a Universidade Estadual de Santa Cruz (Uesc) na área de concentração em Docência de Saúde da Família, da qual participaram profissionais da saúde da região de Ilhéus/Itabuna, que atuam ou podem 
vir a atuar como docentes do curso de medicina da Uesc; a segunda (novembro 2001-março 2003) em parceria do ISC com a antiga Secretaria de Políticas de Saúde/MS, na área de concentração de Gestão de Sistemas de Saúde, dirigida a profissionais que atuam no âmbito do Ministério da Saúde; a terceira (2003-2004), em parceria ISC - Secretaria de Saúde do Estado da Bahia, na área de concentração de Epidemiologia em Serviços de Saúde, dirigida a profissionais que atuam no âmbito da secretaria estadual; a quarta (2003-2004) em parceria ISC - Secretaria Estadual de Saúde de Goiás/MS, na área de concentração de Gestão de Sistemas de Saúde, dirigida a profissionais que atuam no âmbito da Secretaria Estadual; a quinta (2004-2005), em parceria entre o ISC e a Secretaria de Gestão do Trabalho em Saúde (Segets), na área de concentração em Gestão de Sistemas de Saúde, cuja clientela contempla dirigentes e técnicos do SUS que trabalham no Distrito Federal ou na região Centro-Oeste do país. Já foram concluídos os dois primeiros cursos, o terceiro e quarto encontram-se na fase final, com conclusão estimada para outubro e dezembro, respectivamente, e a última turma se encontra em fase inicial do curso.

\section{Mestrado Profissionalizante em Docência de Saúde da Família}

Na seleção inscreveram-se 35 candidatos, dos quais 15 foram aprovados. A maioria atuava como professores dos cursos de medicina e enfermagem da Universidade Estadual de Santa Cruz (Ilhéus/Itabuna). Os módulos e oficinas de PO foram realizados como previsto, tendo sido monitorados por oficinas pedagógicas, reunindo docentes envolvidos nos módulos e nas orientações aos alunos, o que contribuiu para o aprendizado conjunto acerca dessa nova modalidade de formação. Ao final do primeiro semestre do curso, os mestrandos submeteram-se a um exame de qualificação, conforme proposta do regimento do curso, no qual fizeram uma prova que abarcou o conteúdo teórico dos módulos ministrados e a avaliação do projeto de trabalho de conclusão do curso, tendo sido aprovados 14 dos 15 selecionados. Durante o segundo semestre, foram ministradas as disciplinas optativas, que contemplaram a apresentação de debate de experiências municipais de implantação do Programa Saúde da Família e experiências inovadoras de formação e capacitação de pessoal, tendo em vista a adequação de seu perfil às competências exigidas pelo processo de mudança do modelo de atenção à saúde no país. Ao término do curso foram realizadas as defesas de dissertação, alcançando-se a titulação de 14 mestres que cumpriram a creditação exigida e tiveram seus produtos finais defendidos, obtendo-se um conjunto significativo de produtos sob a forma de artigos de síntese, estudos de caso e projetos de intervenção (Anexo 1). 


\section{Mestrado Profissionalizante em Gestão de Sistemas de Saúde}

A oferta do mestrado profissional no âmbito do Ministério de Saúde gerou uma demanda considerável por parte dos técnicos que atuavam no órgão no segundo semestre de 2001, quando se inscreveram 75 candidatos. Desse modo, a Secretaria de Políticas de Saúde, então parceira do ISC na realização do curso, solicitou uma ampliação do número de vagas, o que foi aprovado pelo Colegiado, tendo sido aprovados, ao final do processo seletivo, 19 alunos. Os módulos e oficinas de $\mathrm{PO}$ foram realizados como previsto. No processo de orientação, além do modelo tradicional aluno/orientador, foram organizados quatro grupos de docentes e alunos envolvidos com o desenvolvimento de projetos em linhas específicas, quais sejam: a) Avaliação de Sistemas e Serviços de Saúde; b) Gestão de Sistemas de Saúde; c) Planejamento e Programação em Saúde; d) Saúde da Família. Ao final do primeiro semestre do curso, os mestrandos submeteram-se a um exame de qualificação, conforme proposta do regimento do curso, no qual fizeram uma prova que abarcou o conteúdo teórico dos módulos ministrados e a avaliação do projeto de trabalho de conclusão do curso, tendo sido aprovados. Durante o segundo semestre foram ministradas as duas disciplinas optativas, denominadas Tópicos especiais de saúde coletiva, I e II, cuja temática foi definida a partir de discussão com a turma de alunos, buscando-se incluir temas relacionados com as questões que não haviam sido abordadas com profundidade nos módulos anteriores. Assim, a primeira foi dedicada ao debate sobre promoção da saúde e a outra à política de recursos humanos em saúde e à economia da saúde. Finalmente, ocorreu a defesa das dissertações, as quais contemplaram a apresentação de artigos, projetos, propostas tecnológicas e estudos de caso, alcançando titulação como mestres um número de 18 alunos (Anexo 1).

\section{Mestrado Profissionalizante em Epidemiologia em Serviços de Saúde}

Trata-se de um curso para profissionais da vigilância epidemiológica da Secretaria de Saúde do Estado da Bahia, instituição com uma longa história de parceira com ISC. Foram selecionados 12 alunos de um total de 17 inscritos na seleção. Os módulos e oficinas de PO foram realizados conforme previsão. Os projetos apresentados para exame de qualificação referem-se a temas de vigilância epidemiológica, avaliação de impacto de tecnologias em saúde (vacinas e tratamento), avaliação de sistemas de informação e epidemiologia no planejamento e programação de serviços de saúde. Todos os projetos (Anexo 1) foram aprovados no exame de qualificação, com defesa prevista para novembro de 2004. Vale ressaltar que 
cada aluno vem trabalhando com temas relacionados com a sua prática como profissional da vigilância epidemiológica no âmbito da Secretaria da Saúde do Estado da Bahia (Sesab).

\section{Mestrado Profissionalizante em Gestão de Sistemas de Saúde - Goiás}

Uma característica interessante desta edição do curso é o fato de haver contemplado a realização de uma atividade preparatória à seleção, negociada com a Secretaria Estadual de Saúde de Goiás, instituição parceira, que solicitou a realização de um 'curso de atualização em saúde coletiva' no primeiro semestre de 2003, antes do processo seletivo para o mestrado profissionalizante. A seleção aprovou 15 candidatos entre 28 inscritos, sendo a grande maioria constituída de técnicos que trabalham no nível central da Secretaria de Estado da Saúde (SES-GO). Os módulos e oficinas de pesquisa foram realizados conforme previsão, tendo ocorrido o exame de qualificação dos projetos (Anexo 1) durante o mês de agosto de 2004. No momento atual, encontram-se em fase de execução os módulos relativos às disciplinas optativas do curso, estando programada a entrega dos produtos finais e a defesa das dissertações para o final de 2004, início de 2005. Nota-se a diversidade de projetos de avaliação de programas/sistemas/serviços de saúde, e um na área de educação em saúde.

\section{Mestrado Profissionalizante em Gestão de Sistemas de Saúde - Distrito Federal}

A quinta edição de curso e terceira turma do mestrado profissionalizante na área de concentração em Gestão de Sistemas de Saúde foi negociada com a Segets/MS, durante o ano de 2003, quando se decidiu ampliar a oferta de vagas aos profissionais da saúde que atuam na região Centro-Oeste do país. Com isso, obteve-se a inscrição de 116 candidatos, tendo sido selecionados 15, que estão cursando o mestrado desde maio do corrente ano. Ainda é cedo para se fazer uma apreciação dos resultados do curso, podendo-se adiantar, entretanto, a relação dos projetos (Anexo 1) apresentados ao processo seletivo como temas de interesse dos alunos, os quais vêm sendo trabalhados durante as oficinas de pesquisa orientada e nas atividades de orientação à distância. Está prevista a qualificação para janeiro de 2005 e o término do curso em junho do próximo ano.

\section{FINANCIAMENTO}

O financiamento das cinco edições do curso se viabilizou mediante a celebração de convênios entre a Universidade Federal da Bahia, tendo o Instituto de Saúde Coletiva como 
unidade executora, e outras instituições públicas, tais como o Ministério da Saúde, a Secretaria Estadual de Saúde da Bahia e a Agência Nacional de Vigilância em Saúde (Anvisa), como financiadoras. Os recursos têm sido repassados para a Fundação de Apoio à Pesquisa (Fapex), vinculada à universidade, com vistas a uma gestão mais ágil. Embora direcionados a clientelas específicas, os editais de seleção têm sido públicos e universais, ou seja, todos que atendam aos requisitos explicitados podem se inscrever. Os recursos assim captados têm beneficiado o programa de pós-graduação como um todo, principalmente no que diz respeito à sua infraestrutura administrativa.

\section{PRODUTOS ALCANCCADOS}

O produto final do mestrado, além da constituição de "sujeitos epistêmicos" (Testa, 1991), capazes de gerar conhecimento e tecnologias de intervenção na organização e gestão do sistema público de saúde, expressa-se nas dissertações e artigos produzidos pelos mestrandos (Anexo 1), os quais constituem um rico material a ser analisado, tanto do ponto de vista do conteúdo quando da possibilidade de incorporação à prática concreta no âmbito das instituições que deram origem aos problemas das investigações realizadas.

\section{A CONTRIBUICÃAO DO MP AO ISC E AO CAMPO DA SAÚDE COLETIVA}

Nos últimos dois anos, o ISC vem recebendo numerosas solicitações para a realização de mestrados profissionais. Essas solicitações são amplamente discutidas e avaliadas nas instâncias de gestão do instituto em relação à pertinência, à instituição demandante, à proposta apresentada, à clientela etc. Eà disponibilidade de professores para orientação de modo a não interferir nos cursos acadêmicos. Constata-se uma demanda crescente por essa modalidade de curso, haja vista o número de inscritos na última seleção: 116 candidatos para 15 vagas.

A oferta de mestrados profissionalizantes representa uma das oportunidades de formação de quadros, induzida pelas demandas específicas de instituições públicas relevantes para o desenvolvimento do Sistema Único de Saúde no país. Além disso, os produtos finais dos alunos, de natureza aplicada, incluindo tecnologias, tais como manuais, instrumentos de screening, diagnósticos de saúde e projetos de intervenção em áreas específicas da prática políticoinstitucional, não só contribuem para o aperfeiçoamento das práticas sanitárias como agregam conhecimento ao campo da saúde coletiva. A equipe docente envolvida nos cursos tem apontado como aspectos críticos o tempo de duração dos cursos, avaliando a opção por oferecer o 
conteúdo teórico de forma condensada e intensiva; as vantagens e desvantagens da orientação semipresencial eà distância; a natureza do produto final, quanto à forma (artigo, dissertação ou projeto) e ao conteúdo (vínculo com a temática central e com a prática institucional dos alunos). Do ponto de vista do corpo discente, a avaliação sistemática dos módulos e oficinas revelou também que, em linhas gerais, os alunos consideram o curso bem organizado, avaliando favoravelmente o conteúdo apresentado e as estratégias pedagógicas utilizadas.

Além disso, a experiência acumulada com a realização dessa modalidade de curso tem tido um impacto extremamente positivo para o PPGSC, na medida em que vem estimulando a reflexão coletiva sobre a natureza do processo de produção de conhecimentos e tecnologias no campo da saúde coletiva, sobre a especificidade do processo de formação dos sujeitos capazes de desencadear processos de mudança organizacional, por meio da introdução de inovações tecnológicas nas práticas de planejamento, gestão e avaliação de sistemas e serviços de saúde. Ademais, tal modalidade prioriza a organização do cuidado à saúde das populações levando em conta as dimensões política, técnica e ética voltadas para a efetividade, a qualidade e a 'humanização' da atenção à saúde e da resolução dos problemas no setor.

Do ponto de vista estritamente pedagógico, a experiência dos mestrados profissionalizantes tem estimulado o corpo docente do programa a avançar na utilização de tecnologias de educação à distância, especialmente o uso dos meios eletrônicos para potencializar a orientação de alunos. A experiência dos MPs tem extrapolado o espaço do PPGSC, na medida em que, com o envolvimento de docentes de outros centros acadêmicos em saúde coletiva no país, como membros de bancas examinadoras, ela vem contribuindo para o desenvolvimento de uma reflexão coletiva e uma compreensão mais objetiva dos limites e das possibilidades abertas com esta modalidade de formação pós-graduada no país.

\section{COMENTÁRIO FINAL}

Pelo exposto, percebe-se que a realização do mestrado profissionalizante constituiu-se em uma experiência relevante para o corpo docente do Instituto de Saúde Coletiva, na medida em que consolidou a opção institucional por oferecer esta modalidade de formação pós-graduada, ao tempo que contribuiu para o aperfeiçoamento da prática pedagógica na área. Apesar do pouco tempo de implantação do mestrado profissionalizante, conclui-se que a experiência tem sido bem-sucedida e que a avaliação do MP vem gerando um processo de reflexão interna ao programa de pós-graduação, na busca de alternativas pedagógicas que conduzam a uma organicidade cada vez maior com as tendências da produção científica na área de saúde coletiva e com o processo de transformação das práticas de saúde em nosso meio. 


\section{REFERÊNCIAS BIBLIOGRÁFICAS}

BRASIL. Ministério da Educação. CES/MEC-Parecer n. 977/65, de 3 de dezembro de 1965.

CAPES. Portaria n. 47, de 17 de outubro de 1995.

CAPES. Portaria n. 080, de 16 de dezembro de 1998.

TESTA, M. Pensar em Saúde. Porto Alegre: Intermédica, 1991.

VIRMOND, M. Mestrado profissional: uma síntese. Salusvita, 21(2):117-129, 2002.

\section{ANEXO 1 \\ Produtos do Mestrado Profissionalizante \\ em DocênCia de SaÚde da Família}

AROUCA, Jorge. A experiência do Conselho local de Saúde de Sambaituba no planejamento estratégico e programação local em saúde, 2002. Salvador: ISC, UFBA.

AZEVEDO, Leônidas. Vacinação de crianças abaixo de 5 anos: oportunidades perdidas pelo PSF e outros serviços de saúde, 2002. Salvador: ISC, UFBA.

BARRETO DE JESUS, Humberto. Implantação das ações de controle de hanseníase nas unidades de saúde do M4 em Itabuna, 2002. Salvador: ISC, UFBA.

BICALHO, Paulo. A amplitude de participação no Conselho Municipal de Saúde de Itabuna, 2002. Salvador: ISC, UFBA.

CONRADO, Emanuel. Evolução da mortalidade infantil por causas evitáveis em Ilhéus e Itabuna, Bahia, 1980-2000, 2002. Salvador: ISC, UFBA.

COSTA, Mônica Moura. Educação para a saúde no espaço escolar: uma experiência educacional para a promoção da saúde sobre aleitamento materno aplicada a escolares em área do PSF em Ilhéus, 2002. Salvador: ISC, UFBA.

FERREIRA, Maria Bittencourt. Distrito Sanitário Especial Indígena: a teoria no papel e a prática no território, 2002. Salvador: ISC, UFBA.

GUSMAN, Julio Diaz. Aids e informação do diagnóstico: aspectos bioéticos na relação médico-paciente, 2002. Salvador: ISC, UFBA.

LINS, Augusto César. Triagem do vírus da hepatite B em gestantes: revisão de literatura, 2002. Salvador: ISC, UFBA. 
MARGOTTO, Mercia. Planejamento familiar: um estudo das práticas das equipes do PSF em Ilhéus, 2002. Salvador: ISC, UFBA.

MELO, Rosângela Carvalho de. Um médico para o Programa de Saúde da Família, 2002. Salvador: ISC, UFBA.

NASCIMENTO, Jaime Oliveira. Avaliação da assistência pré-natal em unidades do PSFBahia, 2002. Salvador: ISC, UFBA.

PEREIRA, Nelson Nunes. Inserção da saúde mental na atenção básica: um plano de intervenção para o município de Itabuna-Bahia, 2002. Salvador: ISC, UFBA.

SAPUCAIA, Nadja. Anemia falciforme: os laços do cuidado. Um estudo de práticas referidas por familiares de falcêmicos, 2002. Salvador: ISC, UFBA.

\section{Produtos do Mestrado Profissionalizante}

em Gestão de Sistemas de Saúde

ARAÚJO, Cinthia Lociks. Promoção da eqüidade: limites e possibilidades da Norma Operacional da Assistência à Saúde, 2003. Salvador: ISC, UFBA.

ARRUDA, Maria Arindelita Neves de. O processo de trabalho do enfermeiro no Programa Saúde da Família: limites e possibilidades, 2003. Salvador: ISC, UFBA.

CACHOEIRA, Vaneide M. Implantação do Plano de Reorganização da Atenção à Hipertensão Arterial e ao Diabetes Mellitus: subsídios para a elaboração de Manual do Gestor Municipal, 2003. Salvador: ISC, UFBA.

CAVALCANTI, Regina A. S. O técnico em higiene dental e a reorganização das ações de saúde bucal na atenção básica: a necessidade de um novo perfil profissional, 2003. Salvador: ISC, UFBA.

COELHO, Marta Roberta. Atenção básica à saúde da mulher: subsidios para a elaboração do Manual do Gestor Municipal, 2003. Salvador: ISC, UFBA.

CORREA, Ana Paula R. A influência do projeto de fortalecimento sobre a capacidade de gestão da Secretaria de Saúde de Goiás: estudo de caso, 2003. Salvador: ISC, UFBA.

DUARTE, Cláudio. Iniciativas comunitárias para a promoção da saúde em centros urbanos: uma análise dos estudos de avaliação, 2003. Salvador: ISC, UFBA.

ELIAS, Flávia T. S. Proposta de sistema de informação para monitoramento de pesquisas no Ministério da Saúde, 2003. Salvador: ISC, UFBA. 
FREIRE, Margarida Maria P. Processo de implantação do projeto de fortalecimento e apoio ao desenvolvimento institucional da gestão estadual do Sistema Único de Saúde, 2003. Salvador: ISC, UFBA.

MOTA, Márcia Luz da. Capacitação de gestores municipais de saúde: desafios e perspectivas, 2003. Salvador: ISC, UFBA.

NASCIMENTO, Regina L. Projeto para avaliar a implantação do plano de intensificação das ações de controle da malária na Amazônia Legal, 2003. Salvador: ISC, UFBA.

OLIVEIRA, Neilton. O Plano Nacional de Mobilização e Intensificação das Ações para a Eliminação da Hanseníase e Controle da Tuberculose no Brasil: uma proposta de avaliação, 2003. Salvador: ISC, UFBA.

REHEM, Tânia Cristina M. Assistência domiciliar em saúde: subsídios para a atenção básica, 2003. Salvador: ISC, UFBA.

SALDANHA, Sônia. A mudança organizacional na Secretaria de Estado da Saúde de Santa Catarina, 2003. Salvador: ISC, UFBA.

SAMPAIO, Luís Fernando R. Integralidade da atenção à saúde: análise crítica da programação da atenção básica - PPI/AB, 2001/2002, 2003. Salvador: ISC, UFBA.

\section{Produtos do Mestrado Profissional}

em Epidemiologia em Serviços de Saúde

CARVALHO, Marlene T. B. de. Uso da epidemiologia no planejamento, programação, gestão e avaliação das ações em serviços básicos de saúde: o caso de controle da tuberculose, 2004. Salvador: ISC, UFBA.

DORZEE, Irani P. Proposta de guia para implementação da vigilância epidemiológica do óbito materno no estado da Bahia, 2004. Salvador: ISC, UFBA.

DOURADO, Adriana. Análise da evolução do risco potencial para a ocorrência do sarampo na Bahia e em Salvador, 2004. Salvador: ISC, UFBA.

GUIRRA, Maria de Fátima. Efetividade do tratamento supervisionado (Dots) para tuberculose em alguns municípios no estado da Bahia - 1996 a 2002, 2004. Salvador: ISC, UFBA.

IVO, Nilda Lucia N. Oportunidades perdidas de vacinação e identificação de fatores que influenciam no alcance da homogeneidade de coberturas vacinais no município de Camaçari, 2004. Salvador: ISC, UFBA. 
MATOS, Jorge Fernando M. de. Perfil da infecção chagásica no estado da Bahia: avaliação da situação da transmissão da doença de Chagas, 2004. Salvador: ISC, UFBA.

OLIVEIRA, Maria Helena de. Hepatite C: perfil epidemiológico e fatores determinantes do abandono do tratamento com medicação de alto custo, 2004. ISC, UFBA.

SANTOS, Eleuzina F. S. Avaliação do impacto da vacinação associada contra influenza e pneumococos 23 valente, na população de 60 anos e mais do município de Salvador, 2004. Salvador: ISC, UFBA.

SANTOS, Judith P. dos. Avaliação da qualidade do Sistema de Informação de Nascidos Vivos no município de Salvador - 2000 a 2003, 2004. Salvador: ISC, UFBA.

SANTOS, Raimunda M. C. Fatores de risco para ocorrência de óbito por tétano acidental. Estudo do caso: controle em hospital de Salvador-BA, 2004. Salvador: ISC, UFBA.

TELES, Maria Dolores de S. Qualidade do Sistema de Informações de Agravos de Notificação Sinan: uma avaliação a partir dos dados de meningite no município de Salvador 2000 a 2003, 2004. Salvador: ISC, UFBA.

WILL, Rosane M. M. Perfil sorológico para rubéola em gestantes vacinadas inadvertidamente na campanha de vacinação contra a rubéola na Bahia, em junho de 2002, 2004. Salvador: ISC, UFBA.

Projetos aprovados no exame de qualificação do Mestrado Profissional em Gestão de Sistemas de Saúde

ALVAREZ, William. A qualidade das informações constantes nas Autorizações de Internação Hospitalar (AIH) relacionadas ao tipo de parto realizado em Goiás no ano de 2002. Salvador: ISC, UFBA, 2004.

BARROS, Fernando Passos Cupertino de. Evolução das intervenções hospitalares do SUS: impacto das políticas de saúde no perfil de serviços hospitalares no estado de Goiás, no período de 1995 a 2003. Salvador: ISC, UFBA, 2004.

CAMPOS, Elizabeth de Souza. Projeto piloto para implantação de um serviço de farmacovigilância em uma unidade hospitalar. Salvador: ISC, UFBA, 2004.

FAUSTO, Jaime. A regulação da Política Nacional de Saúde pelo gestor federal do SUS. Salvador: ISC, UFBA, 2004.

GOMES FILHO, Clidenor. Desigualdades e mortalidade materna em Goiás. ISC, UFBA, 2004. 
LIMA, Ângela Carneiro N. Agendas de Saúde (2001): limites e possibilidades - microrregião Goiânia/Estado de Goiás. Salvador: ISC, UFBA, 2004.

LIMA, Lázara Ribeiro Ferreira. Ampliação do acesso à cirurgia de catarata: um projeto para avaliação da campanha De Olho na Visão - Goiás 2004. Salvador: ISC, UFBA, 2004.

PAULA, Viviane Moraes Batista de. Análise do Programa Saúde da Família em grandes centros urbanos na perspectiva dos gestores e gerentes. ISC, UFBA, 2004.

PEREIRA, Edsaura Maria. Gestão demográfica e controle social: construção de uma proposta de consulta ampliada para a escolha dos gerentes das unidades de saúde de Goiânia. Salvador: ISC, UFBA, 2004.

REGO, Joana. Escola promotora da saúde. Salvador: ISC, UFBA, 2004.

ROCHA, Kênia Barbosa. Análise de implantação da estratégia Saúde da Família no estado de Goiás nos últimos dez anos: estudo de viabilidade política para sua implantação em grandes centros urbanos. Salvador: ISC, UFBA, 2004.

SILVA, Graciano. Como a lógica é utilizada no suprimento de materiais e medicamentos no Hospital de Urgência de Goiânia? Salvador: ISC, UFBA, 2004.

SILVA, Marilúcia Batista Antônio. Perfil de demanda do Hospital de Urgência de Goiânia. Salvador: ISC, UFBA, 2004.

SIRICO, Suely Cunha Albernaz. Acidentes de trabalho com material perfurocortante em profissionais de saúde do Hospital Geral de Goiânia. Salvador: ISC, UFBA, 2004.

SOUZA, Jorge Alves de. Gerências de Administração Regional de Saúde: problematizando sua função e sugerindo estratégias para o desenvolvimento de suas atribuições. Salvador: ISC, UFBA, 2004.

Projetos apresentados para seleção do Mestrado

Profissionalizante em Gestão de Sistemas de Saúde. Brasília, 2004

CERQUEIRA E SILVA, Celina Márcia Passos de. Análise do grau de implantação das práticas assistenciais na área de Saúde da Criança nas equipes do PSF.

DE SIMONI, Carmem Lúcia. Adoção de práticas complementares corporais nos serviços de saúde.

DIMECH, Cristiane Penaforte do Nascimento. Avaliação do Sistema de Vigilância Epidemiológica da Febre Tifóide nas regiões Norte e Nordeste do Brasil. 
ELKHOURY, Ana Nilce Silveira Maia. Leishmaniose visceral: modelo de gestão municipal e qualidade da assistência.

GAVA, Marilia. Análise do trabalho em saúde para subsidiar os processos de informação e informatização do SUS.

HOFFMANN, Maria Cristina Correia. Avaliação de políticas públicas de atenção à saúde mental de crianças e adolescentes no Brasil.

LANZIERI, Tatiana Miranda. Avaliação do Sistema de Vigilância Epidemiológica da Síndrome Rubéola Congênita.

LEMOS, Maria do Socorro Alves. Contribuição da promoção da saúde na abordagem da violência.

LUNA, Stella Maris Malpici. Avaliação da gestão do Sistema Municipal de Saúde sob a estratégia de SAF.

PAIVA FILHO, Ozório. A contribuição da Anvisa na implementação da Política Nacional de Medicamentos.

PINTO, José Bruno de Alencar. Saúde da família nos grandes centros urbanos: uma estratégia de reordenamento dos Silos.

RODRIGUES, Eduardo Santos. Saúde bucal no PSF em Mato Grosso do SUL: análise de implantação.

SANTOS, Isabel Cristina Pimentel dos. Análise da implantação do Programa Nacional de Triagem Neonatal.

SERRA, Ana Sudária de Lemos. Rede de significações: sua influência no atendimento a adolescentes cumprindo medidas socioeducativas em meio fechado.

TORRES, Odete Messa. A formação dos profissionais de saúde voltados para o SUS: um recorte na região Centro-Oeste do Brasil. 


\title{
FORMAC̦ÃO DE GESTORES PARA O SISTEMA DE SAÚDE
}

\author{
A EXPERIENCIA DO MESTRADO PROFISSIONAL \\ DO INSTITUTO DE MEDICINA SOCIAL DA UERJ
}

\section{Célia Regina Pierantoni}

O Mestrado Profissional ${ }^{1}$ em Administração de Saúde do Instituto de Medicina Social da Universidade do Estado do Rio Janeiro (IMS/Uerj) surgiu a partir do desenvolvimento e consolidação de seu Programa de Pós-Graduação em Saúde Coletiva (processo iniciado em fins de 1978 e homologado pelo Conselho Federal de Educação em 1982) e da experiência acumulada desde 1976 com o Curso de Especialização (pós-graduação lato sensu) em Administração Hospitalar (Resolução Uerj 042/99). Especialmente nesta área o movimento de transformação da gestão nas organizações de saúde pôde ser acompanhado por mudanças detectadas no perfil da clientela desse curso: antes composta predominantemente de médicos, ela incorporou, progressivamente, outros profissionais da área da saúde. Uma realidade atual agrega, além desses profissionais, aqueles com formação em administração e áreas diversas como engenharia, arquitetura, direito, informática, entre outras, e amplia o foco para além das unidades hospitalares, abrangendo a complexidade de sistemas e serviços de saúde.

\footnotetext{
${ }^{1} \mathrm{O}$ mestrado profissional é uma modalidade de especialização stricto sensu, com a finalidade de formar profissionais não necessariamente ligados à carreira de docência e pesquisa. Visa à qualificação e produção de conhecimento aplicados em áreas específicas e é credenciado pela Capes.
} 
A diversidade da clientela, por outra via, promoveu, ao longo desse processo, o desenvolvimento e acúmulo de experiência no uso de metodologias de ensino-aprendizado voltadas para a valorização da experiência dos participantes, agregada à de profissionais da área. Mais ainda, estimulou a adoção de mecanismos de avaliação capazes de considerar a troca de experiências entre os alunos e a competência para o trabalho em equipe.

Essas preocupações refletem, de um lado, as mudanças observadas nas organizações de saúde e espelham as operadas no chamado 'mundo do trabalho'; de outro, as questões inerentes aos processos de mudança e de implementação da política de saúde para a construção do Sistema Único de Saúde (SUS) nos anos recentes.

O mundo do trabalho vem sofrendo transformações que acompanham as da sociedade pós-industrial relativas ao desenvolvimento e à incorporação tecnológica. Tais transformações são traduzidas em produtos, processos de trabalho ou gestão e, para além da incorporação de tecnologia armada, dos trabalhadores são exigidos novos perfis adaptativos. Esses perfis demandam uma nova conformação da capacidade de adaptação de labor de diversos setores da economia ditada por tendências, por vezes contraditórias, relacionadas com a polivalência, a ausência de especialização, a capacidade de inovar, a ênfase do trabalho em equipe, a qualificação, a autonomia e a responsabilização, o desenvolvimento de habilidades cognitivas e de novas competências (Pierantoni, Varella \& França, 2004).

É consensual a observação de que a velocidade da demanda por esses novos perfis, aliada a proposições inovadoras aplicadas em estruturas organizacionais rígidas ou com metodologias tradicionais, determina convivência de formas de organização do trabalho híbridas. Assim, persistem processos de trabalho com a ausência de participação efetiva dos trabalhadores, a rotatividade da ocupação dos postos de trabalho, os treinamentos ou especializações que visam a mudanças comportamentais, e não à formação específica mais qualificada, entre outras (Pierantoni, Varella \& França, 2004).

A necessidade de novas competências, com a criação de novas ocupações e especializações, enfrenta, por outro lado, interesses corporativos tanto por parte de corporações mais organizadas como do sistema educacional, o que afeta não só a velocidade mas também a qualidade e a institucionalização da incorporação desses novos perfis profissionais (Pierantoni, Varella \& França, 2004).

No campo da saúde, a reforma do sistema em seus momentos relativos à definição constitucional do Sistema Único de Saúde (SUS) na década de 80, à definição macropolítica da reforma do Estado na década de 90 , à fixação de políticas relacionadas com a criação ou mudança do modelo assistencial (particularmente em meados da última década) e o forta- 
lecimento das instâncias de participação social vêm gerando transformações específicas relativas a produtos, processos de trabalho e gestão para a área. Tais transformações fortalecem a necessidade de qualificação de quadros para o exercício dessa função (Pierantoni \& Vianna, 2003, 2004).

\section{ESPECIFICIDADE DA ÁREA E DA CLIENTELA}

Os sistemas e serviços de saúde, em sentido mais geral, apresentam regras próprias e soluções particulares que exigem um conhecimento aplicado das teorias da administração e de princípios do planejamento, adotados pelas diversas escolas da área de administração. Assim, a forma de conduzir os problemas de administração de sistemas e serviços de saúde não se configura em simples variante da 'administração de negócios', mas em campo preciso e conseqüente de aplicação de diversas técnicas, apoiadas em um quadro teórico-prático e de responsabilidade social definido e diversificado.

A formação para essa área apresenta uma precariedade do ensino da administração e organização dos serviços de saúde, em diferentes cursos de graduação, tanto na área das ciências sociais e da saúde quanto em outros setores do conhecimento. Esse fato traduz-se, no nível da pós-graduação, em um acúmulo limitado de investigações e pesquisas que contribuam para o diagnóstico da gestão de sistemas e de serviços de saúde e a conseqüente formulação de planos e projetos alternativos, com base na nossa realidade institucional e social.

A clientela para esse tipo de formação (gestores e profissionais engajados no mercado de trabalho de prestação de serviços de saúde) tem recorrido aos programas de pós-graduação em saúde coletiva. $\mathrm{O}$ aperfeiçoamento do mestrado acadêmico, pela dimensão e complexidade do campo, não atende às necessidades daquele tipo de formação e de clientela: trata-se de formar gestores e produzir conhecimento sistematizado, com qualidade reflexiva e crítica, representativo da pluralidade e da dinâmica da gestão de sistemas e serviços de saúde que possa ser rapidamente disseminado.

Dessa forma, a partir da experiência acumulada tanto no programa de pós-graduação como na especificidade da clientela da área de gestão, a opção do IMS/Uerj foi por focalizar o Mestrado Profissional (MP) nas áreas de gestão de sistemas e serviços de saúde. ${ }^{2}$

\footnotetext{
${ }^{2}$ O título 'Mestrado em Administração de Saúde' foi escolhido por favorecer condições institucionais que localizassem com clareza a proposta e a clientela.
} 


\section{Estrutura curricular básica do Mestrado Profissional do IMS/Uerj}

A estrutura curricular do Mestrado Profissional em Administração de Saúde do IMS/Uerj é integrada por disciplinas obrigatórias e eletivas.

São consideradas disciplinas obrigatórias as que se destinam à formação básica do aluno no contexto da proposição do projeto. A grade das disciplinas obrigatórias contém oito disciplinas, sendo cinco comuns e três específicas para cada área (Administração Hospitalar e Gestão de Sistemas de Saúde). As disciplinas eletivas têm como objetivo aprofundar o conhecimento do aluno em áreas estratégicas, tanto do ponto de vista teórico como da prática em administração de saúde. A grade das disciplinas eletivas contém dois conjuntos de disciplinas, um para cada área.

Para integralização das disciplinas do curso, o aluno deverá fazer as cinco obrigatórias comuns, as três específicas e duas eletivas da área.

Os temas desenvolvidos tanto nos trabalhos de avaliações intermediárias como no trabalho final devem estar relacionados com a prática do aluno na instituição em que ele trabalha ou no sistema de saúde.

O prazo de integralização previsto para o programa é de até 18 meses.

Está em fase de aprovação, via reformulação do regimento, a criação de duas áreas de concentração: Recursos Humanos e Vigilância Sanitária.

\section{MESTRADO PROFISSIONAL EM ADMINISTRAÇÃO DE SAÚDE DO INSTITUTO DE MEDICINA SOCIAL DA UERJ: TURMA MINISTÉRIO DA SAÚDE}

O Mestrado Profissional em Administração de Saúde do Instituto de Medicina Social da Uerj foi oferecido ao Ministério da Saúde (MS) na área de concentração de Gestão de Sistemas de Saúde no período 1999-2000. ${ }^{3}$ Esta área de concentração tem como objetivo a qualificação de gestores em saúde que, em uma perspectiva interdisciplinar, sejam capazes de formular ações de planejamento, gestão e avaliação de sistemas e serviços de saúde.

O curso foi ministrado em cinco módulos, com duas disciplinas em cada um, perfazendo um total de dez disciplinas. Os módulos, com aulas em horários compatíveis com a manutenção das atividades profissionais dos alunos, tiveram duração de dois meses, integralizados em um período de 12 meses.

Para que tais premissas se validassem, era fundamental que a situação ensino-aprendizado se estruturasse convenientemente. Assim, a responsabilidade do professor (e também dos alunos) transcendeu o período dedicado às aulas. Tal fato gerou compromissos com a criação de mecanismos eficazes de orientação e avaliação, que objetivaram resultados bem definidos,

${ }^{3}$ Essa turma foi a primeira na modalidade Mestrado Profissional na área de Saúde Coletiva. 
nas diferentes fases de desenvolvimento da disciplina. A eficácia do curso foi medida não só pela qualidade das aulas dadas, no sentido tradicional, mas também pela capacidade de articulação dos conhecimentos com as modernas metodologias de ensino, que propiciam a participação ativa dos alunos.

\section{Corpo Docente}

O curso contou com o apoio de professores doutores e orientadores do quadro do Instituto de Medicina Social, de convidados de outras instituições de ensino, assim como de profissionais vinculados aos serviços de saúde que, por sua experiência, pudessem efetivamente contribuir com uma melhor visão da realidade das instituições de saúde.

Suas principais atribuições e responsabilidades foram:

- Conhecer o curso: sua filosofia, seus objetivos, grade curricular, seu regulamento, entre outras, articulando-o à disciplina ministrada, à realidade da organização e do sistema de saúde e às demandas da clientela.

- Elaborar o material didático específico para o curso, com texto básico produzido especialmente para a turma, bibliografia mínima e complementar, com base nas orientações dadas pela coordenação do curso.

- Disponibilizar, com no mínimo 30 dias de antecedência, para a coordenação, o material didático utilizado nas aulas, indicando, nesse momento, os recursos audiovisuais (vídeo, retroprojetor, projetor, computador etc.) necessários.

\section{Seleção dos Alunos}

Os alunos foram selecionados de acordo com as determinações do regimento do PPG do IMS/Uerj. A banca foi constituída por docentes do programa e um gestor do MS que acompanhou todo o processo. Realizaram-se prova escrita, entrevista e análise de currículo. $\mathrm{Na}$ análise de currículo foram estabelecidos previamente critérios de pontuação que incluíam, entre outros, as experiências profissionais e inserções dos candidatos na gestão do Ministério da Saúde. Dos candidatos inscritos, foram selecionados 28 alunos para essa turma.

A suficiência em idioma estrangeiro foi exigida como pré-requisito para qualificação e elaboração de trabalho final.

\section{Estrutura Curricular}

A partir da estrutura curricular básica do Mestrado Profissional em Administração de Saúde (disciplinas do núcleo comum e da área de concentração), foram discutidos e elabora- 
dos conteúdos adequados para a área de gestão de sistemas de saúde, contemplando-se o elenco a seguir:

\begin{tabular}{|l|c|}
\hline Disciplinas & Código \\
Sistema de saúde (Evolução política, desenvolvimento econômico e seguridade social) & IMS02719 \\
Processo gerencial I & IMS02720 \\
Estratégia, planejamento e programação (Estratégia, gestão de projetos e situações) & IMS02710 \\
Gerência de meios I (Gestão da tecnologia) & IMS02718 \\
Seminário de orientação para trabalho final (Metodologia) & IMS02711 \\
\hline Área de concentração: Gestão de Sistemas de Saúde & IMS02709 \\
\hline $\begin{array}{l}\text { Financiamento do setor Saúde } \\
\text { Políticas sociais e políticas públicas de saúde }\end{array}$ & IMS02712 \\
Sistemas de informação, programação, controle e avaliação & IMS02721 \\
$\begin{array}{l}\text { Prática profissional em gestão de sistemas de saúde I (Organização governamental e } \\
\text { cultura política) }\end{array}$ & IMS02716 \\
Prática profissional em gestão de sistemas de saúde II & IMS02717 \\
\hline
\end{tabular}

\section{Resultados e Produtos}

Dosalunos selecionados, um desistiu no início do curso eoutro, ao longo das disciplinas. No final do curso, esperavase que os alunos fossem capazes de produzir um trabalho adequado a seus perfis profissionais e contemplando um elenco de temas ou objetos de interesse do próprio Ministério da Saúde. Mais ainda, que utilizassem a aplicação dos campos teóricos tratados nas disciplinas. Nessa perspectiva, cada aluno escolheu como foco de sua dissertação um dos temas relacionados com a realidade de seu campo de atuação englobando os conteúdos gerais das distintas disciplinas.

Os temas apresentados nas dissertações de conclusão do MP podem ser agrupados em dois grandes blocos. O primeiro reflete o registro e a análise de questões relativas à implementação da política e seus aspectos normativos; o processo de descentralização; os avanços e dificuldades da capacidade gestora de níveis estadual e municipal; a distribuição espacial e o acesso da população ao sistema; os limites e possibilidades de utilização mais abrangente de sistemas de informação vigentes. Um segundo bloco aborda temas relativos à avaliação de programas e à implementação de políticas em áreas específicas. Ao final do curso foram aprovadas 22 dissertações, com temas e resumos listados a seguir.

Controle e avaliação em saúde: enfrentando desafios na gestão do SUS

Partindo da legislação de controle, avaliação e auditoria no SUS, pós-Constituição de 1988, e do tratamento dado pelas normas operacionais a esse componente de gestão nos três níveis de governo, o estudo objetiva discorrer sobre a cultura acumulada nessa área, apresentan- 
do um breve diagnóstico sobre a situação atual em que se encontra este componente de gestão no SUS. Pretende, ainda, propor alternativas para superar os desafios quanto à sistematização das competências e atribuições na área de controle e avaliação da assistência à saúde.

Ampliação do acesso a medicamentos de alto custo: uma análise da política brasileira

Objetiva analisar a política brasileira de medicamentos, aspectos relativos à assistência farmacêutica de alto custo no país, sua evolução, o comportamento do mercado farmacêutico, o processo de gerenciamento do chamado Programa de Medicamentos Excepcionais, a regulação da atividade, o processo de ampliação da capacidade gestora do Ministério da Saúde e dos estados nessa área e a ampliação do acesso da população a medicamentos de alto custo.

Uma análise do processo de implantação dos centros de referência para o tratamento da retinopatia diabética na rede de serviços do Sistema Único de Saúde do Brasil ocorrido em 2000-2001

Tem como objetivo avaliaro processo, ocorrido no período de 2000 a 2001, de implantação de trinta centros de referência especializada em oftalmologia no Sistema Único Saúde do Brasil, destinados ao tratamento das lesões oftalmológicas, em especial para os pacientes diabéticos portadores da retinopatia diabética. Descreve as circunstâncias do processo de decisão para implantação desse programa e os instrumentos para sua formalização, bem como as dificuldades encontradas na implantação e os possíveis resultados no quadro atual da atenção oftalmológica no Brasil.

As idéias e as práticas: a construção do SUS

Visa a registrar os vários fatos e momentos históricos do movimento sanitário que vai do período da fundação do Centro Brasileiro de Estudos de Saúde(Cebes) e a publicação da revista Saúde em Debate, em 1976, até a promulgação da Constituição Federal de 1988. Pretende demonstrar, além do registro histórico dos fatos e momentos do período, a evolução das propostas do movimento sanitário, cotejando seus conteúdos com os da Constituição Federal de 1988. A distribuição dos recursos para as ações de atenção básica no Brasil. A criação do Piso de Atenção Básica (PAB) fixo: uma análise da distribuição dos recursos a partir de 1996 e a portaria que estabelece os novos valores por município

Objetiva analisar a distribuição dos recursos para as ações básicas de saúde, a partir da criação do Piso de Atenção Básica (PAB). Pode-se constatar que, com as simplificações do modelo de gestão (introduzidas pela NOB/SUS 01/96, que possibilitou a criação do PAB), ocorreu uma aceleração da municipalização das ações básicas de saúde, de forma extremamente rápida e em todos os estados e regiões do país. 
Projeto de expansão da assistência oncológica (Expande): um ovo modelo de assistência

Estudo que visa a descrever o Expande - Projeto de Expansão da Assistência Oncológica, atualmente desenvolvido pelo Ministério da Saúde. O modelo analisado permitiu verificar uma melhoria na distribuição eqüitativa e universal, garantindo ao paciente um atendimento integral. Distribuição espacial e acesso da população aos serviços de saúde

Trata da questão da distribuição espacial e do acesso da população aos serviços de saúde. Faz uma discussão em torno dos conceitos de eqüidade e acesso como uma de suas vertentes. O objetivo geral foi avaliar a oferta de serviços de saúde no Brasil na década de 90 , especialmente dos serviços públicos, no que se refere à sua distribuição espacial, e a percepção da população quanto ao acesso às unidades de saúde.

Descentralização da saúde: situação da gestão estadual 'Um retrato em preto e branco sem retoque'

Procura descrever o impacto do processo de descentralização das ações e dos serviços de saúde, no âmbito da gestão estadual, no período de 1993 a 2000. Busca identificar os principais problemas, impasses e dificuldades motivados pela mudança do modelo e aqueles induzidos pela forma como foi implantado o processo de descentralização no Brasil. Questiona a existência de uma 'crise de identidade' ocorrida no âmbito da gestão estadual, supostamente provocada pela indefinição dos papéis e competências das três esferas de governo e pela fragilidade técnico-operacional das secretarias estaduais de Saúde.

Análise das práticas assistenciais na área de saúde da mulher nas equipes do Programa Saúde da Família: um estudo de caso em um estado selecionado

Visa a analisar as práticas assistenciais relativas à área de saúde da mulher nas equipes do Programa Saúde da Família e o contexto de sua implantação em um estado previamente selecionado. O estudo possibilitou classificar as equipes de acordo com o grau de implantação das práticas assistenciais na área de saúde da mulher, tendo verificado que a maioria das equipes apresenta graus intermediários de implantação e que um pequeno percentual encontra-se nos extremos das classificações 'muito crítica' ou 'adequada'.

Análise do repasse de recursos financeiros, no biênio 1997-1998, a municipios prioritários para o alcance da meta de eliminação da hanseniase no Brasil

Analisa o repasse dos recursos financeiros da Fundação Nacional de Saúde para municípios com alta prevalência de hanseníase no Brasil. Foram levantadas informações de formulá- 
rios e documentos sobre a concepção e organização da estratégia de repasse, definição dos municípios prioritários, celebração e execução de convênios, prestação de contas, resultados obtidos e entrevistas. Conclui-se que a intervenção assegurou o aumento da capacidade gerencial do nível central na execução financeira do orçamento, direcionando o recurso para as áreas prioritárias, e que o repasse foi regular e contínuo, embora não tenha garantido o monitoramento da execução físico-financeira e a alocação dos recursos, de acordo com o plano municipal.

Avaliação do mutirão nacional de catarata senil na organização dos serviços oftalmológicos: análise comparativa das açôes de cirurgias eletivas de catarata, desenvolvidas nos serviços de saúde, do SUS, no periodo de 1998 a 2001

Visa a analisar a estratégia de organização dos serviços de oftalmologia no SUS a partir da implantação do mutirão de cirurgia de catarata pelo Ministério da Saúde. Pôde concluir que de fato o mutirão atingiu o objetivo ao qual se propôs - reduzir a demanda reprimida e conseqüentemente o tempo na fila de espera -, ainda que não tenha acontecido igualmente em todos os municípios do país.

Sistema de informações sobre orçamentos públicos em saúde (Siops): um instrumento de controle do gasto público no setor de saúde

Tem como objeto de estudo o Sistema de Informações sobre Orçamentos Públicos em Saúde (Siops), visto a partir da sua criação, implantação, funcionamento e aplicabilidade.

A análise tem o intuito de recomendar o Siops como instrumento de apoio à elaboração de políticas de saúde, nas três esferas de governo, o planejamento, a gestão e o controle do gasto público na área da saúde, a elaboração das Contas Nacionais em Saúde e como mecanismo de controle referente à Emenda Constitucional - EC-29/2000 eà Lei de Responsabilidade Fiscal. Textos normativos e contextos locais: dilemas do processo de consolidação do SUS no estado do Tocantins

Trata do recente processo de descentralização da gestão assistencial de ações e de serviços de saúde, como aspecto atual da consolidação do Sistema Único de Saúde (SUS) no país. Foram analisados fatores relacionados ao processo de criação de capacidade gestora no nível estadual e às estratégias de superação e de enfrentamento das dificuldades relativas à formulação descentralizada das políticas de saúde. 
Eqüidade na alocação de recursos do sistema único de saúde: uma avaliação através da utilização de uma cesta de indicadores de desigualdade social entre os estados brasileiros

Pretende, a partir da análise de indicadores de desigualdade social e de saúde de uso corrente, analisar a sua correlação com a alocação de recursos federais destinados ao custeio da assistência à saúde, entre os vários estados brasileiros. Objetiva criar a possibilidade de debater a instrumentalização do conceito de eqüidade como um critério para a alocação de recursos no interior do SUS, visando à diminuição das desigualdades inter-regionais seja no nível nacional, entre as unidades federadas, seja no nível estadual, entre suas regiões ou municípios, ou até mesmo no nível municipal, orientando a alocação de recursos conforme avaliação das desigualdades e riscos dentro de seu próprio território.

O banco de preços em saúde: uma tecnologia a serviço da gestão pública

Examina alguns pontos básicos capazes de oferecer subsídios necessários para descrever a metodologia do sistema Banco de Preços em Saúde, que visa a proporcionar maior transparência no uso dos recursos públicos do SUS e oferecer ao mercado novo instrumento regulador de preços de medicamentos e outros insumos da área da saúde.

O serviço de atendimento ao cidadão/usuário do Sistema Único de Saúde como sistemática regular de fiscalização e avaliação dos serviços hospitalares no Brasil

Apresenta uma síntese do trabalho desenvolvido pelo Serviço de Atendimento ao Cidadão/Usuário do Sistema Único de Saúde (Sacsus), instituído no âmbito da Secretaria de Assistência à Saúde, do Ministério da Saúde, visando à fiscalização dos recursos aplicados e à aferição da qualidade da assistência prestada. Já o Sacsus agrega a esses objetivos o desafio de consolidar-se como um canal de comunicação com o cidadão/usuário do Sistema Único de Saúde, onde é possível, de forma igualmente sistemática e sistêmica, identificar sua opinião e suas necessidades e desenvolver serviços, produtos e processos necessárias ao seu atendimento.

Estudo sobre os pactos de gestão estabelecidos entre estados e municipios, a partir da implantação da NOB-SUS 01/96

Procurou refletir sobre determinados instrumentos criados para operacionalizar a estratégia de descentralização do Sistema Único de Saúde, enfocando especialmente a divisão de responsabilidades que se estabeleceu entre estados e municípios durante a vigência da Norma 
Operacional Básica - NOB SUS 01/96. Para se examinar as relações entre estados e municípios, realizou-se uma avaliação dos pactos interesferas governamentais mediados direta ou indiretamente pelas normas operacionais. A análise indica que alguns pactos estabelecidos entre estados e municípios em GPMS não contribuíram para a organização do sistema, mostrando também como a Norma Operacional da Assistência à Saúde - Noas-SUS 01/02 busca a superação desse problema.

Centros colaboradores para a qualidade da gestão e assistência hospitalar: uma experiência inovadora

Objetivou apresentar uma experiência inovadora implementada pelo Ministério da Saúde como uma forma de permitir o intercâmbio, entre instituições hospitalares distintas, de conhecimento e tecnologia suficientes para formar hospitais capacitados a gerenciar racionalmente os recursos disponíveis, minimizando custos administrativos e de produção, otimizando resultados e buscando a ampliação da oferta e da qualidade dos serviços prestados, intitulada Programa Centros Colaboradores para a Qualidade da Gestão da Assistência Hospitalar.

O processo de regulamentação da assistência médica suplementar no Brasil

O objetivo do estudo foi o desenvolvimento de investigações sobre a construção da assistência médica suplementar no Brasil e sua respectiva regulação, a partir de pesquisas acadêmicas disponíveis a respeito desse segmento do sistema de saúde, publicações das entidades representativas das operadoras, artigos publicados e dados estatísticos gerados pela Agência Nacional de Saúde Suplementar (ANS) e pelas próprias operadoras.

Construindo o SUS: a lógica do financiamento e o processo de divisão de responsabilidades entre as esferas de governo

A hipótese desenvolvida neste trabalho é a de que ao se adotar a lógica de um 'Inamps universal' sob um modelo de federalismo que não define claramente os limites entre os seus entes, determinou-se o modelo de financiamento que, por sua vez, produziu a estratégia de organização do novo sistema.

O estudo objetivou analisar o financiamento e a divisão de responsabilidades entre os níveis de governo no processo de implantação do Sistema Único de Saúde. Na análise desse processo, destacou-se que o SUS começou a ser implantado por meio de uma estratégia que buscou dar caráter universal à cobertura das ações de saúde, até então proporcionada pelo Inamps para os seus beneficiários. 
Mortalidade hospitalar na rede SUS: espelho dos óbitos ocorridos na população brasileira?

Com o propósito de verificar a possibilidade de uso do Sistema de Informações Hospitalares do SUS (SIH/SUS) em uma perspectiva mais abrangente, nesta pesquisa optou-se pela comparação dos óbitos registrados no referido sistema e no Sistema de Informações sobre Mortalidade (SIM), para verificar se o perfil da mortalidade hospitalar na rede SUS reflete os óbitos ocorridos na população brasileira.

Com base nos resultados obtidos, constatou-se que, apesar da similaridade entre o perfil da mortalidade proporcional registrado nos dois sistemas, na maior parte das capitais consolidadas por região ainda há uma grande variabilidade em relação à compatibilidade e à consistência dos dados brutos levantados tanto no SIH/SUS quanto no SIM, o que aponta para a necessidade de ajustes, bem como de maior controle e avaliação das informações prestadas.

Os sistemas de informações assistenciais do SUS: oferecendo subsídios para a construção de um sistema único e integrado de informações

Baseou-se na avaliação das vantagens e desvantagens dos sistemas de informações assistenciais disponiveis no SUS, o SIA (Sistema de Informações Ambulatoriais) e o SIH (Sistema de Informações Hospitalares), fornecendo subsídios para a construção de um novo sistema de informações, integrando suas vantagens e agregando outras funcionalidades e características capazes de otimizar a utilização dos dados, transformando-os em informações importantes para a gestão, o planejamento, o controle e a avaliação da assistência à saúde.

A divulgação e disseminação das dissertações aprovadas foi organizada em CD-ROM (Pierantoni \& Viana, 2004). Dessas dissertações, 12 foram escolhidas, conforme o tema, e publicadas sob a forma de texto em publicação específica com tiragem limitada. Esses produtos têm sido objeto de consulta por instituições de ensino e de serviço.

\section{CONSIDERACฺÕES FINAIS}

Para o Instituto de Medicina Social, é um momento de avançar sobre a sua própria experiência de ensino: na graduação via inserção acadêmica disciplinar em cursos de graduação da área da saúde e no aperfeiçoamento de seu Programa de Pós-Graduação em Saúde Coletiva. Entre esses, configura-se a modalidade Mestrado Profissional em Administração de 
Saúde. Aliado a experiências acumuladas em outras instituições da área de saúde coletiva, o programa cumpre uma importante função formadora: capacitar profissionais qualificados para enfrentar e vencer as dificuldades de gerenciamento de instituições e sistemas de saúde com capacidade crítica e reflexiva, fugindo do modismo e imediatismo dos MBA (especializações lato sensu), particularmente em saúde, atualmente oferecidos pelo mercado.

A experiência com esta modalidade de pós-graduação sinaliza que o desenvolvimento do Programa de Mestrado Profissional em Administração de Saúde e na área da Saúde Coletiva representa um desafio constante para as instituições de ensino e de serviço, que só poderá ser enfrentado com discussões e aprendizados mútuos. Exige audácia para o novo e o reconhecimento dos limites e possibilidades dos campos da educação e do trabalho, em aspectos tanto da formação como da produção de conhecimento.

Esses programas, além de prover uma sistematização de conhecimentos relativos àárea, têm sido um importante estímulo para o desenvolvimento e a disseminação de pesquisas nos serviços de saúde. Mais ainda, pela possibilidade de troca de experiências entre os alunos, eles têm propiciado oportunidades de desenvolvimento institucional entre as esferas da gestão, por um lado, e qualificado os processos de reflexão e avaliação com base no acúmulo sistematizado de conhecimentos teóricos aplicados à prática das organizações de serviços de saúde, por outro.

Do ponto de vista acadêmico, têm sido um importante facilitador para a sistematização de conhecimentos e a avaliação dos processos relacionados ao campo da gestão e das políticas públicas, aproximando os campos teóricos de produção de conhecimento da área de saúde coletiva com a prática e a dinâmica observadas na gestão dessas políticas. Mais ainda, têm sido um desafio para docentes e alunos: para os docentes, esses desafios estão determinados, entre outros, pela adaptação de conteúdos dos diversificados campos de conhecimentos à expertise dos alunos; para os alunos, pela retomada de hábitos de leitura e reflexão sobre aqueles campos de conhecimento por vezes não exercidos em função de necessidades inerentes à urgência das demandas cotidianas da gestão do sistema de saúde.

Quanto à regulação dos mestrados profissionais e, em particular, na área da saúde coletiva e afins (prioritariamente desenvolvida em instituições de ensino superior da área pública), é necessário que a Associação Brasileira de Pós-Graduação em Saúde Coletiva (Abrasco) e sua representação no comitê de avaliação da Coordenação de Aperfeiçoamento de Pessoal de Nível Superior (Capes) assumam um posicionamento claro e 'específico', relativo não só aos processos de credenciamento mas também aos de 'avaliação e aperfeiçoamen- 
to’ dessa modalidade de pós-graduação. Mais ainda, é preciso inseri-la no contexto mais ampliado do campo, respeitando as especificidades da formação em saúde coletiva, de modo a cumprir o importante compromisso das instituições de ensino e pesquisa com o sistema e os serviços de saúde e a sociedade.

\section{REFERÊNCIAS BIBLIOGRÁFICAS}

PIERANTONI, C.; VARELLA, T. C. \& FRANÇA, T. Recursos humanos e gestão do trabalho em saúde: da teoria para a prática. In: BARROS, A. F. do R. (Org.) Observatório de Recursos Humanos em Saúde no Brasil: estudos e análises. v. 2. Brasília: Ministério da Saúde, 2004.

PIERANTONI, C. \& VIANNA, C. M. M. (Orgs.) Gestão de Sistemas de Saúde. Rio de Janeiro: IMS/Uerj, Segrecar, 2003.

PIERANTONI, C. \& VIANNA, C. M. M. (Orgs.) Gestão de Sistemas de Saúde: mestrado profissional IMS-Uerj, dissertações. Rio de Janeiro: 2004. CD-ROM.

RESOLUÇÃO UERJ 042/99. Regulamento específico da pós-graduação em saúde e do mestrado profissional. 


\title{
MESTRADO PROFISSIONAL EM GESTÃO DE CIÊNCIA E TECNOLOGIA EM SAÚDE
}

\author{
A EXPERIENCIA DA FIOCRUZ
}

\author{
Carlos Augusto Grabois Gadelha \\ Cristiane Quental
}

O Mestrado Profissional em Gestão de Ciência e Tecnologia em Saúde nasce de uma iniciativa da Presidência da Fundação Oswaldo Cruz (Fiocruz), voltada para a promoção do desenvolvimento institucional por meio da capacitação de seus quadros gestores. Essa iniciativa constitui uma das diretrizes centrais do Plano Quadrienal 2001-2004 proposto pela Presidência e aprovado pelo Conselho Deliberativo da instituição.

A Vice-Presidência de Ensino e Recursos Humanos constituiu, em janeiro de 2001, uma comissão para elaborar a proposta do mestrado profissional a ser criado. Dessa discussão, concluiu-se pela necessidade de implantação de cursos distintos, atendendo a requisitos específicos dos diversos processos de trabalho presentes na Fiocruz. A Vice-Presidência chamou a si a implantação de dois destes cursos: o Mestrado Profissional em Gestão de Ciência e Tecnologia em Saúde e o Mestrado Profissional em Informação e Comunicação em Saúde, este último de implantação mais recente.

A gestão de organizações públicas de C\&T foi priorizada por ser considerada um ponto crítico - muitas vezes mesmo um entrave - para o desenvolvimento institucional. Também para a Fiocruz e demais instituições voltadas para a ciência e tecnologia em saúde o seu desenvolvimento constitui-se numa necessidade estratégica. Como desdobramento, 
foi criado um grupo técnico de trabalho, ${ }^{1}$ que elaborou a proposta conceitual preliminar. A área foi pensada, então, como um suporte gerencial essencial para o funcionamento e o cumprimento das finalidades de uma Instituição Pública de Ciência e Tecnologia em Saúde (IPC\&T/S) e, como tal, demarcada do ponto de vista tanto da oferta inerente a este campo de conhecimento quanto da demanda concreta de gestão dessas organizações.

Essa proposta está sendo desenvolvida no âmbito da Escola Nacional de Saúde Pública Sergio Arouca (Ensp), da Fiocruz. O ganho que se obtém ao localizar numa escola de saúde pública uma iniciativa como essa é enorme, uma vez que propicia a convivência e a fertilização cruzada de áreas normalmente estanques tanto no âmbito acadêmico como no campo das políticas - a área da ciência e tecnologia e a área da saúde. Esse fato é especialmente relevante se temos em mente que um dos fatores inibidores do desenvolvimento nacional em saúde é precisamente a dicotomia que separa o sistema de C\&T em saúde das necessidades sociais, implicando baixo aproveitamento das pesquisas desenvolvidas, o subdesenvolvimento tecnológico e a incorporação desregulada das inovações no âmbito da saúde (Gadelha, Quental \& Fialho, 2003). Comprometida com a capacitação de profissionais para o sistema de saúde, a Ensp não se furtou ao desafio de incorporar a nova área de política e gestão de ciência e tecnologia em saúde nas suas atividades de ensino e pesquisa, como parte integrante desse sistema.

\section{AS ESPECIFICIDADES DOS INSTITUTOS PÚBLICOS DE PESQUISA E DESENVOLVIMENTO EM SAÚDE: OPORTUNIDADE E DELINEAMENTO CONCEITUAL DA INICIATIVA}

O contexto atual se caracteriza por mudanças aceleradas nas tecnologias e nos mercados, tendo em vista a emergência do paradigma das tecnologias de informação e comunicação, o acirramento da competição econômica e a aceleração do processo de globalização. A rapidez com que as atuais mudanças ocorrem e sua penetração e difusão por todos os setores econômicos produzem significativos impactos no desenvolvimento econômico e social de uma nação. Assim, é cada vez mais crucial a aquisição de capacidade para gerar e

\footnotetext{
${ }^{1}$ A proposta preliminar do curso foi desenvolvida por um grupo de trabalho composto por: Carlos A. Grabois Gadelha (Ensp/Fiocruz), Cristiane Quental (Diretoria de Planejamento Estratégico - Diplan/ Fiocruz), Eduardo Martins (Cict/Fiocruz), Miriam Struchiner (Núcleo de Tecnologia em Educação em Saúde - Nutes/UFRJ)) e José Maldonado (Instituto Nacional de Tecnologia - INT), tendo incorporado sugestões da Comissão de Pós-Graduação e do Departamento de Administração e Planejamento da Ensp. A despeito do esforço para incorporar as contribuições citadas, a responsabilidade do documento final é de Carlos A. Grabois Gadelha e de Cristiane Quental.
} 
absorver conhecimentos e inovações para um país se tornar ou se manter competitivo, o que, por sua vez, exige novos e maiores investimentos em pesquisa, desenvolvimento, educação e treinamento.

Nesse cenário, a gestão do conhecimento coloca-se como um fator essencial para vincular ciência e tecnologia ao desenvolvimento nacional. Torna-se necessário considerar a revolução em curso nos processos de produção de conhecimento. Se antes o desenvolvimento científico associava-se, em grande medida, ao aumento do conhecimento inerente a cada disciplina, atualmente o contexto socioeconômico em que o conhecimento é gerado e aplicado emerge como um fator determinante. As necessidades sociais, do meio ambiente, do setor produtivo, entre outras, passam a ter um peso decisivo na orientação da pesquisa, deixando mesmo de haver uma divisão nítida entre pesquisa básica e aplicada. A sociedade, o Estado e a economia passam a ser elementos essenciais para a definição dos focos das investigações, somando-se aos requerimentos internos à própria ciência e tecnologia (Gibbons et al., 1997).

Nesse processo, novos requisitos se impõem tanto no que se refere a relações de trabalho, mais flexíveis e pautadas em hierarquias mais fluidas, quanto aos formatos organizacionais, consubstanciados em redes de instituições, envolvendo a comunidade científica e tecnológica, fornecedores, consumidores, empresas, organizações sociais, Estado, entre outros, para a geração e difusão do conhecimento (Rothwell, 1992; Edquist, 1997). Sem flexibilidade e agilidade gerencial, os desafios do futuro dificilmente poderão ser enfrentados.

Os desafios que se colocam para um país como o Brasil, de reconhecido atraso relativo no que tange ao desenvolvimento científico e tecnológico interno, são imensos. Esses desafios são ainda mais significativos para as instituições de pesquisa brasileiras pelo relevante papel que têm, no momento atual, de dar uma contribuição fundamental ao processo de desenvolvimento econômico e social (Quental, Gadelha \& Fialho, 2001; Salles-Filho, 2000). Antigas e ainda dominantes formas de gestão do conhecimento presentes no Brasil mostram-se obsoletas e restritivas aos avanços requeridos ao conhecimento eà inovação.

Modelos organizacionais matriciais e estruturas ágeis e flexíveis que permitam a organização de grupos de pesquisa multidisciplinares, voltados para a resolução de problemas, tornam-se elementos essenciais para o novo paradigma do conhecimento científico e tecnológico. A introdução sistemática de formas de pensar o futuro e de definição de focos e de estratégias em modelos interativos, sem a rigidez dos sistemas tradicionais de planejamento, impõe-se como uma necessidade da administração pública na área (Maculan \& Zouain, 1997). A ciência e a inovação não podem ser tratadas com os modelos burocráticos rígidos ainda existentes. As inovações organizacionais e a gestão estratégica emergem como parte essencial para a geração e o uso do conhecimento humano. 
Esse contexto faz sobressaírem as especificidades organizacionais e gerenciais das IPC\&T/S diante das organizações privadas e demais organizações públicas:

- O objetivo último dessas organizações éa geração de conhecimento científico e tecnológico para ser utilizado pela sociedade na área de saúde, seja por meio de trabalhos escritos (difusão de resultados de pesquisa que levem a novas práticas, à geração e absorção de inovações de produtos e processos, difusão de inovações organizacionais etc.) ou incorporado nas pessoas que são formadas e qualificadas. Desse modo, já na missão dessas organizações coloca-se uma especificidade essencial que as distingue das organizações privadas, das organizações públicas em geral e das organizações prestadoras de serviços de atenção à saúde, sejam públicas ou privadas.

- O processo de trabalho em que a geração de conhecimentos ocorre é completamente diferenciado. A incerteza quanto aos resultados permeia toda a atividade. Muitas vezes o fracasso de uma iniciativa fornece informações da mais alta relevância acerca de caminhos que não devem ser seguidos e de vias alternativas em que os esforços devem ser concentrados. Num contexto como esse, o planejamento, a avaliação e a prospecção continuam sendo essenciais (talvez até mais do que em atividades tradicionais), mas devem ocorrer de modo distinto (Arnold et al., 1998; Roussel, Saad \& Bohlin, 1992).

- Mesmo os processos administrativos usuais na administração pública ganham especificidade. A gestão de um simples almoxarifado, por exemplo, pode requerer treinamento específico, por envolver materiais biológicos e químicos altamente sensíveis às condições ambientais. A política de treinamento para a área de compras não pode se restringir a um bom aprendizado da legislação pública, porque muitos bens e serviços não são facilmente substituídos por outros. As necessidades de parcerias públicas e privadas requerem um trabalho difícil de conscientização e de treinamento para o estabelecimento de acordos e contratos de longa duração que dificilmente podem ser enquadrados na legislação vigente.

- As estruturas organizacionais e hierárquicas são radicalmente diferentes. Nessas organizações, a hierarquia pelo mérito tende a ser tão ou mais importante do que a hierarquia pela delegação de poder. As estruturas decisórias devem ser mais leves, temporárias e mesmo mais 'brandas' do que as verificadas no setor produtivo público ou privado (Quental \& Gadelha, 2000). As experiências de enquadramento dessas organizações na lógica rígida da hierarquia da administração pública levam a proposições muitas vezes inconcebíveis numa organização de ciência e tecnologia. 
Diante dessas e de muitas outras especificidades, podemos dizer que estamos trabalhando com um ente bastante diferenciado, cujo treinamento de seus profissionais requer um enorme esforço de tradução. Isso porque, a despeito do amplo e rico conjunto de iniciativas que trabalham a questão da gestão e da importância crescente de temas essenciais para as IPC\&T/S, tais como a gestão da inovação e do conhecimento, não existe uma demarcação da área de gestão por parte de instituições acadêmicas que atenda às necessidades colocadas pela proposta. A despeito da riqueza dos enfoques existentes, nenhum dá conta, isoladamente, das necessidades particulares de gestão das IPC\&T/S.

A pós-graduação em administração de empresas incorpora a questão da ciência e tecnologia no contexto da política de inovação e tecnológica das empresas. Muitas das ferramentas estudadas podem contribuir para a administração pública na área de ciência e tecnologia, mas não é este o campo privilegiado para sua aplicação. Essa área não é enfatizada, entretanto, pela pós-graduação voltada especificamente para a administração pública, que costuma enfocar as especificidades do setor público e o estudo de questões particulares ao funcionamento do Estado. No campo da gestão em saúde, que trabalha a gestão de sistemas e serviços de saúde, a questão da ciência e da tecnologia é tratada com um foco bastante restrito, de avaliação de tecnologias com vistas à sua incorporação aos serviços assistenciais.

As IPC\&T/S possuem especificidades gerenciais cujo enfrentamento não pode ser tratado com recurso apenas a esses enfoques isoladamente. Os universos da ciência $\&$ tecnologia, da saúde e da administração pública condicionam conjuntamente as novas formas de gestão que devem ser buscadas por essas organizações, seguindo uma estratégia de qualificação de recursos humanos voltados para seu desenvolvimento institucional. A arte e o desafio da iniciativa da Fiocruz estão em como dar conta desses três universos simultaneamente.

O impacto da iniciativa no Sistema Nacional de Inovação em Saúde pode ser grande, não só pelo tamanho do setor (o setor Saúde é responsável pela execução de 25\% do orçamento para pesquisa e desenvolvimento das agências brasileiras de fomento, por exemplo), mas também pelo seu enorme potencial de alavancagem do desenvolvimento econômico e social, uma vez que combina os efeitos da geração de inovações em indústrias intensivas em ciência e difusoras de tecnologias com a melhoria do bem-estar social (Albuquerque \& Cassiolato, 2000). Ressalte-se também a importância das IPC\&T/S na produção nacional de vacinas, no desenvolvimento e produção de fármacos e medicamentos estratégicos, no controle de qualidade de referência nacional dos produtos em saúde, na assistência de referência, além da pesquisa e da formação de recursos humanos na área. 


\section{PROPOSTA PEDAGÓGICA²}

Para responder aos desafios atuais colocados para os gestores das IPC\&T/S, são necessários profissionais com perfil questionador e capazes não apenas de adaptar-se, mas de gerar e propor mudanças, motivados e instrumentalizados para se capacitar em caráter permanente e conscientes desta necessidade. Pretende-se, assim, preparar profissionais para atuarem como formadores e indutores de processos de mudança em seus espaços de trabalho mediante a adoção de novos conceitos de gestão estratégica que abarquem os três grandes universos nos quais a proposta se insere, quais sejam: universo da ciência e tecnologia, universo da saúde e universo da gestão pública.

Entende-se que, dado o caráter 'profissional' deste mestrado, deve-se valorizar o papel e a experiência do aluno, integrando questões da prática ao processo de aprendizagem, evice-versa. Assim, o profissional évalorizado por sua experiência e pelos seus conhecimentos, mesmo ainda não sistematizados, e pode utilizar/aplicar na prática de resolução de problemas e tomada de decisões em seu cotidiano os conceitos e procedimentos estudados, observando e analisando as atividades envolvidas no trabalho do gestor de ciência e tecnologia em saúde com base nas teorias, nos fenômenos e nos exemplos de casos do curso, bem como nas experiências e visões compartilhadas de professores e colegas no processo de ensino-aprendizagem.

Desse modo, o programa de trabalho deste mestrado objetiva promover a integração da teoria com a prática permitindo repensar o significado da gestão em $C \& T$ em saúde não apenas como um recurso, um meio, uma técnica ou um instrumento auxiliar, mas como um conhecimento em processo que envolve pessoas, procedimentos, idéias, dispositivos e cujo propósito maior é a condução do corpo discente nas tarefas de analisar, planejar, implementar, avaliar e gerenciar soluções para a instituição.

Essa perspectiva está presente na proposta pedagógica que orienta a estrutura curricular que se oferece no curso e que tem os seguintes princípios:

- Garantir que os alunos adquiram autonomia de pensamento para o diagnóstico situacional, a análise e a busca de informações para a tomada de decisões, bem como para continuar aprendendo ao longo de toda a vida.

- Romper com modelos tradicionais que colocam os alunos apenas como 'agentes passivos' do processo educativo, propondo novos formatos de atividades presenciais evirtuais, tais como seminários, estudos de caso, projetos, visitas técnicas e fóruns de discussão.

${ }^{2}$ Formalizada por Miriam Struchiner (Nutes/UFRJ) e José Maldonado (INT). 
- Integrar as atividades didáticas com as questões institucionais, possibilitando que a formação gere conhecimentos que contribuam para mudanças efetivas nas práticas e nos contextos de trabalho dos participantes.

- Incentivar sistemática e permanentemente a busca de informações, a análise crítica e a proposição de práticas inovadoras contextualizadas no processo de trabalho e nas áreas de atuação em gestão em C\&T em saúde e respectivos fundamentos teóricos.

- Refletir sobre as experiências e os conhecimentos no processo de formação e compartilhálos por meio de trabalhos práticos e teórico-práticos em equipe.

Como principal resultado do processo de formação em nível de mestrado profissional, esperam-se mudanças nos modelos de gestão das instituições cujos quadros estejam se capacitando nesses cursos, bem como a conformação de modelos paradigmáticos neste campo, fundamentados e descritos, que sirvam de exemplo para outras organizações. Em função disso, a definição e adoção de critérios de seleção estratégica de alunos, compromissados com processos de mudança e que atendam primordialmente aos novos desafios gerenciais de suas unidades, é peça-chave no processo de construção deste mestrado.

Os alunos são estimulados a vincular suas dissertações aos novos processos de gestão estratégica nas instituições de C\&T em saúde e, especialmente, às questões centrais para o desenvolvimento de suas instituições/unidades de origem. Com base nesse referencial, os estudos devem ser necessariamente associados ao estabelecimento de subsídios para a promoção de intervenções no processo de trabalho, utilizando novos conhecimentos, métodos e ferramentas para a introdução de inovações gerenciais.

Por se tratar de um mestrado com perspectiva multidisciplinar, consubstanciada na articulação intrínseca de diferentes campos de conhecimento, deve-se contar com professores de formação e experiência de trabalho a eles relacionados. Para viabilizar uma formação com essas características, o corpo docente desta área foi formado por pesquisadoresdoutores credenciados no Programa de Pós-Graduação da Ensp e por profissionais ligados às diferentes áreas de atuação no campo da gestão em $C \& T$, reconhecidos por sua experiência, por suas práticas inovadoras e pelos resultados obtidos em seus contextos de trabalho. A atuação dos docentes doutores se dá tanto na administração de disciplinas como na orientação dos alunos no processo de dissertação. Os docentes profissionais participam em disciplinas e co-orientam. 


\section{ESTRUTURA DO CURSO}

O curso foi pensado levando-se em conta as necessidades e especificidades das IPC\&T/S. Dado que o que se espera da área de gestão é articular todas as funções dessas organizações no suporte às suas finalidades (Stoner \& Freeman, 1985), torna-se importante a difusão da missão e dos objetivos institucionais para todos os profissionais que trabalham para uma determinada organização ou empresa.

Assim, não se pode ter uma postura excessivamente pragmática e restritiva das necessidades de formação dos profissionais das IPC\&T/S. É absolutamente essencial que esses profissionais conheçam o contexto que permeia os três universos anteriormente mencionados e o papel da organização em que trabalham nesse ambiente. Talvez a principal mudança cultural num tratamento como este da área de gestão seja a imersão daqueles que trabalham nas IPC\&T/S nos problemas nacionais das áreas de C\&T e de saúde, pensando e contribuindo para o papel de sua organização no sistema nacional.

Entendemos, portanto, que um programa de qualificação na área de gestão de $C \& T$ em saúde deve contemplar um bloco básico que permita entender o contexto em que as IPC\&T/S estão imersas. A partir desse bloco básico, caminhos específicos podem ser escolhidos e trilhados, dentro do objetivo de acoplar a formação dos profissionais com o fornecimento de soluções e inovações para as IPC\&T/S em que estão inseridos. Para organizar esses caminhos particulares, adotamos um bloco 'gerencial', fornecendo ferramentas aos profissionais, eum bloco'aplicado', voltado para as áreas de aplicação dos conhecimentos no contexto específico do profissional.

\section{Bloco 1 - Contextual}

O Bloco 1, essencialmente teórico, estabelece os fundamentos conceituais para uma compreensão sistemática do campo finalístico de atuação do gestor de C\&T em saúde. Este bloco objetiva apoiar os alunos na compreensão dos contextos nos quais as organizações de C\& T em saúde estão envolvidas, incorporando conhecimentos teóricos e conceituais, históricos, socioculturais, econômicos e políticos. Os universos da ciência e tecnologia e da saúde demarcam este bloco, procurando-se especificar os atuais processos de mudança e o papel das instituições de pesquisa e desenvolvimento em saúde. O bloco compõe-se de disciplinas presenciais formadas por aulas expositivas, apoiadas por seminários, palestras e discussões.

\section{Bloco 2 - Gerencial}

O Bloco 2, prático-teórico, enfatiza a gestão estratégica e tem como finalidade introduzir os alunos no campo dos principais conhecimentos que norteiam as novas ferramentas de 
gerenciamento. Obloco também procura fornecer uma visão gerencial específica das instituições de C\&T em saúde e da incorporação de novas tendências de administração.

O bloco compõe-se de disciplinas presenciais formadas por aulas expositivas, com ênfase em estudos de caso baseados em situações reais.

\section{Bloco 3 - Aplicado}

O Bloco 3, essencialmente prático e central na perspectiva do mestrado profissional, permeia o curso do início ao fim e objetiva estabelecer um processo de aprendizagem interativo e, ao mesmo tempo, induzir a um processo de construção da dissertação desde as primeiras etapas do curso.

Dada a tradicional separação entre as áreas acadêmicas de C\&T e da saúde, com poucos docentes que transitam entre estas duas áreas, este bloco é conduzido pelos coordenadores do curso, que buscam integrar as teorias e conceitos aprendidos nos dois outros blocos à realidade institucional dos alunos.

Neste bloco procede-se também à identificação dos problemas de gestão nos ambientes de trabalho e à sua discussão com os dirigentes institucionais, como forma de definição dos objetos de trabalho, assim como à discussão das propostas de inovação e intervenção institucional e das necessidades para o desenvolvimento do trabalho de dissertação.

O bloco compõe-se basicamente de seminários, palestras e trabalhos e discussões em grupo, além de atendimento individual aos alunos, sempre que necessário.

\section{A IMPLANTAC̣ÃO DO CURSO E PRIMEIROS RESULTADOS}

A primeira turma deste curso foi formada unicamente por gestores da própria Fiocruz. Assim, todo o curso foi articulado com o planejamento estratégico da Fundação Oswaldo Cruz, tendo sido incorporado, inclusive, profissional da Diretoria de Planejamento Estratégico da Fiocruz à sua equipe coordenadora.

Em consonância com a missão institucional e com a orientação estratégica da atual presidência da Fiocruz, que enfatizam a aplicação social do conhecimento gerado na instituição, o mestrado teve como eixo temático central a inovação institucional e aplicação do conhecimento científico e tecnológico em saúde.

Para fazer face aos desafios que a área envolve, as competências existentes na Ensp foram complementadas por meio de parcerias com outras unidades da Fiocruz e com outras instituições acadêmicas, como o Instituto de Economia (IE/UFRJ) e o Instituto Nacional de Tecnologia (INT/MCT). 
A envergadura da tarefa, considerando-se que constitui uma área nova, foi grande. Envolveu a definição de escopo, disciplinas, áreas temáticas, a atração de um corpo de docentes qualificados para se dedicar ao programa, a articulação com outras organizações de ensino e toda a montagem de uma infra-estrutura razoavelmente complexa (desde a obtenção de aprovação na Capes até salas de aula, suporte, coordenação etc.), além da seleção dos alunos.

Sendo o principal objetivo deste mestrado profissional a capacitação de alunos compromissados com processos dinâmicos de transformação institucional e inovação gerencial, impôs-se a adoção de critérios de seleção para recrutar alunos efetivamente engajados no cumprimento destas metas. Com base nessa perspectiva, a seleção considerou os seguintes elementos: apoio formal da direção da instituição, explicitando a contribuição esperada pela participação do candidato; proposta descritiva do trabalho de dissertação pelo candidato; capacidade de leitura no idioma inglês; currículo do candidato.

Foram selecionados 33 alunos, entre os setenta candidatos que se apresentaram, todos envolvidos com a gestão institucional em um conjunto amplo de unidades - de pesquisa, produção de medicamentos e vacinas, controle de qualidade, ensino e assistência de referência. Assim, nesta turma os projetos tiveram como objeto:

- 'A gestão da pesquisa e do desenvolvimento tecnológico para a inovação', incluindo o desenvolvimento de instrumentos para a gestão da pesquisa (1 projeto); políticas, modelos de gestão e indicadores para fomento ao desenvolvimento tecnológico e à inovação (3); gestão de redes de inovação e promoção da cooperação interna e externa (3); políticas e programas para tornar mais eficaz e efetiva a comunicação; a transferência de conhecimento e tecnologia para a sociedade (2).

• 'A gestão das atividades de suporte à inovação', incluindo projetos que tratam da gestão do suporte de uma forma integrada (1) ou em suas diferentes funções, tais como planejamento (5), gestão de projetos (1), gestão de custos (2), gestão da qualidade de laboratórios e da produção (2), biossegurança (2), contratação e capacitação de recursos humanos (2).

- 'As condições de sustentabilidade dos investimentos da Fiocruz', especialmente nas áreas de produção (3), ensino (1) e museologia (1).

Todos os alunos tiveram seus projetos qualificados, e a maior parte dessas dissertações (94\%) já foi defendida. 


\section{A SEGUNDA TURMA: ESTRUTURA MODULAR \\ E ABERTURA PARA OUTRAS IPC\&T/S}

Uma segunda turma foi iniciada em setembro de 2004, incorporando duas modificações principais. A primeira delas foi a adoção de uma estrutura modular, passando o curso a ser composto por dois módulos: uma especialização, de 12 meses, na qual estão concentradas as disciplinas, e um mestrado profissional propriamente dito, também de 12 meses, em que o trabalho se concentra na elaboração da dissertação. A passagem da especialização ao mestrado não é automática, ela se dá em função da avaliação do aluno no curso e da qualidade de seu projeto de dissertação, julgada por banca da Ensp com participação externa.

A adoção de uma estrutura modular integrando lato e stricto sensu é uma discussão que vem tomando corpo na Ensp. O Mestrado Profissional em Gestão de Ciência e Tecnologia em Saúde foi o primeiro curso a adotá-la. Tal formato pareceu atraente, permitindo a abertura de um número de vagas maior do que a instituição teria como oferecer exclusivamente para o mestrado, limitado pela sua capacidade de orientação. Permitiu também maior flexibilidade no processo de seleção, viabilizando a qualificação de profissionais estratégicos para suas instituições por meio da especialização enquanto se ganha tempo para avaliar se ele apresenta as habilidades específicas para produzir uma dissertação.

Uma outra mudança foi a abertura de vagas para a participação de outra IPC\&T/S no curso - o Instituto Nacional do Câncer (Inca). Essa abertura traz consigo o desafio de se incorporar uma nova perspectiva de análise ao curso, de nível mais elevado, evidenciando as posições relativas das instituições participantes no Sistema Nacional de Inovação em Saúde. Contamos nesta turma com 27 alunos: 23 da Fiocruz e quatro do Inca.

\section{QUESTÕES CRÍTICAS E CONSIDERAÇÕES FINAIS}

Ocurso pode ser considerado um sucesso, tanto pelo percentual de defesas como pela qualidade das dissertações, assim como pela apreciação dos alunos da primeira turma, que avaliaram muito bem seus objetivos, conteúdo, metodologia e impacto sobre a prática profissional.

Um novo curso, no mesmo formato, será oferecido pela Fiocruz na região Nordeste a partir de 2005. A motivação inicial foi oferecer a mesma oportunidade aos gestores dos Centros de Pesquisa da Fiocruz localizados em Recife, PE (Centro de Pesquisas Aggeu Magathães) e Salvador, BA (Centro de Pesquisas Gonçalo Moniz). Essa proposta logo foi ampliada para incluir também outras instituições de C\&T em saúde da região. Para atender a essa 
clientela geograficamente dispersa, o curso será oferecido em módulos, ministrados alternadamente em Recife e em Salvador.

Algumas questões, entretanto, não estão completamente resolvidas. A partir da experiência vivida com a primeira turma, pretendemos enfatizar a familiaridade dos alunos com as questões acadêmicas. Acreditamos que, especialmente num curso de gestão de instituições de C\&T, essa familiaridade é importante para propiciar maior diálogo e integração dos profissionais de gestão com aqueles das atividades-fim da instituição. Por isso, elegemos como produtos finais do mestrado profissional os mesmos produtos do mestrado acadêmico. Esta questão, inserida na discussão maior sobre os produtos esperados dos mestrados profissionais, não pode ser tomada como fechada, pois merece maior reflexão.

A implementação das propostas geradas nas dissertações, embora não esteja sob a responsabilidade do curso, não foi esquecida. Uma vez que os alunos vieram indicados institucionalmente, seu trabalho já conta, em geral, com o interesse de suas chefias/ unidades de origem. Foi sugerido aos orientadores que, sempre que possível/desejável, incluíssem nas bancas de qualificação e de defesa das dissertações pessoas com responsabilidade direta sobre as questões trabalhadas, incorporando-as à discussão da proposta desde a concepção do trabalho, esperando com isso aumentar suas chances de implementação no futuro. Estamos agora iniciando o processo de agregação e articulação dessas dissertações, que serão entregues formalmente à Presidência da Fiocruz para serem discutidas institucionalmente e, dessa forma, contribuir mais efetivamente para o desenvolvimento institucional.

Embora de caráter mais operacional, um outro desafio da coordenação do curso é reduzir o prazo das defesas, uma vez que quando acabam os créditos e os alunos voltam ao trabalho, eles tendem a reduzir a dedicação à dissertação. $O$ prazo médio de defesa da primeira turma tem sido de 26 meses.

Espera-se, com a iniciativa, contribuir para a profissionalização da gestão das IPC\&T/S, com impacto positivo sobre o desempenho das organizaçoes participantes, caso uma razoável massa crítica vá se acumulando. A Fiocruz toma a frente da iniciativa, não só assegurando a formação de seus quadros profissionais, mas reforçando sua responsabilidade na formação de recursos humanos especializados para a formulação da política de C\&T em saúde e para a gestão das instituições do sistema. 


\section{REFERÊNCIAS BIBLIOGRÁFICAS}

ALBUQUERQUE, E. M. \& CASSIOLATO, J. E. As Especificidades do Sistema de Inovação do Setor Saúde. Belo Horizonte: Fesbe, 2000.

ARNOLD, E. et al. Strategic planning in reasearch and technology institutes. RED Management, 28(2):89-100, April 1998.

EDQUIST, C. (Ed.) Systems of Innovation: technologies, Institutions and organizations. London, Washington: Pinter, 1997.

GADELHA, C. A. G.; QUENTAL, C. \& FIALHO, B. C. Saúde e inovação. Cadernos de Saúde Pública, 19(1):47-60, jan.-fev.2003.

GIBBONS, M. et al. The New Production of Knowledge. London: Sage Publications, 1997.

MACULAN, A. M. \& ZOUAIN, D. M. Um novo paradigma para as instituições públicas de pesquisa. Revista de Administração Pública, 31(6):7-27, nov.-dez .1997.

QUENTAL, C. \& GADELHA, C. A. G. Incorporação de demandas e gestão de P\&D em instituições de pesquisa. Revista de Administração Pública, 34(1):57-78, jan.fev.2000.

QUENTAL, C.; GADELHA, C.A. G. \& FIALHO, B. C. O papel dos institutos públicos de pesquisa na inovação farmacêutica. Revista de Administração Pública, 35(5):135-162, set.out.2001.

ROUSSEL, P.; SAAD, K. N. \& BOHLIN, N. Pesquisa e Desenvolvimento: como integrar PED ao plano estratégico e operacional das empresas como fator de produtividade e competitividade. São Paulo: Makron Books, 1992.

ROTHWELL, R. Successful industrial innovation: critical factors for the 90's. RED Management, 22(3):221-239, 1992.

SALLES-FILHO, S. L. M. (Coord.) Ciência, Tecnologia e Inovação: a reorganização da pesquisa pública no Brasil. Campinas: Komedi, 2000.

STONER, A. F. \& FREEMAN. R. E. Administração. São Paulo: Prentice Hall do Brasil Ltda., 1985. 


\title{
DESAFIOS NA FORMAÇÃO DE RECURSOS HUMANOS PARA O SUS
}

\author{
A EXPERIÊNCIA DO MESTRADO PROFISSIONALIZANTE \\ DA ENSP COM A SAS-MS
}

\begin{abstract}
Elizabeth Artmann ${ }^{1}$
A crescente complexidade da realidade de saúde da população gera demandas na qualificação de gestores para o sistema de saúde, com novas exigências e desafios. Um desses desafios constitui-se em uma necessária aproximação entre a academia e os serviços, visando a obter maior adequação na formação dos quadros estratégicos e, conseqüentemente, um desempenho de maior qualidade na busca de soluções que elevem as condições de saúde de nossa população. Os cursos de Mestrado Profissionalizante (MP) vêem ao encontro da tentativa de responder a esses desafios, bem como às demandas por formação específica de recursos humanos do Ministério da Saúde, das secretarias de Saúde e de outros órgãos governamentais, ancorados na iniciativa da Coordenação de Aperfeiçoamento de Pessoal de Nivel Superior (Capes) de propor e regular esta nova modalidade de mestrado. ${ }^{2}$ Os MPs inserem-se ainda na

\footnotetext{
${ }^{1}$ Agradecimento especial a Virginia Hortale pela preciosa contribuição e interlocução neste trabalho.

${ }^{2}$ De acordo com a definição da Capes, o mestrado profissional "enfatiza estudos e técnicas diretamente voltados ao desempenho de um alto nível de qualificação profissional. (...) Responde a uma necessidade socialmente definida de capacitação profissional de natureza diferente da propiciada pelo mestrado acadêmico e não se contrapõe, sob nenhum ponto de vista, à oferta e expansão desta modalidade de curso, nem se constitui em uma alternativa para a formação de mestres segundo padrões de exigência mais simples ou mais rigorosos do que aqueles tradicionalmente adotados pela Pós-graduação" (Brasil, 2003).
} 
proposta político-pedagógica da Escola Nacional de Saúde Pública Sergio Arouca (Ensp) e da Fundação Oswaldo Cruz (Fiocruz), que objetiva diminuir a dicotomia serviços versus academia, propondo, além de formação mais adequada, produtos finais/dissertações que reflitam a produção do conhecimento articulada à implementação e gestão de políticas e práticas em saúde. $^{3}$

Os mestrados profissionalizantes vêm se afirmando como uma tendência a longo prazo, ao contrário do que se acreditava anteriormente, ${ }^{4}$ e têm já acumulado uma trajetória de discussões, propostas de regulamentação e alguma experiência ao longo dos últimos anos. Os novos programas de pós-graduação stricto sensu, que então surgiram em algumas áreas do conhecimento, procuraram adaptar-se a essa realidade e ao grau terminal apropriado à formação de profissionais que não pretendiam dedicar-se à carreira acadêmica, mas capacitar-se para desenvolver novas técnicas e processos nas suas áreas específicas de atuação. Tais programas eram distintos de outros na orientação dos currículos, na composição do corpo docente e discente, nas formas de financiamento e nos arranjos institucionais.

No final de 1998, com o reconhecimento pela Capes dos mestrados profissionalizantes, a Ensp é estimulada a implantar a modalidade 'Profissionalizante' em seu programa de pósgraduação stricto sensu, tendo em vista a experiência anterior e as demandas de gestores e profissionais da saúde pertencentes aos diversos níveis do sistema de saúde (Capes, 1998). O MP em Gestão de Sistemas e Serviços de Saúde, objeto de análise deste estudo, insere-se na área de concentração Gestão em Saúde, oferecido para responder à demanda da Secretaria de Assistência à Saúde (SAS) do Ministério da Saúde (MS) de formação de quadros altamente qualificados do ponto de vista técnico e estratégico com capacidade de reflexão crítica para

\footnotetext{
3 Em um cenário de reexame do papel das escolas de saúde pública para atender a demandas tanto de natureza de produção/reprodução do conhecimento quanto de preparação de profissionais para o sistema de saúde, a Ensp desenvolve, entre os anos 1994 e 1998, experiências de reestruturação do seu programa de ensino, baseando-se na evidência de que, embora os cursos lato sensu oferecidos tivessem como proposta a preparação e qualificação de profissionais para a prática no âmbito dos serviços, uma parte de sua clientela se candidatava ao mestrado acadêmico para complementar sua formação em pesquisa. Além disso, para o egresso deste programa, o mestrado profissional representaria o aumento das possibilidades no mercado de trabalho e de sua progressão na carreira profissional, além de diminuir o tempo para sua formação.

4 Em 1995, a Capes torna oficial, com a Portaria n. 47 (Programa de Flexibilização do Modelo de PósGraduação Senso Estrito em Nivel de Mestrado), a discussão sobre a flexibilização do sistema tradicional de formação de pessoal em nivel de mestrado com a criação da modalidade profissionalizante. Sua justificativa era de que a qualificação denominada 'acadêmico-científica' estava voltada de forma predominante para a carreira docente, e que as mudanças técnicas e as transformações econômico-sociais estariam exigindo a presença de profissionais com perfis de especialização distintos dos tradicionais, caracterizados pela alta qualificação e produtividade nos serviços que prestam. Para maiores detalhes sobre o atual entendimento dessa modalidade pelos principais atores, ver o capitulo 11 desta coletânea.
} 
enfrentar os desafios na construção do Sistema Único de Saúde (SUS) diante do atual processo de regionalização e descentralização.

O curso realizou-se entre 2002 e 2004. Durante o desenvolvimento dos conteúdos teóricos, que se deu entre os meses de fevereiro de 2002 e março de 2003, foi utilizado um instrumento de avaliação, aplicado ao final de cada disciplina, com quesitos fechados e abertos para se conhecer a opinião dos alunos sobre a clareza dos objetivos da disciplina em relação aos objetivos do curso; a concordância entre os objetivos anunciados e o que foi realmente ensinado; a clareza dos critérios de avaliação dos alunos e os aspectos pedagógicos do desempenho do professor (organização do material apresentado, habilidade para explicar conteúdos, disponibilidade para consultas e comentários dos alunos, uso do tempo em aula e resposta às questões e comentários dos alunos). Os resultados (Ensp, 2003) dos quesitos fechados evidenciaram um alto grau de satisfação com o curso (entre os graus 'excelente' e 'muito bom'), podendo significar que os pressupostos do MP foram expressos em objetivos pedagógicos viáveis e atenderam às necessidades da formação. No entanto, na análise dos comentários escritos (quesito aberto), observamos opiniões divergentes, tanto de natureza pedagógica quanto de organização do curso. ${ }^{5}$

Tal observação levou à necessidade de aprofundar o estudo, com base em um método que pudesse abarcar o contexto dessas contradições/divergências, que permitisse aos alunos desenvolver melhor suas questões e nos trouxessem maiores informações/contribuições com vistas ao aperfeiçoamento do curso.

Portanto, com a intenção de aprofundar o conhecimento sobre a percepção dos alunos especificamente no que diz respeito ao alcance dos objetivos do curso, possíveis impactos/

\footnotetext{
${ }^{5}$ Questões e sugestões referentes ao processo educativo: 1) excesso de textos e muitos conteúdos teóricos em pouco tempo prejudicaram um pouco a assimilação por parte dos alunos; 2) cobrança excessiva e muito rigor nas provas e trabalhos; 3) aumentar o tempo do módulo (esta é uma sugestão que foi feita na avaliação de todos os módulos); 4) a carga de trabalho 'doméstico' deve ser diminuída, e intensificada a do trabalho em sala de aula; 5) as técnicas de ensino foram adequadas, resultando no total domínio da turma, devendo ser aproveitadas em módulos seguintes; 6) pouca utilização de ferramentas tecnológicas para que os alunos se exercitassem em seu uso; 7) fazer exercícios na própria sala de aula e exigir leituras prévias do assunto; 8) pouco objetivo prático na utilização das bases de dados e aplicativos disponíveis. Resultados alcançados com a formação: 1) estimulou a reflexão crítica sobre a realidade; 2) permitiu conhecer as possibilidades/métodos atuais para avaliar os serviços de saúde; 3) estimulou a reflexão sobre o papel dos alunos como gestores do SUS; 4) identificou com objetividade os métodos utilizados no MS na definição de projetos e programas no aspecto econômico; 5) proporcionou maior clareza para a escolha do método a ser utilizado na pesquisa e na dissertação; 6) trouxe elementos da sociologia, que são muito úteis para a dissertação e também para o cotidiano de trabalho; 7) trouxe aos alunos o mundo da informação, que hoje é tão vasto e amplo; 8) destacou a informação como elemento fundamental para a tomada de decisões e gestão em geral (Ensp, 2003).
} 
resultados do curso, aspectos relacionados à seleção, à avaliação, articulação e adequação dos conteúdos, prazos, ao processo pedagógico, entre outros, e de colher sugestões para aperfeiçoamento dos cursos de MP, desenvolveu-se este estudo, a partir de entrevistas semi-estruturadas com os alunos na fase final do curso. Os resultados foram sistematizados e analisados com base no método de construção do discurso do sujeito coletivo (Lefèvre \& Lefèvre, 2003).

O trabalho tem a seguinte estrutura: 1) Apresentação do curso; 2) Análise das entrevistas e construção do discurso do sujeito coletivo e 3) Considerações finais e busca de discutir os desafios e perspectivas que o MP oferece para a formação de quadros nas instituições públicas com capacidade de responder às exigências de qualidade e ao mesmo tempo produzir maior impacto na resolução dos problemas de saúde de nosso país.

\section{O MESTRADO PROFISSIONAL EM GESTÃO DE SISTEMAS E SERVIÇOS DE SAÚDE DA SECRETARIA DE ASSISTÊNCIA À SAÚDE DO MINISTÉRIO DA SAUUDE}

O curso foi resultado de uma parceria com a Secretaria de Assistência à Saúde (SAS) (hoje Secretaria de Atenção à Saúde) do Ministério da Saúde que, mediante convênio, disponibilizou recursos financeiros para a realização do mestrado profissional visando à formação de quadros estratégicos da própria secretaria.

Teve os seguintes objetivos: a) capacitar gestores em planejamento e avaliação de políticas de saúde públicas e apoiar o desenvolvimento de tecnologias para diagnóstico e resolução de problemas; b) desenvolver diagnósticos de saúde orientados para as funções de descentralização do SUS no âmbito do MS/SAS e c) favorecer as ações governamentais de regionalização do SUS.

Diante da especial característica do curso, sua estrutura seguiu um desenho modular com conteúdos considerados fundamentais e articulados ao tema-eixo 'Descentralização e regionalização do SUS', subdivido em cinco módulos: Estado, políticas de saúde e organização de sistemas de saúde; Planejamento e gestão de sistemas de saúde; Economia da saúde, avaliação em saúde; Tecnologias de informação; Gestão estratégica. Cada módulo se subdividiu em disciplinas, cujo número variou segundo o módulo específico. Além dos cinco módulos, as disciplinas Métodos e técnicas de pesquisa e Seminários operacionais de pesquisa, oferecidas de forma transversal durante o curso, tiveram o objetivo de servir a uma homogeneização conceitual e apoiar o desenvolvimento dos projetos de dissertações, cujos objetos e temas foram discutidos com a direção da instituição demandante. Foram adotados, em cada disciplina, na medida do possível e quando indicado, exercícios práticos e operacionais centrados na temática-eixo 
e utilizando dados reais do Ministério da Saúde. Deu-se especial ênfase também à questão pedagógica, na tentativa de articular teoria e prática e permitir a construção conjunta do conhecimento pelos alunos e professores.

É importante salientar que, embora, cada coordenador de módulo tivesse autonomia para pensar as ferramentas de avaliação, várias discussões foram feitas nas primeiras reuniões do Colegiado de Coordenação do Curso (que acabou se desfazendo como colegiado, mantendo-se reuniões com grupos menores de professores), a respeito da 'intenção' pedagógica na utilização de diferentes instrumentos de avaliação da aprendizagem dos alunos. Assim, além da referência ao Regimento de Ensino da Ensp, considerando índice de freqüência etc., optou-se principalmente nos primeiros módulos por uma estratégia que começasse por instrumentos mais simples, como resumos de textos e que fosse aos poucos se tornando mais complexa, com solicitação de resenhas que exigem já, além da identificação das idéias principais do(s) autor(es), um posicionamento do aluno, num 'diálogo' maior com o texto. Os alunos receberam roteiros elaborados para apoiá-los e incentivá-los na arte da escrita, da explicitação de idéias próprias, com a finalidade de prepará-los paulatinamente para a tarefa de elaboração de dissertação. Considerando-se o perfil da turma e o contexto do curso em que os alunos não se afastavam de suas atividades e compromissos de trabalho, optou-se por provas em sala de aula, com consulta a textos e exercícios e leituras em sala de aula, visando a diminuir o trabalho extraclasse. Diante das reclamações dos alunos, algumas vezes essas 'provas' se tornaram avaliações individuais escritas, com prazo maior para entrega. Especialmente no módulo de Planejamento, os trabalhos em grupos, ou oficinas de trabalho, pela própria característica do tema, formaram o principal componente da avaliação, embora não se abdicasse de um instrumento de avaliação individual para aferir o crescimento de cada um dos alunos e identificar as principais dificuldades visando a proporcionar apoio específico. Buscou-se especial ênfase em estratégias que ajudassem os alunos no desafio de escrever um trabalho final e de apresentá-lo e defendê-lo de modo argumentativo. Por isso, os debates em sala de aula e seminários também exigiam que os alunos se exprimissem oralmente. Os Seminários operacionais de pesquisa visaram especialmente, além da incorporação da lógica e de métodos de pesquisa, ao 'treinamento' dos alunos na apresentação de suas idéias. A coordenação do curso esteve presente em todos os momentos, em todos os módulos. É fundamental salientar a participação de todos os orientadores que se dispuseram a ir a Brasília, onde se realizaram dois grandes eventos/seminários, cada um de três dias de duração, nos quais os alunos puderam apresentar seus projetos aos colegas e aos diferentes professores que puderam dar suas contribuições. 
A carga horária total foi de 1.770 horas, considerandose 450 horas para pesquisa operacional, 540 horas para elaboração da dissertação, incluindo orientações. Foram selecionados inicialmente trinta alunos, dos quais três não chegaram a fazer o curso por motivo de doença. Os alunos que cumpriram os requisitos de freqüência (de acordo com o regimento de ensino da Enspé exigida a freqüência mínima de $85 \%$ da carga horária teórico-conceitual prevista), de aproveitamento (realização de seminários, exercícios, provas) e elaboraram a dissertação devidamente avaliada e aprovada em defesa pública por uma banca examinadora, constituída por três doutores (um externo), concluíram o curso recebendo o certificado de Mestre na área de Saúde Pública, modalidade Profissionalizante. É importante observar que alguns alunos saíram da SAS na época da transição do governo e desistiram do curso. Houve três casos de reprovação e um caso de progressão para o doutorado após a qualificação do projeto.

Os encontros para as aulas teóricas, debates e exercícios aconteceram às quintas-feiras à noite, às sextas-feiras e aos sábados o dia todo, horários que permitiam ao aluno não se afastar totalmente de suas atividades, característica essencial dos mestrados profissionais. As dissertações concluídas foram:

- Análise do modelo de colaboração do Programa Centros Colaboradores para a Qualidade da Gestão e da Assistência.

- Uma revisão da acreditação hospitalar como método de avaliação da qualidade e a experiência brasileira.

- Eqüidade no financiamento de saúde: uma avaliação de recursos para a atenção básica no estado do Rio de Janeiro.

- Serviços residenciais terapêuticos no estado do Rio de Janeiro: um diagnóstico inicial.

- Implantação da Política Nacional de Redução da Morbimortalidade por Acidentes e Violências: a experiência no estado do Amapá.

- Estudo sobre a organização dos serviços de reabilitação: o caso do Rio de Janeiro.

- Melhoria do cuidado ao paciente queimado: elaboração de um instrumento de avaliação.

- Organização dos espaços microrregionais de saúde do estado do Mato Grosso do Sul: uma revisão do papel dos hospitais de pequeno porte no SUS.

- A humanização no atendimento à saúde: construindo uma nova cultura.

- Avaliação da organização das unidades não hospitalares de pronto atendimento do município de Goiânia como referência à Política Nacional de Atenção às Urgências.

- Retrato do estado do Rio de Janeiro na ótica do laboratório. 
- Estudo exploratório da atenção Hospitalar de alta complexidade prestada pelos hospitais do SUS.

- Cadastro Nacional de Estabelecimentos de Saúde - CNES: seu desenvolvimento, implantação e uma proposta para sua atualização/manutenção.

- Sistema de Informação Ambulatorial: processo de registro de atendimentos aos portadores de deficiência no subsistema Apac/SAI/SUS.

- Programação Pactuada e Integrada (PPI) no contexto da Norma de Assistência à Saúde (Noas) e o Conselho Nacional de Saúde: uma discussão sobre a gestão do SUS.

- Uma análise das internações obstétricas e neonatais no estado de Alagoas, Brasil, 2000.

- Mutirão de Catarata: uma estratégia nacional de atenção à saúde.

- A situação contratual de rede hospitalar privada vinculada ao SUS.

\section{ANÁLISE DAS ENTREVISTAS E DA CONSTRUÇÃO DOS DISCURSOS COLETIVOS}

Entrevistamos para fins desta pesquisa seis alunos, selecionados por sua representatividade e capacidade de verbalizar questões e fazer críticas sobre o curso, apresentada durante a sua vigência, por dois anos, considerando a noção de informante-chave.

Os objetivos que nortearam essa fase do estudo foram:

- Conhecer a percepção dos alunos-gestores especificamente no que diz respeito ao alcance dos objetivos do curso, aos possíveis impactos/resultados do curso e aos aspectos relacionados à seleção, avaliação, articulação e adequação dos conteúdos e prazos ao processo pedagógico, entre outros.

- Complementar a análise da experiência aqui relatada.

- Colher sugestões para o aperfeiçoamento dos cursos de mestrado profissionalizante.

\section{Roteiro de Entrevistas}

As seguintes questões constituíram o roteiro de entrevistas, deixando-se espaço para que os entrevistados manifestassem outras que considerassem importantes:

- Quanto aos objetivos do curso de Mestrado Profissionalizante em Gestão de Sistemas e Serviços de Saúde contratado pela SAS: você acha que foram adequados? Em que medida foram alcançados? Pode fazer comentários sobre os resultados. 
- Com relação aos conteúdos do curso, comente aspectos como adequação aos objetivos e ao perfil da turma e a articulação entre os mesmos, que foram algumas das preocupações da coordenação.

- Comente os critérios de seleção.

- Comente os critérios de avaliação dos alunos: provas, resumos, resenhas, trabalhos em grupo e oficinas de trabalho. Foram adequados do ponto de vista pedagógico?

- Fale sobre os prazos de liberação dos alunos, prazos para defesa etc.

- Tem sugestões a fazer para o aperfeiçoamento do curso?

\section{Descrição do Método de Análise dos Discursos}

A seleção dos entrevistados não teve o critério de amostra quantitativa representativa, e seguiu os princípios do método de análise qualitativa adotado. Foram realizadas entrevistas conduzidas pelo roteiro de questões aqui apresentado, escolhidas em função dos objetivos de avaliação do curso. Os entrevistados puderam manifestar opiniões referentes a questões que porventura não estivessem no roteiro. A escolha desse tipo de entrevista semi-estruturada deveu-se à intenção de valorizar a presença do investigador e ao mesmo tempo permitir ao informante/entrevistado a liberdade de expressão. As entrevistas foram gravadas em fita, transcritas e em seguida analisadas na perspectiva qualitativa por nós adaptada.

Todas as entrevistas foram feitas e sistematizadas pela coordenadora do curso, fato que, acreditamos, pode trazer vantagens e desvantagens para a análise de resultados. A pesquisa qualitativa e a inserção do pesquisador no próprio objeto de pesquisa, fator densamente trabalhado nas aulas teóricas de métodos de pesquisa do MP (Minayo, 1992, 1994; Minayo; Richardson, 1999; Thiollent, 1982; Cruz Neto, Moreira \& Sucena, 2002, Becker, 1993, entre outros) e que caracterizou os objetos de pesquisa dos trabalhos finais, exigem um método que proporcione a capacidade de sistematização e um certo distanciamento, e ao mesmo tempo valorize o próprio olhar do pesquisador. Assim, escolhemos o método de construção de Discursos do Sujeito Coletivo (DSC), descrito a seguir, para analisar os resultados deste estudo.

Organizamos as falas, seguindo a abordagem metodológica em pesquisa qualitativa fundamentada no método de construção de discursos do sujeito coletivo (Lefèvre \& Lefrève, 2003; Lefèvre, Lefèvre \& Teixeira, 2000) e que, a partir de Minayo (1992), considera o pressuposto de que o significado e a intencionalidade ocupam posição importante na pesquisa de tipo qualitativa e aparecem clara e naturalmente nos discursos ou falas dos atores. 
Após a transcrição das entrevistas, organizamos os dados, utilizando e adaptando quatro figuras metodológicas, apoiados na abordagem de Levèfre e Lefrève (2003), as quais nos ajudaram na interpretação e análise dos depoimentos:

- Ancoragem: inspirados na teoria da representação social de Jodelet(1989), os autores anteriormente mencionados afirmam que todo discurso está ancorado ou alicerçado em determinados pressupostos, hipóteses, teorias ou conceitos e ideologias que podem se expressar por meio de marcas lingüísticas claras pelo ator ou estar apenas subjacentes às práticas cotidianas dos profissionais, portanto inconscientes. Segundo Lefèvre, Lefèvre e Teixeira (2000), uma das principais funções das representações sociais seria a de 'ancorar' os eventos da vida cotidiana em discursos, justificativas que tragam sentido para os indivíduos que os vivenciam.

- Idéia central: traduz o essencial do conteúdo discursivo explicitado, por meio da identificação da(s) idéia(s) central(is) de cada depoimento.

- Expressões-chave: são partes dos depoimentos literalmente transcritas que representam a essência do conteúdo discursivo e permitem uma comparação com as afirmativas reconstruídas na forma de idéias centrais ou ancoragens, objetivando o julgamento da pertinência das seleções e reconstruções. Constituem-se em matéria-prima para a elaboração dos discursos do sujeito coletivo ou discursos dos atores coletivos.

- Discurso do sujeito coletivo: principal figura metodológica, implica romper com a lógica quantitativo-classificatória, buscando resgatar o discurso como signo do conhecimento dos próprios discursos. A reconstrução dos fragmentos de discursos individuais deve ser realizada a partir de quantos discursos-síntese se julguem necessários para expressar uma forma de pensar sobre um dado fenômeno. É uma estratégica metodológica que busca tornar mais claros os significados que conformam o imaginário de um grupo de pessoas ou atores sociais. Para a elaboração dos discursos dos sujeitos coletivos, usamos a estratégia categorização, ou seja, as idéias centrais e/ou expressõeschave equivalentes são representadas numa mesma categoria.

\section{Os Discursos Coletivos Encontrados}

Na presente análise, selecionamos as principais idéias centrais e expressões-chave presentes em cada depoimento, relativas a cada questão do roteiro de entrevistas, classificandoas nas diferentes categorias de discursos encontrados e, em seguida, reconstruímos de forma sintética cada discurso a partir dos fragmentos das falas dos diversos sujeitos/atores. Vários 
discursos podem aparecer na fala de um único sujeito ou, ao contrário, podemos encontrar um mesmo discurso nas falas de diversos sujeitos. Cabe salientar que nem sempre as falas dos entrevistados obedeceram rigorosamente ao roteiro proposto. As diferentes questões, muitas vezes, foram abordadas de forma entrelaçada, o que nos parece natural, já que as questões possuem de fato inter-relações e as respostas aparecem nos depoimentos dessa forma. A reconstrução dos depoimentos com base nos discursos do sujeito coletivo considera, portanto, essa característica.

\section{Sobre os Objetivos}

Com relação à primeira questão: "Quanto aos objetivos do curso de Mestrado Profissionalizante em Gestão de Sistemas e Serviços de Saúde contratado pela SAS: você acha que foram adequados? Em que medida foram alcançados? Pode fazer comentários sobre os resultados", encontramos seis discursos, a seguir apresentados.

DSC1/1 - O MP quebra falsas dicotomias - academia versus serviços, serviços versus pesquisa - e mostra a capacidade de produção de conhecimentos nos serviços, trazendo-a ao público.

Idéias centrais

OMP atingiu o objetivo de quebrar um preconceito mútuo que existe entre as pessoas, quebra a falsa dicotomia entre serviços e pesquisa, academia e serviços, pessoas que trabalham e pessoas que pensam.

O MP tem uma ligação direta com os serviços, capaz de produzir pesquisa e produzir conhecimento, o qual, sem o MP, não viria a público.

Conseguiu fazer a interface entre a academia e o serviço.

Discurso do sujeito coletivo

O objetivo do MP se justifica plenamente porque tem uma ligação direta com o serviço, capaz de produzir pesquisa e produzir conhecimento, os quais, se não fosse este MP, ficariam nas práticas cotidianas, não viriam a público; além disso, não haveria a sistematização e a produção de certos conhecimentos. O MP atingiu o objetivo de quebrar um preconceito mútuo que existe entre as pessoas. Quebra essa falsa dicotomia, na minha opinião, entre serviços e pesquisa, academia e serviços, entre as pessoas que trabalham e pessoas que pensam. Todo mundo que trabalha pensa, e todo mundo que pensa trabalha. São modus operandi diferentes, mas eu acho que a gente tem que acabar com esse 
preconceito mútuo. Conseguiu fazer bem a interface entre a academia e o serviço; os trabalhos finais, por exemplo, refletem isso. (...) foi bastante gratificante, para nós como funcionários do Ministério da Saúde, termos feito este curso. Porque nós, como funcionários, eu principalmente, da área técnica, tenho uma experiência assistencial, de trabalho na ponta com os serviços. E foi muito importante essa interface entre o serviço, o conhecimento, a prática e a experiência que temos na assistência com os serviços: discutir com a academia e levar para a academia essa nossa experiência e esse nosso conhecimento, enquanto trabalhadores técnicos nos serviços. O objetivo do curso para a SAS, eu acho que era muito mais, que os profissionais tivessem condições de mesclar questões da academia, da formalidade e rigor na análise, da capacidade de elaboração, de organização, que isso, no serviço, você tem muito pouco. DSC1/2 - Há ganhos mútuos para a academia, os serviços e as pessoas (alunos/profissionais).

Idéias centrais

Pesquisa no serviço é bom para as pessoas e para a instituição.

Práticas e projetos serão mais qualificados, e a comunidade acadêmica também ganha.

Discurso do sujeito coletivo

Trazer esses conhecimentos, essas práticas do campo da pesquisa científica à luz, defrontando-se com metodologia científica, para poder produzir este trabalho é bom tanto para as pessoas que estão produzindo individualmente como para a instituição que recebe isso. Vai ter profissionais mais qualificados, práticas e projetos melhores, porque até avaliadas academicamente. E, também, acho que a comunidade acadêmica ganha com isso. Tem conhecimentos que sem o MP não teriam vindo a público, não teriam sido divulgados. Eu achei fantástico o mestrado profissionalizante na questão de saber articular trabalho, ensino, pesquisa. Fantástico! Você tem que articular trabalho, ensino e pesquisa para atingir um objetivo maior, uma ação maior, para propor para a melhoria do Sistema Único de Saúde. Eu acho que quem está no ministério nunca poderia perder o contato com a academia. As práticas e projetos serão mais qualificados e a comunidade acadêmica também ganha. E falando em termos de resultados, acho que é muito importante o que aconteceu, é que uma universidade daqui ter convidado alunos do MP para dar aulas num curso de especialização em gestão de sistema do serviço de saúde. 
DSC1/3 - O MP atinge o objetivo de dar um retorno à sociedade, não só para a instituição e para o aluno, mas para o SUS.

Idéias centrais

O uso de recursos públicos tem que ser voltado para a perspectiva de dar um retorno à sociedade, e acho que consegue atender este objetivo.

Destaca-se a importância dos resultados, dos trabalhos que foram realizados, de se conseguir a elaboração de novas políticas a partir da incorporação dos produtos do MP.

O MP alcança o objetivo de que os produtos sejam úteis para a SAS, a instituição demandante, e para o SUS.

Discurso do sujeito coletivo

Acho que atingiu o objetivo de dar um retorno à sociedade, não só para a instituição e para o aluno individualmente, sobre o bom uso dos recursos públicos. Outro objetivo era que a gente tivesse trabalhos, ou que trouxesse instrumentos para melhorar tanto a atenção à saúde, a assistência, a questão da gestão da atenção à saúde de fato, e acho que tiveram vários bons resultados. Destaco a importância dos resultados, dos trabalhos que foram realizados. A gente conseguir a elaboração de novas políticas, que estavam em andamento aqui no ministério e ao mesmo tempo as pessoas estavam desenvolvendo suas dissertações. Como o caso de pequenos hospitais, do novo pacto de gestão que está sendo construído pelo ministério. Tem o trabalho que tem aquele instrumento para a organização dos laboratórios clínicos. Então, vários produtos estão sendo utilizados pelo ministério, e isto é muito importante.

Que os produtos fossem úteis para a instituição demandante, este foi um superalcançado. E acho que muito importante também foram essas informações que obtivemos nesses cursos da academia, para que a gente traga para discussões de planejamento de ações para melhorar o Sistema Único de Saúde. Eu acho que o MP atingiu os objetivos. Tanto deu conta de atingir os objetivos, que eu já disse isso várias vezes a várias pessoas: depois que eu fiz este curso de mestrado, eu me senti responsável e me senti habilitada a estar assumindo esse cargo que hoje estou ocupando no ministério da Saúde. E então foi com esses conhecimentos do mestrado, toda essa discussão, que recebi muitas informações e aprendi muito e hoje estou muito mais apto a participar de todo o planejamento, da realização do projeto e estou executando o projeto, graças a esses conhecimentos. Tem muitas dissertações muito interessantes. Primeiro, eu acho que tem um aproveitamento. Poucas são as pessoas que se desligaram por opção, ou por falta de condições mesmo de tocar a dissertação. Então eu acho que nada 
melhor do que os resultados das trinta, 25 ou 24 dissertações, em termos tanto de cumprimento de metas mesmo, quanto da divulgação disso e da incorporação do conteúdo delas nos processos do próprio ministério. Acho que isso é extremamente importante, a incorporação dos produtos, das propostas, mas uma incorporação inclusive da crítica que é feita. Então, só para completar aqui, já que estamos falando de resultados, do impacto, vale a pena registrar que já temos impactos em nível internacional. Para esse trabalho que nós estamos desenvolvendo, e que tem a ver com o tema de minha dissertação, trouxemos todo um conhecimento e um aprendizado a partir do modelo francês, e já o adaptamos considerando nossas normatizações, nossas leis. E agora como gratificação mesmo desse trabalho, acabo de receber um convite, pelo ministério da França, para que eu váà França levar essa experiência que é diferente. Os alunos viraram professores, porque nós estamos ganhando uma grande experiência implantando esse serviço no país e o Brasil vai ganhando uma expertise própria queévalorizada lá fora. EoMP tem um papel, inclusive, de divulgar. Então, eu acho que tem que registrar essas questões também.

DSC1/4 - Problematiza a aproximação entre academia e serviços pelas dificuldades relacionadas às diferentes expectativas de um e outro grupo e destaca o processo coletivo de construção do curso.

Idéias centrais

Houve uma dificuldade inicial de adaptação entre a expectativa de um grupo e a de outro grupo: os professores com uma expectativa e o grupo com outra.

Houve uma compreensão de que era um processo em construção, flexibilização dos critérios e do modo de fazer.

Passou a ser um processo de construção coletiva e todo mundo saiu ganhando.

Discurso do sujeito coletivo

Eu acho que tem um primeiro movimento que é essa aproximação entre a academia e o Executivo. Eas pessoas que estão no seu trabalho no dia-a-dia...é énteressante, mas assusta um pouco no início. Eu acho que o primeiro contato com os módulos, com esse meio acadêmico até porque era uma turma que foi aprendendo ao longo do tempo, foi se adaptando e aprendendo, mas eu acho que tem um choque inicial que, para um outro curso, tem que ser pensado. A primeira reflexão é: como é que faz essa quebra de gelo mesmo entre a academia e os serviços? E aí entra um pouco já na discussão do ordenamento dos módulos. Por exemplo, a gente teve o primeiro módulo, foi um módulo muito difícil, muito complicado. Ele trouxe toda 
uma discussão teórica, mas eu acho que, olhando hoje, já com o distanciamento permitido, não mais como aluna, vivenciando o curso, eu acho que a gente aproveitou muito pouco desse módulo. Basicamente, eu relaciono isso com a dificuldade que houve de adaptação entre a expectativa de um grupo e a expectativa de outro grupo. Os professores trazendo toda um expectativa também em relação ao grupo e o grupo em relação ao mestrado, mas não havia uma aproximação real. Acho que foi o módulo mais difícil para todos do curso. Eu estou falando assim, porque esse era o comentário que a gente tinha, não é? De difícil apreensão. Porque a gente estava muito longe dessa crítica que a academia faz em relação ao sistema de saúde e muito dentro do dia-a-dia de trabalho. Então eu acho que isso chocou no primeiro módulo. Mas ao longo do tempo, como eu já falei, eu acho que as pessoas se adaptaram. As duas partes se adaptaram. Acho que houve um esforço dos professores, e os alunos abriram mão de muita coisa. Eu acho que tem que marcar isso, que era um processo em construção conjunta mesmo. E todo mundo saiu ganhando. Os alunos identificaram o grau de comprometimento que era preciso ter com a proposta também.

DSC1/5 - Destaca o processo de incorporação de novos conhecimentos como interessante e único no MP.

Idéias centrais

A questão da incorporação de novos conhecimentos foi muito interessante! Uma experiência única no sentido de pensar o agir, de interpretar, aprender a contextualizar.

A importância de aprender a ler e continuar a pesquisar.

Discurso do sujeito coletivo

A questão da incorporação de novos conhecimentos foi muito interessante! É uma experiência única, no sentido da gente pensar o nosso agir, da gente criar métodos, aprender a ler! Isso não é nenhuma novidade assim, não é nenhuma vergonha. Eu acho que a gente aprendeu a ler no mestrado. A gente vai perdendo esse hábito. E de interpretar... e de saber ler de verdade, não é? Entender o que está sendo dito, entender a intencionalidade, contextualizar. O conteúdo, o momento em que foi escrito. Acho que isso é um ganho... Porque é importante ouvir vocês, a avaliação que vocês conseguem fazer de certas questões que não se enxerga quando se está na rotina... é muito importante para nós. E eu acho que a pesquisa paralela ao trabalho, às ações cotidianas, ela enriquece muito. Fiz a revisão bibliográfica relacionada ao tema da minha dissertação, que é o meu trabalho mesmo, do dia-a-dia. Aprendi muito. Eu estou aqui pensando em como vamos acompanhar esse projeto. Nós vamos ter que fazer pesquisa, continuar a fazer pesquisa. 
DSC1/6 - Destaca a capacidade do MP de proporcionar a oportunidade de um debate sobre as questões internas da instituição e ensejar um diálogo entre as pessoas e os departamentos.

Idéias centrais

O mestrado teve a capacidade de proporcionar um debate sobre as questões internas da instituição, romper determinados paradigmas, o que do ponto de vista de formação de recursos humanos e do processo de trabalho interno à instituição foi muito interessante.

Discurso do sujeito coletivo

O mestrado proporciona uma oportunidade, um momento de reflexão, de posicionamento diante dos problemas, dos temas. Acho que essa foi uma riqueza do mestrado! O mestrado teve uma capacidade de aproximar as pessoas dentro do ministério. Especificamente. Romper mesmo determinados paradigmas que tinha lá dentro. Acho que isso foi muito interessante! Acho que esse talvez tenha sido, embora difícil de mensurar, um dos objetivos que quem contrata curso de mestrado deveria ter bem, bem claro. Porque às vezes as pessoas precisam só de um estímulo para que isso aconteça. Elas ficam assim ensimesmadas, trabalhando com a sua agenda. Do ponto de vista de formação de recursos humanos e processo de trabalho interno das instituições, eu acho que é muito interessante. Porque tem a oportunidade formal de fazer um debate sobre as questões internas também da instituição. Tem uma questão que eu acho superimportante no curso, que eu até não falei é que, além da troca entre a academia e o serviço, tivemos momentos em que se permitia, se induzia a troca entre os alunos que estavam no mesmo serviço. Então havia áreas que a gente não conhecia. Foi conhecer lá dentro. E isso nos permitiu articular melhor o processo de trabalho aqui.

\section{Comentários}

Vale a pena um breve comentário sobre esses seis primeiros DSCs encontrados, sistematizados a partir da primeira pergunta do roteiro sobre os objetivos do curso: 1) a quebra de uma falsa dicotomia academia versus serviços, serviços versus pesquisa e a capacidade do MP de facilitar a produção de conhecimentos nos serviços; 2) ganhos mútuos para a academia, os serviços e as pessoas (alunos/profissionais); 3) O MP atinge o objetivo de dar um retorno à sociedade, não só para a instituição e para o aluno, mas para o SUS; 4) a aproximação entre academia e serviços pelas dificuldades relacionadas às diferentes expectativas de um e outro grupo, com destaque para o processo coletivo de construção do curso; 5) o processo de incorporação de novos conhecimentos como interessante e único no MP; 6) a capacidade do 
MP de proporcionar a oportunidade de um debate sobre as questões internas da instituição e ensejar um diálogo entre as pessoas e os departamentos.

Podemos considerar que os objetivos do curso são de natureza pedagógica (capacitar gestores em planejamento e avaliação de políticas de saúde públicas e apoiar o desenvolvimento de tecnologias para diagnóstico e resolução de problemas; desenvolver diagnósticos de saúde orientados para as funções de descentralização do SUS no âmbito do MS/SAS e favorecer as ações governamentais de regionalização do SUS). Os quatro primeiros DSCs não têm relação direta com esses objetivos, e sim com o entendimento dos entrevistados sobre a tradição de afastamento da academia dos serviços. Como esta foi uma preocupação relevante da coordenação do curso, consideramos que esses discursos relacionam-se com a estratégia política adotada pela coordenação, de buscar maior aproximação entre os serviços e a academia, o que, em nossa concepção, articula-se com o próprio objetivo do MP. Os DSCs 1/5 e 1 / 6 têm relação mais direta com os objetivos do curso.

\section{Sobre os Conteúdos e sua Adequação}

Para a segunda questão, "Com relação aos conteúdos do curso, comente aspectos como a adequação aos objetivos e ao perfil da turma e a articulação entre os mesmos, que foram algumas das preocupações da coordenação", encontramos quatro discursos do sujeito coletivo.

DSC 2/1 - Sugere que os conteúdos do módulo de Planejamento e o de Métodos de Pesquisa deveriam permear o curso todo, pela sua importância.

Idéias centrais

Trabalhar o planejamento de forma mais horizontal, passando por todos os módulos, pela importância das discussões, pela capacidade de organizar.

A metodologia é de difícil absorção num módulo único, difícil para quem está na execução. Já os Seminários Avançados articulados aos projetos foram superimportantes.

Discurso do sujeito coletivo

Acho que tem dois módulos, o de planejamento e o de metodologia, que deveriam permear o curso inteiro. Mesmo considerando a dificuldade para trazer professores, acho que, pela importância desses conteúdos, vale a pena repensar. Para dar conta do planejamento em todas as discussões que são feitas, ou pelo menos em algumas mais importantes, se deveria trabalhar o planejamento de forma mais horizontal, passando por todos os módulos. E a metodologia, assim, ela não agrada... É uma disciplina que não agrada o profissional da 
saúde de forma geral. Quando se trabalha num módulo único, como ele não é uma questão muito agradável para quem está na execução, você pode não absorver de fato, embora eu reconheça que tem uma importância tão grande... que quando se vai trabalhando no miudinho, vai-se vendo a inserção dele em cada uma das áreas. E acho que tem que ter um choque no início, conceitos, tal. E procurar trabalhar na metodologia um pouquinho, sendo que no final se trabalha mais a coisa da pesquisa, com a metodologia apoiando a elaboração dos projetos. Que é uma coisa que foi pensada e a gente teve seminários avançados para acompanhar os projetos e foi superimportante.

DSC 2/2 - Os conteúdos foram adequados e tiveram boa articulação entre eles.

Idéias centrais

Toda a condução das aulas teóricas foi adequada ao que se esperava em termos de conteúdo. Foram articuladas, sim, porque no decorrer do curso a disciplina, de uma certa forma, sempre procurava resgatar ou interagir com as disciplinas anteriores.

Discurso do sujeito coletivo

Acho que toda a condução das aulas teóricas foi adequada ao esperado, ao que a gente esperava em termos de conteúdo. Penso que foram articuladas, sim, porque no decorrer do curso, a disciplina, de uma certa forma, sempre procurava resgatar ou interagir com as disciplinas anteriores. Muitos textos para leitura, que se não foram utilizados, às vezes por falta de tempo de leitura, por este ou aquele motivo, estão lá e poderão ser resgatados a qualquer momento. Então acho super, superválido. Não tenho nenhuma crítica a respeito disso também. O curso organizado em módulos eu achei que foi muito interessante, porque deu para ter uma visão bem ampla. Nós passeamos por vários campos da saúde pública. A questão do planejamento, a questão das políticas... Eu gostei muito de como foi estruturado assim, o começo... Naquele primeiro módulo que deu aquela visão geral, do panorama, da agenda da saúde... Aquilo ali foi muito importante. E depois foi mostrando especificamente cada linha de atuação. Eu acho que nisso foi um formato bem, bem interessante. Eu acho que teve uma articulação entre os módulos... Agora, quando a gente chega no final e que vai produzir a dissertação, aí a gente sente bem que teve essa articulação. No momento que a gente está vivendo, nem tanto... tem essa questão aí do tempo, que tumultua um pouco a vida de quem está fazendo o mestrado profissional. Mesmo assim, acho que teve, sim, uma articulação. Por exemplo, vimos a questão do planejamento, articulado aos temas como subjetividade, liderança, cultura... Pelo menos para o meu trabalho foi dando uma linha. Depois eu, em 
casa, isso ficou bem claro assim, eu separei por módulos, eu separei nas caixinhas temáticas. Então, na hora em que eu precisava uma coisa, quando eu fui montando o meu trabalho, essa ligação de um tema com outro nas discussões, isso eu achei interessante.

DSC 2/3 - O conteúdo foi adequado, embora pudessem ser feitas pequenas reorganizações, como o aprofundamento de temas específicos de alguns alunos.

\section{Idéias centrais}

Os conteúdos foram adequados, embora antes de ter a disciplina de avaliação em si devêssemos ter tido alguma coisa de epidemiologia.

Talvez um aprofundamento de epidemiologia e outros temas para algumas pessoas, dependendo do tema da dissertação em algumas áreas.

Discurso do sujeito coletivo

Em termos de conteúdo eu acho que foi adequado. Se faltou alguma coisa, talvez a gente pudesse ter tido antes de ter a avaliação em si, ter alguma coisa de epidemiologia. Eu acho que a gente tem que conseguir retomar a epidemiologia. Não a epidemiologia positivista, tal... Acho que a gente precisa trazer a epidemiologia na articulação com o serviço. Ela pode ser aplicada. Tem alguns grupos que vêm discutindo isso um pouquinho mais e de forma interessante. Então, a epidemiologia junto com a avaliação única e simplesmente, ela fica muito essa epidemiologia e essa avaliação positivista, pura, direcionada. Então, quando a gente trabalha, e a gente sabe da importância dela em outros módulos, talvez a gente conseguisse... Aí não precisa todos os alunos estudarem com tanta profundidade, tudo. A epidemiologia é talvez uma disciplina que eu acho que mereça ser mais aprofundada. Ela foi muito bem dada, mas eu acho que a carga horária foi restrita, precisa de mais carga horária. E tem alguns conteúdos que eu acho que também merecem ser mais aprofundados, como a questão de avaliação em saúde. Até a utilização de pacotes estatísticos mesmo... ou pacotes de informática, eu não sei. Essa questão... Porque quem trabalha com banco de dados às vezes não tem essa destreza para avaliar um banco de dados. E no Ministério da Saúde a gente usa muito banco de dados. Ou se poderia pensar num formato de apoios de... Com conteúdos disciplinares, dependendo das áreas temáticas que os alunos... Pode ser uma disciplina que a gente aprofunde... Não sei se o mestrado profissionalizante poderia ter isso, uma que você faz optativa, de repente, conforme o tema. Pode ser uma disciplina optativa. Porque tem gente que não tem interesse nessa área. Acho que pode ser uma boa opção. Talvez um aprofundamento para algumas pessoas, dependendo do tema da dissertação em algumas áreas. 


\section{Comentários}

Um comentário se faz necessário aqui. Embora tenhamos optado por manter aqui um único discurso, observam-se dois temas: o aprofundamento e abordagem diferenciada em epidemiologia e a necessidade de aprofundamento de áreas temáticas específicas, de acordo com o recorte temático das dissertações.

DSC 2/4 - Destaca a excelência dos professores e dos profissionais do Executivo e dos serviços, que foram trazidos para o curso, enriquecendo os debates.

\section{Idéias centrais}

Destacam-se a excelência dos professores e a importância da articulação com alguns profissionais não professores, pessoas do serviço, os secretários municipais e estaduais de Saúde.

Ter trazido esses profissionais para o debate aproxima e enriquece a discussão, tanto da academia quanto do serviço.

Discurso do sujeito coletivo

Eu acho que os professores foram excelentes, de boa qualidade. Eu acho que outra coisa importante foi essa articulação com alguns profissionais não professores. Trazer pessoas do serviço, os secretários municipais e estaduais de Saúde... Teve uma mesa, no fim do primeiro módulo, por exemplo... Ter trazido esses profissionais para o debate, isso aproxima, não é? Enriquece a discussão, tanto da academia quanto do serviço. E isso seduz o aluno. Você vê que o que está sendo discutido pode ser aplicado no seu trabalho. Eu achei esses momentos bem positivos. Pessoas daqui mesmo da SAS que foram para a sala de aula, ter as chefias participando foi muito interessante.

\section{Comentários}

É importante observar aqui que a adequação dos conteúdos em si e a forma adequada de trazer os conteúdos (métodos pedagógicos, formas de abordagem etc.), considerando as características do curso e o perfil da turma, aparecem, muitas vezes, entrelaçadas nas falas, nos discursos dos alunos, pois trata-se de temas extremamente interligados.

Vale a pena ainda destacar que algumas questões como a sugestão de um módulo de homogeneização, com aulas de gramática, português etc., relacionam-se também às temáticas seleção, perfil dos quadros do MS e à discussão sobre formação de quadros/RH. O DSC2/4 (destacando a excelência dos professores e dos profissionais do Executivo e dos serviços que contribuíram enriquecendo os debates) está aqui incluído porque faz parte de uma estratégia 
pedagógica relacionada à intenção de facilitar a assimilação dos conteúdos e proporcionar um debate crítico. Não cabe em nenhuma pergunta mais específica do roteiro.

Sobre o Processo de Seleção

Sobre o processo de seleção, seis discursos foram encontrados.

Aqui vale observar que o processo de seleção desta turma especificamente teve dois momentos. Um primeiro momento, em dezembro de 2000, quando uma banca de seleção composta por três professores da Ensp selecionou os trinta alunos que deveriam preencher as vagas previstas. A seleção foi feita com base nos currículos, nas cartas de intenções, em que os alunos apresentavam seus pré-projetos, na carta do gestor indicando e liberando o aluno, e nas entrevistas realizadas pela banca.

Houve um atraso no início do curso, devido a dois fatores: primeiro, a SAS - demandante do MP - estava com outro MP em andamento, em parceria com o Instituto de Medicina Social da Universidade do Estado do Rio de Janeiro (Uerj), e o secretário solicitou que a segunda turma (agora em parceria com a Ensp/Fiocruz) adiasse o início, de março para setembro de 2001. Além disso, a própria Ensp só conseguiu se organizar para iniciar o curso em março do ano seguinte (2002). Nesse período, cerca 30\% dos alunos selecionados não confirmaram a participação no curso; procedeu-se, assim, a um segundo momento de seleção para preenchimento das vagas, tendo-se o cuidado de observar os mesmos critérios anteriores (currículo, carta de intenções, carta do gestor comprometendo-se a liberar o aluno) e entrevistas realizadas por banca de seleção da qual participaram a Coordenação da Pós-Graduação da Ensp, a coordenadora do curso indicada pela Ensp, mantendo-se um dos professores da banca anterior para permitir um elo com a etapa anterior. A seguir apresentamos os quatro DSCs sobre o processo seletivo.

DSC 3/1 - A seleção deveria priorizar quadros permanentes do MS, embora a situação dos RH seja tão precária que torna impossivel não considerar consultores. Destaca a necessidade de regras que garantam o retorno do investimento e a falta de politica de formação para os quadros permanentes.

Idéias centrais

Os servidores públicos do quadro são muito esquecidos.

O curso deveria ser voltado exclusivamente para o servidor público e, com essa regra, quem passar um determinado tempo fazendo mestrado vai ter que ficar não sei quanto tempo no serviço, no SUS. 


\section{Discurso do sujeito coletivo}

Deve-se pensar a quem se destina este curso. Na minha opinião, é uma falha permitir que consultores façam esse tipo de curso. Porque consultores têm um determinado vínculo com a administração pública, daqui a pouco vão ter outro e não vão, eventualmente, ter o compromisso de dar retorno do investimento que o recurso público financiou. E eu acho que devia ter algo mais amarrado. Se não for só para servidor público, tem que ter uma cláusula qualquer nas regras que obrigue essa pessoa a passar determinado tempo trabalhando no serviço público, até como uma forma de dar retorno. Agora, na minha opinião, deveria ser mais fechado, voltado exclusivamente para servidor público e com esta regra: passou tanto tempo fazendo mestrado vai ter que ficar não sei quanto tempo no serviço, não necessariamente na instituição que contratou o mestrado, mas no serviço, no SUS. Embora hoje no MS haja um problema, que esta gestão está tentando enfrentar, de que o número de consultores é enorme! Pegando esse argumento, até se aceita, entre aspas. Porque estão se formando recursos para o SUS. Mas do ponto de vista de quem é o financiador direto, para o Ministério da Saúde, não é interessante você qualificar uma pessoa, para essa pessoa te vender o próprio serviço, mais caro ali na frente, às custas do conhecimento que adquiriu financiado com recursos públicos. Não tenho um posicionamento totalmente fechado sobre isso, por causa desse problema. É uma dimensão grande de consultores e tal, mas eu acho que deveria centrar mais para servidor público do quadro. E eu digo isso porque os servidores públicos do quadro são muito esquecidos. A não ser algumas carreiras, tipo a do gestor e outras... Os servidores de nível médio do nível intermediário também estão no serviço há muito tempo, estão principalmente esquecidos.

DSC 3/2 - Necessidade de haver critérios claros para a seleção e regras específicas para o funcionamento geral do curso de MP.

Idéias centrais

É fundamental ter critérios claros para a seleção, critérios claros para regras de funcionamento. Deve haver um regimento específico. Agora já tem, mas durante nosso curso, isso fez falta.

Discurso do sujeito coletivo

Eu acho fundamental ter critérios claros para a seleção, critérios claros para regras de funcionamento. Tem que ter regras muito claras. $\mathrm{O}$ regimento tem que estar muito claro. $\mathrm{E}$ eu acho que essa primeira experiência que nós tivemos, nós não tínhamos condição ainda, eu acho que a escola também não tinha condições, de ter já essas regras prontas e acabadas, e 
foram aplicadas as do regimento geral, sem considerar a especificidade do MP. Porque senão acaba sobrecarregando a pessoa que está coordenando o curso, que tem que se ver diante de situações, tem que tomar decisões... Eu acho que deve ter um regimento específico. Sei que agora já tem, mas durante nosso curso, isso fez falta.

DSC 3/3 - A seleção foi adequada, com critérios qualitativos e autonomia da banca para considerar estes critérios.

Idéias centrais

Deve haver a carta do gestor indicando e liberando o aluno, mas a banca deve ter autonomia para fazer a seleção segundo os critérios definidos, para correr menos riscos de perdas de alunos depois.

O processo de seleção foi qualitativo e teve critérios adequados.

Discurso do sujeito coletivo

Sobre o processo de seleção, acompanhei a segunda etapa do processo, que me pareceu muito mais qualitativa e teve critérios adequados. Acho que tem que tentar manter no processo de seleção um certo distanciamento de quem propõe o curso, de quem contrata. Eu acho que quem vai fazer a seleção tem que ter autonomia em relação aos selecionados. Isso eu acho que é premissa, e outra é que o processo de seleção acho que tem que ser como foi esse: qualitativo. Foram exigidas algumas documentações que deixavam clara a intenção, o comprometimento, os posicionamentos de quem estava concorrendo, mas tinha uma análise que era da própria banca de seleção. Estou falando da segunda etapa, pois este curso teve uma seleção anterior. Quanto à interferência e participação de quem contrata, do gestor, acho que deve haver a carta do gestor indicando e liberando o aluno, mas a banca deve ter autonomia para fazer a seleção segundo os critérios definidos, para correr menos riscos de perdas de alunos depois.

DSC 3/4 - Discurso valorizando critérios rigorosos de seleção, considerando o compromisso dos alunos com o SUS e o seu perfil/qualidade.

Idéias centrais

O rigor é importante, pois reforça a credibilidade do curso.

Discurso do sujeito coletivo

Este curso teve um primeiro momento, em que se fez uma seleção, aí depois várias pessoas desistiram e depois vieram outras pessoas, numa segunda etapa. Na segunda seleção 
parece que foi mais rigorosa... Foi uma época em que estavam saindo dois cursos aqui pela SAS. Nessa primeira etapa da seleção, alguns que tinham feito a seleção para esse primeiro curso, via outra instituição, e que não tinham passado, se apresentaram. Eu sei que um dos critérios de seleção do primeiro curso era ser dirigente... Acho que teve um pouco esse perfil. Na minha opinião havia alunos com qualidade melhor do que alguns dirigentes, que não entraram. E parece que a Ensp não se preocupou muito com isso, a gente percebe. E sim com qualidade do aluno, principalmente na segunda etapa. Quem estava ali fazendo o curso para ter só o mestrado, a gente percebe que o compromisso era diferenciado de quem estava ali tentando construir uma situação melhor, para contribuir para um Sistema Único de Saúde melhor. Então eu acho que teve um pouquinho essa diferenciação dos alunos. E eu acho que tem que ter este rigor. Eu acho que o rigor é importante, porque reforça a credibilidade do curso.

Sobre os Critérios de Avaliação dos Alunos

Sobre os critérios de avaliação dos alunos (provas, resumos, resenhas, oficinas de trabalho etc.), foram observados três DSCs.

DSC 4/1 - Destaca a importância de manter o rigor nas avaliações, pois ele valoriza o curso.

Idéias centrais

Das provas, há algumas coisas da organização, do processo de trabalho acadêmico, que não dá para flexibilizar. E uma delas é o rigor de alguns critérios que a Ensp manteve e que ajudaram no crescimento e desenvolvimento dos alunos. Isso apareceu inclusive na avaliação oral durante o curso.

Critérios rigorosos para manter a qualidade do curso devem permanecer, pois a academia, a área de ensino, pesquisa, é responsável pelo produto que joga no mercado.

Discurso do sujeito coletivo

Eu acho uma questão que foi importante, primeiro, foi não abrir mão do inglês. $\mathrm{O}$ exercício de estar lendo em espanhol. Isso para a gente é importante porque a gente tem feito articulação com outros países, e isso de fato ajudou. E quando não tem inglês, o curso é menos valorizado (estou comparando com outros), então eu acho que precisava, sim, ter a prova de inglês, porque valoriza o mestrado e mantém a equivalência com o acadêmico, o que é importante, até porque o certificado tem o mesmo valor. Na avaliação do aluno, algumas avaliações escritas eu acho que foram importantes. E tem a avaliação feita pelo aluno também, as orais e as escritas, em cada módulo ou disciplina, e a gente percebe que alguns alunos se desenvolveram muito do início para o final. Não falavam no início do curso e foram 
desenvolvendo a capacidade de fala mesmo, de se expressar, de articular seus pensamentos. Então eu acho esse foi um ponto bem positivo. A questão da avaliação escrita, o fato dela não ter sido aquela avaliação em que pega-se um texto e se quer saber só a opinião de determinado autor, mas que permitiu a expressão da opinião do aluno... eu acho que foi muito importante e ajudou muito nosso desenvolvimento, para na hora da dissertação a gente escrever. Das provas, eu acho que tem algumas coisas da organização, do processo de trabalho acadêmico, que não dá para flexibilizar. E uma delas eu acho que é o rigor de alguns critérios que a Ensp manteve e que ajudaram no crescimento e desenvolvimento dos alunos. Isso apareceu inclusive na avaliação oral durante o curso, eu lembro. Critérios rigorosos para manter a qualidade do curso devem permanecer. Eu acho que a academia, área de ensino, pesquisa, é responsável pelo produto que joga no mercado. Se você me dá um título, conseqüentemente você está me habilitando. E eu vou ser contratada pelo meu título. E aí é que eu vou sentir, vou desenvolver aquilo que foi proposto. Eé isso que é responsabilidade, profissionais titulados devem ser competentes. A gente valoriza o título Ensp, da Fiocruz, para mim é muito gratificante... Eu acho que é até bom para nós, porque a gente sabia que havia algumas pessoas que realmente não tinham capacidade de absorção e trabalho. Quer dizer, vocês realmente cumpriram com a obrigação, independente de qualquer coisa. E é por isso que a gente ainda acredita nesse país. Porque existem instituições sérias, não é? Porque se parar de existir essas instituições sérias, a gente passa a desacreditar nesse país. E sobre a proposta de uma comissão para avaliar os produtos finais, concordo plenamente e parabenizo a academia por manter essa conduta, que eu acho fundamental, no desenvolvimento das pessoas mesmo.

DSC 4/2 - Marca a importância de haver regras claras para o curso, inclusive para a avaliação, o que nem sempre ocorreu.

Idéias centrais

O sistema de avaliação não ficou muito claro para mim e acho que talvez não tenha ficado muito claro lá para os alunos.

As regras e os critérios devem ficar mais claros para todos, desde o início.

Discurso do sujeito coletivo

O sistema de avaliação não ficou muito claro para mim e acho que talvez não tenha ficado muito claro lá para os alunos. Teve módulos mais longos, outros menores, e as avaliações não tinham um padrão, cada professor decidia... Embora você diga que foi resolvido com a coordenação. Em termos de nota, valiam as avaliações dos módulos. Os das disciplinas 
tinham peso igual? Eu estou me lembrando disso. É verdade. Depois foi feita uma média nas notas dos módulos (e disciplinas) e o que valia para avaliação, inclusive reprovação, era a média do módulo. Três notas baixas (conceito C), seguindo o regimento da Ensp, reprovavam. Faltou também um regimento específico para os MPs, que só agora tem. Mas, de toda forma, eu acho que devia ficar mais claro isto, para os alunos: ter regras. E as regras ficarem mais claras para todos desde o início, não é? Critérios e as regras claras.

DSC 4/3 - Reconhece como importante a opção pedagógica das avaliações que foram se tornando mais complexas ao longo do curso.

Idéias centrais

A questão pedagógica de começar fazendo resumo, depois um texto mais articulado, uma resenha, foi fantástica.

Essa opção pedagógica foi muito boa porque já foi um preparo para ir aprendendo a escrever a dissertação, tanto que os alunos evoluíram nesse processo. Foi perfeita.

Discurso do sujeito coletivo

Aquela questão pedagógica de começar fazendo resumo, depois um texto mais articulado, uma resenha, achei fantástico. A gente estava acostumada a fazer é relatório. A resenha já é um diálogo com o autor, e não tínhamos a menor noção disso. Achei essa opção pedagógica muito boa, porque já foi um preparo para ir aprendendo a escrever a dissertação, não é? Tanto que, em uma reunião de avaliação de um módulo, eu queria a minha primeira resenha de volta porque já estava muito crítica e queria fazer de novo. Para ver o tanto que nós evoluímos nesse processo. Então, essa pedagogia foi perfeita! Eu aprendi muito! Só achei que tinha muita tarefa, por isso a gente criticava, embora reconhecesse a importância.

\section{Comentários}

Aqui vemos discursos bastante díspares, desde o que solicita maior explicitação dos critérios de avaliação desde o início do curso até o reconhecimento da estratégia pedagógica embutida nas formas e nos critérios de avaliação utilizados. No item 1, relacionado à apresentação do curso, apresentamos brevemente os critérios utilizados, embora sem um grande aprofundamento. Durante o desenvolvimento das aulas teóricas, várias foram as queixas sobre o excesso de obrigações/deveres exigidos dos alunos, que, acima de tudo, estavam sobrecarregados com o trabalho. Por outro lado, nas falas aparece de forma mais contundente o reconhecimento da necessidade e do objetivo pedagógico dos exercícios, provas e demais ferramentas de avaliação para o processo de aprendizagem. 


\section{Sobre os Prazos}

Sobre a questão dos prazos (liberação dos alunos e horários das aulas, prazos para realização e defesa das dissertações etc.), encontramos cinco DSCs, a seguir apresentados.

Sobre esta questão especificamente, mas não só, pois os interesses e motivações também mudaram, vale a pena observar o impacto causado por um importante fato: as eleições para presidente e suas conseqüências para a SAS/MS, como mudança de gestão e de objeto mesmo, no meio do curso. Podemos dizer que o fator atraso no início do curso, anteriormente apontado, está relacionado a este. O primeiro discurso aqui apresentado refere-se exatamente a esse impacto.

Vale a pena, ainda, ressaltar que ao falar em prazos para a defesa das dissertações, os alunos falam também de seus objetos, e a nossa sistematização a seguir considerou essas inter-relações.

DSC 5/1 - Com relação aos prazos, a grande dificuldade foi a mudança de governo, que trouxe muitas outras mudanças nas motivações, nos interesses, no próprio objeto da SAS, e a necessidade de renegociar tudo com a nova gestão; o papel da coordenação foi fundamental nessa transição.

Idéias centrais

A grande dificuldade deste curso foi o momento do curso: ter começado atrasado e pegar a mudança de governo. As motivações, os interesses, os resultados mudaram. Inclusive o objeto da SAS mudou!

A coordenação conseguiu resgatar algumas questões importantes de interesse para aSAShoje.

Discurso do sujeito coletivo

Eu acho que a grande dificuldade deste curso (e eu acho que fomos todos um pouco heróis, incluindo a coordenação) foi o momento do curso. O fato de ter começado atrasado e pegar a mudança de governo. Quais os programas que a gente teve na mudança de governo? É importante contextualizar isso. Algumas pessoas saíram do ministério, outras chegaram no ministério, outras assumiram cargos, outras, que tinham um cargo, perderam. As motivações, os interesses, os resultados mudaram. Inclusive o objeto da SAS mudou! A gente não teve um trabalho, uma dissertação sobre atenção básica! E atenção básica hoje é uma das prioridades da atenção à saúde. Então, eu acho que o interesse naquela época era um, então a gente teve que fazer adaptações. Eu acho que a coordenação fez bem isso, resgatar algumas questões importantes de interesse para a SAS hoje. Isso foi fundamental. Essa dificuldade foi grande. A não liberação dos alunos foi outra. Eu acho que a gente teve uma liberação muito importante durante as aulas, era o fim de governo, tinha tempo para isso. Com a entrada do governo, na 
transição, o problema dos prazos foi para o término das dissertações e as defesas. Aí algumas pessoas assumiram cargos estratégicos e não deram conta do processo. Foi-se empurrando, tanto que este curso está atrasado, não é? Já tinha que ter acabado. Mas não tinha como ter sido diferente, pelo menos agora na defesa. Acho que os resultados que temos, resultados bons, ocorreram porque a academia enxergou esse contexto de transição, flexibilizou alguns prazos, senão não tinha dado certo. As pessoas tinham desistido mesmo. Então, eu acho que o problema foi a transição mesmo e o prazo de entrega da dissertação, que aí as pessoas, naquele momento, não tiveram como se afastar do serviço. Acho que pelo menos para conclusão da dissertação precisaria, deveria ter um mês de afastamento para todos. Tentou-se negociar isso, mas foi impossível, pelo momento político inclusive. Por mais que o chefe falasse: "Tudo bem, eu libero", o compromisso das pessoas com o serviço não permitia, no momento. Eu acho que os professores entenderam bem. Alguns mais do que outros.

DSC 5/2 - Considerou os prazos adequados, a disponibilidade dos orientadores boa e valorizou a capacidade da instituição (Ensp) de se adaptar a uma proposta inovadora. Considera que os prazos de liberação devem ser parciais, para não afastar o aluno de seu objeto de trabalho.

\section{Idéias centrais}

Os prazos para o curso, para as defesas, para o preparo, para tudo, foi absolutamente adequado.

A disponibilidade da Ensp para entrar numa proposta inovadora.

Tem que ter liberação, sim, mas não uma liberação total, porque senão o aluno se afasta do trabalho, que é seu objeto de estudo, e também não é interessante.

\section{Discurso do sujeito coletivo}

Os prazos para o curso, para as defesas, para o preparo, para tudo, eu acho que foi absolutamente adequado. Acho que foi na medida certa, o que não quer dizer que a gente tenha disciplina necessária para cumprir esses prazos. Acho que qualquer tipo de crítica em relação a prazos, à forma como foi conduzido o processo, é preciso contextualizar. Por exemplo, considerando a agenda de orientadores, eu, pelo que conheço do conjunto da obra, pouquíssimos alunos tiveram dificuldade em relação ao seu orientador. Que é uma outra questão importante, porque numa instituição do porte da Ensp, com a carga que os professores têm, com as agendas que já tinham, valorizo, primeiro, a disponibilidade de entrar numa proposta inovadora. Acho que demonstra uma capacidade de desapego e de adesão ao novo. E de quem procura propostas inovadoras. Que eu acho que tem que ser a posição do 
pesquisador mesmo: procurar novas formas e tal. Eu sei de apenas um caso de aluno que teve dificuldade de agenda com o orientador. E se não tiver prazo, a gente acaba não cumprindo mesmo, pela agenda do próprio ministério. Então eu acho que foram adequados, sim. Talvez a gente tivesse que ter mais responsabilidade na questão da agenda das pessoas em relação a viagens (do MS). Eu acho que tem que ter liberação, sim, mas não uma liberação total. Porque senão o aluno se afasta do trabalho, que é seu objeto de estudo, e também não é interessante. Além disso, se não fosse assim, nós jamais teríamos feito mestrado. Mesmo a forma como a gente teve aula eu acho que até foi interessante, porque sexta-feira não é um dia em que se perde muito. Tivemos aula na quinta à noite e aos sábados, e a turma se comprometeu muito. Os professores entenderam bem alguns atrasos para a entrega dos trabalhos, leituras etc., durante o curso, entendendo que as pessoas estavam em serviço.

DSC 5/3 - Diferencia liberação formal e liberação real dos alunos, associando tal diferença a dificuldades no cumprimento dos prazos, e frisa a necessidade de um acordo com a instituição demandante.

Idéias centrais

Em termos de liberação do trabalho em função do mestrado, mas já na época das aulas teóricas, ela era muito formal, e não na vida real.

Discurso do sujeito coletivo

Em termos de liberação do trabalho em função do mestrado, do ponto de vista formal ela foi tranqüila. Desde a época da parte teórica do curso, como agora ainda, na época das dissertações, das conversas que precisa ter com o orientador e tal, ela foi muito complicada. Mas já na época das aulas teóricas, eu acho que ela era muito formal e não na vida real. Várias vezes a gente teve pessoas saindo da aula. Estavam na aula e tiveram que se retirar por um processo de trabalho, ou nem ir à aula. Acho que isso deve ser melhor acordado, melhor pactuado.

DSC 5/4 - Considera os prazos apertados, principalmente pelo excesso de trabalho, que deixava pouca disponibilidade para leituras e estudo, mas reconhece a importância do MP na articulação entre serviço e pesquisa e avanços na implementação dos projetos.

Idéias centrais

Os prazos foram pequenos para quem trabalha o dia todo.

A reflexão da tese e a implantação do próprio projeto, resultante dessa reflexão, tiveram que avançar paralelamente. Para os alunos fazerem uma tese eles têm que ter uma liberação maior do serviço, um tempo parcial. 
O MP, apesar da exigüidade do tempo, forçou os alunos também a fazerem várias outras coisas e a evoluir na questão de saber articular trabalho, ensino, pesquisa.

Discurso do sujeito coletivo

Esta questão dos prazos foi um grande problema, que eu achei muito preocupante. Porque os prazos foram pequenos para quem trabalha o dia todo. Porque nosso mestrado é profissionalizante, quer dizer, fizemos enquanto trabalhávamos, não é? Foi uma experiência muito gratificante, mas, por outro lado, nós sentimos muito, porque não conseguimos fazer aquilo que gostaríamos. Como os prazos foram muito curtos, a gente tinha muito pouco tempo para escrever, para pesquisar, para ler. Então, nós não conseguimos ler em tempo hábil todas as informações repassadas pelo mestrado. E assim, poderíamos estar rendendo muito mais, fazendo muito mais, se tivéssemos um tempo maior para pesquisar, ler mais. Essa é uma grande contradição, eu acho, deste mestrado, porque por outro lado, sem ser nesse formato, nós não seríamos liberados. Talvez a questão seja amarrar e negociar melhor esses prazos. Nós éramos liberados na sexta o dia todo. E tínhamos aula na quinta à noite e sábados, quinzenalmente, o dia todo. Mas pelo trabalho todo de sexta a gente continua responsável, porque no Ministério da Saúde a gente não trabalha só durante o dia. A gente trabalha à noite. $\mathrm{O}$ trabalho de quinta à noite e o trabalho de sexta, nós continuamos responsáveis. Então, conclusão: a gente fica com mais trabalho e menos tempo para realizar as nossas tarefas do mestrado. Portanto, o trabalho se acumula, há cada vez mais trabalho, e o nosso tempo fica mais curto e a vontade de estar aproveitando aqueles módulos, lendo, discutindo, levando propostas aumenta, não é? O que era impossível com o nosso tempo. Eu acho, até, que nos trabalhos apresentados, ficou muito a desejar. Eu penso que os meus, as minhas resenhas, ficaram a desejar, embora eu ache que deu para a gente fazer, com muito esforço. A realização da tese foi outro nó crítico. Porque não tendo aula, se não sendo liberado aquele dia, nós passamos a voltar no trabalho normal. E coincidiu exatamente com a realização desse projeto, na aprovação desse projeto e na implantação desse grandioso projeto. Quer dizer, a reflexão da tese e a implantação do próprio projeto resultante dessa reflexão tiveram que avançar paralelamente, não é? Eu acho que para a gente fazer uma tese a gente tem que ter uma liberação maior do serviço, um tempo parcial. Por outro lado, eu achei fantástico o mestrado profissionalizante. No MP, a exigüidade do tempo nos forçou também a fazer várias outras coisas e a evoluir na questão de saber articular trabalho, ensino, pesquisa. 
DSC 5/5 - Analisa os prazos em diversas perspectivas: a do compromisso do aluno, a do gestor (demandante), a dos professores/orientadores, a do contexto de transição na época da mudança de governo.

\section{Idéias centrais}

A questão dos prazos deve ser olhada de diversas maneiras. Houve dificuldades do próprio ministério, da SAS, dos compromissos de trabalho, viagens, dificuldades com os prazos/disponibilidade do orientador, transição do governo e necessidades de adaptações e compreensão do contexto do curso que tinha sido contratado pela gestão anterior.

Discurso do sujeito coletivo

A questão dos prazos deve ser olhada de diversas maneiras. Alguns alunos conseguiram estar absolutamente dentro dos prazos, apesar de todos os percalços. Outros não tiveram a disciplina necessária para cumprir esses prazos, alguns poucos tiveram dificuldades com os prazos/disponibilidade do orientador, além de toda a dificuldade do próprio ministério, da SAS, dos compromissos de trabalho, viagens, que exigiam muito de determinados alunos, principalmente dos que assumiram funções de coordenação e responsabilidade maiores, como às vezes até representar o ministro em momentos em que deveriam estar em sala de aula. Ainda teve o problema da transição do governo, que trouxe outros tantos problemas como inseguranças, mudanças nos diversos níveis de cargos e posições, técnicos que saíram, pessoas que chegaram e a necessidade de adaptações e compreensão do contexto do curso que tinha sido contratado pela gestão anterior.

\section{Comentários}

A maior parte dos discursos diz respeito a questões extracurso referentes a um contexto, e são poucas as questões relacionadas à governabilidade direta da coordenação do curso ou da Ensp. Apesar dessa ressalva, consideramos bastante pertinentes as questões, pois um curso não se realiza jamais fora de um contexto, e este deve ser levado em consideração. Como diria Matus (1993), não há plano sem contexto, não há avaliação sem contexto. Assim, nesta primeira experiência de mestrado profissional a Pós-Graduação da Ensp precisou, diante desse contexto, flexibilizar os prazos, principalmente da defesa das dissertações.

Apesar de todas as dificuldades, o curso cumpriu relativamente bem seus objetivos, embora tenhamos perdido alguns alunos que não conseguiram cumprir os prazos determinados, e desistiram. 


\section{Sobre as Sugestões para o Aperfeiçoamento do Curso}

Das respostas à última questão do roteiro de entrevistas, sobre as sugestões para o aperfeiçoamento do curso, destacamos, das várias sugestões encontradas, cinco DSCs mais significativos.

Aqui, observamos que várias sugestões já haviam sido abordadas anteriormente, inseridas nas falas relacionadas a outras questões.

DSC 6/1 - Discurso sobre a diferença de disponibilidade de professores/orientadores, sugerindo pensar em perfis adequados de professores para esta modalidade de curso.

Idéias centrais

É perceptível que os trabalhos que deram certo e que andaram, conseguiram ir até o final, é porque os orientadores (além dos alunos) se empenharam nisso.

Discurso do sujeito coletivo

Eu acho queé importante pontuar: a gente percebe que os trabalhos que deram certo eque andaram, conseguiram ir até o final, é porque os orientadores (além dos alunos) se empenharam nisso. Se empenharam, resolveram, ajudaram, diferente de algumas outras pessoas, que tiveram dificuldades (tirando as exceções de alunos reprovados que não tinham condições de acompanhar, nem se qualificaram). Mas, em alguns casos, o orientador não entendeu esse contexto (de dificuldade de liberação, principalmente na transição do governo). É claro que alguns alunos estavam indisciplinados do ponto de vista acadêmico, mas os trabalhos que foram até o final, que deram certo, é porque os orientadores conseguiram contextualizar isso. Temos perfis de alunos, perfis de professores, em contextos diferentes. Então, isso eu acho que tem que ser considerado. Esta talvez tenha sido uma das dificuldades, eque não sei como melhorar. Não tenho sugestão em relação a isso não. Talveza sugestão para isso équeé preciso ter um pouco de feeling. Tanto os alunos quanto os professores devem pensar em entender qual o professor mais adequado aos diferentes perfis. De toda forma, acabou sendo exceção, e a maioria dos professores estava inserida no projeto do curso, o que ajudou a compreensão do contexto particular do curso.

DSC 6/2 - Sugere pensar o processo pedagógico evitando fragmentação e um número grande de professores.

\section{Idéias centrais}

Os módulos um pouco mais longos são melhores do que os módulos fragmentados.

Os módulos e atividade pontuais, seminários, mesas-redondas, têm que ser mais bem organizados. 
Discurso do sujeito coletivo

Eu acho que os módulos um pouco mais longos são melhores do que os módulos fragmentados. Eu acho que se pode criar uma dinâmica de ter seminários e mesas-redondas, como chegou a ter. Tem professor que você nem lembra direito do nome dele, foi para dar uma aula. Eu não estou falando que isso é ruim ou bom. Eu estou falando que é algo que se tem que pensar sobre isso, para o processo educativo. A fragmentação também cria um problema, que é problema de agenda. Então, eu acho que essa questão de módulos e de fragmentos e de atividade pontuais, seminários, mesas-redondas tem que ser mais bem organizada. Talvez pensar períodos, não é? Após um mês faz um, após outro mês faz... Enfim, organizar melhor isso para ter melhor questão de agendas, porque nós tivemos problemas de agenda, não é? Nesse curso aí eu acho que é natural, é isso mesmo. As pessoas são ocupadas, então sempre teremos este problema, mas causa prejuízo no andamento do curso.

DSC 6/3 - Sugere agregar aos conteúdos do curso alguns conteúdos básicos, como português, gramática, redação, para se ter um mínimo de homogeneidade no perfil da turma e do público-alvo do curso.

\section{Idéias centrais}

Nem sempre aquele público que a instituição está dizendo que deve ser capacitado tem as condições e o perfil adequado para fazer o curso.

Todo curso de mestrado deste tipo deveria ter aula de gramática, redação, português e, mais do que só metodologia, ter essas coisas de ensinar as pessoas a escrever e a ler mesmo.

Discurso do sujeito coletivo

Em relação a quem é que vai ser o público-alvo desse tipo de curso, entra num outro problema também. Nem sempre aquele público que a instituição está dizendo que deve ser capacitado tem as condições e o perfil adequado para fazer o curso. São várias pessoas, com várias histórias diferentes, com perfis diferentes, com profissões diferentes e que de repente precisariam passar por algum critério básico para nivelar as pessoas. E eu falo nivelar mesmo. Até ensinar a escrever e a ler de vez em quando. Ter aula de português, eu acho. Eu acho que todo curso de mestrado deveria ter aula de gramática, redação, português. Mais do que só metodologia, ensinar as pessoas a escrever e a ler mesmo. Você olha e vê que as pessoas não têm ainda um nível de igualdade. Eu acho que tem a questão da seleção também, mas talvez fazer um módulo de homogeneização para todo mundo. 
DSC 6/4 - Relaciona seleção e formação de RH e problematiza a 'precarização' dos quadros do MS.

\section{Idéias centrais}

OMinistériodaSaúdehojefazum investimento nos técnicos enão tem um quadro permanente.

A contratação, que é feita por concurso, está sendo pensada de uma maneira específica, levando em consideração esse investimento que já foi feito (o investimento nos MPs e outros cursos)? Isso deveria estar atrelado.

Discurso do sujeito coletivo

A minha questão é relativa ao investimento que o ministério hoje faz nos técnicos e à falta de um quadro permanente. Quando a gente pega uma turma, como foi a nossa, de 27 pessoas, em que apenas, eu acho que 11, eram do quadro, então é o retrato do que é o ministério hoje. E essa forma de contrato está de certa forma se encerrando. E assim, está-se investindo nesses técnicos, qualificando esses técnicos, para dar o seu retorno, a sua contribuição, e como isso vai acontecer? Se essa forma de contrato está acabando, será que a forma de contratação, que é por concurso, está sendo pensada de uma maneira específica, levando em consideração esse investimento que já foi feito (o investimento nos MP e outros cursos)? Eu acho que deveria estar atrelado. Como pensar isso, se você não tem nenhuma segurança de que você vai ter esse profissional lá no SUS, pelo menos? Se a pessoa está fazendo uma capacitação, uma formação no caso, é preciso respeitar esta prioridade. Porque a gente vive o tempo inteiro uma questão de estar com culpa, porque está estudando e não está resolvendo as situações que deveria estar resolvendo, ou então está resolvendo e está com culpa, porque estão te dando a oportunidade de fazer um mestrado profissional e você não está se dedicando como gostaria. Acaba acontecendo o que se vê muito nas universidades públicas: as pessoas se aposentam muito cedo, de alguma forma saem e vão para as universidades privadas. Quando não antes. Então eu acho que isso é uma questão muito maior do que aqui, este mestrado profissional, mas que está ligado com ele (o MP).

DSC 6/5 - Necessidade de se pensar e implementar estratégias mais globais, numa perspectiva de política de $R H$, de formação de quadros do serviço público e do SUS.

Idéias centrais

Quando se pensa numa formação permanente para o servidor, é preciso chamar todos os servidores públicos e pensar de forma mais global. 
Esta é uma questão relevante, não só considerando o mestrado profissional, mas uma questão de política de recursos humanos, política de educação e trabalho. E tem que se pensar uma forma de fazer com que os recursos investidos retornem para a população.

Cursos como o MP formam para o SUS, não só para determinados departamentos do MS, nem só para o MS, mas para o SUS como um todo, e é isto que deve estar garantido.

Discurso do sujeito coletivo

Porque quando se pensa numa formação permanente para o servidor, temos que chamar todos servidores públicos, não é? E pensar de forma mais global. Esta é uma questão muito maior do que este mestrado profissional. O investimento em RHé uma questão que tem que ser bem pactuada, com as secretarias e as coordenações, que estão querendo promover a formação de seus técnicos. A prioridade deveria ser formar os quadros permanentes, mas há um grave problema no MS, queéo enorme número de consultores, técnicos sem dedicação exclusiva, com tempo determinado de contrato, que é um problema que esta gestão está tentando enfrentar e propondo concursos públicos. Cursos como o MP formam para oSUS, não só para determinados departamentos doMS, nem só para oMS, mas para oSUS como um todo, eé isso que deve estargarantido. Algumas questões aí devem ser pensadas, embora eu não tenha um posicionamento totalmente fechado sobre isso, por causa deste problema: a dimensão grande de consultores e tal, mas eu acho que devia centrar mais para servidor público do quadro. Eeu digo isso porque servidores públicos do quadro são muito esquecidos, a não ser algumas carreiras, tipo a do gestor e outras. Para os servidores de nível médio do nível intermediário também, que estão no serviço há muito tempo, não tem nenhuma política para graduá-los, quanto mais para pós-graduá-los. Este é um buraco grave, um nó crítico. Estaé uma questão relevante, não só considerando o mestrado profissional, mas uma questão de política de recursos humanos, política de educação e trabalho. E tem que se pensar uma forma de esses recursos investidos retornarem. Exigir um compromisso das pessoas beneficiadas com estes cursos de ter alguma maneira de devolver isso para a população, considerando inclusive os custos de todo esse investimento.

DSC 6/6 - Sugere uma avaliação do quanto as propostas das dissertações estão sendo realmente incorporadas pela instituição, bem como a divulgação e publicação dos resultados, além de ressaltar a necessidade de continuidade das reflexões, da pesquisa para implementação e atualização dos projetos.

Idéias centrais

Sugere, além da publicação desses resultados, fazer uma avaliação do processo, a avaliação dos resultados. 
É fundamental avaliar esses resultados como um processo de implantação no ministério: verificar se as sugestões das dissertações de fato foram implementadas, e se não o foram, por que não.

Discurso do sujeito coletivo

Para marcar a importância dos resultados, dos trabalhos e dissertações, principalmente, que foram realizados, queria destacar a elaboração de novas políticas e a implantação de projetos no MS, noSUS, e sugerir, além da publicação desses resultados, fazer uma avaliação do processo, a avaliação dos resultados. Eu acho que poderíamos, daqui para o começo do ano que vem, que aí todo mundo encerrou direitinho, passou a eleição, passou Natal, férias, essas coisas, talvez a gente pudesse fazer uma avaliação de como esses resultados estão sendo implantados no serviço, a continuidade dos projetos. Por exemplo, a política para os hospitais de pequeno porte, a nova organização dos espaços microrregionais de saúde, o novo pacto de gestão, os centros colaboradores, a proposta para os laboratórios, enfim, eu não acompanhei todas as dissertações, mas acho importante avaliar como as propostas dos alunos, nossas propostas, estão sendo encaminhadas, pois foram todas propostas concretas e úteis. Acho importante ver como que isso está funcionando no serviço. Acho fundamental a gente avaliar esses resultados enquanto um processo de implantação no ministério, se as sugestões das dissertações de fato foram implementadas, e se não foram, por quê. Registrar, publicar e continuar a refletir. Acho uma grande oportunidade. Temos a proposta de apresentar os projetos, de fazer o livro, de disponibilizar na biblioteca do MS e da Ensp. E, principalmente, avaliar a implementação.

\section{Comentários}

Neste item reunindo as sugestões, temos um discurso sobre a fragmentação(DSC6/2), no qual é importante marcar que a idéia da fragmentação refere-se mais à divisão de horários, ao tamanho dos módulos e à quantidade de professores e menos à fragmentação do saber. Os discursos relacionados à política de $\mathrm{RH}$ para o MS e sobre a precarização dos quadros do MS (DSC6/4 e DSC6/5), embora não estejam relacionados diretamente ao âmbito do curso, e exijam uma governabilidade que inclui vários outros atores, para além da coordenação do curso e da Ensp, referem-se a um contexto importante que deve ser explicitado. Esses discursos ajudam a tornar mais claras algumas das dificuldades e desafios na formação de quadros estratégicos para o SUS. Trata-se de um grande nó crítico que deve ser enfrentado num horizonte de prazo mais longo pelos vários atores envolvidos nessa situação, inclusive as instituições de pós-graduação. 
Já o último discurso, sugerindo uma avaliação do grau de incorporação das propostas advindas dos trabalhos finais dos cursos de MP, é de interesse imediato para a pós-graduação da Ensp; tais propostas devem ser consideradas como objetos de estudo imediato.

\section{CONSIDERAÇÕES FINAIS}

Alguns pontos comuns importantes podem ser observados entre as críticas e sugestões escritas dos alunos, sistematizadas no Relatório de avaliação do curso da Coordenação de PósGraduação da Ensp (ver nota 5), e nas falas dos alunos entrevistados já ao final do curso. Desses pontos, destacamos: a reflexão crítica sobre a realidade; a oportunidade de conhecer as possibilidades e métodos atuais de avaliação dos serviços de saúde; a adequação das técnicas de ensino; a oportunidade de conhecer métodos de pesquisa úteis tanto para a dissertação como para o cotidiano e a reflexão sobre o papel como gestores do SUS. Esses temas são retomados nas entrevistas e aparecem em vários dos DSCs.

Outras questões, algumas referentes ao processo educativo - o excesso de textos e muitos conteúdos teóricos, trabalhados em pouco tempo, prejudicando a assimilação por parte dos alunos; a cobrança excessiva e o rigor nas provas e trabalhos; a pesada carga de trabalho 'doméstico', que deve ser diminuída e compensada pela intensificação do trabatho em sala de aula - reaparecem de forma reelaborada. Algumas vezes ressurgem, como no DSC 4/3, por exemplo, com aspectos contraditórios, como a queixa sobre a exigência de resenhas e exercícios junto com o reconhecimento, agora possível pelo próprio distanciamento, da importância pedagógica da estratégia e com a valorização da utilização de critérios rigorosos por parte da Ensp.

Há, ainda, sugestões importantes de reorganização do curso, como a idéia de um aprofundamento diferenciado para os alunos, dependendo do recorte temático das dissertações, para além da orientação que já se traduz em um acompanhamento com indicações bibliográficas e trabalho temático específico. Observa-se nos alunos uma crítica madura, com sugestões muito pertinentes.

Isso nos faz refletir sobre a importância de avaliar nossos cursos em diferentes tempos: durante o andamento das disciplinas, buscando corrigir o que for possível; ao final, como este exemplo de entrevistas com os egressos dos cursos, que trazem, muitas vezes, maior maturidade nas análises e sugestões propostas. Além disso, faz-se necessário, especialmente nesta modalidade de curso, avaliar os impactos, já que um dos principais objetivos era trazer contribuições mais imediatas para a instituição e para o sistema de saúde. Alguns alunos 
afirmam que já há um bom nível de incorporação de várias propostas, algumas com impacto internacional, como é o caso da proposta para urgência e emergência.

Várias foram as sugestões relativas à importância de avaliar o nível de incorporação, pela instituição demandante, das propostas e análises consubstanciadas nas dissertações e a implementação concreta dos projetos, sintetizadas por exemplo no DSC6/6.

Outra sugestão que merece destaque é a de implementação de estratégias mais globais, numa perspectiva de política de formação de recursos humanos, visando à qualificação dos quadros do MS e para o SUS como um todo. Para tanto, acreditamos que seja importante repensar a pirâmide de formação de RH desde o doutorado, os mestrados (acadêmico e profissionalizante), os cursos lato sensu, articulando linhas de pesquisa e linhas de cooperação técnica complementares.

A sugestão do módulo de nivelamento poderia ser incorporada, por exemplo, à proposta da Ensp de articulação do MP ao lato sensu, considerando-se o primeiro ano de formação como possibilidade também de um curso de especialização, e o segundo ano com disciplinas complementares e defesa da dissertação. De todo modo, essa é uma discussão que precisa ser amadurecida. O curso deve ser desenhado especialmente para esse fim, e não é qualquer curso de especialização que poderá cumprir tal função. É importante ainda reafirmar a importância de cada nível de formação para o sucesso de política de RH que atenda de forma adequada às necessidades e desafios do SUS, embora nosso foco aqui seja o mestrado profissional. A experiência específica do MP da SAS/MS aqui relatada tem permitido reflexões críticas sobre a atuação da SAS e propiciado maior interação e discussão entre os vários departamentos que a compõem. As chefias dos principais departamentos participaram, em vários momentos, de discussões em sala de aula, e as oficinas de trabalho problematizaram temas referentes aos desafios estratégicos da missão institucional. Com a mudança de governo, depois das eleições para a presidência da República, novos desafios se constituíram e houve necessidade de uma nova pactuação em termos de prazos, objetivos, que resultou na adaptação e atualização na discussão de alguns dos temas de dissertações em andamento.

Para além da questão dos produtos finais/dissertações que devem refletir temas relacionados aos projetos e áreas de interesse da SAS/ Ms e do SUS, podemos destacar outras, como:

- O importante resultado/impacto do MP na ampliação de parcerias em vários projetos entre a Ensp e o MS, questão apontada nas entrevistas dos alunos.

- O impacto do MP na própria Pós-Graduação da Ensp e na própria Pós-Graduação em Saúde Coletiva, questão para a qual se chama a atenção em outro texto sobre o MP nos cenários da Ensp, também presente neste volume. 
Para finalizar, marcamos alguns desafios que merecem ser enfrentados:

- Avaliar de forma mais sistemática os produtos do MP e seus impactos.

- Aperfeiçoar o MP, considerando as sugestões e uma melhor pactuação entre a instituição demandante e a ofertante, visando a melhor alcançar os objetivos de formação de quadros estratégicos para o SUS.

- Aprender com a experiência e trazer para a Ensp e a área da saúde coletiva contribuições sobre critérios de avaliação, novas estratégias pedagógicas, entre outras importantes questões levantadas, como a necessidade de um enfoque amplo e interdisciplinar.

- Refletir sobre a política de RH do MS e o contexto em que estamos inseridos, repensando estratégias de formação de quadros estratégicos.

Portanto, embora possamos considerar a experiência aqui discutida como de relativo sucesso diante dos objetivos propostos, concluímos que os MPs devem ainda ser aperfeiçoados com vistas à construção de um modelo pedagógico que permita enfrentar os importantes desafios que se impõem, principalmente o de produzir impactos positivos em nosso Sistema de Único de Saúde.

Os produtos finais (dissertações defendidas) têm mostrado boa qualidade em sua maioria, trazido contribuições práticas para as políticas e projetos em andamento na SAS/MS e aumentado a capacidade crítica de reflexão e proposição, embora se destaque que mecanismos estratégicos de pactuação entre as instituições (demandante e ofertante) devam ser aperfeiçoados com vistas à maximização dos resultados.

\section{REFERÊNCIAS BIBLIOGRÁFICAS}

BECKER, H. S. Sobre metodologia. In: BECKER, H. S. Métodos de Pesquisa em Ciências Sociais. São Paulo: Hucitec, 1993.

BRASIL. CAPES. Portaria n. 47, de 17 de outubro de 1995. Programa de Flexibilização do Modelo de Pós-Graduação Senso Estrito em Nivel de Mestrado.

BRASIL. CAPES. Definição de mestrado profissionalizante. Disponível em: http://www.capes.gov.br/legislacao/index.html. Acesso em 25/3/2003.

BRASIL. CAPES. Portaria n. 48, de 16 de dezembro de 1998. Dispõe sobre o reconhecimento dos mestrados profissionais e dá outras providências. 
CRUZ NETO, O.; MOREIRA; M. R. \& SUCENA, L. F. M. Grupos focais e pesquisa social qualitativa: o debate orientado como técnica de investigação. Ser Social, 9:159. 186, jul.-dez. 2001.

ENSP.Coordenação da PósGraduação. Relatório de Avaliação do Curso deMP/SAS, maio 2003.

JODELET, D. Représentations sociales: un domaine en expansion. In: JODELET, D. (Org.) Des Représentations Sociales. Paris: PUF,1989.

LEFÈVRE, F. \& LEFÈVRE, A. M. C. O Discurso do Sujeito Coletivo: um novo enfoque em pesquisa qualitativa. Caxias do Sul: Educs, 2003.

LEFÈVRE, F. \& LEFĖVRE, A. M. C. \& TEIXEIRA, J. J. V. O Discurso do Sujeito Coletivo: uma nova abordagem metodológica em pesquisa qualitativa. Caxias do Sul: Educs, 2000.

MATUS, C. Política, Planejamento e Governo. Brasília: Ipea, 1993.

MINAYO, M. C. S. Introdução à metodologia de pesquisa social. In: MINAYO, M. C. S. O Desafio do Conhecimento: pesquisa qualitativa em saúde. Rio de Janeiro, São Paulo: Hucitec, Abrasco, 1992.

MINAYO, M. C. S. (Org.) Pesquisa Social: teoria, método e criatividade. Petrópolis: Vozes, 1994.

RICHARDSON, R. J. et al. 3. ed. Pesquisa Social: métodos e técnicas. São Paulo: Atlas, 1999.

THIOLLENT, M. J. M., 1982. O processo de entrevista. In: THIOLLENT, M. J. M. Crítica Metodológica, Investigação Social e Enquete Operária. São Paulo: Polis, 1982. 


\title{
GESTÃO DA INFORMACุÃO E COMUNICAÇÃO EM SAÚDE

\author{
DESENHO E IMPLEMENTAÇÃO DE UMA \\ PROPOSTA DE ENSINO-APRENDIZAGEM
}

\author{
Ilara Hämmerli Sozzi de Moraes \\ Miguel Murat Vasconcellos
}

\begin{abstract}
Talvez a condição mais premente da democracia, aquela que incide nas anteriores (...), seja a questão da informação. Seja qual for o estatuto econômico, a posição dentro de um sistema global de dependências sociais, um indivíduo participa da vida social em proporção ao volume è qualidade das informações que possui, mas, especialmente, em função de sua possibilidade de acesso às fontes de informação, de suas possibilidades de aproveitálas e, sobretudo, de sua possibilidade de nelas intervir como produto do saber.

Marilena Chauí, Cultura e Democracia: o discurso competente e outras falas, 1993
\end{abstract}

Desafio! Esta é a força motivadora do processo coletivo de construção do Mestrado Profissional de Gestão da Informação e Comunicação em Saúde(MPGICS) da Ensp/Fiocruz. Motivação suscitada tanto pelo caráter inovador da proposta quanto por seu potencial para atender a uma necessidade identificada no Sistema Único de Saúde (SUS), cumprindo mais uma vez o compromisso institucional com a melhoria das condições de saúde da população.

Inovação vinculada à responsabilidade com a gestão qualificada da saúde, a democratização dos saberes e o fortalecimento do controle social. Eis o compromisso do Mestrado Profissional de Gestão da Informação e Comunicação em Saúde: capacitar trabalhadores do SUS em um campo temático - informação e comunicação em saúde - cada vez mais estratégico para a 
melhoria da saúde da população, para maior efetividade de sua gestão e para a socialização dos conhecimentos produzidos, contribuindo para uma práxis em saúde calcada em intensa circulação de saberes, ampliando as bases para o exercício da participação da sociedade na definição da política de saúde no país. Seu caráter inovador está presente em, pelo menos, duas dimensões.

A primeira, inserida na delimitação do escopo da proposta, articula três campos de saberes: saúde, informação e comunicação. Historicamente, os conteúdos de cada um desses campos se constituíram em grandes domínios de conhecimento. Como trabalhá-los em um enfoque integrador sem negar suas especificidades? Quais são os pontos de inflexão entre esses saberes? Quais são os espaços de confluência entre os três campos, e o que os diferencia? Quais os resultados esperados em um processo de ensino-aprendizagem ao se adotar essa perspectiva articuladora? Essas são algumas das questões colocadas para o Grupo Técnico $(\mathrm{GT} / \text { Fiocruz })^{1}$ que elaborou a proposta do MPGICS.

Os componentes do grupo têm clareza de que essa experiência irá trazer subsídios para a própria constituição epistemológica das fronteiras/interseções entre esses campos, contribuindo com novas perspectivas para o cenário da produção do conhecimento no Brasil acerca da inserção do campo da informação e comunicação na saúde coletiva. Lena Vânia Pinheiro, já em 1999, afirmava:

A Ciência da Informação, a Comunicação e a Ciência da Computação formam um ângulo disciplinar altamente dependente da nova ordem tecnocultural, principalmente as duas primeiras, o que poderá, no futuro, levar à formação de uma disciplina com características transdisciplinares, do tipo Infocomunicação. (Pinheiro, 1999:177)

A saúde coletiva, por seu turno, vem historicamente se conformando também como um campo de saberes e práticas inter e transdisciplinar. O desafio do MPGICS é grande: adotar a inter e a transdisciplinaridade como marcos constitutivos e, ao mesmo tempo, fomentar o desenvolvimento de conhecimentos/estudos voltados para a solução prática de problemas das instituições de saúde, com a incorporação de tecnologias e inovações, ampliando a capacidade de intervenção e governança.

${ }^{1}$ Grupo Técnico da Fiocruz responsável pela elaboração da Proposta do Mestrado Profissional de Gestão da Informação e Comunicação em Saúde: Fernando Pires (Casa Oswaldo Cruz - COC), Ilara Hämmerli Sozzi de Moraes (Escola Nacional de Saúde Pública - Ensp), Ilma Noronha (Centro de Informação Científica e Tecnológica - Cict), Janine Miranda Cardoso (Cict), Miguel Murat Vasconcellos (Ensp). O grupo contou também com a consultoria da Profa. Dra. Maria Nélida González de Gómez (ECO/UFRJ e Ibict/MCT). 
A segunda dimensão inovadora refere-se à opção pela modalidade de Mestrado Profissional (MP), ainda que persistissem indagações em torno da forma de estruturação da modalidade, de sua regulação e de seus impactos sobre os cursos acadêmicos de pós-graduação quando o MPGICS começou a ser delineado em 2000. A perspectiva de ancorar o processo de ensinoaprendizagem nas questões enfrentadas pelas instituições de origem do corpo discente, com desenvolvimento de aplicações a problemas identificados como relevantes pelas organizações, mostrou-se extremamente coerente com o compromisso do GT/Fiocruz de contribuir para a melhoria da saúde da população no Brasil.

Desse modo, podese assim definir o objetivo do MPGICS: contribuir para qualificar e ampliar a capacidade das organizações daárea de saúde de dar respostas aos problemas e desafios postos pela sociedade brasileira, por meio da capacitação de seus profissionais para a gestão e o desenvolvimento de sistemas, redes, serviços, processos e produtos de informação e comunicação no âmbito da saúde, incorporando de forma crítica e criativa inovações relevantes para a melhoria de sua eficácia, eficiência e efetividade e para a apropriação mais equânime dos seus benefícios pelo conjunto da população brasileira. Cabe, também, destacar os seguintes objetivos específicos:

- Capacitar os alunos para enfrentar os problemas encontrados em sua atuação profissional, estimulando o desenvolvimento permanente de práticas inovadoras em seus espaços concretos de trabalho.

- Habilitar sujeitos para atuar de forma crítica na gestão das inovações tecnológicas e no desenvolvimento de soluções relacionadas ao planejamento e à implantação, gestão, operação e avaliação de politicas, sistemas e redes, serviços e atividades em informação e comunicação nos ambientes em saúde e em ciência e tecnologia em saúde.

- Capacitar os alunos para utilizar e promover o emprego dos recursos de informação, comunicação e tecnologias associadas nos processos de tomada de decisão.

- Capacitar os alunos para atuar em processos de informação e comunicação com a população e suas organizações, visando à democratização dos processos decisórios, tanto na formulação de políticas como na gestão de serviços e processos.

Com base nesses objetivos, definiu-se como público-alvo do MPGICS profissionais que atuam na gestão e otimização de fluxos, estruturas, processos, serviços e atividades de informação e comunicação em saúde e C\&T para a saúde.

Tanto a delimitação do escopo do MPGICS quanto sua modalidade e objetivos foram definidos em um amplo processo de discussão e reflexão coletiva, envolvendo diferentes atores inseridos em instituições de ensino e pesquisa bem como em sistemas e serviços de 
saúde vinculados ao SUS. Nesse percurso foi possível obter indicativos consistentes de uma grande demanda no setor Saúde por oportunidades de formação de pós-graduação nas áreas contempladas pela proposta, em especial em moldes profissionalizantes. É fruto de um longo processo de amadurecimento, em especial no que tange à sua inserção institucional. Nessa trajetória podem ser destacados os seguintes marcos:

- A inclusão da proposta de desenvolvimento do MP em pauta no Programa Integrado de Informação e Comunicação da Fiocruz.

- A deliberação da plenária do IV Congresso Interno da Fiocruz quanto ao desenvolvimento na Fiocruz de um programa de pós-graduação em informação e comunicação em saúde, proposta derivada da discussão em torno da implementação do MP.

Todo esse processo de interlocuções, interno e externo à Fiocruz, confirmou as evidências já identificadas (Moraes, 2002; Vasconcellos, Moraes \& Cavalcante, 2002) de que este MP se insere no esforço setorial de respostas a carências por formação de qualidade no conjunto do setor Saúde, como uma modalidade de pós-graduação adequada a tais necessidades. Quanto a esta questão, o Programa Integrado de Informação e Comunicação da Fiocruz assinala:

Ponto importante a ser considerado é a quase inexistência no país de iniciativas voltadas para a formação de profissionais de Informação e Comunicação em Saúde e CËT em Saúde, em especial no âmbito da pós-graduação. Sabidamente esta área se constitui num campo especifico de intervenção, de natureza diversificada no que tange a fenômenos e processos, em constante mutação, e que tem requerido crescentemente profissionais especializados. Compreende-se que esta carência compromete a atividade de pesquisa, sobretudo de caráter operacional ou aplicado, e o desenvolvimento de soluções. Entende-se que a Fiocruz, pela sua inserção institucional, pelo acúmulo de experiências e pela abrangência de suas frentes de atuação neste âmbito, deve ser protagonista de iniciativas voltadas para a supressão desta lacuna, o que se constituiria em agregação de um importante componente estratégico. (Fundação Oswaldo Cruz, 2003)

A inserção do MPGCIS na Escola Nacional de Saúde Pública se apóia: 1) no caráter de referência nacional da Ensp na pós-graduação em saúde pública; 2) na constituição anterior da modalidade de mestrado profissional; 3) na experiência docente acumulada no campo da informação e comunicação em saúde-Curso de Especialização em Informação e Informática 
em Saúde, ministrado desde 1991, disciplina Informação e informática em saúde no âmbito do mestrado/doutorado acadêmicos (ministrada desde 1993) e Curso de Especialização de Comunicação em Saúde (em conjunto Ensp e Centro de Informação Científica e Tecnológica - Cict); 4) na experiência de desenvolvimento científico e tecnológico - Grupo de Pesquisa do CNPq: Informação e Saúde; 5) no plantel de doutores credenciados para orientar alunos e 6) na existência, na Fiocruz e nas instituições parceiras, de um conjunto de atividades e serviços de referência em informação e comunicação em saúde como campo de desenvolvimento e aplicação de novos processos e produtos.

O entendimento institucional do escopo e da abrangência da saúde coletiva/saúde pública (Buss, 1999) define, ao mesmo tempo, os domínios de problemas, necessidades e demandas de informação e comunicação a serem atendidos pelos objetivos, conteúdos e orientações pedagógicas do curso: a gestão da saúde, a promoção da saúde e a ciência e tecnologia em saúde, colocando-as a serviço da atenção à saúde disponível com eqüidade e qualidade para os cidadãos.

\section{INFORMAÇÃO E COMUNICAÇÃO EM SAÚDE: CAMPO TEMÁTICO ESTRATÉGICO PARA A TOMADA DE DECISÃO}

Pactos internacionais estabelecidos (United Nations, 2002) e pressões políticas e econômicas internas impõem, diante das profundas desigualdades sociais e econômicas que agravam os problemas de saúde prevalentes no Brasil (Fundação Getúlio Vargas, 2001; UNDP, 2002), a necessidade de uma ampla e consistente capacidade de intervenção, alcançada com a qualificação da força de trabalho das instituições de saúde e a incorporação ágil e efetiva de resultados de pesquisa e desenvolvimento tecnológico ao processo de tomada de decisão em torno das políticas e ações de saúde.

Esses desafios demandam respostas do Estado brasileiro, que, para tal, precisa estar suficientemente capacitado e informado sobre o emaranhado de questões que envolvem os problemas a serem superados. É nesse contexto que a gestão da informação e comunicação em saúde se insere como estratégica para o desenvolvimento e a consolidação da capacidade de intervenção das organizações em contextos sociais em mudança. Assim, capacitar os profissionais que atuam na gestão e otimização de fluxos, estruturas, processos, serviços e atividades de informação e comunicação em saúde e $C \& T$ para a saúde torna-se pré-requisito para o salto de qualidade necessário. 
O desafio apresentado é estruturar um processo de ensino-aprendizagem que atenda a esse pré-requisito, em um campo de atuação profundamente modificado pela dinâmica de implementação do SUS e de incorporação de novas tecnologias com forte impacto no processo de trabalho. Essas transformações impõem a necessidade de profissionais com perfil de qualificação altamente especializada, com capacidades e habilidades relacionadas com 1) a identificação das tendências dos processos de mudança em seus contextos de atuação; 2) a permanente atualização conceitual, metodológica e tecnológica e 3) a aplicação prática desses recursos na superação de problemas gerenciais, organizacionais e operacionais concretos de ordem gerencial, organizacional e operacional em sua prática profissional.

Para atender a esse desafio, é importante também que se desenvolvam as seguintes competências: 1) conhecimento e compreensão dos domínios de problemas do campo da saúde e de ciência e tecnologia em saúde e de suas condições de resolução; 2) reconhecimento e incorporação crítica dos conhecimentos e tecnologias de informação e comunicação, politicamente contextualizados e praticamente eficazes para enfrentar os problemas comunicacionais e informacionais desses domínios; 3) capacidade de promover a busca de soluções e de mudanças concretas nas práticas institucionais. São essas competências que o MPGICS objetiva desenvolver e expandir num amplo setor de práticas profissionais, de forma coerente com os compromissos institucionais de excelência acadêmica e universalidade democrática, em um processo sinérgico, contínuo e ampliado de fomento/indução de um salto de qualidade nos processos de gestão da saúde e da informação e comunicação no país.

A modalidade de Mestrado Profissional em Gestão da Informação e Comunicação em Saúde está orientada para atender a essa crescente demanda detectada no setor Saúde, que se expressa na Fiocruz, no âmbito do SUS e nas instituições de C\& T em saúde. Ao propiciar a articulação das experiências práticas dos profissionais-alunos com os conhecimentos atualizados, a contextualização política e a inovação tecnológica tornam-se uma alternativa para agilizar a incorporação dos conhecimentos científicos e tecnológicos na cultura e no processo decisório das instituições em saúde. O rigor na obediência à definição de que os trabalhos finais dos alunos necessariamente devam versar sobre problemas/soluções identificados como prioritários pelas organizações vem impondo um círculo virtuoso que aproxima os sistemas e serviços de saúde do sistema de pesquisa e ensino em saúde.

Nesse contexto, o principal resultado a ser alcançado é a transformação do conhecimento produzido no decorrer do MPGICS em novas e melhores intervenções e ações de saúde nas instituições de origem dos profissionais-alunos. Articulam-se, desse modo, a pesquisa, o 
ensino e o sistema e serviços de saúde, estabelecendo-se uma sinergia criativa e produtiva que traz benefícios para o cidadão.

A proposta do MPGICS parte da premissa que o 'melhor ensino' está diretamente relacionado à 'melhor pesquisa' e vice-versa. Daí o cuidado redobrado com os orientadores dos alunos, que são selecionados tendo como critério o vínculo existente entre o objeto de estudo do trabalho final dos alunos (problema/solução de questão prioritária para a organização) e a linha de pesquisa desenvolvida pelo orientador.

Morel (2004:266) afirma que "a transformação da pesquisa em ações de saúde - from bench to bed to bush - é um processo complexo, árduo, dispendioso, e algumas vezes extremamente demorado". A hipótese aqui adotada é que a modalidade de mestrado profissional, desenvolvida nos moldes propostos pela experiência do MPGICS, pode se apresentar como uma das alternativas que contribuirão para tornar esse processo menos árduo, dispendioso e demorado, apesar de complexo.

Ao articular as necessidades das organizações de origem do corpo discente e os interesses dos alunos às linhas de pesquisa dos orientadores, em um processo de ensino/aprendizagem focado na solução de problemas, talvez a proposta do MPGICS esteja próxima do que Sauerbon e colaboradores (1999, apud Morel, 2004) suscitam, ao afirmarem que somente quando as necessidades de todos os atores são levadas em consideração, desde a fase inicial de planejamento até a implementação dos projetos e disseminação dos resultados, é que a pesquisa (desenvolvimento tecnológico) tem alguma chance de influenciar as políticas de saúde.

De fato, o que está subjacente a essa proposta é um novo modo de 'fazer pesquisa e ensino' aliado a um novo modo de 'implementar ações em saúde e de tomada de decisão'. A idéia aqui esboçada é que a modalidade de mestrado profissional propicia um espaço fecundo de construção conjunta (pesquisa - ensino - intervenção em saúde) que permita atender aos objetivos e interesses dos atores desta tríade.

O profissional-aluno conhece o modus faciendi da organização em que trabalha ou que gerencia, os interesses em disputa, os atores sociais atuantes e quais as questões substantivas envolvidas na tomada de decisão institucional. Essa experiência acumulada está presente no diálogo com o corpo docente e principalmente com o orientador, que formaliza essa interlocução empregando métodos e técnicas originados de seu trabalho de pesquisador.

No MPGICS está prevista uma etapa, acompanhada pela coordenação do curso e pelo orientador (esteé convidado), de apresentação e discussão do produto final, depois de cumpridas as exigências regimentais (qualificação, defesa pública oral do trabalho final e aprovação por banca de doutores), para o corpo diretivo da instituição do aluno. Esse momento constitui-se 
em marco inicial (e não final) de um processo contínuo de interlocuções entre a instituição de ensino/pesquisa e o sistema e serviços de saúde, com o objetivo de contribuir para a apropriação do conhecimento produzido no processo de gestão institucional.

Para tal, a proposta pedagógica do MPGICS adota modelos de ensino-aprendizagem que favorecem a articulação dos conteúdos didáticos propostos com os processos de trabalho no quais os alunos estão inseridos, de tal forma que o resultado final se caracterize pelo desenvolvimento de competências adequadas e aplicáveis em processos de mudança nas instituições de origem do corpo discente. Fortalece-se, assim, a constituição de redes de conhecimento social que incorporem e gerem soluções de problemas vivenciados nas instituições, com modelos apropriados de utilização das novas tecnologias de informação e comunicação, conforme os fins éticos e políticos de uma concepção democrática e responsável no campo da saúde pública e da ciência e tecnologia em saúde.

\section{A ARTICULAC̣ÃO DE PRÁTICAS E SABERES NA BUSCA DA SUPERAÇÃO DA LÓGICA FRAGMENTADORA}

O avanço da democracia, com igualdade entre os homens e justiça social, não se resume à informação, mas, necessariamente, passa por ela. Esse entendimento significa mais um desafio para o Estado brasileiro: assumir, como compromisso, a ampliação dos espaços democráticos em sua práxis. Um dos componentes fundamentais nesse processo éo papel do Estado no fomento a amplos processos de desenvolvimento científico-tecnológicoeducacional.

O campo temático da informação e comunicação em saúde, como visto anteriormente, é estratégico para a melhoria da saúde da população brasileira. Qual o papel do Ministério da Saúde, do Ministério de Ciência e Tecnologia e do Ministério da Educação nesse processo? É importante a construção de mecanismos que permitam pactuar uma agenda de prioridades entre todos os atores envolvidos, nos moldes da I e da II Conferências Nacionais de Ciência e Tecnologia em Saúde, realizadas em 1994 e 2004, respectivamente. Nessa agenda devem estar estabelecidas as metas a serem alcançadas no que se refere à informação e comunicação em saúde, enfrentando: 1) a defasagem de apropriação pelos sistemas e serviços de saúde dos avanços tecnológicos da informação, comunicação e tecnologias associadas e 2) a dissociação entre a formação da força de trabalho especializada (em todos os níveis) e as necessidades do SUS, de modo a ampliar a 'massa crítica' de profissionais inseridos nas instituições de saúde.

Ao se adotar a expressão 'tecnologias associadas à informação e comunicação' ou 'informática em saúde', cabe uma breve reflexão em torno dessas denominações. Conforme 
Mac Dougall e Brittain, a "informática em saúde" designa a gestão da informação que se origina no uso sistemático de dados na administração e provisão de serviços de saúde; a "informática médica" refere-se ao uso de tecnologias de informação e computação no diagnóstico e tratamento de doenças:

There has been much confusion and misunderstanding over the terms 'medical informatics' and 'health informatics'. Health informatics is the new term for healthcare information management, originaing in the systematic use of data to manage and provide health services. Medical informatics, in the strict sense of the term, has a longer history, involving the use of IT and computing for the diagnosis and treatment of disease (e.g. x-rays, imaging, magnetic resonance, scanning magnetic techniques, molecular design and receptor site modeling, eletrophisiology). (Mac Dougall \& Brittain, 1994:183)

Outros associam, estabelecendo entre elas uma relação interdisciplinar, a informática aplicada à saúde com as ciências da informação e da tecnologia da informação, orientadas para o benefício global de pacientes, cientistas, administradores e outros prestadores de serviços envolvidos em todas as categorias de atividades referentes ao cuidado da saúde, médicas e não médicas. Lunin \& Ball (citados em Mac Dougall \& Brittain, 1994:184) adotam uma definição ampla de informática aplicada à saúde, visando a incluir assuntos relacionados à informação, assim como a formação de recursos humanos no uso das novas tecnologias.

No âmbito do MPGICS, 'tecnologias associadas à informação e comunicação' ou 'informática em saúde' constituem uma área de conhecimentos, metodologias e competências tecnológicas que se diferencia da informática médica e se associa, por seus produtos e destinação, à política, gestão e promoção da saúde, em uma abordagem ampla, para além de uma visão focada em aplicações voltadas para o pensamento clínico.

Nessa perspectiva, o grande desafio não está apenas na construção e incorporação de grandes bancos de dados, de dispositivos de manipulação de grandes volumes de informações nem, ainda, na disponibilização de tecnologias de acesso e meios de comunicação. $\mathrm{O}$ desafio maior encontra-se 1) na mudança das práticas subjetivas, orientadas para o uso e compartilhamento das informações; 2) na valorização da informação e da comunicação como configuradoras de formas mais eficazes, responsáveis e democráticas de intervenção profissional e 3) na convicção das organizações e seus gestores acerca do valor estratégico da informação e da comunicação na tomada de decisão e no desenvolvimento de programas de ação/ projetos de governo/políticas públicas capazes de coordenar diferentes atores e interesses, em ambientes complexos em mudança. 
Há importantes iniciativas específicas de fomento ao desenvolvimento da pesquisa e do ensino para a saúde, para a informação e para a comunicação, mas para abordagens que articulem esses três grandes campos, elas são ainda incipientes. Entretanto, estudos (Moraes, 2002; Vasconcellos, Moraes \& Cavalcante, 2002) indicam que a articulação inter e transdisciplinar é a que vem se consubstanciando como a de maior potencial de efetividade para o SUS. Observam-se dificuldades de compreensão na própria delimitação de campos transdisciplinares. A mudança ou enriquecimento informacional e comunicacional das práticas subjetivas e organizacionais requer, ao mesmo tempo, o domínio intelectual e tecnológico de modelos, metodologias e procedimentos de tratamento e disseminação das informações, assim como da comunicação organizacional e social. Tais capacidades são necessárias para facilitar tanto o uso seletivo e crítico das informações como a incorporação de procedimentos horizontais e eficazes de exercício comunicativo nas práticas em saúde e na tomada de decisão.

Nesse quadro, a integração de recursos, tecnologias e meios de informação e comunicação é uma demanda crescente nos diferentes contextos sociais, políticos, econômicos e, de maneira muito especial, no campo da saúde e do desenvolvimento científico e tecnológico no setor. A proposta do campo temático 'gestão da informação e comunicação em saúde' visa à formação de novos gestores capazes de responder às expectativas e às demandas de informação e comunicação em saúde - as atuais, as reprimidas, as emergentes - nesses novos cenários.

Os desafios a que devem atender os profissionais reúnem conhecimentos e aptidões no campo da saúde, da informação e da comunicação que podem ser caracterizados por três grandes 'domínios de problemas'/questões e demandas. A 'orientação por domínios' é uma abordagem adotada nos estudos da ciência da informação e da educação. Caracteriza formas de organizar ou descrever conhecimentos e agregados informacionais que não respondem unicamente às categorias analíticas de classificação disciplinar, mas compõem, a partir de diferentes fontes e saberes, unidades significativas para o desenvolvimento de atividades sociais concretas, para o diagnóstico e resolução de problemas em sua área de intervenção. $\mathrm{O}$ conhecimento e a informação são olhados em contextos amplos de desenvolvimento e aplicação (Hjorland, 1995; Hjorland \& Albrechtsen, 1997). Com esse referencial, o MPGICS organiza-se a partir dos seguintes domínios de problemas:

1 - Os ambientes tradicionalmente identificados às atividades de produção do conhecimento e ao desenvolvimento científico e tecnológico em saúde.

A exemplo de outros domínios científico-tecnológicos, esses ambientes vêm sendo impactados por transformações recentes que modificam seus princípios organizadores e apon- 
tam para a centralidade, em seu interior, dos fenômenos e processos de informação e de comunicação. Alteram-se com rapidez e se tornam crescentemente complexos os processos de informação e comunicação científica em todo o ciclo de produção e disseminação do conhecimento e de suas aplicações: na mediação de formas cooperativas de pesquisa e desenvolvimento entre instituições científicas e entre estas, o Estado e agentes empresariais privados; na formatação e gestão editorial de periódicos científicos; na aquisição, armazenamento, representação e disseminação de informação científica atualizada; na representação, armazenamento e manejo de coleções científicas e de registros resultantes do processo de pesquisa, do controle da qualidade, da proteção de direitos de propriedade intelectual; na constituição e uso de acervos de fontes históricas; na divulgação de resultados, entre outros âmbitos que poderiam ser mencionados.

Cresce a importância também das mediações entre a ciência e a sociedade, seja pelas implicações sociais e visibilidade pública dos desenvolvimentos recentes em áreas como modificação transgênica de alimentos, genética humana, segurança biológica e políticas públicas de medicamentos, seja porque as agendas estratégicas em C\&Te inovação passam a valorizar, cada vez mais, os aspectos combinados de divulgação e educação em ciência como fundamentais para a constituição de uma cultura científica e tecnológica coletivamente compartilhada e para a própria governança participativa da ciência e tecnologia (MCT, 2001).

2 - As mudanças e tendências trazidas pelas tecnologias da informação potencializam o apoio às decisões em estruturas colegiadas de gestão e mesmo em estruturas gerenciais dos sistemas e serviços em saúde. No entanto, ainda persiste a reduzida utilização das informações no processo decisório em saúde pública, apesar da existência de grande número de dados, de indicadores consensualmente definidos e de diversos sistemas de informações de saúde implementados (Moraes, 1994; Vasconcellos, Moraes \& Cavalcante, 2002). Mesmo considerando o incremento da disponibilização desses dados e indicadores em anos recentes, a preocupação com este problema continua procedente, basicamente por dois motivos. Em primeiro lugar, porque a dificuldade em acessar aos dados existentes e em tratá-los rotineiramente impede que as informações adequadas estejam disponíveis no momento necessário. Em segundo lugar, porque ainda não se efetuou a necessária articulação dos processos de planejamento e de gestão da saúde com os sistemas de informações e com os indicadores existentes. Portanto, permanecem desarticulados o acompanhamento dos indicadores de saúde, a gerência dos sistemas de informação e o monitoramento dos processos de planejamento e de gestão. 
O ritmo acelerado de mudanças, próprio das novas tecnologias de informação, também está presente nesse quadro, trazendo para profissionais e instituições o desafio de trabalhar com tecnologias inconstantes, passíveis de rápida defasagem. Portanto, na estruturação de sistemas de informação é preciso pensar em formas de incorporar mudanças futuras e manter-se em constante atualização (Vasconcellos, Moraes \& Cavalcante, 2002). Essa tarefa complexa, pouco trivial, é um dos motores do presente mestrado profissional. Assim, com foco na integração das informações, pretende-se contribuir para articular as tecnologias de informação, tecnologias de saúde e tecnologias gerenciais, ampliando as bases de seu uso na gestão do Sistema Único de Saúde (SUS), voltadas para instrumentalizar a tomada de decisão e o processo de controle social.

Com uma necessidade de abordagem claramente interdisciplinar, essa integração precisa ser considerada com base em múltiplos aspectos relacionados às tecnologias de informação, como: 1) sistemas automatizados de gestão; 2) sistemas distribuídos com ampla possibilidade de articulação de cadastros - de serviços de saúde, ambientais, recursos humanos e populacionais, inclusive o Cartão SUS -, de eventos e registros da área da saúde (óbitos, nascimentos, atendimentos; prontuário eletrônico, notificação compulsória de doenças), e aqueles de outra natureza, em caso de incorporação de questões intersetoriais; 3) ferramentas automatizadas potentes para modelagem de dados sociais, epidemiológicos e financeiros; 4) sistemas de informações geográficas voltados para a estatística espacial e para modelos de regionalização/hierarquização de serviços e 5) internet, como agregadora de tecnologia e disseminadora de informações.

3 - Nas últimas décadas também são mais intensivas as relações e intercâmbios entre as ciências da saúde e as demandas sociais visando a um compromisso maior com a reformulação emancipatória do valor educacional e democrático da comunicação e da informação. A partir da Constituição de 88, com a implementação dos Conselhos de Saúde, vai sendo gerada uma vasta malha de relações entre a cidadania, o Estado e os serviços de saúde, que abrange hoje toda a escala geográfica do poder, da esfera federal à municipal. Com o alargamento dos espaços de participação, intensificaram-se não só as demandas por acesso às informações oficiais, recursos e tecnologias, mas também a busca pelo reconhecimento e legitimidade de outros saberes e fontes de informação de que se vale a população. Esse processo envolve, simultaneamente, pressões para que as posições e reivindicações de diferentes movimentos e segmentos sociais tenham maior visibilidade na cena pública, particularmente na mídia.

Atualmente, o fortalecimento das demandas democráticas de compartilhamento e articulação de interesses e demandas ocorre num contexto de acelerada convergência entre o que 
tradicionalmente se compreende como comunicação de massa (a imprensa, o rádio e a TV) e os sistemas de telefonia e computação (telecomunicações). Em conseqüência, deve ser pensada a necessidade não apenas de estreitamento da articulação entre os campos da informação e da comunicação em saúde, mas de articulações entre tecnologias de informação e comunicação a serem consideradas e incorporadas ao setor da saúde, sempre atendendo às demandas sociais de transparência, controle social e maior participação na tomada de decisão e na elaboração de políticas, como forma de garantir a construção da eqüidade em saúde.

Essa ampla e complexa abordagem organizada nos três grandes domínios de problemas/questões e demandas constitui um importante desafio para o avanço do SUS no Brasil e, por seu caráter inovador, requer, nessa etapa, uma política efetiva de fomento para as iniciativas se consolidarem.

Essa abordagem foi adotada pelo MPGICS por ter sido considerada a mais adequada para atender às expectativas e demandas do MP e às motivações da proposta; assim, optou-se por organizar o currículo com base nesses 'domínios de problemas' relacionados com as áreas de atuação dos profissionais/alunos. Os domínios de problemas definem a trajetória curricular do curso, desde o processo seletivo até o desenvolvimento do seu projeto, requerido como produto final do mestrado profissional. Os três domínios de problemas aqui tratados podem ser sintetizados da seguinte forma:

- O domínio de problemas de informação e comunicação associados às atividades de ciência e tecnologia em saúde.

- O domínio de problemas de informação e comunicação das organizações e serviços em saúde, de atendimento em saúde, de gestão, regulação e monitoramento da saúde; administração pública da saúde e agências especializadas do Estado.

- O domínio de problemas de informação e comunicação da saúde, em diferentes contextos sociais - coletivos e organizacionais -, com base em questões e ações voltadas para a interlocução entre saberes da saúde e saberes da população: saúde, comunicação e sociedade.

Procura-se, desse modo, dar conta de dois tipos de condições: umas próprias da demanda de maior transversalidade interdisciplinar e de articulação entre os conhecimentos e as práticas - as quais requerem atividades curriculares comuns; outras, resultantes da singularidade e complexidade dos problemas e demandas - que solicitam desdobramentos curriculares diferenciados e específicos.

Considerando essa situação, a estrutura curricular distribui atividades e experiências em alguns módulos ou 'espaços' curriculares, todos igualmente obrigatórios para os mestrandos, 
nos quais são equilibradas as ofertas de disciplinas e outras atividades de caráter comum, que terão como fim atender aos objetivos de vinculação e convergência entre os saberes e as práticas profissionais diversas, junto às ofertas de outros conteúdos científico-tecnológicos, metodologias e práticas, organizados em função do projeto específico que motiva e justifica o ingresso do profissional no MPGICS, engajando-o num domínio concreto de ação, demandas de inovação e tratamento de problemas.

Essa organização amplia as possibilidades de o MPGICS contemplar os mais diversos problemas e questões apresentados pelas organizações de origem dos profissionais-alunos, $\mathrm{O}$ que por sua vez potencializa a capacidade de seus produtos/resultados efetivamente responderem às necessidades do SUS, tornando-se estratégico, ao articular pesquisa, ensino e gestão da saúde, para o salto de qualidade que se impõe como premente.

\section{PENSAR, CRIAR, AGIR: O FAZER COLETIVO E SOLIDÁRIO DO MPGICS NA CONSTRUÇÃO DOS ESPAC̣OS CURRICULARES}

Desafios complexos pressupõem um "agir comunicativo" (Habermas, 2002) entre os atores envolvidos, para que sejam superados em toda a sua potência. Do mesmo modo amplificam-se suas possibilidades se o "agir" estiver alicerçado em um pacto calcado na solidariedade e não na competitividade, no qual a participação dos envolvidos é fundamental em todas as etapas.

Deve-se ainda acrescentar, como parte desse trígono, a opção por uma ética da responsabilidade (Jonas, 1974) pautando as ações dos partícipes na busca do cumprimento dos compromissos assumidos diante dos desafios que se quer superar.

Esses três marcos (agir comunicativo, pacto da solidariedade e ética da responsabilidade) constituem as referências em que o GT que elaborou a proposta do MPGICS encontrou as fontes orientadoras para a dinâmica de construção, implementação e gestão do curso. A avaliação realizada pelo corpo docente e discente da primeira turma (2003) indica que foi válida a adoção desses marcos referenciais.

Procurando manter coerência com eles, compartilham-se aqui mais algumas características de sua trajetória, objetivando o intercâmbio de idéias e experiências na expectativa de que suscite críticas e sugestões que certamente contribuirão para o aprimoramento do MPGCIS.

A adoção da premissa de que o MPGICS deve potencializar a interação entre pesquisa, ensino, processo decisório e gestão de sistemas e serviços de saúde impõe que o processo ensino-aprendizagem contemple novos formatos de atividades docente-didáticas. 
O pensar/criar em torno desses novos formatos teve como pontos de partida: a) as propostas do Grupo de Trabalho do MPGICS e da Oficina de Trabalho ocorrida em Petrópolis, em 2001, com o objetivo de discutir a proposta do MPGICS; b) outras experiências institucionais, tais como o Curso de Especialização de Informação e Informática em Saúde, da Ensp, e o Curso de Especialização de Comunicação em Saúde(Ensp e CICT)e c) as demandas das organizações de origem do corpo discente, bem como o perfil dos alunos selecionados.

Foram utilizadas, ao mesmo tempo, como fontes de consulta, diferentes currículos e análises de pós-graduação e formação profissional nas áreas envolvidas na proposta, entre os quais: 'Statement from the Ucla Department of Information Studies on LIS curricula for the ALA Congress on Professional Education', apresentado por Márcia J. Bates, 1999; 'Recomendations of the International Medical Informatics Association (Imia) on education in health and medical informatics', 1999; 'Competencies for special librarians of the 21 ${ }^{\text {st }}$ Century-SLA', 1996; a programação do Master of Library \& Information Science-MLIS, da Faculty of Information and Media Studes, Ontário, Canadá, 2001; os currículos de programas de pós-graduação de biblioteconomia e ciência da informação e de comunicação das universidades brasileiras, tais como os da UFRJ, UFBA, assim como de outros mestrados em saúde pública.

Do ponto de vista formal, as atividades curriculares estão distribuídas nas categorias abaixo relacionadas, podendo adotar-se, em cada caso, as estratégias e os modelos pedagógicos mais adequados a cada convocatória do MPGICS:

- Disciplinas: podendo ser específicas ou gerais, atendem a uma temática, abordagem e conteúdos sistematizados, correspondentes a áreas do conhecimento relativamente consolidadas e organizadas, ministradas em aulas expositivas, palestras, dinâmicas de grupo, debates e aulas práticas.

- Seminários: constituem espaços de integração e interlocução em torno de temas que requerem um tratamento transversal e simultâneo por diferentes áreas do conhecimento, experiências e abordagens. Têm como objetivo e abordagem a articulação dos conteúdos teóricos e metodológicos com o campo de aplicação correspondente, através de diferentes atividades que contribuam para o desenvolvimento coletivo e individual dos projetos dos mestrandos.

- Laboratórios e estágios: têm como objetivo a aquisição e o desenvolvimento de habilidades e competências específicas do ponto de vista técnico-funcional, sendo realizados nos campos de aplicação, seja dentro das atividades institucionais da Fiocruz (Ensp, Cict, COC, outros) ou em parceria com outras instituições e agentes (Centro Latino- 
Americano e do Caribe de Informação em Ciências da Saúde - Bireme, Scientific Electronic Library Online-SciELO, SUS, entre outros).

- Desenvolvimento de projetos: atividades relacionadas ao desenvolvimento de projetos realizadas, total ou parcialmente, em laboratórios e em outros contextos organizacionais, conforme demandarem o projeto e o domínio de aplicação dos produtos e/ou resultados esperados. Inclui, entre outras atividades, reuniões de orientação, seminários, oficinas e as atividades de pesquisa e desenvolvimento pertinentes aos projetos individuais dos mestrandos.

A estrutura curricular/programática está organizada em três módulos complementares: Integração, Transição e Orientado aos projetos. Esses módulos estão articulados de forma a contemplarem os três domínios de problemas. A Figura 1 ilustra essa estruturação:

Figura 1 - Estrutura curricular/programática

\begin{tabular}{|c|c|c|}
\hline Domínios de Problemas & \multicolumn{2}{|c|}{$\begin{array}{l}\text { Conhecimentos, Metodologias, } \\
\text { Habilidades e Competências }\end{array}$} \\
\hline Ciência e tecnologia em saúde & Módulo de integração & 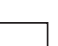 \\
\hline Sistemas e serviços em saúde & Módulo de transição & - \\
\hline Saúde, comunicação e sociedade & Módulo orientado aos projetos & - \\
\hline \multicolumn{2}{|c|}{$\downarrow$} & $\checkmark$ \\
\hline \multicolumn{3}{|c|}{ DESENVOLVIMENTO DO TRABALHO FINAL } \\
\hline
\end{tabular}

O módulo de integração trata de forma articulada os conhecimentos, abordagens e competências pertinentes aos três campos científicos que se articulam nesta área de concentração (saúde, informação, comunicação), procurando ampliar a compreensão dos problemas e do contexto onde se insere o corpo discente. Inclui disciplinas, seminários e dinâmicas comuns a todos os alunos, tendo como objetivo atualizar e ampliar os quadros teóricoconceituais dos especialistas participantes, favorecendo a circulação, o confronto e a reformulação de seus pontos de partida.

O módulo de transição realiza uma passagem dos conteúdos mais gerais aos mais específicos. Essas disciplinas estão divididas em conteúdos comuns e conteúdos específicos. Enfatizando as interfaces, tratará, ao mesmo tempo, de teorias, metodologias e modelos referentes a funções e dimensões comuns aos processos de produção de conhecimento, de informação e de comunicação, e dos desdobramentos dessas grandes dimensões e funções nos domínios de atividades e problemas da saúde (ICT, sistemas e serviços, comunicação). 
O módulo orientado aos projetos refere-se à execução e apresentação do projeto final do mestrando. $\mathrm{O}$ resultado esperado, de caráter tanto conceitual e crítico quanto prático e aplicado, é o seu princípio organizador. O desenho pedagógico e curricular foi elaborado para possibilitar o desenvolvimento de dissertações e/ou projetos orientados para a aplicação prática de metodologias, modelos, aplicativos, ferramentas, assim como para seu desenvolvimento ou adaptação ao campo da saúde e da ciência e tecnologia em saúde, tendo como resultado desejável um produto, ferramenta, aplicativo, sempre acompanhado da documentação textual e argumentativa de seus processos de produção.

Culmina assim o encaminhamento progressivo do currículo em direção às diferentes dinâmicas e espaços de aprendizagem prática (laboratórios e estágios), além das atividades próprias de desenvolvimento de projeto (tais como a participação em oficinas, reuniões com $\mathrm{o}(\mathrm{s})$ orientador(es) de projeto, e outras tarefas próprias ao desenvolvimento do estudo), das quais os alunos participam em função de seu projeto final.

Conforme as regras gerais do MP em Saúde Pública/Ensp, a duração do curso é de no mínimo 18 meses, distribuídos em trimestres (do primeiro ao quarto com atividades conjuntas com a turma e os demais trimestres - quinto e sexto - para elaboração do trabalho final), com dedicação parcial; admite-se uma prorrogação de mais três meses, de modo a perfazer, no máximo, 21 meses. O total de horas teórico-conceituais, seminários, laboratórios, estágios e elaboração do produto final é de 1.530 horas. O sétimo trimestre está previsto apenas se necessário, a critério do orientador, para conclusão do trabalho final. Nessa hipótese, o total será de 1.755 horas.

O modelo de distribuição das atividades de ensino-aprendizagem é definido em comum acordo com as instituições de origem dos alunos, levando-se em conta a dinâmica de trabalho das organizações e o impacto financeiro que garanta a viabilidade da manutenção dos alunos de fora do estado do Rio de Janeiro, onde se situa a Ensp. A alternativa que tem se apresentado, até o presente momento, como a mais adequada é a que concentra as aulas em uma semana por mês. De fato, o período que exige a presença física do aluno se restringe a quatro trimestres, pois os demais estão diretamente vinculados às atividades de elaboração do produto final, e por isso possuem dinâmica específica em seu desenvolvimento, definida pelo orientador, o aluno e a coordenação do curso.

A orientação é um fator fundamental no desenvolvimento desta proposta, pois seu sucesso depende da constante interação de saberes científicos e tecnológicos em atividades intensivas na demanda por conhecimento e informação, em contextos concretos, histórica, cultural, econômica e politicamente definidos de atividades e situações do setor Saúde, hoje, e em especial do SUS em seu atual estágio de implementação no país. 
Há a possibilidade de contar com uma dupla orientação, analisada pela qualificação profissional reconhecida e pela total afinidade entre seu domínio de competência e o projeto a ser desenvolvido pelo mestrando. O segundo orientador poderá, quando assim for definido pelas coordenações pertinentes, ser um profissional externo à Ensp e à Fiocruz, representativo de instituições e empreendimentos de interesse para o desenvolvimento do projeto. São estabelecidas então, com esse fim, diferentes formas de parcerias, consórcios, convênios.

Do mesmo modo, tendo em vista os objetivos deste mestrado, é importante garantir que seu corpo discente seja formado por alunos comprometidos com a transformação das práticas profissionais em que estão envolvidos. São ofertadas vintevagas, mas, em sua primeira turma (2003), foram selecionados 16 profissionais dos 35 inscritos, todos inseridos na Fiocruz (a instituição demandante), considerando um processo seletivo fundamentado na análise: das respostas elaboradas a partir de prova; do pré-projeto do candidato, indicando o tema ou problema a ser investigado, o produto esperado, a relação com sua prática profissional e seu potencial inovador; da carta da instituição formalizando o apoio, apresentando o candidato e explicitando o interesse no desenvolvimento do projeto; do currículo do candidato; da entrevista.

\section{AVALIAÇÃO CONTÍNUA: PRÉ-REQUISITO PARA O ALCANCE DOS RESULTADOS ESPERADOS}

Manter um processo contínuo de interlocução entre a coordenação do curso, coordenadores das disciplinas, corpo discente e orientadores significa ampliar as possibilidades de alcance dos resultados esperados. Essa é a dinâmica de trabalho que vem caracterizando a gestão do MPGICS, desde o próprio planejamento dos conteúdos das disciplinas, debatidos com os docentes em oficinas de trabalho realizadas antes do início das aulas, nas quais, a partir do perfil dos selecionados, definiu-se por uma melhor adequação da proposta inicial com a realidade do corpo discente constituído.

Esse processo de busca de maior adequação entre a prática dos alunos e os principais interesses das organizações de origem com o conteúdo das disciplinas tem sido contínuo, em diálogo permanente dos coordenadores de disciplina com a coordenação do MPGICS, bem como por iniciativa dos próprios coordenadores de disciplinas em entendimentos com os alunos.

A marca de um trabalho coletivo está presente em todas as etapas - elaboração da proposta, seleção do corpo discente, definição de grade curricular e um rigoroso processo de seleção dos doutores-orientadores -, pelo cuidado em garantir a circulação comunicativa de saberes e interesses que potencializem a apropriação da produção de pesquisas dos orientadores e a 
produção do conhecimento fruto do processo de ensino-aprendizagem pelas instituições de origem do corpo discente.

Do mesmo modo, a organização dos seminários de integração e a seleção dos espaços mais adequados como laboratórios e estágios vêm recebendo um acurado tratamento, com a preocupação de tornar os alunos mais efetivos na elaboração de produtos finais com alto grau de qualidade e utilidade para as suas organizações de origem.

Apresentam-se a seguir alguns indicativos úteis para um processo de avaliação da primeira turma do MPGICS (2003), tais como o cumprimento do cronograma, com as disciplinas tendo sido ministradas conforme o planejado, e o cumprimento, por parte do corpo discente, do prazo determinado para realização das tarefas propostas pelo corpo docente, o que denota também o elevado grau de entendimento e interlocução dos alunos com os professores, bem como a adequação da proposta pedagógica construída.

Todo o processo de ensino-aprendizagem transcorreu em um clima de profundo enriquecimento mútuo entre os envolvidos: corpo docente e discente. Ao final do primeiro trimestre, os alunos expuseram suas idéias relacionando seus respectivos projetos com os conhecimentos adquiridos em sala de aula. Os coordenadores do curso e das disciplinas deram orientações pertinentes ao aprimoramento desses projetos. Iniciou-se, então, o processo de interlocução da coordenação do MPGICS, coordenadores de disciplinas, de seminários e de laboratórios e estudos dirigidos na busca de definição dos orientadores. Todos os alunos foram aprovados na qualificação de seus projetos, no prazo previsto. No Anexo 1 estão apresentados os temas dos produtos finais.

Elaboraram-se dois instrumentos de avaliação que foram aplicados pela coordenação do curso, um entre os membros do corpo docente e outro entre os membros do corpo discente. Com o objetivo de compartilhar esse rico processo, apresenta-se, a seguir, uma síntese das avaliações dos coordenadores de disciplina e dos alunos. Primeiramente, as respostas dos coordenadores de disciplina:

1 - Você considera que o objetivo da disciplina coordenada por você foi atingido?

$$
82 \% \text { - Sim } \quad 18 \% \text { - Apenas parcialmente } \quad 0 \% \text { - Não }
$$

- A turma se mostrou vivamente interessada e participativa.

- A participação no processo ensino-aprendizado foi bastante satisfatória, o que resultou em bons desempenhos na avaliação.

- Cumpriu-se o conjunto dos objetivos, garantindo-se ao final que a turma mostrasse um conhecimento razoável do processo de desenvolvimento das políticas públicas de saúde ao longo do século XX com ênfase na constituição do SUS. 
- Se considerarmos que se trata da primeira versão de um curso com uma proposta muito corajosa e difícil, considero realizado o objetivo.

2 - Como você classificaria o conteúdo da sua disciplina em relação ao curso como um todo? 43\% - Totalmente válido $57 \%$ - Válido na maior parte 0\% - Válido parcialmente $\quad 0 \%$ - Totalmente inválido

- No decorrer das aulas os alunos sempre correlacionaram o conteúdo que estava sendo ministrado com o de outras disciplinas, tanto do ponto de vista teórico como metodológico. Assim, apesar da especificidade do assunto, pude perceber uma perfeita articulação com as disciplinas antecedentes.

- O que mais me motivou na participação - como desafio - foi justamente o duplo fato da interdisciplinaridade da proposta e do caráter de mestrado profissional. Nesse sentido, achei que minha disciplina tinha que colocar em questão o que é a construção de saberes e práticas transdisciplinares.

3 - Relacione os aspectos que você destacaria como mais positivos na realização da sua disciplina.

- O esforço por olhar a comunicação e a informação não só como setores de atividades ou como campos, mas principalmente como condição e dimensões da vida social e individual indissociáveis.

- A abertura e o arcabouço para acolher, metodologicamente, todas as formas de produção de conhecimento, do científico ao social. A tentativa é desconstruir a complexidade e fazer uma pregação pela simplicidade.

- Interesse dos alunos, tanto pelos conteúdos como pela bibliografia, acredito que foi de grande ajuda para os projetos.

4 - Relacione os aspectos que você considera que mais dificultaram sua atuação como coordenador(a) da disciplina:

- Garantir o compromisso dos docentes convidados para discussão de questões específicas que compunham o conteúdo da disciplina. A indicação de especialistas em certas questões é fundamental, embora a sua pouca familiaridade com a turma cause um excesso de expectativas tanto no convidado como nos alunos.

- Aquantidade e concentração de horas-aula.

- Se o mundo se apresenta como simples, só o é como fruto de uma complexidade que se transformou graças a leitura, reflexão, muito de análise e síntese, muita e muita produção 
de texto. Reforço minha visão de que os alunos têm muito pouco tempo para ler e pensar. E nós bem sabemos como o aprendizado é um processo individual, particular. Na minha visão, professor não ensina, só desperta/estimula.

Do corpo discente, foram destacadas as seguintes respostas:

1 - Você considera que os objetivos das disciplinas foram atingidos?

$$
\text { 100\% - Sim \% - Apenas parcialmente } \quad 0 \% \text { - Não }
$$

- Os conceitos apresentados que perpassam as três áreas (...) permitiram um repensar de nossas certezas e um caminhar mais fundamentado e alerta.

- Parafraseando a Profa. Nélida, a turma adquiriu uma doxa, que reflete o conhecimento acumulado da instituição.

- Como a turma é composta de alunos de diversas áreas, foi possivel uma integração entre os alunos através do conteúdo.

- Abriu horizontes teóricos e trouxe conhecimentos válidos sobre a problemática da informação na saúde sob a ótica tecnológica, política, histórica e social.

2 - Essas disciplinas influenciaram sua maneira de pensar sobre gestão da informação e comunicação em saúde?

$$
\text { 100\% - Sim } \quad 0 \% \text { - Apenas parcialmente } \quad 0 \% \text { - Não }
$$

- Conhecer a história da saúde, as dificuldades, as oportunidades e o desafio do homem público fez perceber questões importantes como ética, necessidade de contemplar a audiência e a responsabilidade do gestor público dentro do contexto social.

- Uma nova noção do que constitui o campo da informação e comunicação em saúde nos foi oferecida.

- Entendi que a gestão não é simplesmente o uso da técnica, o espaço de negociação é bastante forte e interfere em todo o processo.

- Descobri e redescobri muito com a literatura indicada, debates em sala e com os professores.

- Recebi tantas informações novas que mudaram minha forma de perceber e compreender não só a gestão da informação e comunicação em saúde, mas o setor Saúde de forma geral.

3 - Como você classificaria o conteúdo das disciplinas em relação aos objetivos do MPGICS? 70\% - Totalmente válido 30\% - Válido na maior parte

0\% - Válido parcialmente $\quad \%$ - Totalmente inválido 
- A grade das disciplinas foi muito pertinente à proposta, atual e objetiva.

- Estamos passando por um processo de aprendizagem e de crescimento profissional maravilhoso, mesmo com toda a tensão/nervosismo/insegurança dos alunos durante os seminários.

- As disciplinas simplesmente se completaram e nos ajudaram a construir uma base para as nossas dissertações dentro do contexto da saúde.

4 - Relacione os aspectos que mais dificultaram sua participação:

- A semana de aula de segunda a sábado, das 9 às 18 horas.

- Se estuda trabalhando ou se trabalha estudando. É um grande desafio. Estou exausta.

- Acúmulo de leitura.

- A exigência de trabalhos a serem realizados de um dia para o outro durante a semana de aula.

5 - Relacione os aspectos que você destaca como mais positivos:

- A própria turma, que se integrou muito bem e sempre que possível tenta se ajudar.

- A atenção e disposição dos professores. São atenciosos e carinhosos, atendendo a cada um com muito interesse.

- Os professores, sempre que possível, trazerem o projeto de cada aluno para discussão em sala, fazendo links com o conteúdo, foi muito proveitoso.

- O alto nível dos professores foi um dado marcante.

\section{CONSIDERACุÕES FINAIS}

Tanto a saúde quanto a informação, a comunicação e suas tecnologias possuem um forte componente operacional, com parte significativa da produção do conhecimento voltada para a busca de soluções de problemas. Essa racionalidade instrumental está associada à racionalidade política, com seus conflitos, contradições e disputas. Ou seja, a lógica instrumental insere-se no cotidiano da correlação de forças da sociedade, na implementação das políticas de Estado, na dinâmica das instituições de saúde. O desenvolvimento desses saberes está imerso em relações de poder no cotidiano tanto das instituições de ensino, pesquisa e desenvolvimento tecnológico quanto naquele dos sistemas e serviços de atenção à saúde.

O processo de apropriação desses saberes é complexo e envolve dimensões variadas: política, econômica, social, ideológica e científica. Depende da dinâmica e dos pactos democráticos estabelecidos entre os atores sociais envolvidos no processo de tomada de decisão em torno da política nacional de saúde. Pressupõe a construção de um projeto de país comprometido com a emancipação e com a democracia participativa (Santos, 1996). 
A luta por um projeto emancipador e democrático se trava no cotidiano, na ação local, que se expande para o global, difundindo novas possibilidades de vida. Essas lutas que se dão nas trincheiras diárias devem ser respeitadas em si mesmas e não subordinadas a uma racionalidade superior de 'uma grande luta final'. Não há um discurso definitivo superior, 'A Proposta', mas, sim, a possibilidade de novas falas e ações. (Moraes, 2002:153)

É na busca de espaços para essas novas falas e ações que se insere a experiência do Mestrado Profissional de Gestão da Informação e Comunicação em Saúde da Escola Nacional de Saúde Pública/Fiocruz. Ele representa um amplo processo de amadurecimento institucional e reflexão coletiva, em um esforço por atender a uma necessidade identificada na Saúde, coerente com os compromissos históricos da Ensp e da Fiocruz. A ética da responsabilidade suscita o desafio de desempenhar um papel estruturante em uma área de crescente importância estratégica no âmbito do setor Saúde, pois, no cenário contemporâneo, a informação, a comunicação e as tecnologias a elas relacionadas possuem tal centralidade e relevância que sua excelência ou precariedade afeta o desenvolvimento de cada área de atividade social e a obtenção de seus objetivos e dos resultados desejados.

Quando se avalia o caminho já percorrido, constata-se que o grande desafio deste MP continua sendo a busca de integração entre campos temáticos - saúde, informação e comunicação - e suas tecnologias. Percebe-se a dificuldade de alunos oriundos de um dos campos em apropriar-se de conteúdos dos outros campos. Portanto, o desafio continua sendo a busca da superação de uma lógica fragmentadora.

No processo de ensino-aprendizagem adotado no MPGICS, a idéia-força tem sido semear nos profissionais-alunos a esperança e o encantamento na luta pela construção coletiva de um projeto nacional fundado, de um lado, na dignidade e na solidariedade e, de outro lado, na consolidação da excelência inovadora. Conscientes da opção de viver a partir de valores calcados na busca do respeito à singularidade de cada ser e à humanidade.

\section{REFERÊNCIAS BIBLIOGRÁFICAS}

BATES, M. J. A tour of information science through the pages of Jasis. Journal of the American Society for Information Science, 50(11):975-993, 1999

BUSS, P. M. Promoção e educação em saúde no âmbito da Escola de Governo em Saúde da Escola Nacional de Saúde Pública. Cadernos de Saúde Pública, 15(supl.2):177-185, 1999. 
FUNDAÇÃO GETÚLIO VARGAS. Mapa do fim da fome: metas sociais contra a miséria nos municípios fluminenses. FGV: 2001. Disponível em htpp://www.fgv.br/ibre/cps/ pesq_recentes/ESM_MAPAS_RJ.PDF

FUNDAÇÃO OSWALDO CRUZ. Programa Integrado de Informação e Comunicação da Fiocruz. Rio de Janeiro: Fiocruz, 2003

HABERMAS, J. Agir Comunicativo e Razão Destrancendentalizada. Rio de Janeiro: Tempo Brasileiro, 2002.

HJORLAND, B. Information Seeking and Subject Representation: a activity-theoretical approach to information science. Connecticut, London: Wesport, 1997.

HJORLAND, B. \& ALBRECHTSEN, H. Toward a new horizon in information science: domain-alysis. Journal of the American Society for Information Science, 46(6):400425, 1995.

INTERNATIONALMEDICAL INFORMATICSASSOCIATION-IMIA. Recommendations of The International Medical Informatics Association (Imia) on education in health and medical informaticas. Disponivel em: http://www.rzuser.uni-heidelberg.de/ d16/ rec.pdf. Acesso em 03/09/2001.

JONAS, H. Philosophical Essays: from ancient creed to technological man. Chicago, London: The University of Chicago Press, 1974.

MAC DOUGALL, J. \& BRITTAIN, J. M. Health informatics. Annual Review of Information Science and Technology (Arist), 29:183-217, 1994.

MINISTÉRIO DA CIÊNCIA E TECNOLOGIA. Livro verde da ciência e da tecnologia. Brasilia, maio 2001. (Mimeo.)

MORAES, I. H. S de. Informações em Saúde: da prática fragmentada ao exercício da cidadania. São Paulo: Hucitec, Abrasco, 1994.

MORAES, I. H. S. de. Política, Tecnologia e Informação em Saúde: a utopia da emancipação. Salvador: UFBA, Casa da Qualidade Editora, 2002.

MOREL, C. M. A pesquisa em saúde e os objetivos do milênio: desafios e oportunidades globais, soluções e políticas nacionais. Ciência Ė Saúde Coletiva, 9(2):261-270, 2004.

PINHEIRO, L. V. R. Campo interdisciplinar da ciência da informação: fronteiras remotas e recentes. In: PINHEIRO, L. V. R. (Org.) Ciência da Informação, Ciências Sociais e Interdisciplinaridade. Brasília, Rio de Janeiro: Ibict, 1999. 
SANTOS, B. de S. Pela Mão de Alice: o social e o político na pós-modernidade. São Paulo: Cortez, 1996.

UNDP. Human Development Report 2002. Deepening democracy in a fragmented world. United Nations Development Programme. New York: UNDP, 2002.

UNITED NATIONS. UN Millennium Development Goals. 2002. Disponível em http:// www.un.org/millenniumgoals/

VASCONCELLOS, M. M; MORAES, I. H. S. \& CAVALCANTE, M. T. Política de saúde e potencialidades de uso das tecnologias de informação. Saúde em Debate, (61):219-235, 2002.

\section{ANEXO 1}

Temas dos Produtos Finais dos Alunos da Primeira Turma

- Alex Príncipe - A gestão da informação para apoio à decisão no setor público em saúde: uma proposta de sistema informatizado para a comunicação de compromissos institucionais na Fiocruz.

- Angélica Baptista - Convergência de mídias e interlocução nos Conselhos de Saúde.

- Edna Maria Baptista Padrão - Projetos sociais da Fiocruz: circular para divulgar, integrar e fazer ecoar.

- Ednelson Pereira - A construção de um sistema de informação para a cooperação internacional: o caso Fiocruz/Inserm.

- Else B. Gribel - Atenção básica: do processo de trabalho ao sistema de informação.

- Ivone P. de Sá - A face oculta da interface: serviços de informação arquivística na web centrados no usuário.

- Leandro Ferreira de Carvalho - Bibliometria e saúde coletiva: análise dos periódicos Cadernos de Saúde Pública e Revista de Saúde Pública.

- Maria Elisa Andries dos Reis - Portal corporativo como ferramenta de gestão do conhecimento.

- Maria Estela - Sistema de informação para pesquisa clínica: um estudo de caso. [Hospital] Instituto de Pesquisa Evandro Chagas/Fiocruz.

- Maria de Lourdes Vasques da Silva - Descrição de documentos fotográficos: aspectos teórico-metodológicos e modelo de aplicação 
- Mario Dimas - Quem é dono da voz? O movimento de radiodifusão comunitária e uma aproximação ao campo da saúde coletiva.

- Rejane Machado - Representação e recuperação dos relatórios de pesquisa da Fiocruz: proposta de metodologia para ampliação do acesso.

- Rosane Abdala - Sistema Nacional de Informações Tóxicofarmacológicas: o desafio da padronização dos dados.

- Ruben Carlos Fernandes de Oliveira - O design gráfico como lugar de produção de sentidos no campo da saúde coletiva.

- Sandra Rocha Suzano Benigno - Gestão da informação em educação profissional em saúde: trabalho em rede e inclusão social.

- Viviane Santos - Buscando interoperabilidade entre diferentes bases de dados: o caso da biblioteca do Instituto Fernandes Figueira. 


\title{
O MESTRADO PROFISSIONALIZANTE EM VIGILÂNCIA EM SAUUDE DA ESCOLA NACIONAL DE SAÚDE PÚBLICA SERGIO AROUCA
}

\author{
Paulo Sabroza \\ Maria do Carmo Leal \\ Silvana Granado Nogueira da Gama \\ Inês Matos
}

\section{ANTECEDENTES HISTÓRICOS}

A prática da vigilância epidemiológica, com as características atuais, teve início na Europa, no século XIX, a partir da organização do campo da saúde pública e de modelos de registro e classificação de doenças (Langmuir, 1976). Utilizando métodos estatísticos propostos por Willian Farr, tinha como objetivo a identificação precoce das epidemias com grande potencial de difusão e de letalidade que acompanharam a urbanização e a etapa inicial da industrialização na Europa, procurando proteger a vida e os interesses dos grupos sociais dominantes, que precisavam de tempo para se afastar das cidades em perigo.

Antes dessa modalidade de vigilância, já haviam sido regulamentadas e implementadas ações de fiscalização sanitária com o objetivo de reordenar os espaços de trabalho e de moradia, reduzindo a exposição das pessoas a lugares insalubres, segundo as concepções da higiene e da teoria dos miasmas. Essa proposta de controle público dos espaços urbanos, na época justificada pela necessidade de reduzir a mortalidade e assegurar a reprodução da força de trabalho, ficou conhecida como polícia médica, e foi um importante componente do movimento sanitário que deu início ao processo de transição demográfica nos centros industriais urbanos em formação (Rosen, 1994). 
Odesenvolvimento da teoria do processo infeccioso, com a identificação de muitos agentes causais de doenças e seus modos de transmissão, veio possibilitar outras formas mais diretas de controle, que não dependiam mais de reformas da cidade e do processo de trabalho (Wislow, 1967). Inicialmente restrita ao monitoramento e controle das enfermidades transmissiveis, a vigilância de doenças tinha como principal instrumento a notificação compulsória de casos. Quando era identificado um surto, ou mesmo um caso isolado com potencial de dar início à propagação do processo infeccioso, seguiam-se ações de investigação epidemiológica, identificação de agentes infecciosos, isolamento físico do doente e controle focal.

As listas de agravos de notificação compulsória, identificando aquelas doenças reconhecidas no período como problemas de saúde pública, refletiam a necessidade de controlar epidemias que pudessem resultar em crises sociais e limitar a expansão econômica naquela conjuntura, marcada pelo aumento das cidades e pela intensificação do comércio internacional. À conseqüente intensificação da circulação de pessoas e mercadorias, seguiu-se a emergência de processos epidêmicos em muitas partes do mundo: febre amarela, malária, cólera, tifo transmitido por piolho, febre tifóide, varíola, escarlatina, difteria e outras (Berlinguer, 1982).

Nas colônias e países de desenvolvimento tardio, a vigilância e controle focal de processos epidêmicos, em grandes centros urbanos, áreas portuárias e nas principais frentes de expansão capitalistas, organizadas a partir de campanhas sanitárias temporárias, apresentaram uma grande efetividade, alcançada independentemente de transformação das condições de vida e saúde dos trabalhadores. Tornou-se, então, um modelo de intervenção estratégico, amplamente reconhecido e disseminado, de importância fundamental para a reprodução das formações sociais capitalistas, naquele primeiro ciclo de globalização (Costa, 1985).

A formação do profissional da saúde pública que atuava na detecção e no controle de processos epidêmicos era orientada para as áreas de microbiologia, imunologia e higiene, sendo o método experimental o modelo de validação do conhecimento que fundamentava as técnicas de saúde pública.

No Brasil, os cursos de medicina experimental e saúde pública do Instituto Oswaldo Cruz formaram diversas gerações de pesquisadores. Estes atuaram como referências profissionais nas campanhas sanitárias focais que reduziram o impacto dos processos epidêmicos nas áreas de interesse estratégico durante o primeiro quartil do século XX, as quais seguiam as orientações difundidas pelo Instituto Pasteur, na França, e pelo Serviço de Saúde do Exército dos EUA (Stephan, 1976).

Mas a grande pandemia de gripe de 1918, que acarretou mais de dez milhões de mortes, distribuídas em diversos países e todas as classes sociais, antecipou da forma mais dolorosa a 
incapacidade do modelo focal de vigilância e controle de doenças de prever, controlar ou mesmo limitar o impacto de processos epidêmicos que eventualmente viessem a se adaptar à circulação naquelas redes urbanas integradas, que passaram a ser características das organizações socioespaciais do século XX.

Depois que os Estados nacionais assumiram as funções de planejamento econômico e social, por meio de políticas públicas implementadas a partir de corporações burocráticas complexas, próprias do período denominado fordista ou de capitalismo monopolista de Estado, o controle de doenças passou a ser realizado por meio de programas institucionais permanentes, caracterizados pela rígida divisão técnica do trabalho, pela implementação de práticas padronizadas e pelo vínculo permanente do trabalhador de saúde com corporações estatais de atuação em todo o território nacional (Cleaver, 1977). Técnicas de controle estatístico de qualidade utilizadas nas linhas de montagem do processo de produção industrial foram adaptadas para uso nos serviços de saúde, para o monitoramento de agravos e identificação de epidemias (Albuquerque, 1975).

A bioestatística e a epidemiologia descritiva aplicada à análise de dados obtidos em sistemas de registro contínuo e as técnicas de programação passaram a ter um papel essencial na prática da vigilância e controle de doenças nos serviços de saúde, vindo a ter presença obrigatória na composição dos currículos utilizados na formação dos sanitaristas. A Fundação Rockefeller, dos EUA, passou a ter um papel destacado na difusão do modelo, no Brasil como em vários outros países (Franco-Agudelo, 1984).

As enfermidades eram consideradas ao mesmo tempo determinantes e resultantes da condição de subdesenvolvimento, e acreditava-se que as ações de controle, quando implementadas com técnica, programação e cobertura adequadas, seriam uma estratégia eficaz e eficiente de intervenção no ciclo vicioso da doença e da pobreza.

Na segunda metade do século XX, a competição entre as duas grandes potências internacionais na disputa por hegemonia, durante o período da Guerra Fria, incluiu também a preocupação com o desenvolvimento dos países periféricos em suas áreas de influência. Tal preocupação resultou, de forma coerente com o pensamento sanitário daquela conjuntura, em propostas de apoio externo a programas de controle e erradicação daquelas endemias consideradas capazes de reduzir a produtividade dos trabalhadores, mediante transferência de tecnologia e financiamento dos países centrais para os países dependentes.

Com o envolvimento dos Estados nacionais e das agências internacionais em campanhas de erradicação de doenças, a vigilância epidemiológica passou a ser reconhecida como uma etapa essencial dos programas verticais para a consolidação e manutenção dos seus resultados (Handerson, 1976; Verani, 1991). 
No modelo institucional de controle de doenças proposto pela $\mathrm{OMS}$, as atividades de vigilância e controle deveriam ser integradas, com o conhecimento epidemiológico orientando as práticas de controle e estas definindo as necessidades de coleta e análise de informação (Raska, 1966).

Na programação da erradicação da malária, o conceito de vigilância não se aplicava mais apenas à detecção precoce de casos individuais da doença, mas procurava conhecer o potencial de transmissão da endemia em diferentes unidades territoriais, com base na análise de suas condições de vulnerabilidade e receptividade (Pampana, 1969). Essa abordagem, na época limitada ao estudo das doenças transmitidas por vetor, pode ser considerada precursora da vigilância de base territorial, que integra componentes de vigilância de casos e de fatores ambientais de risco.

Mas o modelo de organização institucional burocrático e centralizado, orientado para a aplicação sistemática de medidas de controle simples e padronizadas, não promoveu o desenvolvimento de propostas de intervenção baseadas em análises de situações epidemiológicas particulares. Se o conhecimento sobre os determinantes dos problemas de saúde ainda era considerado um recurso indispensável para o planejamento e a programação das atividades de controle, a confiança, adquirida a partir da descoberta e do uso de antibióticos, de quimioterápicos e de inseticidas de ação residual, resultou em um modelo no qual os sistemas de informação eram orientados quase exclusivamente para monitoramento de indicadores operacionais de cobertura, concentração e rendimento das ações de controle.

Os conhecimentos acumulados sobre a diversidade de situações e experiências adquiridas nos trabalhos de campo eram transmitidos oralmente dentro das corporações, contribuindo para a construção de culturas institucionais, importantes para sua coesão e orientação técnica dos programas, mas restritas a seus limites de atuação operacional.

No Brasil, a primeira experiência de abrangência nacional de um sistema de informação concebido para vigilância articulado com ações programáticas de controle de um agravo ocorreu no Programa Nacional de Erradicação da Varíola. No período de 1968 a 1973 foi implementado um modelo ajustado às características do país, concebido por sanitaristas da Fundação Serviço de Saúde Pública (Sesp) que também atuaram como docentes na Escola Nacional de Saúde Pública (Fossaert, Llopis \& Tigre, 1974). As ações de controle por vacinação eram orientadas diretamente pelas informações das unidades de vigilância, distribuídas por todo o território. Essas práticas de saúde tinham que ter qualidade, oportunidade e cobertura adequadas, e se mostraram indispensáveis para a consolidação da interrupção da transmissão da varíla em grandes populações, pois apenas a vacinação em massa não havia atingido os resultados esperados. 
Embora a rede nacional de unidades de vigilância da varíola não tenha sobrevivido após a eliminação daquela doença, a experiência profissional acumulada foi fundamental para a elaboração de uma proposta de vigilância que viria a superá-la no período seguinte. No início da década de 70, os serviços de vigilância específicos de programas verticais já pareciam obsoletos, e a concepção de vigilância e sua abrangência estavam sendo redefinidas. Em parte porque o modelo de transição epidemiológica amplamente difundido justificava o questionamento da prioridade dada até então pelos serviços de saúde apenas à vigilância e controle das doenças transmissíveis. Mas principalmente porque concepções mais elaboradas sobre a atenção à saúde e a relevância estratégica da informação em saúde passaram a prevalecer.

O sucesso alcançado pela utilização da vigilância no controle e erradicação da varíola no mundo levou a 21 ${ }^{\text {a }}$ Assembléia Mundial da Saúde da Organização Mundial da Saúde (OMS), realizada em 1968, a estender o conceito de vigilância de saúde pública a outros problemas além das doenças transmissíveis. Nas discussões técnicas desse encontro, a vigilância passa a ser concebida como uma função essencial do conjunto das práticas de saúde pública (Buehler, 1998).

A vigilância, entendida como um componente de informação em saúde que deveria permear todo o sistema, havia sido definida já em 1963 como a "análise atualizada e contínua da distribuição e tendência da incidência, através da coleta, consolidação e avaliação sistemáticas dos registros de morbidade, mortalidade e outros dados relevantes" (Langmuir, 1989:930). Essa nova concepção da vigilância como um componente da inteligência em saúde pública, centrada no processamento, na análise e na divulgação de informações, com a função de orientar as diferentes estratégias de atenção à saúde, mas separada das ações de controle de agravos, passou a prevalecer nos EUA e ficou conhecida como o modelo CDC de vigilância em saúde, em referência ao sistema coordenado a partir do Centro de Controle de Doenças de Atlanta.

O uso intensivo de técnicas estatísticas e métodos epidemiológicos na vigilância, monitoramento e avaliação de problemas de saúde (Devine \& Parrish, 1998; Brookmeyer \& Stroup, 2004; Janes et al., 2000) fez com que durante algum tempo esta área fosse confundida, mesmo pelos profissionais, com a própria epidemiologia. Mas com o seu desenvolvimento, a vigilância passou a ser considerada como uma função diferenciada da saúde pública e, portanto, distinta da epidemiologia, devendo ser entendida como disciplina específica (Thacker \& Berkelman, 1988). Esses autores enfatizaram a relevância de se utilizar o termo 'vigilância em saúde pública' (VSP), em lugar de 'vigilância epidemiológica'. 


\section{VIGILÂNCIA EM SAÚDE COMO PROPOSTA DA CONJUNTURA ATUAL}

Essa evolução do conceito e da abrangência da vigilância, já observada no início da década de 80, acompanhava as transformações que estavam ocorrendo nos serviços de saúde, nos perfis epidemiológicos das populações e na percepção da saúde durante o período de transição do capitalismo monopolista de Estado para uma outra conjuntura, o capitalismo pós-fordista ou técnico-científico-informacional (Sabroza, Kawa \& Queiroz, 1995).

Uma das características marcantes dessa nova etapa do capitalismo é o uso intensivo de informação, tanto nos processo produtivos como no controle social (Santos, 1994). Tal controle apresenta-se, então, caracteristicamente descentralizado, distribuído de modo difuso na sociedade, enfatizando a função de indivíduos interligados pelos meios de comunicação na formação de opinião pública, em detrimento dos grupos sociais organizados e das representações sindicais dos trabalhadores.

A prioridade à proteção dos trabalhadores e à atenção a suas necessidades, como modo de assegurar sua capacidade produtiva e aumentar seu padrão de consumo, característica do modelo fordista, foi substituída por uma orientação dirigida para o papel social do consumidor, sem destacar sua inserção no processo de trabalho. A saúde da maior parte da população deixara de ser um fator relevante para a produção, passando a ser cada vez mais um problema de interesse individual. Ao contrário, pode-se constatar que muitas vezes o conjunto dos doentes, intensificando e diversificando sua participação no consumo, tem um papel relevante no processo econômico, contribuindo para a realização do capital por meio da ampliação do consumo de bens e serviços (Sabroza, 2001). Mesmo porque, com o aumento da expectativa de vida e o desgaste decorrente da exposição prolongada da maior parte das pessoas a condições de risco e situações permanentes de estresse, tornou-se quase inevitável a utilização de próteses químicas e físicas, aumentando continuamente a necessidade de incorporação de inovações tecnológicas na atenção à saúde.

Refletindo os resultados dessas transformações sociais no campo teórico da saúde pública, uma nova ideologia científica, o modelo epidemiológico dos fatores de risco deslocou completamente, em menos de vinte anos, a teoria do ciclo vicioso da doença e da pobreza. $\mathrm{O}$ modelo teórico dos fatores de risco passou a ser amplamente utilizado na vigilância em saúde, principalmente em relação às doenças crônicas, à vigilância da saúde do trabalhador e à vigilância ambiental. A produção e divulgação de informações permanentes e atualizadas sobre as condições de saúde, mas também sobre a distribuição dos fatores de risco, tanto para os gestores como para o conjunto da sociedade, passou a ser o objetivo central dos sistemas de vigilância em saúde nos países centrais (Bonita et al., 2005). 
A amplitude da aplicação da vigilância em saúde no período contemporâneo pode ser apreciada no artigo de Thacker e Berkelman (1988), que descreve o complexo sistema de vigilância em saúde pública nos Estados Unidos da América. Em consonância com as prioridades da nova saúde pública daquele país, os autores utilizam dados de muitos sistemas de informação, alguns dos quais fora do escopo restrito da saúde pública, tentando incorporar outras dimensões da saúde e da vida.

No fim da década de 80 já estavam envolvidas no sistema de vigilância em saúde dos EUA 29 bases de dados de cobertura nacional, abrangendo, além das doenças de notificação compulsória, várias doenças crônico-degenerativas, problemas nutricionais, ocupacionais, efeitos decorrentes da exposição a agentes tóxicos no ambiente, acidentes intencionais e não intencionais, comportamentos de risco para a saúde, tecnologias preventivas de saúde como uso de fármacos, vacinas, procedimentos médicos e cirúrgicos de diferentes complexidades. Essa profunda mudança na função social da vigilância necessariamente resultou em importantes transformações nos seus objetivos e modelos de organização institucional.

Para a avaliação da vigilância em saúde pública, propõe-se que devem ser considerados como elementos essenciais, na nova concepção pluralista, a definição clara dos objetivos da vigilância; aspectos legais e éticos; a definição das fontes de informação e das bases de dados que podem ser utilizadas; os diferentes métodos de coleta de dados; os diferentes sistemas de vigilância que podem ser utilizados; os métodos para avaliação dos sistemas e as estratégias para sua melhoria (Romanguera, German \& Klauck, 2000). Uma perspectiva muito diferente daquela orientada apenas para a vigilância e controle dos processos endêmico-epidêmicos capazes de criar obstáculos ao crescimento da força de trabalho e à reprodução do capital.

Pode-se afirmar que o modelo de vigilância em saúde implementado nos EUA desde a década de 80 tem duas orientações principais, considerando seus objetivos, sua proposta de organização e os atores sociais para os quais direciona as informações resultantes das suas análises: a segurança da população e a promoção da saúde. Nesse modelo, uma concepção de vigilância integrada de modo sistêmico articula diferentes sistemas de informação e instituições de saúde. Não se pode deixar de reconhecer a relevância social e o nível de organização de tal modelo, que certamente tem sido uma referência sempre considerada na construção dos sistemas de vigilância em saúde nos demais países americanos. Mas, por isso mesmo, seu desempenho diante de diversos desafios tem sido motivo de preocupação.

No concernente à promoção da saúde, a ênfase no monitoramento e na divulgação de informações relacionadas a fatores de risco para doenças cardiovasculares e certas formas de câncer, procurando modificar estilos de vida considerados implicados no processo patogênico, 
contribuiu para importante redução da morbimortalidade por estes agravos, considerados de enorme relevância. Por outro lado, o aumento explosivo da obesidade, o crescente impacto do diabetes, a grande prevalência da drogadição entre jovens, a freqüência de depressão entre os idosos, a inaceitável mortalidade por agressões com armas de fogo, a disseminação do sofrimento difuso, em grupos vulneráveis, e do medo em toda a população são alguns indicadores de uma condição de malestar disseminado que induz e decorre de diversas formas de consumo patogênicas. A própria concepcão de saúde é posta em xeque em uma sociedade que considera a expansão constante do consumo tanto o resultado como um dos determinantes do desenvolvimento socioeconômico. Essa contradição prejudica a capacidade do modelo hegemônico de vigilância-promocão da saúde de orientar o foco de sua atenção para aqueles problemas que efetivamente passaram a ter maior relevância.

Quanto à dimensão da segurança epidemiológica, que deu início às primeiras propostas de ações de vigilância nos serviços de saúde no século XIX, algumas crises registradas nas duas últimas décadas, em uma conjuntura muito diferente, questionam a competência do modelo: sua incapacidade de identificar precocemente e bloquear a propagação de uma doença como a Aids, a introdução da encefalite do Nilo em Nova York e sua posterior difusão para vários estados americanos e para os países vizinhos, o desenvolvimento e propagação de formas multirresistentes de tuberculose na população, a dificuldade de identificar as fontes e conter a atuação de agentes de bioterrorismo após os atentados contra as torres de Nova York.

Em 1994 a Academia de Ciências de Nova York, em um documento que teve grande repercussão, alertava para inesperada vulnerabilidade da população americana a doenças transmissiveis (Wilson, Levins \& Spielman, 1994). Na mesma época foi proposto o conceito de 'doença emergente' e teve início um amplo debate sobre que modelo de vigilância e contenção seria mais adequado para lidar com este tipo de problema. Três princípios demarcariam essa nova modalidade de vigilância: sua vinculação com tecnologias inovadoras em biotecnologia; a atenção rigorosa com a questão da biossegurança; a necessidade de cooperação internacional na detecção, investigação de foco e contenção de surtos (CDC, 1994).

Com a nova globalização, a segurança epidemiológica e sanitária dos EUA e dos outros países desenvolvidos havia passado a depender tanto da organização de seus sistemas de vigilância em saúde como da consolidação de uma rede de núcleos de vigilância distribuídos em diferentes países, constituindo um cinturão de segurança, assim como da sua capacidade de mobilizar equipes táticas de investigação epidemiológica e contenção para atuarem fora de seu território (Gore, 1996). 
Como havia acontecido nas conjunturas anteriores, os problemas de saúde, o marco conceitual e o modelo organizacional da vigilância elaborado nos países centrais passaram a influenciar fortemente os projetos de todos os outros de sua esfera de influência. Que agora, com o novo ciclo de globalização, passou a abranger própria biosfera.

\section{A CONSTRUC̦ÃO SOCIAL DO SISTEMA DE VIGILÂNCIA EM SAÚDE DO BRASIL}

Nas últimas décadas do século XX, os debates sobre vigilância em saúde passaram a destacar o problema na perspectiva da construção de sistemas integrados de abrangência nacional, superpondo-se às concepções anteriores que destacavam as práticas e a organização de serviços (Waldman, 1991).

A consolidação do Sistema de Vigilância em Saúde do Brasil é um processo que acompanha o projeto da Reforma Sanitária e da construção social do SUS - o Sistema Único de Saúde do Brasil. Esse processo inicia-se com o movimento de modernização da saúde pública, a partir da implantação do modelo preventivista, no fim dos anos 60 , nos currículos das faculdades de medicina e das duas escolas de saúde pública então existentes no Brasil, a Escola Nacional de Saúde Pública do Ministério da Saúde, no Rio de Janeiro, e a Faculdade de Saúde Pública da Universidade de São Paulo. Essas duas instituições tiveram um papel decisivo na incorporação e reprodução, mesmo que tardia, daquele modelo já amplamente utilizado nos EUA desde a década de 40.

A ênfase no ensino do método epidemiológico, da bioestatística e de técnicas de programação normativa contrastava com as práticas dominantes nos serviços de saúde pública, ainda orientadas pelos marcos de referência da higiene, da microbiologia e das campanhas sanitárias.

O Brasil já iniciara desde a década de 50 seu processo de industrialização, acompanhado de intenso fluxo populacional rural-urbano e da região Nordeste para o Sudeste. Nos anos 70, durante o período da ditadura militar, a integração do seu território por rodovias e a concentração dos investimentos em um número restrito de pólos de desenvolvimento produziu grandes deslocamentos populacionais, acompanhados de agravamento dos problemas de saúde nos centros urbanos e nas frentes de expansão agrícola. Ao contrário do que previa o modelo desenvolvimentista, com o crescimento econômico a mortalidade infantil aumentou e diversas epidemias passaram a ser registradas nas principais cidades: poliomielite, meningite meningocócica, leptospirose, hepatite, sarampo (Sabroza, Toledo \& Osanai, 1992). 
Em resposta à crise sanitária, o governo autoritário deu início a um processo de racionalização técnica e de extensão de cobertura das ações básicas de saúde e da atenção médica. Em 1973, criou o Programa Nacional de Imunizações, e em 1975 implantou o Sistema Nacional de Saúde e, como seus componentes, o Sistema de Vigilância Epidemiológica, o Sistema de Vigilância Sanitária e o Sistema de Informação de Mortalidade, todos de abrangência nacional, coordenados por área técnica do Ministério da Saúde e com participação das instituições dos três níveis de governo, mas sem nenhuma articulação entre eles.

Com o apoio da Organização Pan-Americana da Saúde (Opas) e utilizando a experiência recente do programa de erradicação da varíola, iniciou-se um grande esforço de organizar serviços de vigilância e programas de controle de doenças no Ministério da Saúde e nas secretarias estaduais de Saúde, tendo inicialmente como objetivo principal o controle da poliomielite. Foi elaborada então uma nova modalidade de organização das ações de controle, distinta das campanhas anteriores: o programa integrado de controle de doenças, que incorporava princípios e métodos da epidemiologia descritiva e da programação, além de uma concepção sistêmica articulando serviços federais, estaduais, municipais, incluindo também organizações da sociedade civil, mobilizadas para o esforço concentrado nos dias nacionais de vacinação.

Um dos principais componentes do programa foi o treinamento em larga escala de pessoal dos serviços de saúde dos três níveis de governo em vigilância e programação de controle de doenças, utilizando material instrucional padronizado, metodologia de ensino simplificada e orientada para questões práticas dos serviços. Milhares de profissionais da saúde foram matriculados nos cursos do Programa Ampliado de Imunização e nos cursos básicos de Vigilância Epidemiológica, coordenados pela Escola Nacional de Saúde Pública e pela Secretaria Nacional de Ações Básicas de Saúde do Ministério da Saúde, com apoio técnico da Opas, em uma experiência inovadora e extremamente produtiva de parceria entre instituição acadêmica e as coordenações de serviços de vigilância nacional e estaduais (Carvalho, 1990).

A resistência inicial observada nas instituições acadêmicas àquilo que consideravam apenas uma aplicação simplificada do método epidemiológico logo foi substituída por interesse e participação crescentes, na medida em que ficavam patentes os resultados tanto na redução das doenças como na organização dos serviços. No caso do desenvolvimento do modelo conceitual e da implementação do Sistema Nacional de Mortalidade também foi decisiva a articulação entre uma instituição acadêmica, a Faculdade de Saúde Pública da USP, o nível central do Ministério da Saúde e as secretarias estaduais de Saúde. Essa coopera- 
ção passou a ser ainda mais sistemática e produtiva com a agregação das instituições acadêmicas da área da saúde coletiva em uma instituição nacional, a Associação Brasileira de PósGraduação em Saúde Coletiva (Abrasco), que, por intermédio de sua Comissão de Epidemiologia, passou a elaborar periodicamente propostas para o desenvolvimento da disciplina no país, sempre incluindo entre suas prioridades a vigilância e o uso da epidemiologia nos serviços de saúde.

A partir da metade da década de 80, durante os congressos da Abrasco os debates sobre modelos, métodos e técnicas aplicados à vigilância epidemiológica mobilizaram docentes, pesquisadores e profissionais dos diferentes níveis dos serviços de saúde. Uma questão destacada nesses debates era a necessidade de descentralização das práticas de epidemiologia e vigilância em saúde nos serviços, e particularmente a construção de sistemas de informação que permitissem análises adequadas das condições de vida e saúde nos municípios, a partir dos marcos conceituais do pensamento latino-americano em epidemiologia social.

Outra modalidade da vigilância em saúde, a da saúde do trabalhador, passou a receber destaque no debate acadêmico e político nesse período, refletindo a consistência teórica desta área e a conjuntura social, na qual o debate sobre a reforma da sociedade e da nova ordem constitucional possibilitou que a questão do trabalho e da saúde do trabalhador viessem a ser destacadas.

As acumulações teóricas e metodológicas pareciam anunciar importantes transformações nas relações da vigilância em saúde com as propostas de reorganização do modelo assistencial do sistema de saúde brasileiro. Entretanto, o modelo que resultou dos debates durante a VI Conferência Nacional de Saúde e da regulamentação do SUS consolidou a mesma proposta de sistemas de vigilância tradicionais e não integrados da década de 70 .

A vigilância epidemiológica das doenças transmissíveis agudas, a vigilância sanitária e a vigilância da saúde do trabalhador foram as modalidades que conseguiram melhor demarcar seu campo de atuação, referencial teórico e metodologia de trabalho.

Os avanços que puderam ser constatados na década de 90 ocorreram na dimensão organizacional do Sistema Nacional de Vigilância da Saúde(SNVS), e não na transformação de seu objeto e de suas práticas.

A criação do Centro Nacional de Epidemiologia do Ministério da Saúde, vinculado à Fundação Nacional de Saúde, veio materializar o projeto pactuado nacionalmente de um sistema de vigilância integrado em rede, articulando serviços dos diferentes níveis de governo, cada um com autonomia administrativa e coordenados por uma unidade central do nível federal, responsável pela formulação e implementação de projetos de abrangência nacional e pelo apoio ao desenvolvimento da vigilância nos estados e municípios. 
A proposta do projeto organizacional do SNVS era bastante avançada, contemplando a integralidade do Sistema Nacional de Saúde e assegurando a autonomia dos seus componentes, essencial para atender à diversidade e extensão do território, além da multiplicidade de competências e da dimensão do país. No entanto, sua atenção ainda continuava restrita praticamente à vigilância daquelas doenças transmissíveis agudas consideradas de interesse estratégico por seu potencial de produzir epidemias em áreas urbanas e às práticas tradicionais de fiscalização sanitária.

$\mathrm{Na}$ realidade, ao contrário do discurso predominante que enfatizava a necessidade de um sistema nacional de vigilância em saúde direcionado para as funções de inteligência sanitária, semelhante ao modelo do CDC dos EUA, o projeto implementado no SUS foi orientado pelo modelo tradicional de vigilâncias em saúde como componentes de programas de controle de doenças.

Nessa perspectiva de vigilância, um processo importante para a estruturação do SNVS foi a implantação do Sistema Nacional de Agravos Notificáveis (Sinan). Pensado como sistema capaz de articular em rede unidades dos diferentes níveis do sistema de saúde, o Sinan manteve a ênfase na notificação de casos e continuou priorizando apenas as doenças transmissiveis, passando a ser emblemático das suas contradições. OSinan não se mostrou até agora um instrumento adequado para efetivamente orientar as ações de controle de doenças nos diferentes níveis do SUS, limitando-se a ser um sistema de registro, fluxo de informações e tabulação de dados sobre casos de doenças definidas como de notificação obrigatória, apesar de ser um exemplo de integração sistêmica e de modelo com grande potencial de incorporação e difusão de inovações tecnológicas na rede de serviços de saúde. Mas certamente ele foi importante para a coesão do sistema, com o seu fluxo contínuo de dados, normas, equipamentos, capacitação de pessoal e recursos financeiros.

Se a vigilância epidemiológica continuou essencialmente orientada para o controle de doenças (Silva, 2004), a concepção de ações programáticas de controle teve de ser completamente reformulada, para se adequar às novas características da política de saúde brasileira. $\mathrm{O}$ modelo anterior, de centralização normativa e aplicação de práticas padronizadas em serviços locais distribuídos por todo o território nacional, que se mostrara eficaz para a eliminação da poliomielitee dosarampo, foi suplantado por outro, que podemos chamarde controlede problemas de saúde por transferência de fundos e atribuição de responsabilidades. Trata-se de modelo centrado na municipalização, na autonomia local, no repasse de recursos financeiros, no atendimento orientado para o indivíduo, na participação de organizações da sociedade civil, na avaliação e na difusão de informações para o controle difuso dos problemas de saúde, a partir de mudanças de comportamento e mobilização social. 
O exemplo mais pertinente desse tipo de programa implementado no Brasil é o de controle da Aids, mas progressivamente ele vem sendo mais empregado, procurando-se incluir como objetos de vigilância e controle diferentes problemas de saúde, inclusive doenças não-transmissiveis e fatores de risco presentes no ambiente. Entretanto, a ênfase na construção de sistemas de informação apropriados, as prioridades de pesquisas, a preocupação com a incorporação de novas técnicas e métodos aplicados à vigilância e o esforço de capacitação de recursos humanos certamente não refletem ainda as expectativas de mudanças significativas no modelo de vigilância, segundo essa orientação.

Mesmo a vigilância ambiental, que parecia ser uma proposta inovadora e coerente com a ideologia científica predominante, apoiada por desenvolvimento teórico-metodológico consistente e orientada por abordagem sistêmica e interdisciplinar dos problemas de saúde e seus riscos, não conseguiu consolidar um modelo operacional na rede de serviços, ficando, até recentemente, praticamente nos limites dos discursos (Ministério da Saúde, 2002). Decerto porque no presente modelo, fragmentado e hierarquizado, do SNVS e do SUS, não parece haver espaço institucional e político nem para projetos transversais, que envolvam setores, unidades e instituições de saúde, e muito menos para aqueles intersetoriais, capazes de mobilizar outras áreas como educação, ambiente, trabalho, moradia e seguridade social.

Todo o esforço de desenvolvimento atual do sistema parece refletir essencialmente o compromisso político de estender as ações tradicionais de vigilância até o nível municipal. Desse modo, o componente estruturante mais relevante do SNVS foi sua proposta de financiamento das ações de vigilância e controle de doenças do SUS.

A centralização no Centro Nacional de Epidemiologia (Cenepi) e na Fundação Nacional de Saúde (Funasa) dos processos decisórios relativos ao repasse de recursos financeiros aos municípios para suas ações de vigilância e controle de doenças, mediante variados procedimentos administrativos, resultou, no nível central, na hipertrofia do componente de gestão administrativa, em detrimento das práticas inerentes a um sistema de inteligência aplicado às análises dos problemas de saúde de interesse para o país. Por outro lado, essa concentração de poder político e financeiro representou também grande capacidade de induzir os estados e municípios a reproduzir apenas as prioridades e os modelos organizacionais do nível federal.

As recentes orientações na definição do volume financeiro a ser transferido do nível federal para estados e municípios, para vigilância e controle de doenças, acompanhado de novas modalidades de pacto e de repasse de recursos, certamente representaram avanços importantes na consolidação da descentralização do projeto do SNVS (Silva Junior, 2004). Mas a definição das metas e dos indicadores a serem monitorizados reflete mais as prioridades definidas no nível central do que aquelas identificadas nos estados e municípios. 
A questão do financiamento das ações de vigilância e controle de doenças no SUS veio, portanto, explicitar a tensão entre as duas dimensões fundamentais das funções da vigilância em saúde:

- A promoção, compreendida nessa conjuntura como procedimento efetivo de transferência de informação e atribuições para atores institucionais locais e indivíduos singulares, contribuindo para viabilizar o controle difuso dos problemas de saúde por meio de mudanças de comportamento e da participação popular. E, de modo coerente com as diretrizes da nova conjuntura, limitando as responsabilidades das agências de governo central nacional e internacional e desonerando a reprodução do capital no circuito econômico principal.

- O controle estratégico de problemas de saúde emergentes ou definidos como prioritários, implementado mediante ações programáticas definidas em centros políticos e técnicos de decisão, que na conjuntura atual do capitalismo técnico-científico-informacional globalizado ultrapassam muitas vezes as fronteiras dos territórios nacionais.

Decisões políticas recentes, de grande impacto na organização do SNVS, demonstram como prioridades definidas a partir de perspectivas globais repercutem nas escalas nacional, estadual e municipal, fazendo com que as dimensões da promoção ou da segurança da vigilância em saúde se concretizem em uma multiplicidade de propostas que parecem conflitantes, mas na realidade explicitam as possibilidades múltiplas, embora freqüentemente contraditórias, de um mundo de complexidade crescente.

A criação de uma Agência Nacional de Vigilância Sanitária, apartada dos demais componentes do SNVS, com autonomia administrativa e orientada para a regulamentação de produtos industrializados e procedimentos de saúde, seguramente capazes de incorporar inovações tecnológicas de grande interesse para o capital nacional e internacional, veio atender essencialmente aos interesses de setores envolvidos na expansão e regulamentação do comércio internacional. Mas também possibilitou, com a criação de vagas de trabalho em todos os níveis do SUS, a incorporação de muitos profissionais comprometidos com a saúde dos consumidores e com o monitoramento dos processos produtivos e seus impactos na saúde e no ambiente (Costa, 2004).

O projeto Vigilância em Saúde no SUS (Vigisus), financiado pelo Banco Mundial, efetivou a integração do SNVS brasileiro no cinturão de segurança internacional de vigilância epidemiológica, sem maiores ônus para aqueles mais interessados, os países centrais, mas 
também resultou na acumulação de competência técnica em vigilância de doenças emergentes, e principalmente no apoio financeiro à consolidação dos serviços estaduais e municipais de vigilância em saúde. Desse modo, ele foi decisivo para o início de uma prática de detecção, comunicação e investigação de eventos inusitados, com base em dados qualitativos e rumores, procedentes da rede de serviços de saúde e das comunidades.

Um outro vetor de organização do SNVS na sua fase atual foi a criação da Secretaria de Vigilância em Saúde do Ministério da Saúde, que passou a assumir as funções de coordenálo, anteriormente desenvolvidas pelo Cenepi, que estava vinculado diretamente à Funasa. Essa reorganização institucional significou concentração de poder político e uma ênfase ainda maior nas funções de normatização e de gestão administrativa, em prejuízo daquelas específicas da inteligência sanitária, como integração de bases de dados, análises de situações de saúde, produção de estudos de perspectivas de problemas de saúde em cenários futuros. Mas pode também vir a criar as condições para a retomada do compromisso histórico de construção do SNVS como uma rede de instituições diversificadas, distribuídas por todo o território brasileiro, complementares e integradas em um sistema complexo, não hierarquizado, organizado fundamentalmente por seu objetivo de produzir e divulgar conhecimentos sobre as condições de saúde e seus determinantes (Teixeira, Paim \& Vilasbôas, 1998).

Compreende-se que a questão da unificação institucional de todas as vigilâncias deixou de ser relevante, dada a diversidade de problemas, de projetos e de perspectivas que caracteriza a conjuntura atual, mas que é ainda mais essencial uma construção conceitual e ideológica que integre as diferentes propostas e explicite para o conjunto da sociedade suas funções e modelos operacionais, desde a vigilância global de agravos emergentes até a vigilância civil da saúde. E que inclua, portanto, as possibilidades de construção de subsistemas de vigilância orientados para a identificação e investigação de problemas e situações críticas de saúde em comunidades, como proposto por Castellanos (1997). Esse autor propõe que os sistemas de vigilância em saúde, além de priorizar a vigilância de agravos e doenças, incorporem também a análise da tendência das condições de vida e das ações de saúde sobre o bem-estar das populações, destacando a identificação de grupos sociais vulneráveis em que houve recentemente retrocessos nas suas condições de vida e de acesso a serviços de saúde (Castellanos, 1996).

Também nessa direção têm se dado as principais contribuições dos pesquisadores brasileiros da área da saúde coletiva, propondo a construção de modelos de vigilância 
que integrem as diferentes modalidades de vigilância em saúde com as propostas de promoção e a implementação de novos modelos assistenciais. Tais pesquisas destacam a necessidade de se contemplar a dimensão da saúde como expressão da qualidade de vida e de se identificar indicadores e metodologias que permitam monitorá-los em diferentes grupos sociais.

Teixeira, Paim e Vilasbôas (1998), analisando a proposta da criação de uma vigilância da saúde no Brasil, chamam a atenção para as novas possibilidades advindas do próprio desenvolvimento do SUS, que implicaram uma autonomia da esfera municipal na gestão técnica e financeira do sistema de saúde, consorciada com uma prática de atenção integral, baseada no Programa Saúde da Família. Segundo esses autores, tais questões abrem uma real possibilidade de se repensar um modelo de vigilância da saúde de abrangência nacional, coerente com os novos rumos do SUS, que ultrapasse os indicadores de doenças e agravos e incorpore o papel de determinantes das condições de vida das populações na sua constituição. Esses questionamentos sobre as perspectivas da vigilância não deveriam ser considerados isoladamente. Eles são uma das dimensões da própria crise já identificada no campo da saúde pública, também resultante de uma crise social mais ampla, que afeta principalmente países como o Brasil e indica a necessidade de um novo projeto capaz de possibilitar o enfrentamento dos novos desafios que se apresentam para a saúde no século XXI (Paim \& Almeida Filho, 2000).

Um dos eixos desse novo projeto seria a construção de um marco teórico-conceitual que, relacionando a vigilância em saúde com a promoção da saúde, contribua para superar o paradigma científico que sustenta as práticas atuais de saúde e implica um enfraquecimento dos discursos da produção social da saúde, resultando na tecnicização da atenção à saúde e no reducionismo biologista dos modelos conceituais. Esse eixo se volta para a importância da construção da vigilância em saúde como prática e como sistema, mas também como um campo teórico da saúde pública, que integre questões que vão das categorias biológicas e ambientais às econômicas e sociais, do individual ao populacional, do local ao global, ultrapassando os limites impostos pelas disciplinas constituintes do campo (Freitas, 2003). E, como nas conjunturas anteriores, articulando conhecimentos e modelos de vigilância e modelos assistenciais voltados para o controle de problemas de saúde. Mas que desta vez possam de fato priorizar a aplicação do conhecimento acumulado, tanto nas instituições acadêmicas brasileiras como nos serviços do SUS, para a construção de um projeto orientado sobretudo pelo propósito de contribuir para melhorar as condições de vida e saúde do conjunto da população, e particularmente dos seus grupos sociais mais vulneráveis. 


\section{O MESTRADO PROFISSIONALIZANTE EM VIGILÂNCIA EM SAÚDE DA ESCOLA NACIONAL DE SAÚDE PÚBLICA SERGIO AROUCA}

Quando se situam historicamente a vigilância e seus conceitos, indica-se uma perspectiva em que as discussões sobre o Mestrado Profissionalizante em Vigilância em Saúde(MPVS) e os necessários debates acerca da própria definição de vigilância em saúde devem ser no mínimo contextualizados nas discussões sobre a própria saúde pública e sobre o programa de pós-graduação stricto sensu no qual se inserem.

Assim, tendo em vista a crise atual e a necessidade de construção e consolidação de um novo projeto de saúde pública, surge a necessidade de estruturar um MPVS que possibilite formar profissionais capazes de compreender os desafios presentes e futuros que transcendam o campo institucional do tipo de profissional convencionalmente reconhecido como sanitarista (Paim, 2003). Isso revela a possibilidade e a necessidade de um projeto de mestrado inserido em um novo contexto da saúde pública, que propicie a sua construção e consolidação, redimensione seus objetos e desenvolva novos instrumentos de trabalho. A diversificação exigida nas práticas de vigilância deve permitir uma articulação com os movimentos mais amplos da sociedade e os projetos de inclusão social, bem como criar alternativas metodológicas e técnicas para as ações no âmbito da vigilância em saúde.

Assim, os desafios que se apresentam para o MPVS envolvem mais do que capacitar administradores de serviços, mas formar lideranças técnicas e políticas em saúde, bem como contribuir para ampliar a base de inteligência do setor. Na prática isso implica um projeto pedagógico segundo o qual o profissional formado pelo MPVS deva ser capaz não só de manejar bancos de dados, formular protocolos de pesquisa e dominar métodos quantitativos, mas também de, como observam Paim e Almeida Filho (2000), analisar o contexto em relação às práticas que desenvolve; compreender a organização e gestão do processo de trabalho em saúde; exercitar um agir comunicativo ao lado do pensamento estratégico; ter habilidade para proceder a denúncias de situações e para o convencimento de interlocutores; tolerar o diálogo em situações conflituosas; estar atento aos problemas e necessidades de saúde; possuir senso crítico quanto à efetividade e ética das intervenções propostas ou realizadas; manter um permanente questionamento sobre o significado e o sentido do trabalho e dos projetos de vida.

Com base nesses princípios, a Escola Nacional de Saúde Pública, após um longo período de discussão institucional, tendo em vista as particularidades do Programa de Pós-Graduação Stricto Sensu, formulou uma proposta de mestrado profissional, na área de vigilância em 
saúde. Essa proposta nasceu da necessidade de requalificação e capacitação dos profissionais que atuam no âmbito do SUS, visando a aprimorar seus processos de trabalho e adaptando-os às novas exigências do setor, a exemplo da descentralização das ações de epidemiologia, prevenção e controle de doenças.

$\mathrm{Na}$ Ensp, essa experiência ampliou o escopo do programa de pós-graduação. Procurou-se preservar seus níveis de excelência, mas introduzindo como inovações o desenvolvimento de métodos pedagógicos apropriados e a definição de produtos rapidamente aplicáveis à gestão e a um público-alvo oriundo de demandas institucionais. O MPVS da Escola Nacional de Saúde Pública, assim desenhado, tem como objetivo qualificar gestores e profissionais em saúde e estimulá-los a desenvolver atividades de pesquisas e a produzir inovações tecnológicas orientadas para o desempenho de suas funções públicas. Essas atividades visam a capacitar os gestores e profissionais em saúde e áreas afins para o planejamento, a implementação, a operacionalização e a avaliação de políticas e programas em vigilância e para desenvolver ou incorporar novas tecnologias com enfoque epidemiológico, social e ambiental. Nesta perspectiva, o MPVS está particularmente orientado para a produção de diagnósticos de problemas e de soluções aplicadas ao Sistema Único de Saúde.

O MPVS foi construído com o intuito de integrar a gestão, as análises de políticas públicas e de situações de saúde com as práticas de vigilância em saúde. Para responder a esse desafio buscou-se adotar, nesse primeiro momento, uma perspectiva multidisciplinar, orientada para as ações de vigilância, monitoramento e gestão de programas de controle nas áreas de vigilância de doenças transmissíveis, imunopreveníveis, não-transmissíveis, de vigilância da saúde indígena, de monitoramento de indicadores de saneamento, de laboratórios de saúde pública na vigilância em saúde, de vigilância ambiental em saúde e de operacionalização de sistemas de informação em saúde.

Uma característica fundamental do MP é sua realização mediante convênios ou contratos por instituições do SUS. Em 2002 a Funasa estabeleceu um convênio com a Ensp para a implantação da primeira turma de Mestrado Profissionalizante em Vigilância em Saúde, no Distrito Federal (DF). O curso foi especialmente desenhado para atender à demanda de capacitação de gestores e profissionais do nível central, especialmente servidores do Ministério da Saúde. Uma segunda turma teve início em 2004, já como resultado de convênio com a Secretaria de Vigilância do Ministério da Saúde, integrando o componente de capacitação de recursos humanos do Projeto Vigisus.

A experiência do MPVS tem sido a de um curso interdisciplinar e interdepartamental envolvendo, mais especialmente, os departamentos de Epidemiologia e Métodos Quantitati- 
vos em Saúde e de Endemias Samuel Pessoa, mas contando com participação em disciplinas e orientação docente dos departamentos de Administração e Planejamento em Saúde, de Ciências Sociais, de Ciências Biológicas e do Centro de Estudos de Saúde do Trabalhador e Ecologia Humana da Ensp.

Em coerência com a concepção da vigilância em saúde pública desenvolvida em redes, o curso de MPVS organiza-se sob a forma de módulos integrados, tendo como objetivo a formação de equipes institucionais e tomando como referência as práticas dos serviços de saúde de origem dos alunos.

A carga horária proposta é de 680 horas, com regime de dedicação parcial, de forma a permitir atender à necessidade de adequação do curso ao processo de trabalho dos alunos, e obedece a periodicidades distintas (uma semana por mês no Distrito Federal e duas semanas a cada dois meses no curso do Rio de Janeiro).

Entre cada módulo teórico está previsto um período de atividades práticas, com exercícios e atividades monitoradas, acompanhadas pelos orientadores e tutores do mestrado. Assim, essa modalidade de curso exige uma nova estrutura pedagógica, na qual um dos grandes desafios é a adequação de técnicas de auto-aprendizado e de ensino à distância, visando a suprir as limitações de tempo em classe.

Apesar de seguir as normas da pós-graduação stricto sensu, o MPVS se distingue do mestrado acadêmico por algumas particularidades, entre elas o desenvolvimento de dissertações destinadas à resolução de problemas próprios da área em que o aluno está envolvido, empregando metodologias de avaliação de programas, sistemas ou ações de saúde, com forte ênfase no uso de dados secundários gerados pelos próprios programas.

\section{Seleç̃̃o das Turmas}

A seleção dos alunos foi feita com base em critérios formais pela coordenação dos cursos. Na primeira turma foram selecionados, após prova escrita e entrevista, 23 alunos, entre 75 inscritos. Nos primeiros meses de 2004 a turma foi submetida ao processo de qualificação do projeto de dissertação, defendendo as dissertações cerca de um ano depois. As bancas foram compostas por três professores doutores, sendo um vinculado ao Programa de Pós-Graduação da Ensp e outro externo, além do orientador. Apenas uma aluna não chegou à defesa da dissertação.

A segunda turma teve início em março de 2004 e foi constituída por profissionais lotados nas instituições da Secretaria de Vigilância em Saúde, anteriormente vinculada à Funasa sob o nome de Centro Nacional de Epidemiologia (Cenepi), e nas secretarias estaduais de Saúde. 
A seleção constou de aplicação de prova de conhecimentos específicos e de inglês, além de entrevistas, realizadas no Rio de Janeiro, Espírito Santo, Manaus e Belém.

Seguindo a mesma linha da primeira turma, esse segundo curso também foi organizado sob a forma de módulos, com duas semanas de aula a cada dois meses. As etapas presenciais do curso estão ocorrendo na Fundação Oswaldo Cruz no Rio de Janeiro. ${ }^{1}$ A composição dessa turma voltou-se sobretudo para a capacitação dos técnicos de coordenação de programas estaduais, do Sudeste e da Amazônia. Contou com 39 inscritos e 18 selecionados, tendo havido uma desistência após o primeiro módulo. Todos os alunos já cumpriram a etapa de qualificação dos projetos de dissertação, encontrando-se, atualmente, em fase de redação da dissertação.

As turmas se assemelham em relação à faixa etária, mas diferem em relação à formação profissional, pois a primeira turma contou com a participação de engenheiros de saúde pública da Funasa.

\section{Conteúdo Programático}

O curso foi construído em módulos, constituídos por disciplinas inter-relacionadas.

O módulo introdutório é composto por disciplinas que têm como função fundamentar a prática da vigilância em saúde. Fazem parte deste grupo de disciplinas Estado, sociedade e políticas de saúde, Epidemiologia I e II, Estatística I e II, Informações e informática em saúde, Gerência e análise de dados epidemiológicos, Métodos de investigação epidemiológica e Metodologia da pesquisa I.

O segundo módulo visa a instrumentalizar os alunos para o desenvolvimento de seus projetos de dissertação. É composto pelas disciplinas Vigilância em saúde pública, Laboratório de saúde pública, Comunicação e informação em saúde, Planejamento e gestão para a vigilância em saúde, Avaliação de programas de controle de doenças, Metodologia da pesquisa II.

O intervalo entre os módulos 2 e 3 é reservado para a qualificação dos projetos de dissertação.

Os dois últimos módulos têm o papel de contribuir para a redação final da dissertação. O Módulo 3 é composto por disciplinas específicas de Vigilância de doenças transmissíveis e Vigilância de doenças não-transmissiveis.

O quarto módulo tem por objetivos a finalização do projeto e a defesa da dissertação, oportunidade em que o aluno trabalha diretamente com o orientador.

${ }^{1}$ Informação referente ao ano de 2005. 


\section{Avaliação das Disciplinas}

Na elaboração da proposta do MPVS evidenciou-se a necessidade de se estruturar e implementar formas de avaliação internas, que envolvessem os alunos, de modo a permitir que estivéssemos permanentemente melhorando os nossos cursos.

Considerando-se a importância de acompanhar o desenvolvimento de cada disciplina, foi utilizado questionário de avaliação, preenchido pelos alunos, ao término de cada módulo. $\mathrm{O}$ objetivo dessa avaliação era conhecer a percepção dos alunos sobre a disciplina, seu conteúdo em relação às necessidades de aprendizagem deles, e sobre a adequação dos métodos pedagógicos empregados. Com base nas respostas dos alunos, foi possivel não só acompanhar o desempenho dos professores, como também efetuar correções de rumo, sempre que necessário.

Para cada disciplina, a avaliação feita pelos alunos considerava suas características organizativas e seus conteúdos programáticos, bem como aspectos que contribuíram para facilitar/dificultar o aprendizado. Entre os inúmeros itens avaliados, encontravam-se: aspectos organizativos; aspectos técnicos; alcance do programa; conteúdo do programa; carga horária; distribuição do horário; cumprimento do programa; discussões de casos e exercícios; material bibliográfico recebido.

A coordenação do curso, dos módulos, das disciplinas e as orientações recebidas também foram objeto de avaliação por parte dos alunos, considerando-se as seguintes variáveis: aquisição de conhecimento; estabelecimento de relações entre elementos cognitivos e experiências; aplicação dos conhecimentos às práticas de vigilância em saúde; generalização dos conhecimentos específicos dos casos discutidos em sala para outros vivenciados no cotidiano da vigilância em saúde.

Por fim, aspectos como espaço físico (instalações e ambientes especiais), infra-estrutura (salas de aula, salas de administração, biblioteca, salas de informática, serviços de alimentação, toaletes, segurança, entre outros) e equipamentos (mobiliário, recursos audiovisuais, acervo de livros, computadores) também foram avaliados.

\section{Perfil da Clientela}

Com o intuito de traçar o perfil dos alunos das turmas do MPSV, tecemos algumas comparações entre estes e os alunos do mestrado acadêmico em Epidemiologia, tomando por base as turmas de 2003 e 2004 da Ensp.

A análise da distribuição dos alunos no mestrado profissional e no acadêmico mostrou a proporção de alunos matriculados, segundo faixa etária, gênero, local de residência e perfil profissional. 
Depois da experiência profissional, a faixa etária é a variável que mais diferencia os dois mestrados: enquanto o mestrado acadêmico concentra mais de 70\% da turma com menos de 40 anos, no mestrado profissional 92\% dos alunos têm mais de 40 anos de idade. Em relação ao gênero, é mantido o padrão da saúde pública, com predomínio feminino em ambas as modalidades. Também a formação dos alunos se assemelha, havendo predomínio de médicos em ambos.

Um diferencial relevante é a origem dos alunos. No mestrado acadêmico a grande maioria dos alunos reside na cidade do curso; o MP proporciona a profissionais de outras regiões a possibilidade de formação profissional. A turma do DF atendeu basicamente a gestores de Brasilia, reservando $26 \%$ de suas vagas para profissionais de outros estados. No Rio de Janeiro, 42,1\% da turma foram constituídos por alunos da região Norte e uma aluna do Espírito Santo.

\section{CONCLUSÕES E DESAFIOS}

Até agora a oferta de mestrado na modalidade profissional tem se mostrado uma decisão acertada, ainda que demandando algumas adequações, como por exemplo a redução do tamanho das turmas e a conformação do mestrado em duas etapas, ambas postas em prática na turma de Gestão na Fiocruz. A primeira etapa seria composta por módulos básicos no primeiro ano letivo e integra um curso de especialização no tema específico, tendo como produto um projeto aplicado aos serviços. A segunda etapa, com duração máxima de um ano, conformará o mestrado profissional, cuja turma será composta pelos alunos aprovados em processo seletivo e na qualificação do projeto apresentado na primeira etapa. Para a conclusão, o aluno deverá apresentar uma dissertação com propostas de soluções de problemas e melhorias nas ações de vigilância.

Uma das críticas ao formato desta modalidade de mestrado é o fato de a clientela ficar restrita às prioridades das instituições demandantes. Por exemplo, o MPVS da Ensp inclui profissional vinculado às vigilâncias epidemiológica, do ambiente e da saúde da população indígena, não tendo sido contemplada a questão estratégica da vigilância sanitária, o que reproduz o modelo fragmentado de vigilância em saúde ainda praticado no Ministério da Saúde.

A elaboração das dissertações tendo os problemas dos serviços como foco vem contribuindo com a organização e análise de importantes bancos de dados oficiais, até então não explorados, e com a avaliação de diversos programas do Ministério da Saúde e secretarias estaduais. Chama a atenção nesta modalidade de mestrado a riqueza da contribuição dos alunos nas discussões em sala de aula. 
A experiência com as duas primeiras turmas tem mostrado que as práticas de vigilância são, atualmente, mais orientadas para a gestão. O curso tende, então, a enfatizar componentes não suficientemente desenvolvidos, como análise de dados e avaliação de processos e resultados de programas de controle de doenças e agravos.

Apesar de duas turmas já terem feito o curso, muitos desafios ainda precisam ser enfrentados:

- A capacitação de vigilância para outros níveis do SUS.

- A capacitação dos docentes para novas tecnologias de ensino à distância.

- A inclusão da vigilância sanitária no rol das vigilâncias em saúde.

- A programação do projeto de formação dos profissionais a médio e longo prazos, de forma a não comprometer o processo.

- A questão da liberação dos alunos após o término das disciplinas para o desenvolvimento da dissertação.

\section{REFERÊNCIAS BIBLIOGRÁFICAS}

ALBUQUERQUE, A. M. Indicadores gráficos de controle epidemiológico. Revista da Fundação Sesp, 20(1):105-125, 1975.

BERLINGUER, G. Medicina e Política. São Paulo: Cebes, Hucitec, 1982.

BONITA, R. et al. Surveillance of risk factors for noncommunicable diseases: the WHO STEPwise approach, 2005.

http://www.who.int/ncd/surveillance/surveillance_publications.html

BROOKMEYER, R. \& STROUP, D. Monitoring the health of populations. Oxford: Oxford University Press, 2004.

BUEHLER, J. W. Surveillance. In: ROTHMAN, K. \& GREENLAND, S. Modern Epidemiology. 2. ed. Philadelphia: Lippincott Williams e Wilkins, 1998.

CARVALHO, M. S. Avaliação da prática de vigilância epidemiológica nos serviços de saúde no Brasil, 1990. Dissertação de Mestrado, Rio de Janeiro: Escola Nacional de Saúde Pública, Fiocruz. (Mimeo.)

CASTELLANOS, P. L. Sistemas Nacionales de Vigilância de la Situacion de Salud segun Condiciones de Vida y del Impacto de las Acciones de Salud y Bienestar. Washington: Organización Panamericana de la Salud, 1996. (Mimeo.) 
CASTELLANOS, P. L. Epidemiologia, saúde pública, situação de saúde e condições de vida: considerações conceituais. In: BARATA, R. C. (Org.) Condições de Vida e Situação de Saúde. Rio de Janeiro: Abrasco, 1997.

CDC. Addressing Emerging Infectious Disease Threats: a prevention strategy for the United States. Atlanta: Public Health Service, U.S. Department of Health and Human Services, 1994.

CLEAVER, H. Malaria and the political economy of public health. International Journal of Health Service, 7(4):557-579, 1977.

COSTA, E. A. Vigilância sanitária: contribuições para o debate no processo de elaboração da agenda de prioridades de pesquisa em saúde. In: MINISTÉRIO DASAÚDE. Saúde no Brasil: contribuições para a agenda de prioridades de pesquisa. Brasília: Secretaria Nacional de Pesquisa em Saúde, 2004.

COSTA, N. R. Lutas Urbanas e Controle Sanitário. Rio de Janeiro: Vozes, 1985.

DEVINE, O. \& PARRISH, R. G. Monitoring the health of a population. In: STROUP, D.F. \& TEUTSCH, S. M. (Orgs.) Statistic in Public Health: quantitative approaches to public health problems. New York: Oxford University Press, 1998.

FOSSAERT, H.; LLOPIS, A. \& TIGRE, C. H. Sistemas de vigilância epidemiológica. Boletin de la Oficina Sanitaria Panamericana, 1974.

FRANCO-AGUDELO, S. Saúde e imperialismo: a ação antimalárica na América Latina e a Fundação Rockefeller. Rio de Janeiro: PEC, Ensp, Abrasco, 1984. (Texto de apoio de ciências sociais, 2)

FREITAS, C. M. A vigilância da saúde para a promoção da saúde. In: CZERINA, D. \& FREITAS, C. M. (Orgs.) Promoção da Saúde: conceitos, reflexões, tendências. Rio de Janeiro: Editora Fiocruz, 2003.

GORE, A. Emerging infections threaten global and national security. ASM News, 62:448-449, 1996.

HANDERSON, D. A. Surveillance of smalpox. International Journal of Epidemiology, 5(1):19-28, 1976.

JANES, R. G. et al. Descriptive epidemiology: analyzing and interpreting surveillance data. In: TEUTSCH, S. M. \& CHURCHILL, R. E. (Eds.) Principles of Public Health Surveillance. Oxford: Oxford University Press, 2000. 
LANGMUIR, A. Willian Farr: founder of modern concepts of surveillance. International Journal of Epidemiology, 5(1):13-18, 1976.

LANGMUIR, A. La vigilancia de enfermedades transmisibles de importancia nacional. In: BUCK, C. et al. (Orgs.) El Desafio de la Epidemiologia. Washington: Organización Panamericana de la Salud, 1989. (Publicación científica, 505)

MINISTÉRIO DASAÚDE. Vigilância Ambiental em Saúde. Brasilia: Ministério da Saúde, 2002.

PAIM, J. S. Vigilância da saúde: dos modelos assistenciais para a promoção da saúde. In: CZERINA, D. \& FREITAS, C. M. (Orgs.) Promoção da Saúde: conceitos, reflexões, tendências. Rio de Janeiro: Editora Fiocruz, 2003.

PAIM, J. S. \& ALMEIDA FILHO, N. A Crise da Saúde Pública e a Utopia da Saúde Coletiva. Salvador: Casa da Qualidade Editora, 2000.

PAMPANA, C. A. A Textbook of Malaria Eradication. London: Oxford University Press, 1969.

RASKA, K. National and International Surveillance of Communicable Diseases. WHO Cronicle, 20(9): 315-321, 1966.

ROMANGUERA, R. A.; GERMAN, R. R. \& KLAUCK, N. Evaluating public health surveillance. In: TEUTSCH, S. M. \& CHURCHILL, R. E. Principles of Public Health Surveillance. Oxford: Oxford University Press, 2000.

ROSEN, G. Uma História da Saúde Pública. São Paulo: Unesp, Hucitec, Abrasco, 1994.

SABROZA, P. C. Concepções de saúde e doença. Texto de apoio EAD/Ensp, 2001.

http://www.eadensp.fiocruz.br/cursos/autogestao/ags/apresentacao/autogestao/contexto/ tema1/tema1_c.html

SABROZA, P. C.; KAWA, H. \& QUEIROZ, W.S. Doenças transmissiveis: ainda um desafio. In: MINAYO, M. C. S. (Org.) Os Muitos Brasis: saúde e população na década de 80. Rio de Janeiro: Hucitec, Abrasco, 1995.

SABROZA, P. C.; TOLEDO, L. M. \& OSANAI, C. H. A. Organização do espaço e os processos endêmico-epidêmicos. In: LEAL, M. C. et al. (Orgs.) Saúde, Ambiente e Desenvolvimento. vol. 2. São Paulo, Rio de Janeiro: Hucitec, Abrasco, 1992.

SANTOS, M. Técnica, Espaço, Tempo, Globalização e Meio Técnico-CientíficoInformacional. São Paulo: Hucitec, 1994.

SILVA, L. J. Vigilância epidemiológica. In: MINISTÉRIO DA SAÚDE. Saúde no Brasil: contribuições para a agenda de prioridades de pesquisa. Brasília: Secretaria Nacional de Pesquisa em Saúde, 2004. 
SILVA JUNIOR, J. B. V. Epidemiologia em serviço: uma avaliação de desempenho do Sistema Nacional de Vigilância em Saúde, 2004. Tese de Doutorado, Campinas: Faculdade de Ciências Médicas, Universidade Estadual de Campinas.

STEPHAN, N. Gênese e Evolução da Ciência Brasileira. Rio de Janeiro: Artenova, 1976.

TEIXEIRA C. F.; PAIM, J.S. \& VILASBÔAS, A. L.SUS: modelos assistenciais e vigilância da saúde. Informe Epidemiológico do SUS, VII(2):43-7, abr.-jun., 1998.

THACKER, S. B. \& BERKELMAN, R. L. Public health surveillance in the United States. Epidemiologic Reviews, (1):164-190, 1988.

VERANI, J. F. S. A vigilância epidemiológica na erradicação de doenças: o caso da variola e da poliomielite, 1991. Dissertação de Mestrado, Rio de Janeiro: Escola Nacional de Saúde Pública, Fiocruz.

WALDMAN, E. A. Vigilância como prática de saúde pública, 1991. Tese de Doutorado, São Paulo: Faculdade de Saúde Pública, Universidade de São Paulo.

WILSON, M.; LEVINS, R. \& SPIELMAN, A. (Eds.) Disease in Evolution Annals of the New York Academy of Sciences, 740:1-503, 1994.

WISLOW, C. A. The Conquest of Epidemic Diseases: a chapter in the history of ideas. New York: Hanner Publishing Company, 1967. 


\title{
CENÁRIOS FUTUROS DO MESTRADO PROFISSIONAL DA ESCOLA NACIONAL DE SAÚDE PÚBLICA'
}

\author{
Carlos Machado de Freitas \\ Francisco Javier Uribe Rivera \\ Elizabeth Artmann \\ Ricardo Ventura Santos
}

Em 2004 a Escola Nacional de Saúde Pública Sergio Arouca (Ensp) iniciou um processo de reorganização de seu Programa de Pós-Graduação Stricto Sensu (PPGSS), que vem procurando responder a desafios externos e internos.

Observa-se, entre os desafios externos, o grande crescimento da área da saúde coletiva nos últimos anos, expresso, de acordo com Barata e Goldbaum (2003), no aumento do número e na ampliação da distribuição de programas de pós-graduação, na constituição de grupos de pesquisa, no número de pesquisadores qualificados e na consolidação da produção científica. Entre os desafios internos, em função do crescimento do número de docentes, grupos de pesquisa e linhas de pesquisa na Ensp, bem como das novas modalidades de cursos que surgiram internamente procurando atender às demandas externas de formação de quadros altamente qualificados na área da saúde coletiva, como o mestrado e doutorado interinstitucional e o mestrado profissional, destaca-se a necessidade de uma maior articulação na gestão do programa.

Foi proposto um estudo de cenários, como parte do processo de reflexão em torno de alternativas mais adequadas de reorganização do PPGSS, visando a aprofundar as possibilidades

${ }^{1}$ Este texto foi publicado na Revista Brasileira de Pós-Graduação, 2(5), 2006. 
de diferentes cenários, considerando-se os atores concretos e as variáveis importantes em sua constituição, entre as quais está o Mestrado Profissional (MP).

Para a construção dos cenários, consideraram-se alguns tópicos e questões norteadoras do estudo: 1) o objetivo de melhorar a qualidade do PPGSS-Ensp, alcançando um cada vez mais elevado nível de qualificação; 2) o atual quadro de regulação institucional e de financiamento do sistema de C\&T, que inclui a Coordenação de Aperfeiçoamento de Pessoal de Nivel Superior (Capes) e o Conselho Nacional de Desenvolvimento Científico e Tecnológico (CNPq); 3) a interface do sistema de C\&T e o sistema de saúde, considerando-se o contexto de demandas dos sistemas nacionais de C\&T e de saúde; 4) o objetivo e as questões relacionadas ao PPGSS-Ensp e a exigência de sua reorganização de forma sintonizada com o fortalecimento da área de saúde coletiva como pós-graduação e como campo de ação para melhoria das condições de vida da população brasileira; 5) os atores concretos que contribuem para a construção da pós-graduação.

Os resultados desse estudo de cenários (Rivera, Artmann \& Freitas, 2004) revelaram que o MP surge como uma variável de grande importância não só para o PPGSS-Ensp, mas para a própria área da saúde coletiva. Essa nova modalidade permite: 1) ajudar a melhor distinguir a formação de docentes e pesquisadores para a área, situados mais especificamente no mestrado acadêmico e no doutorado, da formação de quadros estratégicos para o Sistema Único de Saúde (SUS) em sua interface com o sistema de C\&T, função mais relacionada ao MP; 2) estabelecer uma relação mais estreita entre a pós-graduação stricto sensu e a lato sensu, ampliando a capacidade de formação de recursos humanos para o SUS, por meio da articulação de cursos de especialização com mestrado profissional.

\section{A ESTRATÉGIA UTILIZADA PARA CONSTRUIR OS CENÁRIOS}

Para a construção dos cenários, utilizamos uma estratégia metodológica que combinou análises quantitativas e métodos qualitativos.

A análise quantitativa considerou e utilizou: 1) dados disponíveis nos relatórios anuais da Capes, principalmente os do último triênio de avaliação (2001-2003); 2) dados disponíveis no Serviço de Gestão Acadêmica. Os dados foram sistematizados de modo a oferecer informações sobre o crescimento do PPGSS-Ensp, diversificação temática, corpo docente, corpo discente, linhas de pesquisas, disciplinas oferecidas e publicações.

Para a análise qualitativa realizamos uma adaptação do protocolo básico de construção de cenários correspondente ao enfoque da prospectiva estratégica de Michel Godet (1993) e Rivera (2003). 
Consideramos cenário um conjunto de hipóteses de comportamento futuro das variáveischave de um sistema - no caso, a pós-graduação - dependentes da dinâmica dos projetos de atores concretos, e que apresenta um bom nivel de coerência, de verossimilhança e de interesse para a estratégia de ação. Essa definição contribui para distinguir quatro propósitos gerais dos cenários: 1) ajudar a situar um plano de ação e apoiar escolhas e decisões considerando alternativas; 2) contribuir para eventuais mudanças de posição a depender de alterações em contextos; 3) questionar a rigidez de posições existentes; 4) exercer uma tensão sobre o 'determinismo cultural' das instituições, ajudando a pensar possibilidades inovadoras.

O protocolo de formulação de cenários de Godet (1993) comporta dois componentes básicos: a) a construção da base do cenário; b) a construção dos cenários. Na construção dos componentes da base do cenário da pósgraduação como um todo, o MP surgiu como uma das variáveis que externamente, segundo avaliação da Capes, e internamente, considerando-se o surgimento de novos cursos, áreas de concentração etc., teria maior impacto futuro sobre o PPGSS-Ensp. As outras variáveis escolhidas foram: a politica de avaliação da Capes; o financiamento externo einterno; as normas de credenciamento interno dos orientadores; a gestão da pósgraduação como um todo; o mercado de trabalho dos formandos/egressos; a política do lato sensu da Ensp. Considerou-se a variável: MP como um fato portador de futuro, isto é, como uma variável cujo comportamento, apesar do caráter recente da experiência, já insinua mudanças importantes na PPGSS-Ensp, que podem se acentuar e adquirir grande relevância na definição dos futuros cenários.

A construção da base do cenário global contemplou a realização de entrevistas semiestruturadas com atores-chave, definidos como aqueles com governabilidade sobre as variáveis propulsoras do cenário. Nessa construção, agrupamos todos os discursos individuais por variável da base do cenário, considerando as falas mais significativas (idéias centrais) e buscando, a partir de cada uma das variáveis e especificamente da variável-chave mestrado profissional, identificar as estratégias possíveis de cada ator.

A seleção dos atores entrevistados norteou-se pelo critério que definiu três tipos de atores: aqueles que controlam variáveis importantes para os cenários; os que representam posições dos diferentes grupos de interesse e/ou ocupam cargos que têm influência sobre as variáveis; aqueles que ocuparam a coordenação do PPGSS-Ensp e ajudaram a construíla. Foram entrevistados todos os coordenadores das subáreas de concentração da Ensp, coordenadores atuais e passados da PPGSS-Ensp, o coordenador atual da Pós-Graduação Stricto Sensu da Fiocruz, equivalente à Pró-Reitoria de Pós-Graduação das Instituições de Ensino Superior (IES), o editor dos Cadernos de Saúde Pública, antigos e o atual representante da 
área da saúde coletiva na Capes, o presidente da Associação Brasileira de Pós-Graduação em Saúde Coletiva (Abrasco), ${ }^{2}$ representantes das diversas secretarias do Ministério da Saúde $(\mathrm{MS})^{3}$ que demandam cursos de PPGSS da Ensp. Foram realizadas 21 entrevistas. Os atores identificados como especificamente implicados no controle da variável MP seriam: Abrasco, Capes, Fiocruz, Ensp e MS.

Para a construção dos cenários, foram identificadas as tendências possíveis por variável-chave, a partir das falas e estratégias verificadas nos discursos individuais e coletivos, e combinaram-se as tendências, simulando-se três cenários. O Quadro 1 mostra as variáveis de impacto, atores e tendências numa análise preliminar envolvendo três cenários (item 2.5). Dentro do quadro geral dos cenários da PPGSS/Ensp, a análise do MP deve ser considerada como um subcenário.

O estudo realizado baseou-se numa adaptação do protocolo de Godet (1993), no qual a ênfase não se colocou na formalização das probabilidades dos cenários e na aplicação rigorosa ou explícita das várias técnicas do protocolo do autor. Mais do que simular o cenário mais provável, o objetivo foi formular visões representativas de futuro que permitissem um diálogo que contribuísse para a possibilidade de estabelecer posições de consenso, de construir uma visão comum. Os cenários são vistos, nesta linha de pensamento, como instrumentos de diálogo, que podem ajudar a distinguir a ancoragem (ideológica) das falas sobre o futuro, explicitando posições no debate. Os cenários previstos podem ser reconstruídos dinamicamente com base nos argumentos e nas estratégias dos atores que agrupamos por variável propulsora do cenário.

As entrevistas foram transcritas por um profissional contratado, e a análise qualitativa do conteúdo das entrevistas utilizou o método de análise do discurso coletivo de Lefèvre, Lefèvre e Teixeira (2000) adaptado por Artmann (2002), considerado mais apto a captar a questão do significado e da intencionalidade como inerentes aos atos, às relações e às estruturas sociais, sendo estas últimas tomadas, tanto no seu advento quanto na sua transformação, como construções humanas significativas. Identificaram-se os discursos coletivos a partir de idéias centrais e palavras-chave dos discursos individuais. Na construção dos discursos coletivos do nosso estudo, foi particularmente útil a análise do material dos discursos individuais

\footnotetext{
2 Entre agosto e dezembro de 2004, as posições de representante de área da saúde coletiva e de presidente da Abrasco foram ocupadas pelo Dr. Moisés Goldbaum.

${ }^{3}$ Secretaria de Atenção à Saúde, Secretaria de Ciência, Tecnologia e Insumos Estratégicos, Secretaria de Gestão do Trabalho e da Educação em Saúde, Secretaria de Vigilância em Saúde.
} 
dos vários atores da Ensp, pela representatividade relativamente maior do levantamento feito dentro da instituição. A análise procurou extrair de cada discurso individual as idéias centrais e expressões-chave, para depois agregar ou articular as idéias-chave semelhantes em discursos coletivos coerentes. O objetivo foi reconstruir, com pedaços de discursos individuais, como em um quebra-cabeça, tantos discursos-síntese quantos necessários para expressar uma dada representação social sobre um fenômeno - no caso do estudo, o futuro da pós-graduação da Ensp e do seu MP. Buscamos construir as visões de futuro que representam discursos coletivos, considerando os discursos individuais e coletivos sobre as tendências futuras como uma base analítica para construção dos cenários possíveis.

\section{O MESTRADO PROFISSIONAL NO DISCURSO DOS ATORES}

Devido à complexidade e ao volume de informações, não é possível detalhar aqui, em termos quantitativos, o quadro atual do PPGSS na Ensp. Contudo, alguns aspectos marcantes merecem atenção. Em primeiro lugar, o PPGSS-Ensp cresceu muito nos últimos cinco anos, havendo uma tendência de estabilização em anos mais recentes. Consideramos como fatores que contribuíram para esse quadro a ampliação da oferta de cursos no PPGSS-Ensp, incluindo turmas de mestrado e doutorado interinstitucional, além do mestrado profissional. Em termos da ampliação da oferta, o MP acabou tornando-se uma variável-chave de grande importância, tanto pelas mudanças qualitativas que vem induzindo no processo de organização da PPGSS-Ensp como por seu impacto quantitativo.

Com relação às mudanças qualitativas, estas se encontram associadas aos próprios objetivos desses cursos na Ensp, que incluem, em particular, a formação de profissionais oriundos de instituições governamentais (municipais, estaduais e federais) comprometidos com processos dinâmicos de transformação institucional e de inovação gerencial. Almeja-se que esses profissionais atuem como formadores e indutores de processos de mudança em suas instituições de trabalho mediante a adoção de novos conceitos e práticas, desenvolvendo produtos aplicáveis ao desenvolvimento do SUS e do sistema de C\&T.

Nessa perspectiva, o MP fortalece no PPGSS-Ensp a necessidade da organização de grupos de pesquisadores/docentes como núcleos básicos para este tipo de formação e exige dos docentes um esforço de desenvolvimento de novas estratégias pedagógicas, de material didático próprio e de tecnologias de ensino que possibilitem atender aos alunos que permanecem nos seus locais de trabalho e têm as atividades de aulas em períodos concentrados. 
Em termos de impactos quantitativos, que acabam por se refletir nas mudanças qualitativas, o MP ocupa hoje na Ensp um papel tão importante, ainda que diferenciado, quanto o do mestrado acadêmico e do doutorado. Em 2003, dos 463 alunos matriculados no PPGSSEnsp no início do ano-base, 168 (36,3\%) estavam no mestrado acadêmico, 144 (31,2\%) no doutorado, 130 (28\%) no mestrado profissional e 21 (4,5\%) no mestrado interinstitucional (ver Gráfico 1). Como podemos verificar no gráfico, mais de um quarto dos alunos estavam no mestrado profissional, e o percentual dos alunos matriculados nesta modalidade de curso pode vir a crescer ainda mais nos próximos anos.

Gráfico 1 - Distribuição dos alunos matriculados em 2003 por tipo de curso

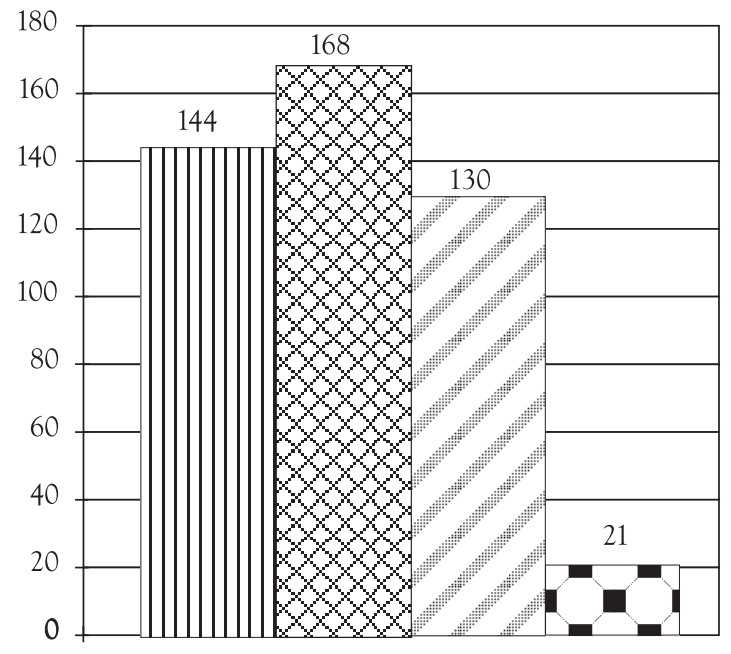

Número de alunos
III Doutorado Acadêmico

\% Mestrado Acadêmico

Mestrado Profissional

Mestrado Interinstitucional

Em 2003, os alunos do MP se encontravam matriculados em duas áreas de concentração: Gestão em Saúde e Vigilância em Saúde. Na área de concentração Gestão em Saúde, estavam em andamento os seguintes cursos: 1) Gestão em Sistemas e Serviços de Saúde, oferecido para técnicos da Secretaria de Atenção à Saúde do Ministério da Saúde; 2) Gestão em C\&T em Saúde, oferecido para técnicos da área de gestão da Fiocruz; 3) Regulação em Saúde Suplementar, oferecido para técnicos da Agência Nacional de Saúde Suplementar; 4) Gestão da Informação e Comunicação em Saúde, oferecido para técnicos da área de informação e comunicação da Fiocruz. Na área de concentração Vigilância em Saúde encontrava-se em andamento o curso de Vigilância em Saúde, oferecido para técnicos da Secretaria de Vigilância em Saúde e da Fundação Nacional de Saúde. O número de alunos matriculados nesses 
quatro cursos pode ser considerado bastante alto, levando-se em conta que se trata de uma experiência inicial que já aponta para o potencial dessa modalidade.

Como procuramos mostrar, o MP é uma variável-chave que não se constitui apenas em uma nova modalidade, mas traz impactos sobre a PPGSS-Ensp e induz a mudanças. De modo a termos elementos de análise que possibilitem melhor incorporar essa modalidade no PPGSSEnsp, apresentamos o discurso individual de alguns dos diferentes atores entrevistados que, em seguida, são agrupados conforme as falas mais significativas (idéias centrais), buscando-se, a partir da variável-chave MP, identificar as estratégias possíveis e os diferentes cenários.

O Discurso Individual dos Atores sobre o Mestrado Profissional

$$
\text { Abrasco e Capes }
$$

Para este ator, com dupla representação na época, o MP é a melhor alternativa para formar, em nível avançado, quadros estratégicos do SUS. Contudo, deve-se evitar sua massificação, preservando-se a importância do mestrado acadêmico. Este ator defende a avaliação em separado do MPe, portanto, considera a necessidade de criação de um comitê de mestrado profissional na Capes, com alguns critérios diferentes dos utilizados para o mestrado acadêmico e o doutorado. Por fim, considera ainda a proposta de redução do mestrado acadêmico, o que ajudaria a liberar recursos para o doutorado e o mestrado profissional.

\section{Secretaria de Gestão do Trabalho - MS}

Para este ator, o MP contribui para diminuir expectativas a que o mestrado acadêmico não poderia atender e observa que, antes da criação desta modalidade, o mestrado acadêmico era a única alternativa para os profissionais/quadros estratégicos do SUS. Em relação ao MP, considera que: 1) deve substituir a especialização na formação de quadros estratégicos, e por isso deve privilegiar na seleção os profissionais mais permanentes do SUS e com ele comprometidos; 2) deve ser de natureza mais interdisciplinar, menos voltado para uma especialização em particular, e interinstitucional, priorizando o objetivo da desconcentração para regiões não incluídas; 3) deve se organizar como um sistema modular de ensino, com ênfase na formação em serviço e na educação permanente. Em relação a este último aspecto, defende um itinerário ou roteiro de aprendizagem em que experiências de ensino em serviço, mais informais, sejam acreditadas, e se somem a cursos mais formais, em um processo que levaria, no final, ao diploma de especialização. O MP é visto como um dos desdobramentos da especialização, dentro desta visão.

Em termos de financiamento, considera a necessidade de o MS ter uma visão de sistema, ou seja, contratar cursos para estados e regiões, priorizando em tais cursos as pro- 
blemáticas específicas envolvidas. Isso significa envolver as secretarias de Saúde, inclusive no financiamento parcial do curso.

No que diz respeito aos critérios de avaliação pela Capes para o MP, considera que o Ministério da Saúde deve ser um ator ativo que contribua para negociar/propor com o Ministério da Educação, e com a própria Capes em particular, critérios de avaliação diferenciados para o MP, que levem em conta a relevância social e o impacto dos cursos e da produção pertinente, assim como a sua qualidade.

\section{Secretaria de Ciência e Tecnologia - MS}

Para este ator, existiria uma tendência de redução ou mesmo extinção do mestrado acadêmico, fortalecendo-se na modalidade acadêmica o doutorado. O MP responderia às necessidades do mercado, havendo uma tensão entre estas e as necessidades de avaliação da Capes. Considera que uma das prioridades é a de um MP sobre o tema 'avaliação tecnológica em saúde', com características interdisciplinares e interinstitucionais. Considera, ainda, para diferentes áreas temáticas, a importância de estratégias de desconcentração regional, com grupos fortes das regiões, como a Sudeste, apoiando grupos incipientes em outras regiões, o que não se restringe somente ao MP.

$$
\text { Ensp/Fiocruz }
$$

$\mathrm{Na}$ Ensp/Fiocruz encontrou-se grande diversidade de discursos. Para dar visibilidade a essa diversidade, apresentamos os diferentes tópicos sobre o MP presentes nas falas dos entrevistados:

- Discurso a favor de uma única modalidade de mestrado profissionalizante, em saúde pública, que permita um padrão de interação entre as pessoas.

- Diferenciação entre os dois mestrados (o acadêmico e o profissional), recortando o conteúdo do MP em função do nicho institucional em que se situa. Posicionamento a favor de resgatar no MP um núcleo transversal de competências básicas de saúde coletiva, apesar de sua especialização. Alguns atores consideram que o MP já é um exemplo de curso com um núcleo mínimo de formação em planejamento, epidemiologia e ciências sociais.

- Fusão do mestrado acadêmico com o mestrado profissional, gerando um curso de caráter mais executivo, simplificado, moderno. Um ator mencionou explicitamente esta possibilidade, sem se referir claramente a formas de regulação da entrada da clientela e defendendo critérios de avaliação próprios ou diferenciados em relação aos critérios atuais do mestrado acadêmico. 
- Articulação do MP com o lato sensu, com cursos de especialização especialmente desenhados para o MP, dentro de uma proposta de sistema modular, regulando o ingresso no curso de modo a receber uma clientela com formação básica em saúde pública ou coletiva, com projetos qualificados, destacados. Os argumentos que sustentam esta posição referem-se à possibilidade de ampliar o corpo docente, de regular a clientela e de integrar áreas distintas da Ensp, como a Escola de Governo e a PósGraduação Stricto Sensu.

- Proposta de estabelecimento de um compromisso mútuo entre o aluno do MP e o gestor superior de sua instituição de origem, de modo a assegurar que o produto da dissertação seja efetivamente implementado. Ou seja, ênfase na concepção de que o processo de produção do MP deve ser visto como uma pesquisa de implementação.

- Reconhecimento de que o mestrado profissional e a educação à distância constituem os braços da pós-graduação junto ao SUS.

- Reconhecimento de que o MP pode ser considerado um dos eixos básicos de estruturação da pesquisa da Ensp, entendendo-se que o que a distingue das universidades é ser uma instituição do MS, devendo gerar instrumentos aplicáveis ao sistema de saúde.

\section{TENDÊNCIAS IDENTIFICADAS}

Com base nos posicionamentos discursivos dos diferentes atores apresentados aqui, alguns refletindo mais claramente estratégias, estabelecemos algumas tendências possiveis:

1. Substituição paulatina do mestrado acadêmico pelo mestrado profissional, ou fusão progressiva dos dois, com alguma forma de regulação da entrada da clientela e com critérios de avaliação que extrapolam os atuais do mestrado acadêmico, incluindo critérios de relevância social e de impacto sobre oSUS, na perspectiva de um mestrado mais executivo.

2. Manutenção das duas formas de mestrado, com uma diferenciação clara que se explica: a) pela interação específica do mestrado acadêmico com o doutorado; b) pela necessidade de um recorte temático e metodológico induzido pelo tipo de demanda institucional específica, no caso do MP; c) pelos critérios de avaliação específicos e diferenciados para ambas as modalidades. Seria uma tendência de manutenção, com um conteúdo de mudança discreta, referente a uma maior precisão de critérios de avaliação e de credenciamento de docentes, e possivelmente de conteúdos, no sentido da eventualidade de uma construção horizontal ou da definição de um núcleo mínimo de saúde coletiva, integrador, para o mestrado acadêmico e para o mestrado profissional, não necessariamente igual. 
3. Mestrado profissional como desdobramento do lato sensu, com regulação da entrada, com a garantia prévia de conhecimentos mínimos de saúde coletiva, oferecidos pela especialização, e com critérios diferenciados de avaliação em relação ao mestrado acadêmico. O MP seria mais claramente diferenciado do mestrado acadêmico, articulando a pósgraduação la to sensu e a stricto sensu.

4. Mestrados profissionais interinstitucionais, de cooperação entre escolas de saúde pública e universidades, entre instituições emergentes e de áreas não incluídas. Esses mestrados estariam voltados para o desenvolvimento de sistemas nestas últimas áreas, em uma perspectiva de desconcentração. Esta tendência poderia se combinar com as anteriores e demandaria uma profunda revisão dos atuais critérios de avaliação da Capes voltados para programas de uma única instituição.

\section{Os Discursos Coletivos dos Atores da Ensp/Fiocruz sobre o Mestrado Profissional}

Tendo como referência os diferentes discursos dos atores da instituição e seus posicionamentos, podemos identificar três discursos coletivos:

\section{Discurso Coletivo 1}

- Menor ênfase no mestrado profissional; poucas referências a ele, e apenas de caráter diagnóstico: curso de muita utilidade para a formação de quadros estratégicos do sistema; uma sobrecarga para o PPGSS-Ensp como um todo; uma alternativa que coloca mais dúvidas sobre a missão indefinida do mestrado acadêmico.

\section{Discurso Coletivo 2}

- Manutenção do mestrado acadêmico e do mestrado profissional como programas diferenciados. O mestrado acadêmico definiria sua especificidade pela sua forte interação com o doutorado, no que diz respeito a temas de fronteira do conhecimento, ao nível de desenvolvimento científico e à metodologia de produção do conhecimento. Já o MP teria sua singularidade delineada em relação às demandas do nicho institucional em que se situa, implicando um recorte técnico específico.

- Defesa da necessidade de um núcleo mínimo, em construção transversal, de competências básicas em saúde pública nos dois mestrados e, em alguma medida, no doutorado.

\section{Discurso Coletivo 3}

- Avança na formulação estratégica ao propor uma articulação entre o mestrado profissional e o lato sensu. Nessa ótica, o mestrado profissional seria um desdobramento de cursos de 
especialização, tendo por clientela os alunos que apresentassem projetos mais consolidados e adequados ao perfil do stricto sensu de recorte profissional. A especialização representaria ou conteria uma construção mais transversal, de conteúdos básicos de saúde pública. Neste caso, não seriam cursos de especialização nos moldes tradicionais, mas cursos especialmente desenhados para tal finalidade, ou seja, servir como primeiro degrau para um mestrado profissional, oriundos de uma demanda institucional específica e relacionada ao Sistema Único de Saúde.

- Uma variante discursiva considera que se processa uma tendência de substituição do mestrado acadêmico pelo mestrado profissional, sublinhando que o primeiro atualmente ainda recebe uma clientela típica do segundo, o que contribui para que se revista de um conteúdo cada vez mais instrumental. Propõe uma fusão progressiva dos dois mestrados, e uma maior flexibilidade, dentro de uma linha mais executiva, modernizante. Chega a assinalar que, dada essa miscigenação, o termo 'profissional' pode vir a desaparecer.

- Esta alternativa inclui a defesa de um sistema modular ou de créditos, em que lato sensu, mestrado (acadêmico e profissional) e doutorado estariam entrelaçados, fazendo parte de uma pirâmide acadêmica.

\section{Combinando os Discursos Individuais e \\ Coletivos e Construindo Cenários}

Dos discursos individuais e coletivos, analisados a partir do pano de fundo das variáveis selecionadas a priori e dos resultados da análise quantitativa realizada de modo detalhado em outro documento (Rivera, Artmann \& Freitas, 2004), foram construídas três possibilidades de cenários.

\section{O MP no Cenário 1}

Este cenário não traz uma mudança substantiva da estrutura do PPGSS-Ensp, mas admite modificações importantes, como: critérios diferenciados de avaliação para o MP; flexibilização/ampliação de critérios de credenciamento de docentes; possibilidade de uma construção transversal ou de um núcleo mínimo de disciplinas ou de conteúdos básicos de saúde pública/coletiva nos dois mestrados, não necessariamente semelhantes e, eventualmente, no doutorado; mais clara diferenciação entre os mestrados. Neste cenário, a hipótese de um único mestrado profissional é pouco representativa, admitindo-se uma variedade de cursos. Inclui a possibilidade de alguma experiência de mestrado profissional interinstitucional. 


\section{O MP no Cenário 2}

O mestrado profissional, neste cenário, évisto como plural, situado no âmbito do PPGSSEnsp, porém diferenciado mais claramente do mestrado acadêmico. As modificações procedimentais e curriculares previstas para o primeiro cenário, sobre critérios de avaliação e de credenciamento de docentes e sobre a necessidade de um núcleo integrador de competências básicas, estariam contempladas. A possibilidade de experiências interinstitucionais eventuais, não como norma, está também aqui prevista. A colocação específica do MP neste cenário difere do seu comportamento no anterior basicamente por uma questão de ênfase. Neste cenário, o MP é mais claramente aceito como uma necessidade de formação de quadros estratégicos do SUS, superando eventuais dúvidas em relação ao seu papel, e o nível de sua diferenciação em relação ao mestrado acadêmico é mais claro em função de um maior aprofundamento de seu desenho estratégico.

\section{O MP no Cenário 3}

O ponto de clivagem aqui corresponde à introdução de um sistema modular de ensino/ aprendizagem, no qual o MP está articulado ao lato sensu, e o núcleo mínimo de conteúdos de epidemiologia e estatística, planejamento e gestão e ciências sociais em saúde estaria garantido pela especialização. No MP seriam selecionados os melhores projetos dos cursos de lato sensu vinculados a uma demanda institucional do SUS. Ou seja, do total de alunos selecionados, apenas o percentual que apresentasse perfil ou competência adequados, em um segundo processo de seleção a partir dos projetos aprovados, iria para o mestrado profissional. Este cenário pressupõe inicialmente critérios diferenciados de avaliação da modalidade acadêmica e profissional, embora admita a influência mútua entre os mestrados. Destaca-se a preocupação com a qualidade e não se descarta como uma tendência possível a integração progressiva de ambos os mestrados.

\section{Pontos Comuns e de Diferenciação para \\ o Mestrado Profissional nos Três Cenários}

Um dos pontos comuns aos vários discursos coletivos e aos cenários possíveis em relação ao MP é a necessidade de critérios diferenciados de avaliação em relação ao mestrado acadêmico. Para ambos é colocada a necessidade de um núcleo de conteúdos básicos de saúde pública (que não precisa ser idêntico para o mestrado profissional e o mestrado acadêmico). 
Entre os pontos de diferenciação mais destacados dos vários discursos coletivos e dos cenários possiveis, temos:

- Com relação aos processos de regulação do MP, temos um discurso a favor de um formato específico para ele, mantendo-o diferenciado do acadêmico, e um discurso favorável a que se mantenha um único curso nesta modalidade, aproximando MP e mestrado acadêmico. Uma ênfase diferenciada sobre o MP também pode ser mencionada como fator secundário de discriminação, havendo menor ênfase para esta modalidade no Cenário 1.

- A proposta de um MP articulado ao lato sensu e ao stricto senso, que se perfila como uma possibilidade para os cursos de mestrado profissional já em andamento, como o de Gestão em C\&T em Saúde e o de Avaliação de Programas de Controle de DST/Aids. Ambos os cursos vêm contribuindo para uma discussão envolvendo a Escola de Governo e a Pós-Graduação Stricto Sensu, sendo, portanto, uma tendência possível em cada um dos três cenários.

- Embora a tendência a favor de uma articulação entre o lato sensu e o stricto sensu em torno do mestrado profissional seja teoricamente possível nos três cenários, pois já se verifica como fato portador de futuro na conjuntura atual, acreditamos que é um ponto que discrimina mais claramente o Cenário 3. Neste cenário essa tendência é mais coerente com o desenvolvimento de uma reestruturação da pesquisa em linhas de pesquisa institucionais e grupos de pesquisa dinâmicos, voltados para o reforço da produtividade necessária à afirmação do PPGSS-Ensp atual e de novos possíveis programas. A necessidade de que os programas sejam sustentáveis exige uma agressiva política de pesquisa, articulando grandes grupos de pesquisa multitemáticos, com os alunos fortemente vinculados. Por outro lado, a necessidade de um uso mais racional do tempo de trabalho dos docentes, que signifique maior inclusão de docentes credenciados e sua interação, propicia uma economia de tempo indispensável ao esforço de pesquisa. Assim, a articulação lato e stricto sensu se verificaria com maior intensidade no Cenário 3, por ser mais coerente com as outras tendências: pluralidade programática e reestruturação da pesquisa nas bases anteriores, numa análise de impactos cruzados, ou seja, da probabilidade de ocorrência de uma tendência em função da ocorrência ou não das outras.

É importante afirmar, em termos de uma análise crítica da construção de cenários, que teria sido mais acertado escolher desde o início do trabalho o aspecto 'política de pesquisa', incluindo a estrutura das linhas e grupos de pesquisas como variável-chave do cenário. 
Corrigimos essa omissão a posteriori, na análise dos cenários possíveis, acrescentando de maneira implícita essa variável, pois ela condiciona significativamente o formato do PPGSS-Ensp, na medida em que a pluralidade programática depende, para se sustentar, como afirmado anteriormente, de uma reorganização significativa da pesquisa nos moldes preconizados. Por outro lado, salientamos que a articulação do MP com o lato sensu enseja a possibilidade de reforçar a articulação de grupos de pesquisas mais dinâmicos, que incluem pesquisadores doutores e mestres, que participariam de forma integrada nos diferentes níveis de formação. A primeira fase seria constituída pela especialização e, com as disciplinas já cursadas e o projeto já concluído, os alunos poderiam passar para a segunda etapa, constituída pelo mestrado profissional, em que desenvolveriam sua dissertação. Essa articulação se apresenta como uma possibilidade que deve ser desenvolvida, de modo a permitir, nos distintos níveis de formação, a participação do maior número de docentes existentes na Ensp.

Vale observar que o discurso que sustenta o Cenário 3 enfeixa tendências típicas de um cenário normativo, ou seja, de um cenário desejado ou desejável do ponto de vista da coordenação da Pós-Graduação e da direção da Ensp. O Cenário 2 é o cenário de um PPGSS plural com um forte orientação acadêmica, ainda que considere o mestrado profissional. $\mathrm{O}$ Cenário 1 é um cenário que admite mudanças procedimentais e de conteúdo do PPGSS sem firmar uma tendência clara rumo à pluralidade ou à mudança de estrutura, o que inclui o mestrado profissional.

Com base nos relatados anteriormente, apresentamos a seguir um quadro-síntese (Quadro 1) de todas as variáveis propulsoras do cenário, os atores que as controlariam, as tendências possiveis por variável, deduzidas das falas e das estratégias dos atores, no nível tanto do discurso individual como no do coletivo, e os cenários possíveis, resultantes das combinações de tendências.

O Cenário 3 apresenta algumas vantagens, entre as quais destacamos a possibilidade de uma maior articulação entre a PPGSS e a Escola de Governo em Saúde (lato sensu), resultando em maior inclusão do corpo docente, com possibilidade de maior articulação e integração entre os pesquisadores docentes doutores e mestres, atuando na especialização articulada com o MP, constituindo grupos de trabalho que atuam de forma interdependente no la to e no stricto sensu. Além disso, este cenário traz consigo a possibilidade de uma seleção mais criteriosa para o MP, propiciando potencialmente dissertações de maior qualidade e um potencial impacto positivo sobre a constituição e dinâmica de funcionamento dos grupos de pesquisa. Há também a possibilidade de usar recursos do MP em benefício da pósgraduação como um todo, o que inclui o lato sensu e o stricto sensu. Um desafio a ser 
enfrentado refere-se ao caráter da construção transversal. Defende-se que, para além de um simples somatório de conteúdos disciplinares oriundos do mestrado acadêmico, os conteúdos sejam mais integrados, articulando equipes mais interdisciplinares, capazes de desenvolver novas estratégias pedagógicas, materiais didáticos próprios e uso de tecnologias de ensino que possibilitem atender os alunos que permanecem nos seus locais de trabalho e têm aí um dos eixos do processo ensino-aprendizagem.

Quadro 1 - Variáveis, atores e tendências para a construção de cenários - análise preliminar

\begin{tabular}{|c|c|c|c|}
\hline $\begin{array}{l}\text { Variáveis de } \\
\text { impacto sobre } \\
\text { o cenário }\end{array}$ & $\begin{array}{l}\text { Atores que as } \\
\text { controlam }\end{array}$ & Tendências & Cenários \\
\hline \multirow[t]{4}{*}{$\begin{array}{l}\text { Política de } \\
\text { mestrado } \\
\text { profissional }\end{array}$} & \multirow[t]{4}{*}{$\begin{array}{l}\text { Capes, Fiocruz, } \\
\text { Ensp, MS }\end{array}$} & $\begin{array}{l}\text { Diferenciação maior entre os dois mestrados, no } \\
\text { que diz respeito às competências básicas e aos } \\
\text { conteúdos específicos. Íntima associação do } \\
\text { mestrado profissional com o mestrado } \\
\text { acadêmico. }\end{array}$ & Cenários 1 e 2 \\
\hline & & $\begin{array}{l}\text { Mestrado profissional articulando níveis distintos } \\
\text { de formação (lato sensu e stricto sensu). Neste caso, } \\
\text { seriam desenhados cursos de especialização } \\
\text { específicos, que poderiam ser articulados com o } \\
\text { mestrado profissional. }\end{array}$ & Cenário 3 \\
\hline & & $\begin{array}{l}\text { Mestrado profissional interinstitucional e } \\
\text { interdisciplinar. }\end{array}$ & Cenários 1,2 e 3 \\
\hline & & $\begin{array}{l}\text { Substituição paulatina do mestrado acadêmico } \\
\text { pelo mestrado profissional. Fusão, pluralidade de } \\
\text { programas, regulação seletiva da entrada e } \\
\text { critérios de avaliação redimensionados. }\end{array}$ & Cenário 3 \\
\hline \multirow{2}{*}{$\begin{array}{l}\text { Financiamento } \\
\text { externo } \\
\text { - Ensino } \\
\text { - Pesquisa }\end{array}$} & \multirow{2}{*}{$\begin{array}{l}\text { CNPq, Capes, } \\
\text { Finep, Faperj, } \\
\text { Fundações } \\
\text { internacionais, } \\
\text { MS, Conasems } \\
\text { e Conass }\end{array}$} & $\begin{array}{l}\text { Aumento incremental do financiamento } \\
\text { acompanhando a tendência histórica. }\end{array}$ & Cenário 1 \\
\hline & & $\begin{array}{l}\text { Aumento significativo do número de bolsas em } \\
\text { função da criação de novos PPGSS e do incentivo } \\
\text { às linhas e grupos de pesquisa. }\end{array}$ & Cenários 2 e 3 \\
\hline \multirow{2}{*}{$\begin{array}{l}\text { Credenciamen } \\
\text { to interno de } \\
\text { docentes }\end{array}$} & \multirow{2}{*}{$\begin{array}{l}\text { Capes, } \\
\text { Ensp/Fiocruz }\end{array}$} & Diversificação e diferenciação de critérios. & Cenários 1 e 2 \\
\hline & & Diversificação de critérios. & Cenário 3 \\
\hline $\begin{array}{l}\text { Política de } \\
\text { avaliação da } \\
\text { Capes }\end{array}$ & $\begin{array}{l}\text { Capes, } \\
\text { Sociedades } \\
\text { cientificas }\end{array}$ & $\begin{array}{l}\text { Continuidade da política, com a possibilidade de } \\
\text { uma diferenciação de critérios para o mestrado } \\
\text { profissional. }\end{array}$ & Cenários 1,2 e 3 \\
\hline
\end{tabular}


Quadro 1 - Variáveis, atores e tendências para a construção de cenários - análise preliminar (continuação)

\begin{tabular}{|l|l|l|l|}
\hline $\begin{array}{c}\text { Variáveis de } \\
\text { impacto sobre } \\
\text { o cenário }\end{array}$ & $\begin{array}{c}\text { Atores que as } \\
\text { controlam }\end{array}$ & \multicolumn{1}{|c|}{ Tendências } & Cenários \\
\hline $\begin{array}{l}\text { Mercado de } \\
\text { trabalho para } \\
\text { formandos }\end{array}$ & $\begin{array}{l}\text { SUS, } \\
\text { Universidades, } \\
\text { Agências }\end{array}$ & $\begin{array}{l}\text { Aumento da demanda pelos cursos em todos os } \\
\text { níveis da pós-graduação, particularmente no } \\
\text { doutorado (devido ao grande déficit de doutores } \\
\text { ainda existente no país, para atuação em } \\
\text { instituições de ensino superior tanto públicas } \\
\text { como privadas, além de no restante da rede de } \\
\text { C\&T) e no mestrado profissional (pelo interesse } \\
\text { do SUS em ter mestres nos seus quadros). }\end{array}$ & Cenários 1, 2 3 \\
\hline $\begin{array}{l}\text { Gestão da pós- } \\
\text { graduação }\end{array}$ & Ensp, Fiocruz & $\begin{array}{l}\text { Manutenção da estrutura da pós-graduação, com } \\
\text { modificações procedimentais e de conteúdos } \\
\text { curriculares. }\end{array}$ & Cenário 1 \\
\cline { 2 - 5 } & $\begin{array}{l}\text { Pós-graduação plural, com o mestrado } \\
\text { profissional como uma das novas modalidades } \\
\text { situadas no âmbito do stricto sensu. }\end{array}$ & Cenário 2 \\
\cline { 2 - 5 } & $\begin{array}{l}\text { Pós-graduação plural, com o mestrado } \\
\text { profissional articulando o lato sensu com o stricto } \\
\text { sensu. }\end{array}$ & Cenário 3 \\
\hline
\end{tabular}

Fonte: Rivera et al., 2004

\section{O MESTRADO PROFISSIONAL NOS CENÁRIOS FUTUROS PARA A PÓS-GRADUAC̣ÃO NA ENSP}

Nas discussões que se seguiram ao projeto de construção de cenários, fortaleceu-se a idéia de que o mestrado profissional corresponde a uma variável-chave no processo de reorganização da PPGSS na Ensp e, talvez, na própria área da saúde coletiva. Contudo, para a continuidade do processo de reorganização que implique impacto positivo a partir da variável MP, não se pode perder de vista os objetivos colocados no início do estudo dos cenários. Em síntese, esses objetivos envolvem tanto melhorar a qualidade do PPGSS-Ensp, considerando o atual quadro de regulação institucional e de financiamento do sistema de C\&T, como ampliar a capacidade de formação de profissionais que atuem na interface do sistema de C\&T com o sistema de saúde, sintonizado com o fortalecimento daárea de saúde coletiva como pósgraduação e como campo de ação para a melhoria das condições de vida da população brasileira.

Para tanto, há a necessidade de um forte comprometimento institucional da Ensp, demonstrado pela aprovação e apoio dos colegiados superiores e da direção. Uma ampla reorgani- 
zação, particularmente considerando um cenário normativo/desejável, como o Cenário 3, terá implicações sobre toda a PPGSS na Ensp, envolvendo desde o processo de trabalho dos docentes, que passaria a ser menos centrado no indivíduo e mais no grupo de pesquisa, até as mudanças na estruturação dos cursos lato sensu e sua interface com o stricto sensu. No nível da direção da Ensp existe hoje um forte comprometimento institucional com as mudanças que devem ocorrer na pós-graduação stricto sensu, particularmente com referência ao Cenário 3 e ao mestrado profissional. Entretanto, para que esse comprometimento institucional se fortaleça, é necessário que o debate sobre essas mudanças se amplie e passe a envolver de forma mais direta a Escola de Governo (lato sensu) e o próprio Conselho Deliberativo da Ensp.

Como se trata de reestruturar o PPGSS, esse processo de organização/reorganização em nenhum momento pode estar desvinculado do perfil da formação profissional que se pretende com os cursos na Ensp e que se relaciona ao próprio campo da saúde coletiva, no qual se articulam a construção de saberes e as ações práticas. Assim, não podemos deixar de considerar algumas tendências de mudanças e/ou continuidade no quadro político, econômico e social do país, que impactam o quadro de saúde da população brasileira. De acordo com o documento 'Brasil 2020: cenários exploratórios', publicado pela Secretaria de Assuntos Estratégicos em 1998, um dos cenários de maior tendência para o país apontava para o seguinte quadro: a) Do ponto de vista político, ampliação do papel da sociedade tanto no controle da gestão pública, como na suplementação ou mesmo substituição de algumas áreas que seriam responsabilidade do Estado, associada a uma maior descentralização político-administrativa, com reforço das instâncias estaduais e municipais na gestão dos recursos e serviços, o que na nossa área reflete-se diretamente na dinâmica e funcionamento do SUS; b) Do ponto de vista econômico, o Estado orienta-se para a gestão da estabilidade econômica e desenvolvimento do mercado, a abertura da economia ao mercado internacional com aumento do volume total do comércio exterior e a competitividade em nichos específicos. Por outro lado, o mercado interno amplia-se de forma segmentada em decorrência dos desníveis de renda e eleva-se a participação do setor terciário, com declínio moderado do peso da agricultura. Como resultado desse processo, tenderia a ocorrer um crescimento econômico, com aumento do PIB e da renda per capita, porém persistindo uma má distribuição de renda e da concentração espacial da economia nas regiões Sul e Sudeste; c) Do ponto de vista social, persistiria o baixo nível de escolaridade e de qualificação para o trabalho, não condizentes com um novo padrão tecnológico, e manter-se-ia uma reduzida capacidade de geração de empregos. Particularmente em relação à geração de empregos, um estudo recentemente realizado pelo Instituto de Pesquisa Econômica Aplicada (Ipea) (Beltrão, Camarano \& Kanso, 2004) estimou que no Brasil, em um cenário conservador, poderão haver 
209 milhões de habitantes em 2020, requerendo a criação de 1,1 milhões de novos empregos por ano para atender a população em idade ativa. Assim, mantendo-se o cenário de reduzida capacidade de geração de empregos, com aumento da população em idade ativa, projeta-se um quadro social bastante preocupante em relação aos seus potenciais impactos negativos sobre a saúde da população.

Como resultado desse processo, do ponto de vista social continuaria a haver desequilíbrios no nível de qualidade de vida e nos indicadores sociais das diferentes regiões, com persistência da violência e de problemas decorrentes da degradação ambiental potencializados pela elevada taxa de urbanização associada a uma tendência de desconcentração metropolitana e formação de grandes núcleos urbanos de porte médio integrados em âmbito mesorregional (SAE, 1998). Projeções realizadas recentemente pelo IBGE (2004) estimam que em 2020 três estados concentrarão quase 90 milhões de habitantes, com cerca de 49 milhões em São Paulo, 22 milhões em Minas Geraise 18 milhões no Rio de Janeiro. A persistência e potencialização de muitos problemas sociais combinados com as tendências de aumento da população brasileira, com maior expectativa de vida, diminuição do número de crianças até 14 anos e aumento de mais de $100 \%$ da população com mais de 60 anos de idade, representarão significativas mudanças no quadro da qualidade de vida e saúde da população (doenças crônicas não transmissiveis poderão ter uma importância relativa maior do que as doenças infectocontagiosas) e nas demandas pelos serviços de saúde e previdência social.

Diante das tendências que apontam para cenários políticos, econômicos, sociais e de saúde cada vez mais complexos, a reestruturação da PPGSS na Ensp deverá estar sintonizada com as demandas de formação de profissionais capazes de gerar conhecimentos científicos e de formular intervenções e soluções de problemas, fortalecendo a articulação da construção de saberes e de ações que se relacionam ao campo da saúde coletiva. Com base nos dados apresentados, nas entrevistas realizadas e nos cenários construídos, acreditamos que em um campo como o nosso, o grande desafio será reestruturar o PPGSS na Ensp de modo que a geração de conhecimentos científicos e a formulação de intervenções e soluções de problemas combinem formações em níveis distintos (cursos do lato sensu, como os de atualização, aperfeiçoamento e especialização, com cursos do stricto sensu, como os de mestrado profissional, mestrado acadêmico e doutorado) de forma articulada e integrada.

Uma forma de pensar essa reestruturação é considerar um processo de formação de profissionais em níveis distintos (Figura 1), tal como proposto no processo de renovação dos programas acadêmicos do Instituto Nacional de Saúde Pública do México (Insp, 1999). Esse processo de formação em níveis distintos deve combinar múltiplas possibilida- 
des de formação, como líderes de pesquisa científica e docência (doutorado), jovens pesquisadores e docentes (mestrado acadêmico), quadros estratégicos e lideranças para as Funções Essenciais da Saúde Pública (FsESP) ${ }^{4}$ (mestrado profissional), quadros especializados para as FsESP (especialização) e aperfeiçoamento e atualização de profissionais que atuam dentro e fora do setor Saúde.

Figura 1 - Hierarquização da formação de profissionais para o Sistema Nacional de Saúde

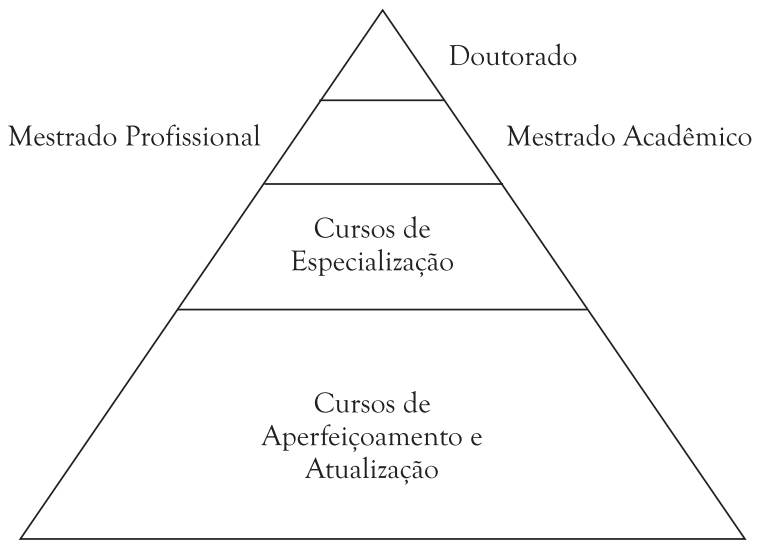

Fonte: Adaptado de Insp, 1999.

Esses diferentes níveis apresentados na Figura 1 de forma vertical podem estar integrados em uma estrutura que os combine horizontalmente. Assim, conforme podemos visualizar na Figura 2, que tem como referência de base o processo de renovação do programa acadêmico do Instituto Nacional de Saúde Pública do México (Insp, 1999), podemos ter um doutorado voltado para uma formação básica, epistemológica e didática no primeiro semestre e uma formação específica e intermediária no tema-problema de tese por meio de disciplinas optativas. $\mathrm{O}$ segundo ano seria voltado para uma formação avançada no tema-problema inserido nas linhas de pesquisa, finalizando-se com a qualificação. Os terceiro e quarto anos seriam dedicados aos seminários de tese articulados com as linhas e grupos de pesquisa, finalizando-se com a defesa da tese. O mestrado acadêmico poderá envolver uma formação básica em saúde pública no

${ }^{4}$ O projeto Saúde Pública nas Américas elaborou uma lista de 11 Funções Essenciais da Saúde Pública (FsESP), que são funções genéricas - e não funções específicas aplicadas a campos de ação determinados - e de responsabilidade institucional da saúde pública. As FsESP constituem a base 'funcional' da saúde pública e se aplicam a diversos campos de ação, envolvendo um conjunto de ações com suficiente homogeneidade que possam ser operacionalizadas de forma adequada e permitam identificar objetivos específicos, bem como componentes e processos produtivos que possam ser verificados e avaliados (OPS, 2002). 
primeiro semestre e uma formação específica e intermediária nas áreas de concentração por meio de disciplinas obrigatórias e eletivas. O segundo ano seria dedicado a seminários de dissertação articulados com as áreas de concentração e linhas de pesquisa. Os cursos de especialização teriam como objetivo oferecer uma formação básica em saúde pública no primeiro semestre e uma formação técnica e especializada orientada para as FsESP no segundo semestre.

Os cursos de especialização com formação mais específica e orientada para as FsESP integrados aos cursos de mestrado profissional teriam, no primeiro ano, também uma formação básica em saúde pública no primeiro semestre e uma formação técnica e especializada orientada para as FsESP no segundo semestre. A diferença é que estes últimos podem se constituir como cursos de especialização específicos e que se orientam para as FsESP. Para subsidiar a discussão procuramos, a partir de um exercício, agrupar algumas das FsESP como possibilidades de cursos especialização/mestrado profissional:

Curso 1 Vigilância, Monitoramento e Análise da Situação de Saúde da População e do Ambiente - FsESP n. 1 - Monitoramento e análise da situação de saúde da população. - FsESP n. 2 - Vigilância da saúde pública, investigação e controle de riscos e danos à saúde pública.

Curso 2 Promoção da Saúde, Participação Social e Eqüidade em Saúde (ou no acesso aos serviços de saúde)

- FsESP n. 3 - Promoção da saúde.

- FsESP n. 4 - Participação social e reforço do poder (empowerment) dos cidadãos em saúde.

- FsESP n. 7 - Avaliação e promoção do acesso eqüitativo da população aos servicosos de saúde necessários.

Curso 3 Desenvolvimento de Políticas e Capacidades Institucionais para

o Planejamento e a Gestão em Saúde Pública (inclui o desenvolvimento

de recursos humanos e capacitação em saúde pública, bem como a

garantia de qualidade e atenção à saúde).

- FsESP n. 5 - Desenvolvimento de políticas e capacidades institucionais para o planejamento e a gestão em saúde pública.

- FsESP n. 8 - Desenvolvimento de recursos humanos e capacitação em saúde pública.

- FsESP n. 9 - Garantia de qualidade e atenção à saúde individual e coletiva. 


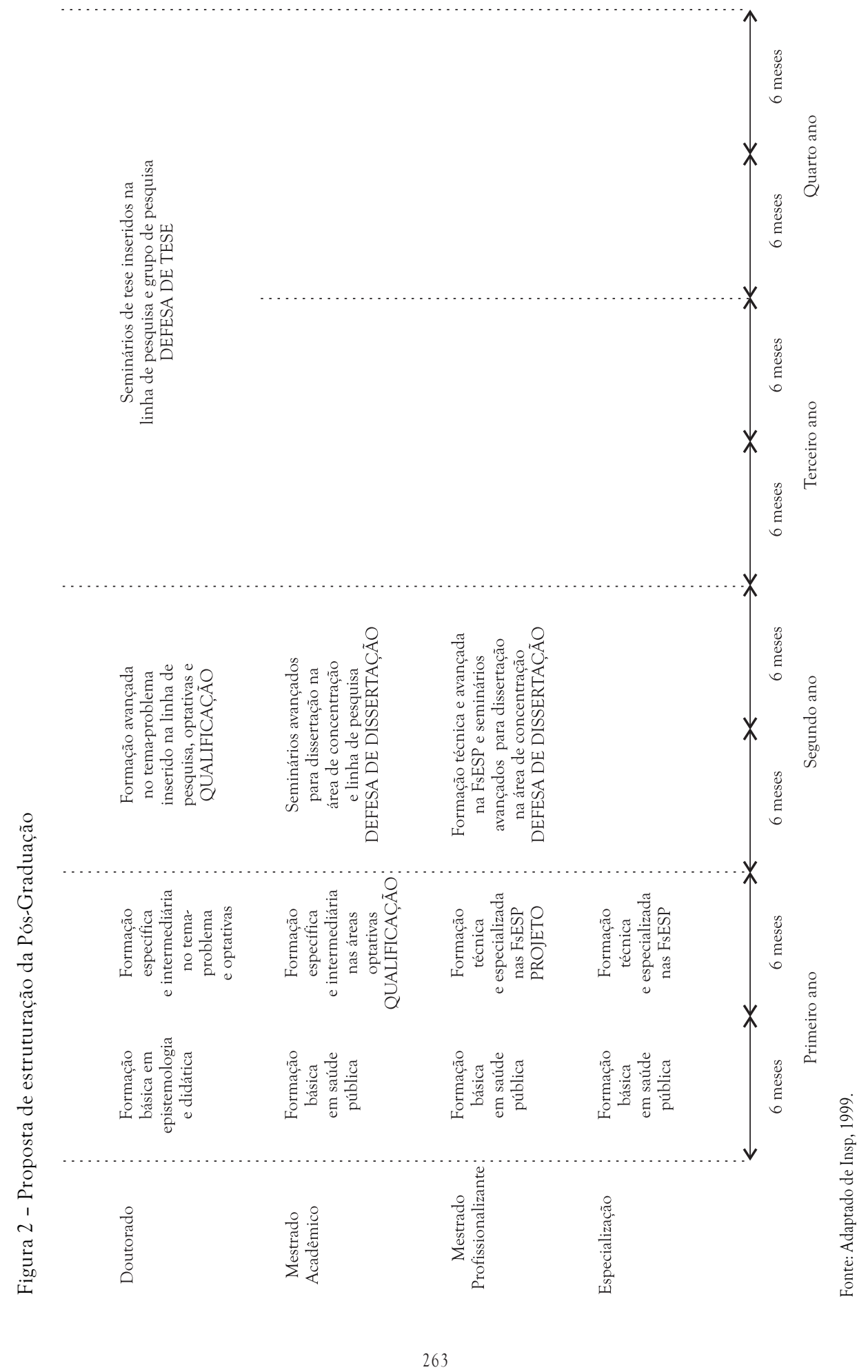


Ao contrário da preocupação mencionada no discurso de alguns atores entrevistados que consideram o MP uma modalidade transitória devido a um possivel e progressivo esgotamento da demanda, chamamos a atenção para o fato de ele afirmar-se como uma tendência mais permanente e de longo prazo, como indicam outros atores. Para estes, o MP é considerado a alternativa mais importante para a formação de quadros estratégicos e lideranças nas FsESP, portanto, como tendência de maior prazo. Com base nos dados atuais de demandas das secretarias do Ministério da Saúde, ${ }^{5}$ temos uma projeção de demanda de formação do MP para pelo menos os próximos dez anos, e podemos afirmar que a demanda por cursos de mestrado profissional e especializações apresenta tendência a ser contínua e crescente.

\section{CONCLUSÃO}

Procuramos aqui identificar os três principais pontos que deverão atravessar o processo para fundamentar mudanças sólidas e que consideramos de vital importância no âmbito do PPGSS-Ensp. O primeiro é o grupo de pesquisa como unidade de articulação entre as linhas de pesquisa e as áreas de concentração. O grupo passa a ser o eixo tanto do desenvolvimento da pesquisa como também do ensino, particularmente o relacionado ao MP, que deverá ter como lógica a formação de equipes de trabalho em instituições. O segundo é o mestrado profissional como unidade de articulação entre o stricto sensu e lato sensu, permitindo uma formação de profissionais ampla e modular, atendendo às demandas atuais e potenciais do Sistema Nacional de Saúde. O terceiro é a necessidade de uma estrutura de suporte que ofereça recursos humanos, infra-estrutura física e tecnologias que supram as condições necessárias para o desenvolvimento articulado do ensino e da pesquisa.

Faz-se também necessária a ressalva de que a situação aqui trabalhada deve ser considerada, em termos de cenários, como um sistema que depende da ação dos atores. Portanto, as tendências apontadas não podem ser consideradas como definitivas, mas resultam necessariamente do compromisso e das estratégias dos diferentes atores envolvidos.

Por fim, é imprescindivel enfatizar que o mestrado profissional, o mestrado acadêmico e o doutorado não devem ser vistos como entidades em competição. Tanto o SUS como o Sistema de Ciência \& Tecnologia em Saúde no Brasil, ambos de grande abrangência e com-

${ }^{5}$ De acordo com a programação da capacitação do Projeto Vigisus II - Secretaria de Vigilância em Saúde, foram programadas até 20061.372 cursos de curta duração, 34 cursos de especialização e cinco cursos de mestrado profissional nos níveis federal, estadual e municipal. 
plexidade, ainda estão longe de ter preenchidas suas demandas de formação de quadros altamente capacitados, o que faz com que haja a premente necessidade de expansão dos mais diversos níveis da formação pós-graduada no país. Cada uma dessas modalidades tem suas próprias características e papel diferenciado no que tange ao processo de formação de recursos humanos. O desafio maior é, menos que subtrair, fomentar da melhor maneira possível a articulação desses diversos níveis de formação com vistas ao aprimoramento do SUS e do Sistema de C\&T em Saúde no país. A Ensp ocupa um lugar estratégico nesse cenário, sendo portanto necessário refletir com vagar e profundidade sobre todas essas questões de grande importância para o sistema de saúde do país como um todo.

\section{REFERÊNCIAS BIBLIOGRÁFICAS}

ARTMANN, E. Démarche stratégique (gestão estratégica hospitalar): um enfoque que busca a mudança através da comunicação e solidariedade em rede, 2002. Tese de Doutorado, Campinas: Faculdade de Ciências Médicas, Universidade Estadual de Campinas.

BARATA, R. B. \& GOLDBAUM, M. Perfil dos pesquisadores com bolsa de produtividade em pesquisa do CNPq da área de saúde coletiva. Cadernos de Saúde Pública, 19:1.863-1.876, 2003

BELTRÃO, K. I., CAMARANO, S. M. \& KANSO, S. Dinâmica Populacional Brasileira na Virada do Século XX. Rio de Janeiro: Ipea, 2004.

GODET, M. Manual de Prospectiva Estratégica: da antecipação à ação. Lisboa: Publicações Dom Quixote,1993.

GRUPO DE TRABAJO del Programa de Innovaciones em Sistemas de Salud y Formación Profesional. Salud Pública de México, 37:63-74, 1995.

INSTITUTO BRASILEIRO DE GEOGRAFIAE ESTATISSTICA. Projeção da população do Brasil: 1980-2050, 2004. http://www.ibge.gov.br/

INSTITUTO NACIONAL DE SALUD PÚBLICA DE MÉXICO. Renovación de los Programas Académicos del Insp-ESPM. Cidade do México: Insp-ESPM, 1999.

LEFÈVRE, F.; LEFÈVRE, A. M. C. \& TEIXEIRA, J. J. V. O Discurso do Sujeito Coletivo: uma nova abordagem metodológica em pesquisa qualitativa. Caxias do Sul: Ed. Educs, 2000. 
ORGANIZACIÓN PANAMERICANA DE LA SALUD. La Salud Pública en las Américas: documento conceptual. Washington: OPS, 2002.

RIVERA, F. J. U. Análise Estratégica em Saúde e Gestão pela Escuta. Rio de Janeiro: Editora Fiocruz, 2003.

RIVERA, F. J. U.; ARTMANN, E. \& FREITAS, C. M. Cenários da Pós-Graduação Stricto Sensu da Ensp. Rio de Janeiro: Escola Nacional de Saúde Pública, 2004.

SECRETARIA DE ASSUNTOS ESTRATÉGICOS. Brasil 2020: cenários exploratórios. Brasília: Secretaria de Assuntos Estratégicos, 1998. 


\title{
AVANÇOS E DESAFIOS DO MESTRADO PROFISSIONALIZANTE
}

\author{
Rita Barradas Barata
}

\section{A EMERGÊNCIA E O CRESCIMENTO DO MESTRADO PROFISSIONAL}

Nos últimos 35 anos observou-se expressivo crescimento e consolidação do programa brasileiro de pós-graduação, regulamentado em todo o país pela Coordenação de Aperfeiçoamento de Pessoal de Nivel Superior (Capes). Na área de saúde coletiva, aos primeiros cursos de mestrado criados em universidades públicas do Rio de Janeiro e de São Paulo, seguiram-se a criação de doutorados ainda na década de 70 e a posterior ampliação e desconcentração de programas para praticamente todas as regiões brasileiras, exceção feita à região Norte (Guimarães, 2004).

O crescimento no número de cursos e também na oferta de vagas para mestrado e doutorado refletiu-se em aumento significativo da produção científica nacional e em processo crescente de internacionalização do debate científico no campo da saúde coletiva (Barata \& Goldbaum, 2003).

Em meados da década de 90, a Associação Brasileira de Pós-Graduação em Saúde Coletiva (Abrasco), após realizar extenso processo de avaliação dos programas de pós-graduação senso estrito, em saúde coletiva, instituiu o Fórum de Coordenadores de Pós-Graduação, colegiado que tem discutido permanentemente as questões relativas a esta modalidade de formação (Minayo, 1997). O fórum tem propiciado espaço privilegiado de reflexão e elabora- 
ção de propostas para o aprimoramento do campo, além de representar um espaço para o debate de todas as proposições oriundas da Capes.

A Portaria 080 da Capes, de 16 de dezembro de 1998, apresentando a proposta do mestrado profissional, provocou verdadeira cisão entre os docentes de pós-graduação do país. Os docentes e pesquisadores que atuam em áreas aplicadas tenderam a ver a proposta como uma inovação positiva para a pós-graduação senso estrito, enquanto os pesquisadores das chamadas áreas básicas receberam a proposta com bastante receio, vendo nela a possibilidade de descaracterização do mestrado e sua transformação em outra modalidade de especialização.

A avaliação dos programas de pós-graduação realizada pela Abrasco mostrou que cerca de $70 \%$ da clientela do mestrado acadêmico eram constituídos por profissionais da saúde que não pretendiam desempenhar atividades acadêmicas mas buscavam no mestrado um aprimoramento de sua formação profissional para responder aos desafios da prática. Assim, pareceu bastante oportuna a discussão do mestrado profissional nesse campo do conhecimento (Tanaka, 1997).

Na área da saúde coletiva, o Fórum de Coordenadores iniciou as discussões acerca dessa modalidade de formação durante o ano de 1999, e em 2000 teve início a oferta de cursos. Nos últimos cinco anos foram oferecidos 12 cursos nessa modalidade, representando $10 \%$ da oferta nacional em todas as áreas.

Cada um dos cursos organizados, conforme evidenciado nos capítulos anteriores, procurou atender a necessidades específicas de qualificação profissional no campo da saúde. Os objetivos e conteúdos, coerentemente com o amplo espectro de objetos do campo da saúde coletiva, apresentam grande diversidade. O primeiro curso oferecido na área foi o Mestrado Profissional em Administração de Saúde do Instituto de Medicina Social da Universidade do Estado do Rio de Janeiro (Uerj). Seguiram-se, em 2001, os cursos de Docência em Saúde da Família e Gestão de Sistemas de Saúde do Instituto de Saúde Coletiva da Universidade Federal da Bahia (ISC/ UFBA). Em 2002 são oferecidos os cursos de Vigilância em Saúde e Gestão de Sistemas e Serviços de Saúde pela Escola Nacional de Saúde Pública (Ensp). Em 2003, têm início outro curso de Gestão de Sistemas de Saúde do ISC/UFBA e um novo curso de Epidemiologia em Serviços de Saúde. Em 2004 são oferecidos mais um curso de Gestão de Sistemas de Saúde pelo ISC/UFBA e outro curso de Vigilância em Saúde da Ensp. Além desses, são criados mais dois cursos pela Ensp: Gestão de Ciência e Tecnologia em Saúde e Gestão da Informação e Comunicação em Saúde; e um curso em Saúde Coletiva com ênfase em controle de doenças e avaliação de sistemas e serviços de saúde, oferecido pelo Departamento de Medicina Social da Faculdade de Ciências Médicas da Santa Casa de São Paulo. 
Observa-se assim, em curto espaço de tempo, não só a ampliação do número de cursos ofertados mas também a diversificação de conteúdos, refletindo a demanda crescente por formação de pessoal na área.

\section{CARACTERÍSTICAS DO MESTRADO PROFISSIONAL}

O mestrado profissional é uma modalidade de formação pós-graduada que visa à qualificação profissional, mais do que à formação de docentes e pesquisadores, finalidades estas cumpridas pelos programas de mestrado e doutorado acadêmicos.

Como formação pós-graduada, o mestrado profissional também está implicado na produção de conhecimentos. Entretanto, diferentemente daquela do mestrado e, principalmente, do doutorado acadêmico, essa produção de conhecimentos está voltada para a solução de problemas práticos, tendo, assim, um caráter mais tecnológico do que propriamente científico.

Outro problema que o mestrado profissional pode ajudar a enfrentar é o distanciamento existente entre a universidade e os setores produtivos da sociedade. Muitos dos conhecimentos produzidos na universidade não encontram sua realização na sociedade, dada a dificuldade que há em seu processo de 'tradução', ou seja, na passagem da teoria para a prática. $\mathrm{O}$ mestrado profissional, por ter como um de seus principais objetivos a produção de conhecimentos para a solução de problemas práticos, certamente irá contribuir para diminuir a distância entre o mundo acadêmico e o mundo da produção.

A maior proximidade entre instituições acadêmicas e prestadores de serviços poderá ainda produzir reflexos sobre a formação de graduação, na medida em que o convivio dos docentes com os profissionais propicie um melhor ajuste dos currículos visando a atender às necessidades do país. Os órgãos prestadores de serviços mencionam, permanentemente, a inadequação entre os egressos dos cursos de formação universitária e os desafios da prática, revelando um desajuste entre os currículos existentes e os problemas concretos da população brasileira. Sem exagerar no pragmatismo, a maior proximidade entre instituições de ensino e prestadores de serviços pode auxiliar na reformulação curricular e realização de cursos de graduação mais eficientes.

O fato de a clientela ser constituída por profissionais em atividade exige maior flexibilidade na concepção dos programas. Em raras situações os profissionais poderão ter dedicação exclusiva às atividades do curso, devendo, assim, haver um equilíbrio entre atividades presenciais e atividades de ensino à distância combinado a processos de auto-instrução que possibilitem aos profissionais cumprir as exigências do curso sem afastar-se completamente de suas atividades profissionais. 
Outra característica própria do mestrado profissional diz respeito ao corpo docente e à avaliação do produto final. A maioria do seu corpo docente apresenta as mesmas características daquele dedicado ao mestrado acadêmico; entretanto, podem ser incorporados profissionais com reconhecida experiência, ainda que não possuam titulação acadêmica, no intuito de complementar a formação por meio do compartilhamento e de reflexões induzidas pelo acúmulo de experiência. Do mesmo modo, a avaliação do produto final pode contar com a participação de profissionais com reconhecida expertise no tema estudado, independentemente de possuírem ou não titulação acadêmica.

O mestrado profissional representa, assim, também um desafio para a formação dos próprios docentes, o desenvolvimento de metodologias pedagógicas e de conteúdos apropriados. Além de fornecer elementos que fortaleçam a formação teórica dos alunos, como nos programas acadêmicos, o mestrado profissional tem o compromisso de preparar indivíduos capazes de solucionar problemas práticos, utilizando conhecimentos científicos na elaboração dessas soluções. Assim, os docentes, além do domínio do campo teórico, terão que trabalhar a habilidade de solucionar problemas.

Um outro aspecto, este de caráter operacional, diz respeito ao financiamento dos cursos. Os recursos para bolsas dos alunos e o custeio do programa devem ser providos pela instituição parceira, ou seja, pela instituição do setor produtivo interessada na qualificação de seus profissionais. A Capes e o Ministério da Educação se desobrigam de financiar essa modalidade de formação, visto que ela não se destina primariamente à formação de docentes, ainda que o título concedido seja equivalente ao do mestrado acadêmico tanto para efeito de contratação docente quanto para o ingresso em programas de doutorado que tenham como pré-requisito o mestrado.

Essas especificidades do mestrado profissional têm provocado intenso debate quanto à necessidade de formular critérios de avaliação específicos, distintos daqueles utilizados para os programas acadêmicos. Por um lado, é necessário preservar o mesmo objetivo de excelência e relevância social existente na modalidade acadêmica, e por outro é importante levar em conta as peculiaridades da modalidade. Até o momento, a Capes tem mantido o mesmo sistema de avaliação para ambas as modalidades.

Talvez a melhor solução seja criar, sempre que necessário, em cada área do conhecimento, dois comitês avaliadores, um voltado para os programas acadêmicos e outro voltado para os programas profissionalizantes, mas ambos formados por docentes do próprio campo em que os cursos estão sendo oferecidos. Os critérios de avaliação terão que ser estabelecidos com base nas experiências em curso, garantindo-se, assim, a atenção às especificidades, sem com isso diminuir em nada o patamar de qualidade a que a pós-graduação brasileira vem aspirando. 


\section{CARACTERÍSTICAS DO MESTRADO PROFISSIONAL EM SAÚDE COLETIVA}

\section{A Questão Tecnológica}

O campo da saúde coletiva constitui um conjunto de teorias e práticas que se organiza e se diferencia para compreender, explicar e modificar o processo saúde-doença, em seus aspectos materiais e não materiais, na dimensão coletiva, assim como as formas de respostas, socialmente organizadas, para o enfrentamento das necessidades de saúde (Paim \& Almeida Filho, 2000).

Como campo de produção de conhecimentos aplicados na solução de problemas práticos, a saúde coletiva apresenta demanda constante de novas tecnologias. As diferentes análises referentes à questão da tecnologia costumam reduzir o conceito à designação de um conjunto de 'coisas' dotadas de capacidade de intervenção prática, produzidas ou descobertas pela ciência. Alternativamente a essa concepção, Mendes Gonçalves (1988) propõe o conceito de organização tecnológica expandindo a idéia de tecnologia para o conjunto da organização técnica do proces so de produção, incluindo o saber como parte dessa organização.

Por organização tecnológica em saúde entende-se a concepção do objeto de trabalho, a seleção de instrumentos de intervenção e a organização desses instrumentos em modalidades de práticas capazes de alcançar cobertura populacional, efetividade de implantação e impacto positivo na modificação da situação de saúde em populações gerais ou grupos vulneráveis.

Na saúde coletiva, o mestrado profissional constitui espaço privilegiado para o desenvolvimento e avaliação de novas organizações tecnológicas do trabalho em saúde, nas diferentes dimensões de atuação que caracterizam o campo.

A expressão 'sociedade do conhecimento' assinala o papel central que a ciência e a inovação desempenham no processo de desenvolvimento socioeconômico. No Brasil, apenas ao final da década de 90 intensificaram-se os esforços para superar o distanciamento entre ciência e inovação com a criação dos fundos setoriais, a realização da primeira conferência nacional de ciência, tecnologia e inovação e a formulação da lei de inovação (Conde \& Araujo-Jorge, 2003). A implementação do mestrado profissionalizante também constitui um dos elementos nessa aproximação entre a produção científica, estrito senso, e o desenvolvimento de tecnologias e inovação.

Em meados do século XX predominava a visão linear do processo de inovação. Nesse modelo a inovação era vista como decorrência natural e lógica do investimento feito na pesquisa básica. Supunha-se que o acúmulo de novos conhecimentos inevitavelmente se traduziria em novas invenções, desenvolvimento tecnológico com produtos e processos inova- 
dores ao final da cadeia. Nas décadas de 70 e 80 a concepção não se modifica, mas sofre uma inversão de sentido, ou seja, o processo passa a ser pensado 'do fim para o começo' e a necessidade tecnológica passa a ser vista como a impulsionadora do desenvolvimento da pesquisa básica. Na última década esses modelos são bastante criticados e passam a ser substituídos por modelos interativos em que predominam as noções de rede, comunicação e expectativas de diferentes atores (Conde \& Araujo-Jorge, 2003).

Por outro lado, a própria concepção de pesquisa científica sofre reformulação, buscando superar a divisão rígida entre pesquisa básica e pesquisa aplicada. Stokes (1997) propõe pensar a produção científica com base em uma matriz definida por dois eixos: o avanço dos conhecimentos científicos e a utilização dos conhecimentos científicos. Do cruzamento desses dois eixos resultam quatro quadrantes definidores dos tipos de produção: pesquisa básica, pesquisa estratégica e pesquisa tecnológica. A pesquisa básica é aquela que visa primordialmente ao avanço do conhecimento científico sem ter em sua origem a preocupação com a aplicação prática dos seus resultados. A pesquisa tecnológica é aquela que se compromete essencialmente com a aplicação prática de seus resultados, não tendo em conta a produção de novos conhecimentos. A pesquisa estratégica é aquela que desde sua concepção está comprometida tanto com o avanço do conhecimento quanto com a sua aplicação prática. O quarto quadrante, vazio, corresponde à situação de baixo ou nenhum avanço no conhecimento e baixa aplicação, ou seja, à situação em que não há pesquisa.

No mestrado profissional a produção de conhecimentos tanto pode ser pensada no quadrante da pesquisa estratégica quanto no quadrante da pesquisa tecnológica, dependendo da área de conhecimento e do objeto de investigação. Portanto, os produtos não devem ser vistos como 'menos científicos' do que aqueles resultantes do mestrado acadêmico, ainda mais que em um campo de práticas como a saúde coletiva boa parte da produção, mesmo na esfera acadêmica, se localiza nesses mesmos quadrantes.

A especificidade dessa modalidade de formação estará menos nos produtos científicos do que nas formas de articulação que ela pode favorecer entre as instituições de ensino e pesquisa e os serviços de saúde.

\section{Os Novos Desafios para a Saúde Coletiva}

A totalidade dos programas de mestrado profissionalizante, em desenvolvimento nesse campo, apresenta como justificativa para sua implantação os desafios atuais da prática em saúde.

A Organização Mundial da Saúde (OMS) avalia que a saúde pública está passando por sua terceira revolução (Kickbusch, 2003). A primeira, ocorrida no século XIX, caracterizou-se 
pelos avanços da engenharia e da legislação sanitária no saneamento do ambiente e pelo controle de doenças transmissíveis baseado no uso de vacinas e no controle vetorial. Do ponto de vista das práticas sanitárias, esse período é caracterizado pelas campanhas de controle e erradicação de doenças e pela vigilância epidemiológica e sanitária como modelos tecnológicos principais.

A segunda revolução teria ocorrido em meados no século XX, privilegiando a análise do processo saúde-doença com base no enfoque nos estilos de vida, fatores de risco individuais; no campo das políticas e gestão dos serviços, seu foco principal foi a reforma dos sistemas de saúde já nas últimas décadas do século. Do ponto de vista tecnológico, as práticas de saúde pública voltaram-se para o atendimento básico aos indivíduos, daí a ênfase na universalização da cobertura da atenção primária e nas políticas de promoção da saúde centradas nas mudanças de hábitos individuais.

A terceira revolução, iniciada a partir do novo século, caracterizar-se-ia pela conceituação positiva de saúde e compreensão da saúde como componente da qualidade de vida; pela ênfase na abordagem coletiva dos determinantes e pela promoção da saúde em uma perspectiva populacional e intersetorial.

O que há de novo na saúde pública mundial que demanda novos esforços e modalidades de formação em saúde coletiva?

Primeiramente, o direito à saúde entendido como responsabilidade do Estado na promoção e defesa da saúde populacional. Nos Estados democráticos a política de saúde passa a ser vista como resultante de um contrato social entre um "Estado estratégico" e "cidadãos ativos", e não mais como produto da deliberação técnica e política de profissionais e gestores do aparelho do Estado (Gostin, 2000a). O direito à saúde, por um lado, confere poderes legais e impõe obrigações ao Estado; por outro, porém, limita o poder do Estado, na medida em que deve garantir certos direitos individuais. Essa nova arquitetura das práticas coletivas em saúde traz novos desafios aos profissionais do campo da saúde coletiva e também novos objetos teóricos, tais como o direito sanitário.

Em segundo lugar, a necessidade crescente de regulação pelo Estado de inúmeros aspectos da vida que possam representar riscos coletivos (princípio de redução do dano), riscos para os próprios indivíduos (princípio da autoproteção) e riscos para as pessoas legalmente incompetentes (princípio do melhor interesse) que o Estado tem o dever de proteger. Aos profissionais em funções públicas cabe demonstrar a existência do risco, a efetividade da regulação, o custo-efetividade das medidas propostas, a existência de alternativas menos restritivas e a garantia de distribuição eqüitativa das intervenções (Gostin, 2000b). Todos 
esses aspectos tornam a prática profissional muito mais complexa e justificam novas modalidades de formação.

Um terceiro aspecto muito desafiador para a prática é o enfrentamento da exclusão social (Kurland, 2000). A nova ordem econômica, social e política produz constantemente novas formas de exclusão, todas com importantes repercussões para a saúde. Oenfrentamento desse problema no campo da saúde coletiva demanda mais do que empenho acadêmico para compreender e quantificar o problema, requerendo o enfrentamento político da questão da pobreza absoluta e relativa e o enfrentamento social do racismo, do sexismo e de outras formas de discriminação, entre as quais a decorrente da posição socioeconômica de classe, para a redução das desigualdades.

Esses e outros aspectos novos do viver e do adoecer dos grupos humanos questionam cotidianamente a capacidade dos profissionais da saúde, em geral, e da saúde coletiva em particular. Ao mesmo tempo, as práticas de promoção, manutenção e recuperação da saúde hoje se dão em âmbitos e situações institucionais muito diversos, incluindo os serviços públicos, as fundações, as empresas e as organizações sociais. As novas formas de parceria públicoprivado e a presença crescente do setor privado e de seus interesses corporativos nas agências internacionais e nos organismos nacionais de definição de políticas públicas são também outros ingredientes a serem considerados.

Finalmente, outro aspecto que merece ser destacado é o crescente protagonismo que o Banco Mundial e outros organismos como o Banco Interamericano para o Desenvolvimento vêm mostrando na condução da agenda política da saúde no continente e em outras partes do mundo. O interesse crescente do setor econômico pelas políticas de saúde, dado o montante de recursos financeiros que elas mobilizam e o potencial econômico que as ações de saúde representam para outros setores produtivos, tem deslocado a liderança das agências setoriais. A OMS e a Organização Pan-Americana da Saúde (Opas) têm tido pouca capacidade de influenciar a agenda política na saúde, chegando mesmo a incorporar a agenda dos organismos financeiros como se fosse sua, modificando bastante o quadro da cooperação multilateral.

Nesse cenário complexo e cambiante a formação profissional vê-se constantemente desafiada, não apenas pela necessidade de incorporação de novos conteúdos teóricos, mas, principalmente, pela necessidade de produzir um novo 'saber-fazer' capaz de responder adequadamente às necessidades sociais em saúde.

O Compromisso Político e a Parceria com o Setor Público

A despeito da ampliação do âmbito de atuação dos mestrados profissionalizantes, todos aqueles oferecidos pela saúde coletiva mantêm um claro compromisso político com o ensino 
superior gratuito. Ainda que os cursos necessitem de recursos para se viabilizar, esses recursos têm sido majoritariamente providos pelas instituições contratantes, habitualmente uma instituição pública de saúde.

Nessa modalidade, portanto, a formação profissional não implica obrigatoriamente investimentos financeiros feitos pelo próprio profissional, mas tem sido propiciada por investimentos institucionais visando à maior e melhor capacitação de seus quadros.

Os investimentos em qualificação profissional têm como principal objetivo, nesses casos, a melhoria dos serviços prestados à população e a melhor utilização dos recursos existentes na concretização dos objetivos desenhados pelas diferentes políticas sociais elaboradas pelo setor.

No campo da saúde, especialmente na saúde coletiva, a parceria entre as instituições de ensino e pesquisa tem sido feita, até o momento, com instituições públicas responsáveis pela formulação, execução e avaliação das políticas de saúde. Nenhum dos programas vigentes está voltado para o atendimento de demandas do setor produtivo lucrativo.

\section{MESTRADOS PROFISSIONALIZANTES JÁ REALIZADOS E PROGRAMAS EM CURSO}

\section{Aspectos Comuns}

Os programas já oferecidos e aqueles que estão em curso apresentam em comum o fato de terem sido organizados em função do novo perfil profissional necessário para o enfrentamento das novas circunstâncias resultantes da complexidade crescente da política de saúde. Cada um deles busca responder a um conjunto particular de necessidades, de modo que cada curso apresenta uma individualidade em si. Não há, como na modalidade acadêmica, a repetição seqüencial de um programa preestabelecido. Cada demanda das instituições e serviços de saúde gera a formulação de um curso particular.

Os cursos são organizados em torno de temáticas específicas, tais como a vigilância em saúde, a formação de gestores para o Sistema Único de Saúde (SUS), a formação de docentes em saúde da família, a regulação no âmbito da vigilância sanitária, a gestão de política científica e tecnológica, a gestão da informação e comunicação em saúde. É importante destacar que o recorte não é disciplinar, senso estrito, mas dado por áreas temáticas de atuação no campo da saúde coletiva.

Todos os programas foram construídos tendo em vista a articulação estreita com a prática profissional. A estrutura curricular e as modalidades de ensino-aprendizagem selecionadas 
buscam valorizar a experiência dos alunos, estão orientadas para a resolução de problemas e para a tomada de decisão. Essa valorização dos resultados não implica, entretanto, descuidar da formação teórica necessária nessa modalidade formativa.

As tecnologias de ensino utilizadas e a flexibilidade do programa diferenciam essa modalidade da acadêmica. Dado que os alunos não podem ser totalmente dispensados de suas atividades profissionais, devendo conciliar o trabalho e a formação, as grades de atividades têm que ser flexíveis e as tecnologias educacionais precisam ser inovadas, passando a incluir formas de ensino à distância, auto-aprendizado, exercícios de problematização, e outras.

A curta duração do mestrado profissional, entre 12 e 24 meses, acaba por definir, no conjunto dos programas analisados, estrutura curricular composta por um conjunto de disciplinas comuns para todos os alunos, podendo ou não haver disciplinas optativas de acordo com a oferta de áreas de concentração específicas. Tendo em vista que a maioria dos cursos já é direcionada para segmentos específicos de atividade profissional no campo da saúde coletiva, o mais freqüente tem sido a oferta de um conjunto preestabelecido de disciplinas ou de conteúdos organizados em torno de determinados problemas, rompendo os limites estritamente disciplinares.

Todos os cursos organizados até o presente foram feitos em parceria entre as instituições de ensino superior e as instituições públicas do setor Saúde ou Educação. A clientela dos cursos tem sido constituída por profissionais dos quadros técnicos dirigentes. Diferentemente dos cursos de capacitação e especialização, cuja tendência é a cobertura de maior número de profissionais ajudando a formar massa crítica para os serviços de saúde, o mestrado profissional tem sido oferecido para uma parcela mais reduzida de técnicos cujas funções de direção requerem formação mais qualificada.

Os produtos finais, ou seja, os trabalhos de conclusão do mestrado, são todos direcionados para a solução de problemas postos pela prática. Isso não significa que não possa haver produção teórica, senso estrito. O desenvolvimento de revisões sistemáticas sobre problemas de interesse, por exemplo, pode ser uma etapa necessária para a formulação de novas tecnologias de trabalho, seja no campo da oferta de serviços seja no campo da regulação. Assim, o caráter distintivo desses produtos é sua inserção no campo da pesquisa estratégica ou da pesquisa tecnológica, independentemente do fato de tratar-se de monografia, manual de treinamento, sistema de informações, guia de atendimento, softwares administrativos ou de análise de dados, vídeos de comunicação em saúde, material educativo e outros.

Em comum com os programas oferecidos em outros países, os programas brasileiros também visam a maior articulação entre a academia e os setores não acadêmicos, apresentam 
organização modular, são destinados a clientela multiprofissional, selecionam seus alunos entre profissionais com inserção no mercado de trabalho e têm como principal objetivo capacitar esses profissionais para a solução de problemas práticos. A carga horária dos programas brasileiros varia entre 800 e 1.400 horas, diferenciando-se de alguns programas estrangeiros que têm menos de 800 horas de duração.

Os programas europeus apresentam certo predomínio do enfoque qualitativo, oferecendo pouco ou nenhum treinamento em técnicas quantitativas, diferentemente do que se observa nos programas norte-americanos e canadenses. No caso brasileiro, as abordagens qualitativas e quantitativas estão presentes, dependendo da temática central.

\section{Nós Críticos dos Programas em Curso}

Há um conjunto de dificuldades que também são comuns aos programas oferecidos até o momento. Entre eles destacam-se alguns relativos à clientela, à condução do programa, à relação com os parceiros e à relação com a Capes.

Com relação à clientela dos cursos, a principal dificuldade é o perfil bastante variado dos alunos. Os alunos freqüentemente apresentam formações profissionais distintas e principalmente experiências de trabalho bastante variadas, o que representa um desafio para os docentes que precisam formular as atividades docentes ajustadas ao perfil profissional desejado. Por outro lado, essa característica, se representa um desafio para a elaboração dos cursos, significa riqueza de experiências que podem ser utilizadas em proveito do grupo como um todo. Os alunos cuja formação graduada apresenta maior componente biológico podem auxiliar aqueles com formação em ciências humanas e sociais, e vice-versa. Para tanto, é necessário que as situações de ensino-aprendizagem utilizadas permitam e estimulem essa troca permanente entre os alunos, e destes com os docentes.

Quanto à condução dos cursos, vários aspectos podem ser destacados. As maiores dificuldades dizem respeito ao fato de os alunos não poderem conviver mais diuturnamente com os docentes e pesquisadores das instituições acadêmicas, uma vez que precisam conciliar as atividades profissionais e de formação. Essa dificuldade é ainda mais acentuada nos cursos 'fora de sede', em que há necessidade de capacitar os docentes nas técnicas pedagógicas do ensino à distância.

Além disso, a ausência ou escassez de apoio logístico e bibliográfico nos locais de trabalho dos alunos e a orientação semipresencial podem tornar mais difícil o acompanhamento dos alunos e a execução do trabalho de conclusão.

Os cursos também têm encontrado dificuldades nos momentos de avaliação formal: o exame de qualificação e o julgamento do produto final. A maioria dos docentes que podem 
compor as bancas não está habituada aos novos formatos previstos pelo mestrado profissional, e não há critérios claros e estabelecidos de argüição nessas situações. Talvez fosse interessante ter como critério de composição dessas bancas a participação obrigatória de um profissional do campo em questão, independentemente de titulação acadêmica.

A natureza, potencialmente bastante diversificada, dos produtos finais torna necessário o acúmulo de experiência por parte daqueles que irão julgá-los. A maioria dos docentes está habituada com a avaliação de teses e dissertações ou artigos científicos, mas não possui experiência na avaliação de materiais mais instrumentais de uso pelos serviços, ou de alguns produtos como vídeos e softwares.

Na relação com os parceiros, um dos problemas mais difíceis de contornar é a mudança de gestão, seja pelo término do mandato, seja pela troca dos dirigentes. Geralmente, nessas circunstâncias os acordos estabelecidos entre as instituições de ensino e os serviços tendem a ser desconsiderados ou cumpridos protocolarmente, sem que haja real interesse na formação daqueles profissionais que estão cursando os programas.

No caso de cursos modulares, as queixas maiores dizem respeito à dificuldade de liberação dos alunos para que cumpram as atividades do mestrado nos períodos de educação à distância, entre os módulos de atividades presenciais.

A situação ideal é aquela em que os alunos são valorizados pela instituição e vistos como agentes de mudança institucional: aqueles que, por sua formação, serão capazes de transmitir aos demais os conhecimentos adquiridos e, através de uma prática de trabalho renovada, serão também capazes de modificar as formas de atuação, buscando maior qualidade no desempenho da missão institucional.

Finalmente, há uma série de indagações acerca das relações do mestrado profissional com a Capes. A estrutura e os critérios de avaliação utilizados pela Capes foram elaborados para o julgamento dos programas acadêmicos, havendo insuficiente experiência acumulada que permita a elaboração de critérios para o mestrado profissional. Embora esteja claro que os cursos profissionalizantes devam ser avaliados por pares da área de conhecimento na qual estão inseridos, critérios específicos deverão ser desenvolvidos para o julgamento desses cursos. Os critérios ora adotados para avaliação dos cursos acadêmicos não parecem dar conta das especificidades do mestrado profissional.

\section{Desafios}

A estrutura convencional das instituições de ensino superior e o tradicional afastamento existente entre o meio acadêmico e outras esferas de organização da sociedade tornam problemática a existência do mestrado profissional em várias universidades brasileiras. 
As pró-reitorias de pós-graduação têm tido dificuldade em flexibilizar os critérios de oferta de cursos de modo a possibilitar a realização do mestrado profissional. Muitas delas apresentam resistências conceituais a essa modalidade de formação, e outras alegam dificuldades burocráticas. A questão da remuneração pelos contratantes também tem sido indicada como fator impeditivo, pois muitos dirigentes acreditam que os professores terão maior interesse em trabalhar nesses programas do que nos programas acadêmicos devido à possibilidade de remuneração adicional.

Para os docentes mais ligados às áreas de ciências básicas, é bastante difícil entender o alcance e as especificidades das ciências aplicadas. Esses docentes têm, geralmente, receio de que o mestrado profissional signifique a desqualificação do mestrado, por tornar a obtenção do título "mais fácil e mais generalizada".

Do lado das instituições do setor produtivo também aparecem dificuldades no estabelecimento de parcerias. No caso da saúde coletiva, os gestores da política de saúde, em qualquer âmbito do setor público, nem sempre conseguem indicar para as instituições de ensino quais são suas prioridades de formação. O maior problema, porém, é representado pela mudança de mandato, como já foi dito aqui.

O desenvolvimento do programa encontra seu maior desafio em garantir a qualidade da formação e obter a conclusão em prazos curtos e sem dedicação integral. Diferentemente do que seria preconizado na pós-graduação acadêmica, os alunos não teriam disponibilidade para participar ativamente da vida cotidiana do grupo de pesquisa ao qual estariam associados. Os alunos do mestrado profissional mantêm suas atividades profissionais enquanto realizam sua formação. Além disso, os programas têm duração estrita de 12 a 24 meses, não podendo se prolongar além desse prazo. Esses aspectos constituem desafios importantes para o desempenho docente em geral, e para as tarefas de orientação em particular.

Outro desafio importante está relacionado ao aproveitamento dos quadros formados, na medida em que não existe uma burocracia estável nos serviços de saúde. A inexistência de carreiras especiais e a precarização dos vínculos de trabalho tornam incerto o aproveitamento dos egressos do programa. Certamente, a formação adquirida pelo profissional não se perde, porém o investimento feito pelo poder público poderá não ter o retorno esperado caso o egresso não possa executar as funções para as quais foi preparado. Esses aspectos estão fora da governabilidade das instituições formadoras, mas podem significar uma demanda inesgotável por formação, na medida em que não haja fixação dos egressos.

Outro aspecto desafiador para o mestrado profissional é a dificuldade de avaliação do impacto deste tipo de formação nos serviços de saúde. Será importante desenvolver 
metodologias de avaliação que permitam documentar de modo adequado os benefícios decorrentes desse investimento. Essa avaliação não se esgota com a potencial incorporação dos produtos resultantes dos trabalhos de conclusão, mas deveria incorporar, em certo grau, a avaliação de possiveis mudanças e alterações no próprio processo de trabalho dos profissionais treinados. Finalmente, como um objetivo menos imediato, no sentido de que está sujeito a um conjunto maior de mediações, seria necessário avaliar o impacto da maior capacitação profissional na qualidade do serviço prestado à população.

Nenhuma dessas etapas e seus potenciais impactos são de fácil avaliação. Entretanto, para firmar essa modalidade de formação, devem ser realizados esforços nessa direção.

\section{PERSPECTIVAS}

As avaliações preliminares do grupo de coordenadores dos programas existentes indicam tendência à ampliação das demandas para mestrados profissionais que pode pressionar as instituições de ensino superior já sobrecarregadas com as demandas de especialização e capacitação.

Assim, será importante buscar formas de articulação entre as diferentes modalidades de educação permanente e a pós-graduação, profissional ou acadêmica, para que seja possível atender a essa demanda.

A forma de organização descentralizada do SUS trouxe necessidade crescente de capacitação profissional que se traduz por pressão de oferta de cursos e treinamentos. As demandas pelo mestrado profissionalizante, além dos profissionais inseridos no nível federal de coordenação do sistema de saúde, têm incluído também dirigentes das secretarias estaduais de Saúde e alguns técnicos de secretarias municipais em municípios grandes. Dada a capilaridade do Sistema Único de Saúde no território nacional e o número relativamente restrito de grupos acadêmicos na área da saúde coletiva, a oferta de cursos é sempre menor do que a demanda.

O atendimento a essa demanda crescente que vem se somar às atividades acadêmicas tradicionais requer para seu enfrentamento maior flexibilidade e criatividade na formatação dos programas. Algumas idéias têm surgido nesse sentido:

- Articulação entre curso de especialização e mestrado profissional utilizando o caráter mais massificado dos cursos de especialização para uma etapa de nivelamento em conhecimentos básicos do campo e para a identificação de alunos com potencial para a realização do mestrado. Haveria, assim, um acoplamento inicial dos dois tipos de for- 
mação, com otimização dos recursos docentes. Entretanto, isso significaria, ao menos para os selecionados, maior tempo de afastamento parcial das atividades profissionais. Tendo em vista que a clientela preferencial dos cursos tem se constituído por quadros dirigentes, este aspecto pode constituir um obstáculo sério à adoção de tal alternativa.

- Articulação entre mestrado profissional e mestrado acadêmico por meio da criação de grupos e da adoção de linhas de pesquisa visando a otimizar os recursos de orientação aos alunos e a permitir maior convivio acadêmico aos alunos da modalidade profissional. Esta alternativa, que permitiria o acoplamento de diferentes projetos em torno de uma mesma linha de pesquisa, tem seu limite na diversidade de problemas práticos trazidos pelos alunos, que nem sempre coincidem com as linhas de pesquisa dos docentes.

- Substituição do mestrado acadêmico pelo mestrado profissional, que tem sido cogitada como solução para a sobrecarga de trabalho docente. Entretanto, esta alternativa pode ter impacto negativo sobre os programas de doutorado. Embora o mestrado acadêmico não deva ser visto como pré-requisito ou etapa prévia obrigatória ao doutorado, a preparação, em termos de condução da pesquisa, dada pelo mestrado, auxilia e qualifica o desempenho dos alunos nos programas de doutoramento.

- Articulação interinstitucional para oferta de mestrado profissional em locais onde não existam grupos acadêmicos consolidados. O Ministério da Saúde iniciou discussões sobre esta idéia com as instituições acadêmicas, mas ela enfrenta muitas dificuldades de ordem prática, pois a maioria ou a totalidade das instituições de ensino não possui mecanismos burocráticos que permitam esse tipo de arranjo e os critérios adotados pela Capes tornam difícil esta solução.

Cada uma dessas propostas apresenta vantagens e desvantagens que precisam ser cuidadosamente avaliadas.

A reflexão continuada sobre as peculiaridades do mestrado profissional deverá gerar o desenvolvimento de critérios de avaliação específicos. Do mesmo modo que para os programas acadêmicos, será imprescindível que os próprios docentes e coordenadores de curso elaborem propostas nessa direção.

A adaptação para o mestrado profissional dos atuais critérios de avaliação dos programas acadêmicos pode ser um passo inicial para a definição de um sistema próprio de avaliação.

Estudos e pesquisas especialmente desenhados para avaliar o impacto do mestrado profissionalizante nas três vertentes indicadas anteriormente - incorporação dos produtos, mudanças no processo de trabalho e qualidade na prestação de serviços - devem ser desen- 
volvidas tanto pelas instituições de ensino envolvidas na oferta dos programas quanto por outros grupos acadêmicos e instituições de pesquisa, visando a aprofundar o conhecimento sobre essa nova modalidade de formação.

\section{REFERÊNCIAS BIBLIOGRÁFICAS}

BARATA, R. B. \& GOLDBAUM, M. Perfil dos pesquisadores com bolsa de produtividade em pesquisa do CNPq da área de saúde coletiva. Cadernos de Saúde Pública, 19(6):1.863$1.876,2003$.

CONDE, M. F. V. \& ARAUJO-JORGE, T. C. Modelos e concepções de inovação: a transição de paradigmas, a reforma da C\&T brasileira e as concepções dos gestores de uma instituição pública de pesquisa em saúde. Ciência Ė Saúde Coletiva, 8(3):727-741, 2003.

GOSTIN, L. O. Public health law in a new century. Part I: Law as a tool to advance the community's health. Journal of the American Medical Association, 283(21):2.8372.841, 2000a.

GOSTIN, L. O. Public health law in a new century. Part III: Public health regulation. Journal of the American Medical Association, 283(22):3.118-3.122, 2000b.

GUIMARÃES, R. Bases para uma política nacional de ciência, tecnologia e inovação em saúde. Ciência EZ Saúde Coletiva, 9(2):375-387, 2004.

KICKBUSCH, I. The contribution of the WHO to a new public health and health promotion. American Journal of Public Health, 93(3):383-388, 2003.

KURLAND, J. Public health in the new millenium I: Technology. Public Health Reports, 115(1):34, 2000.

MENDES GONÇALVES, R. B. Prática de saúde e tecnologia: contribuição para a reflexão teórica, 1988. (Mimeo.)

MINAYO, M. C. S. Pós-graduação em saúde coletiva: um projeto em construção. Ciência $\mathfrak{E}$ Saúde Coletiva, II(1/2): 53-71, 1997.

PAIM, J.S. \& ALMEIDA FILHO, N. A Crise da Saúde Pública. Salvador: Casa da Qualidade Editora, 2000

STOKES, D. E. Pasteur's Quadrant: basic science and technological innovation. Washington, D.C.: Brookings Institution Press, 1997.

TANAKA, A. C. A. Perfil da demanda aos cursos de pós-graduação na área de saúde pública. Ciência Ė Saúde Coletiva, II(1/2):108-116, 1997. 


\author{
Formato: $16 \times 23 \mathrm{~cm}$ \\ Tipologia: Goudy Old Style \\ Papel: $90 \mathrm{~g} / \mathrm{m}^{2}$ (miolo) \\ Cartão Supremo $250 \mathrm{~g} / \mathrm{m}^{2}$ (capa) \\ Fotolitos: Laser vegetal (miolo) \\ Engenho e Arte Editoração Gráfica Ltda. (capa) \\ Impressão e acabamento: \\ Imprinta Express Gráfica e Editora Ltda.
}

Rio de Janeiro, julho de 2006.

Não encontrando nossos titulos em livrarias, contactar a Editora Fiocruz:

Av. Brasil, 4036 - $1^{\circ}$ andar - sala 112 - Manguinhos

21041-361 - Rio de Janeiro - RJ

Tel.: (21) 3882-9039 e 3882-9041 - Telefax: (21) 3882-9006

e-mail: editora@fiocruz.br

http://www.fiocruz.br/editora 
Novas evidências cientificas demonstram a importância de fortalecer os trabalhadores da saúde, de modo que os sistemas de saúde sejam capazes de enfrentar as doenças incapacitantes e alcançar as metas de saúde nacional e global. O Relatório Mundial da Saúde de 2006, publicado pela Organização Mundial da Saúde (OMS), afirma a centralidade dos recursos humanos qualificados no trabalho de reduzir a distância entre as promessas e a realidade sanitária e de antecipar os desafios de saúde do século XXI. A resposta a esses desafios exige compromissos politicos fortes, mas também novas modalidades de articulação entre os serviços de saúde e o aparelho formador.

Este livro analisa o mestrado profissional em saúde coletiva - que vem se desenvolvendo no Brasil - como uma nova modalidade de formação de quadros técnicos e dirigentes do setor Saúde articulada ao Sistema Único de Saúde (SUS). Os autores analisam as experiências de diversos programas, cujo mosaico expressa a diversidade e a riqueza da área de saúde pública/saúde coletiva, ao mesmo tempo que responde às diferentes necessidades de profissionalização emergentes no sistema de saúde brasileiro, como as subáreas de informação, epidemiologia, vigilância, gestão de serviços de saúde e de $C \& T$, entre outras. Merece ser lido por todos aqueles que tomam decisões ou que fazem funcionar os serviços de saúde no Brasil, mas também por todos os interessados na melhoria do sistema de saúde público ou privado.

\section{Mario Dal Poz}

Coordenador para Instrumentos de Avaliação Baseada

em Evidências e Politicas de Saúde

Recursos Humanos para a Saúde

Organização Mundial da Saúde - Genebra

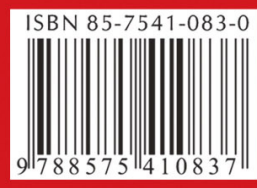

